\title{
Orientação a Objeto: Definição, Implementação e Análise de Recursos de Teste e Validação
}

\author{
Auri Marcelo Rizzo Vincenzi
}

Tese apresentada ao Instituto de Ciências Matemáticas e de Computação - ICMC-USP, como parte dos requisitos para obtenção do título de Doutor em Ciências - Ciências de Computação e Matemática Computacional.

Orientador: Prof. Dr. José Carlos Maldonado Co-orientador: Prof. Dr. Márcio Eduardo Delamaro

USP - São Carlos

Maio de 2004 

Ao Amauri, à Leise e à Elaine. 


\section{Agradecimentos}

- A Deus pela minha vida e pelos dons que me concedeu.

- Ao meu orientador e amigo Prof. Dr. José Carlos Maldonado pelo apoio, pela confiança em mim depositada, pelas sugestões e pelo profissionalismo na orientação desta tese.

- Ao meu co-orientador e também amigo Prof. Dr. Márcio Eduardo Delamaro pelos questionamentos sempre pertinentes e pela pronta ajuda em todos os momentos.

- To the Department of Computer Science at The University of Texas at Dallas. Specially to Dr. W. E. Wong who made possible my stay at The University of Texas at Dallas as a Visiting Scholar and who also contributed to this work.

- À Elaine pela paciência, incentivo, compreensão, e, principalmente, pelo amor em todos os momentos dessa nossa jornada.

- À minha família, em especial aos meus pais, Amauri e Leise, e minhas irmãs pelo constante apoio e confiança que foram fundamentais para a realização de meus sonhos.

- A todos os professores do grupo de Engenharia de Software do ICMC, em especial à Profa. Dra. Rosely Sanches pela recepção e orientação acadêmica em minha chegada ao ICMC.

- Ao Fred pelas orações, amizade, conselhos e incentivo constantes.

- Ao Adenilso, amigo de todas as horas e com quem sempre pude contar para discutir idéias e buscar soluções. Aos amigos André e Rodrigo que também contribuíram com parte das informações utilizadas nesta tese. À Profa. Dra. Sandra Fabbri sempre disposta a ajudar no que for preciso e aos demais amigos e amigas do LABES e do ICMC que tornaram muito mais agradáveis os momentos dentro e fora da USP.

- Aos companheiros de moradia em Richardson - Texas, Tatiana e Paulo, e aos demais brasileiros encontrados por lá por tornar muito mais amistosa e agradável nossa estadia.

A todos os funcionários do ICMC, em especial à Ana Paula, Beth, Enza, Marília, Laura e Tatiana pelo apoio acadêmico.

- À FAPESP, CNPq e a The University of Texas at Dallas pelo suporte financeiro. 
$\mathrm{O}$ DESENVOLVIMENTO de software baseado no paradigma Orientado a Objetos (OO) e baseado em componentes é uma realidade. Este trabalho trata de teste e validação dentro desse contexto. Observa-se que diversos trabalhos relacionados ao teste de programas OO vêm sendo desenvolvidos. Apesar de ser um ponto controverso, alguns pesquisadores consideram que critérios de teste desenvolvidos para o teste de programas procedimentais podem ser facilmente estendidos para o teste de programas $\mathrm{OO}$, pelo menos para o teste de métodos. Ainda são poucas as iniciativas de estender critérios de fluxo de dados e critérios baseados em mutação, tradicionalmente utilizados no teste de programas procedimentais, para o teste de programas OO. O presente trabalho visa a contribuir na identificação e definição de recursos de teste e validação que possam ser utilizados no teste de programas OO, com ênfase nos critérios de teste baseados em fluxo de dados e em mutação, cobrindo as fases do teste de unidade e de integração. Além disso, para apoiar a aplicação desses critérios, é de fundamental importância o desenvolvimento de ferramentas automatizadas que permitam a realização de estudos comparativos e a transferência tecnológica para a indústria. Em suma, o presente trabalho traz contribuições teóricas, com a definição de critérios de teste; empírica, com a realização de estudos empíricos; e de automatização, com a definição e implementação de um ambiente integrado de teste e validação para programas OO. Exemplos são utilizados para ilustrar as idéias e ferramentas apresentadas neste trabalho. 
$\mathrm{T}$ HE development of Object-Oriented (OO) and component-based software is a reality. This work investigates software testing and validation in this context. Several studies related with OO testing have been carried out. In spite of being a controversial point, some researchers state that the procedural testing criteria can be easily extended to OO program testing, for instance to the testing of methods. There are few initiatives aiming at applying data-flow and mutationbased criteria, traditionally used for procedural testing, to the test of OO programs. The present work aims at contributing to identify and define resources for OO program testing and validation, considering data-flow and mutation based testing criteria, involving the unit and integration testing phases. An integrated environment for testing and validation has been developed to support the application of these criteria. This environment provides means to comparative studies amongst the criteria and to technology transfer processes. This work provides contributions to the following testing perspectives: theoretical - with the definition of testing criteria; empirical with the conduction of empirical studies; and to testing automation - with the specification and implementation of an integrated environment for testing and validation of $\mathrm{OO}$ programs. Examples are provided to illustrate the ideas and tools presented in this work. 
2.1 Direções de pesquisa na área de teste de software (Harrold, 2000). . . . . . 20

2.2 Relacionamento entre teste de unidade, de integração e de sistema: programas procedimentais e OO (Binder, 1999). . . . . . . . . . . . 24

2.3 Hierarquia dos critérios de Rapps e Weyuker (1982, 1985) e PotenciaisUsos (Maldonado, 1991). . . . . . . . . . . . . . . . . . 34

2.4 Hierarquia da relação de inclusão entre os critérios de Fluxo de Dados (esquerda) e os Critérios de Exceção (direita) (Sinha e Harrold, 1999). . . . 43

3.1 Exemplo de execução de instruções de bytecode. . . . . . . . . . . . . . . . 72

3.2 Ilustração de um $\mathcal{I} \mathcal{G}$ para o método Vet.average() . . . . . . . . . . . . . . . 75

3.3 Diferentes abordagens para lidar com blocos finally: (a) Único nó de finally (b) Múltiplos nós de finally. . . . . . . . . . . . . . . . . . 77

3.4 Diferentes configurações da pilha de operandos. . . . . . . . . . . . . . 83

3.5 Como são gerados os conjuntos def $(i)$, uso $(i)$ e usol $(i)$ no grafo $\mathcal{D U G}$. . . 86

3.6 Algoritmo para gerar o grafo $\mathcal{D U \mathcal { G }}$ a partir de um grafo $\mathcal{I} \mathcal{G}$. . . . . . . . . 87

3.7 Situações que levam uma instrução de bytecode a encerrar um bloco de instruções. . . . . . . . . . . . . . . . . . . . . . . . . 88

3.8 Grafo $\mathcal{D U G}$ do método Vet.average() . . . . . . . . . . . . . . . . . . . . . 89

3.9 Hierarquia entre os critérios estruturais intra-método. . . . . . . . . . . . . 101

$3.10 \mathcal{D U} \mathcal{G}$ s utilizados para fornecer contra-exemplos nas provas das relações de inclusão estrita entre os critérios primários (Rapps e Weyuker, 1985). . . . 102

$3.11 \mathcal{D U} \mathcal{G}_{\mathrm{S}}$ utilizados para fornecer contra-exemplos nas provas das relações de inclusão estrita entre os critérios dependentes de exceção. . . . . . . . . . . . . 104

3.12 Estrutura de controle que maximiza o número de potenciais-du-caminhos (Maldonado, 1991) . . . . . . . . . . . . . . . . . . 109

4.1 Tipos de erros de integração (Delamaro et al., 2001a): (a) Erro tipo 1, (b) Erro tipo 2, (c) Erro tipo 3. . . . . . . . . . . . . . . . . . . . . 124

4.2 Modelo básico de duas threads compartilhando um objeto (Delamaro et al., 2001b) . . . . . . . . . . . . . . . . . . . 134

4.3 Modelo de duas threads compartilhando um objeto, incluindo os conjuntos de espera (wait sets) (Delamaro et al., 2001b). . . . . . . . . . . . . 136

4.4 Estratégias de teste incrementais baseadas no teste de mutação. . . . . . . . 144 
5.1 Síntese das operações realizadas para análise de cobertura. . . . . . . . . 162

5.2 Módulos principais da ferramenta JaBUTi. . . . . . . . . . . . . . . . . . 163

5.3 Exemplo de uma aplicação Java (Orso et al., 2001) . . . . . . . . . . . . 165

5.4 Janela do gerenciador de projetos. . . . . . . . . . . . . . . . . 166

5.5 Tela da JaBUTi considerando ativo o critério Todos-Nós ${ }_{e i}$ : Bytecode inicial. 167

5.6 Tela da JaBUTi considerando ativo o critério Todos-Nós ${ }_{e i}$ : $\mathcal{D U \mathcal { G }}$ inicial. . . 168

5.7 Tela da JaBUTi considerando ativo o critério Todos-Nós ${ }_{e i}$ : Código fonte inicial. . . . . . . . . . . . . . . . . . . . . 169

5.8 Parte dos requisitos de teste de três critérios estruturais para o método

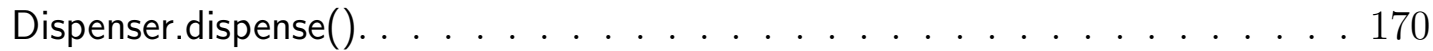

5.9 Tela atualizada do bytecode do método Dispenser dispense() para o critério Todos-Nós $s_{e i}$ após a execução do caso de teste 0001. . . . . . . . . . . . . . 172

5.10 Tela atualizada do $\mathcal{D U \mathcal { G }}$ do método Dispenser.dispense() para o critério Todos-Nós $_{e i}$ após a execução do caso de teste 0001. . . . . . . . . . . . . . 173

5.11 Primeira etapas da exibição dos requisitos do critério Todas-Arestas ${ }_{e i}$ para o método Dispenser dispense() . . . . . . . . . . . . . . . . . . . 174

5.12 Segunda etapa da exibição dos requisitos do critério Todas-Arestas ${ }_{e i}$ para o método Dispenser.dispense() . . . . . . . . . . . . . . . . . . . . . 175

5.13 Relatórios de teste da cobertura em relação a cada método, critério e caso de teste. . . . . . . . . . . . . . . . . 176

5.14 Projeto da base de dados para a ferramenta de mutação - Proteum/OO . 180 5.15 Arquitetura da ferramenta Proteum/OO, adaptada de (Yano et al., 2003). 181

5.16 Reuso das descrições em $\mathcal{M} u \mathcal{D} e \mathcal{L}$ dos operadores intra-método. . . . . . . 182 


\section{Lista de Tabelas}

2.1 Diferenças entre programação OO e procedimental. . . . . . . . . . . . . . 12

2.2 Relação entre fases de teste de programas procedimentais e OO. . . . . . . 26

2.3 Relações definidas por Frankl e Weyuker (1993a) e suas implicações quanto à efetividade em revelar erros. . . . . . . . . . . . . . . . . 36

2.4 Operadores de Mutação de Classe - Class Mutation (Kim et al., 2000a). 48

2.5 Operadores de Mutação de Classe adicionais de Chevalley (2001). . . . . . 48

2.6 Operadores de Mutação para o teste Inter-Classe (Ma et al., 2002). ... . 50

2.7 Relação entre falhas e operadores (Ma et al., 2002). . . . . . . . . . . . . 51

2.8 Resultados da aplicação do método de Partição-Categoria. . . . . . . . . . . 58

2.9 Características apresentadas pelas ferramentas de teste OO. . . . . . . . 65

3.1 Diferentes classes de instruções de bytecode. . . . . . . . . . . . . . . . . 79

3.2 Conjunto de requisitos de teste estruturais derivados pelos critérios de fluxo de controle para o método Vet.average() . . . . . . . . . . . . . . . 97

3.3 Conjunto de requisitos de teste estruturais derivados pelo critério todosusos para o método Vet.average() . . . . . . . . . . . . . . . . . 99

3.4 Conjunto de requisitos de teste estruturais derivados pelo critério todospotenciais-usos para o método Vet.average(). . . . . . . . . . . . . . . . 100

3.5 Conjunto de requisitos de teste derivados a partir do grafo $\mathcal{D U} \mathcal{G}$ da Figura 3.11(a) . . . . . . . . . . . . . . . . . . 105

3.6 Conjunto de requisitos de teste derivados a partir do grafo $\mathcal{D U} \mathcal{G}$ da Figura 3.11(b) . . . . . . . . . . . . . . . . . . . 107

3.7 Seqüência de passos da estratégia incremental. . . . . . . . . . . . . . . . 110

4.1 Operadores de mutação de unidade para o teste intra-método. . . . . . . . . 119

4.2 Conjunto de constantes requeridas . . . . . . . . . . . . . . 126

4.3 Conjunto de constantes requeridas para Java . . . . . . . . . . . . . . . . 127

4.4 Operadores de mutação de interface para o teste inter-método. . . . . . . . . 128

4.5 Operadores de mutação para o teste inter-classe. . . . . . . . . . . . . . 130

4.6 Conjunto de Operadores de Mutação de Concorrência para Java (Delamaro et al., 2001b). . . . . . . . . . . . . . . . . . . . . . . 137

4.7 Síntese das estratégias incrementais. . . . . . . . . . . . . . . . . . 144

4.8 Número total e porcentagem de mutantes gerados para cada classe de operadores. 
4.9 Número total e porcentagem de mutantes equivalentes para cada classe de operadores. . . . . . . . . . . . . . . . . . . . . 149

4.10 Média dos dados coletados para os cinco programas. . . . . . . . . . . 151

4.11 Total e porcentagem de mutantes gerados e equivalentes do programa Sort. 153

4.12 Programa Sort: dados reais $\times$ valores estimados para um conjunto de teste de 20 elementos . . . . . . . . . . . . . . . . . . . . 154

4.13 Programa Sort: dados reais $\times$ valores estimados para um conjunto de teste de 100 elementos . . . . . . . . . . . . . . . . . . . 154

4.14 Taxa de erro: (a) 20 casos de teste; e (b) 100 casos de teste . . . . . . . . 155

5.1 Complexidade dos pacotes que compõem a ferramenta JaBUTi. . . . . . . 163

6.1 Complexidade dos programas do Conjunto $I_{d s} \ldots \ldots \ldots$. . . . . . 186

6.2 Complexidade dos programas do Conjunto $I_{a p p} \ldots \ldots \ldots$. . . . . . . 187

6.3 Complexidade dos pacotes do Conjunto II. . . . . . . . . . . . . . . . . . . 188

6.4 Complexidade das classes do Programa I. . . . . . . . . . . . . . . . . . . . 191

6.5 Complexidade das classes do Programa II. . . . . . . . . . . . . . . . . . . . 191

6.6 Número de requisitos de teste para as classes do Programa II. . . . . . . . . 192

6.7 Cobertura do conjunto de teste $T_{f}$ em relação aos critérios estruturais. . . 193

6.8 Cobertura do conjunto de teste $T_{n}$ em relação aos critérios estruturais. . . 193

6.9 Cobertura do conjunto de teste $T_{u}$ em relação aos critérios estruturais. . . 193

6.10 Custo em termos do número de casos de teste: Programa I. . . . . . . . . . 194

6.11 Cobertura de um conjunto de teste $T_{f}$-adequado em relação aos critérios estruturais. . . . . . . . . . . . . . . . . . 195

6.12 Cobertura de um conjunto de teste $T_{n}$-adequado em relação aos critérios estruturais. . . . . . . . . . . . . . . . . . 196

6.13 Cobertura de um conjunto de teste $T_{a}$-adequado em relação aos critérios estruturais. . . . . . . . . . . . . . . . 196

6.14 Cobertura de um conjunto de teste $T_{u}$-adequado em relação aos critérios estruturais. . . . . . . . . . . . . . . . . . . 197

6.15 Custo em termos do número de casos de teste: Programa II. . . . . . . . . . 197

A.1 Operadores de Mutação de Constantes e Variáveis. . . . . . . . . . . . . 225

A.2 Operadores de Mutação de Operadores. . . . . . . . . . . . . . . . 226

A.3 Operadores de Mutação de Comandos. . . . . . . . . . . . . . . . . . . . . 227

A.4 Operadores de Mutação de Interface. . . . . . . . . . . . . . . . . . . 228

A.5 Operadores de Mutação de Classe - Class Mutation (Kim et al., 2000a). 229

A.6 Operadores de Mutação de Classe adicionais de Chevalley (2001). . . . . . 229

A.7 Operadores de Mutação para o teste Inter-Classe (Ma et al., 2002). . . . 230

A.8 Conjunto de Operadores de Mutação de Concorrência para Java (Delamaro et al., 2001b). . . . . . . . . . . . . . . . . . . . 231 
1 Introdução 1

1.1 Contexto e Motivação . . . . . . . . . . . . . . . . . . . . . . . . 4

1.2 Objetivos da Tese . . . . . . . . . . . . . . . . . . . 6

1.3 Organização da Tese . . . . . . . . . . . . . . . . . . . . 7

2 Revisão Bibliográfica $\quad 9$

2.1 Terminologia e Conceitos Básicos de $\mathrm{OO} \ldots \ldots \ldots$. . . . . . . . 9

2.2 Principais Problemas no Teste de Programas OO . . . . . . . . . . . . . . 12

2.2.1 Efeitos Colaterais do Paradigma OO . . . . . . . . . . . . . . 13

2.2.1.1 Encapsulamento . . . . . . . . . . . . . . . . 13

2.2.1.2 Herança . . . . . . . . . . . . . . . . . . . 14

2.2.1.3 Polimorfismo . . . . . . . . . . . . . . . . 17

2.2.1.4 Outros Problemas . . . . . . . . . . . . . 19

2.3 Direções na Área de Teste . . . . . . . . . . . . . . . . . . . . . . . . . . . . . . . . . . . . . . . . . .

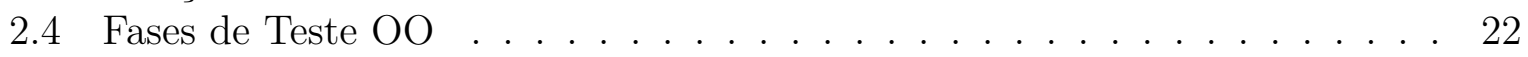

2.5 Estratégias, Técnicas e Critérios de Teste OO . . . . . . . . . . 26

2.5.1 Teste Funcional . . . . . . . . . . . . . . . . . . . . 27

2.5.2 Teste Baseado em Estados . . . . . . . . . . . . . . . . . . . . 29

2.5.3 Teste Baseado em Análise de Fluxo de Dados . . . . . . . . . . . . 32

2.5.4 Teste Baseado em Mutação . . . . . . . . . . . . . . . . . . . . 44

2.6 Teste de Componentes de Software . . . . . . . . . . . . . . . 51

2.7 Avaliação e Comparação entre Critérios de Teste OO $\ldots$. . . . . . . . 56

2.8 Automatização da Atividade de Teste . . . . . . . . . . . . . . . . . . . . 59

2.9 Considerações Finais . . . . . . . . . . . . . . . . . . . . . . 66

3 Teste de Fluxo de Dados OO

3.1 Motivação . . . . . . . . . . . . . . . . . . . 70

3.2 Terminologia e Conceitos Básicos . . . . . . . . . . . . . . 70

3.2 .1 Bytecode Java . . . . . . . . . . . . . . . . . . . . . . . . 71

3.2.2 Construindo o Grafo de Instruções - $\mathcal{I} \mathcal{G}$. . . . . . . . . . . . . . . 72

3.2.3 Incluindo Informações de Fluxo de Dados no $\mathcal{I} \mathcal{G}$. . . . . . . . . . . 78

3.2.3.1 Modelo de Fluxo de Dados para Bytecode Java . . . . . . 78

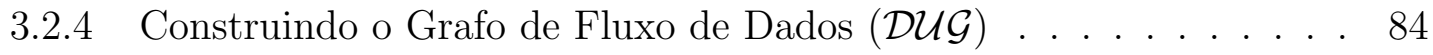


3.3 Definição dos Critérios . . . . . . . . . . . . . . . . . . . . . 94

3.3.1 Critérios de Fluxo de Controle . . . . . . . . . . . . . . . . 95

3.3.2 Critérios de Fluxo de Dados . . . . . . . . . . . . . . . . . . . . 96

3.4 Análise de Propriedades . . . . . . . . . . . . . . . . . . . . . . . . . . . . 99

3.4.1 Análise de Inclusão . . . . . . . . . . . . . . . . . . . . . . . . . . . 99

3.4.2 Análise de Complexidade . . . . . . . . . . . . . . . . . . . 108

3.5 Estratégia de Teste Incremental . . . . . . . . . . . . . . . . . . . 109

3.6 Considerações Finais . . . . . . . . . . . . . . . . . . . . . . . 111

4 Teste de Mutação OO

4.1 Motivação . . . . . . . . . . . . . . . . . . . . . . . 113

4.2 Terminologia e Conceitos Básicos . . . . . . . . . . . . . . . 115

4.3 Definição dos Critérios . . . . . . . . . . . . . . . . . 117

4.3 .1 Teste Intra-Método . . . . . . . . . . . . . . . . . . . . . 118

4.3 .2 Teste Inter-Método . . . . . . . . . . . . . . . . . . . . . . 123

4.3 .3 Teste Inter-Classe . . . . . . . . . . . . . . . . . . . . . 128

4.3.4 Operadores de Mutação para o Teste de Programas Concorrentes 131

4.4 Análise de Propriedades . . . . . . . . . . . . . . . . . . . . 138

4.4 .1 Análise de Inclusão . . . . . . . . . . . . . . . . . . . . . . . . . 138

4.4.2 Análise de Complexidade . . . . . . . . . . . . . . . . . . . . . 140

4.4.2.1 Estabelecendo uma Estratégia Incremental . . . . . . . . . 143

4.4.2.2 Auxiliando a Identificar Mutantes Equivalentes: Estratégia Bayseana . . . . . . . . . . . . . . . 145

4.5 Considerações Finais . . . . . . . . . . . . . . . . . . 156

5 Aspectos de Automatização $\quad 159$

5.1 Motivação . . . . . . . . . . . . . . . . . . . . . 160

5.2 A Ferramenta JaBUTi - Teste de Fluxo de Dados OO . . . . . . . . . . 160

5.2.1 Arquitetura e Aspectos de Implementação . . . . . . . . . . . . . . . . 162

5.2 .2 Aspectos Operacionais . . . . . . . . . . . . . . . 164

5.2.2.1 Programa Exemplo . . . . . . . . . . . . . . 165

5.2.2.2 Criando um Projeto de Teste . . . . . . . . . . . . 166

5.2.2.3 Melhorando a Cobertura dos Requisitos de Teste . . . . . 168

5.2.2.4 Visualizando a Cobertura em Programas/Componentes Java e seus Grafos Def-Uso . . . . . . . . . . . . . . . . . 172

5.2.2.5 Gerando Relatórios de Teste . . . . . . . . . . . . . . . 174

5.2.3 Utilizando JaBUTi em uma Estratégia de Teste . . . . . . . . . . . 177

5.3 A Ferramenta Proteum/OO - Teste de Mutação OO . . . . . . . . . . . 178

5.3.1 Requisitos de Implementação . . . . . . . . . . . . . . . . . . . . . 179

5.3.2 Requisitos Operacionais . . . . . . . . . . . . . . . . . . . 182

5.4 Considerações Finais . . . . . . . . . . . . . . . . . . . . . 184

6 Aplicando os Critérios de Teste Estruturais $\quad 185$

6.1 Programas Utilizados . . . . . . . . . . . . . . . . . . . . . 185

6.2 Análise Estática: Número de Requisitos . . . . . . . . . . . . . . . . . . . . 188

6.3 Exemplo de Aplicação da Estratégia Incremental . . . . . . . . . . . . . . 190

6.4 Considerações Finais . . . . . . . . . . . . . . . . . . . 198 
$\begin{array}{llr}7 & \text { Conclusão } & 199\end{array}$

7.1 Contribuições . . . . . . . . . . . . . . . . . . . . . . . . . . . . . . 199

7.1.1 Contribuições Relacionadas ao Teste Estrutural OO . . . . . . . . . 199

7.1.2 Contribuições Relacionadas ao Teste Baseado em Mutação . . . . . 200

7.1.3 Contribuições Relacionadas ao Teste de Componentes . . . . . . . . . 202

7.2 Trabalhos Futuros . . . . . . . . . . . . . . . . . 203

7.2.1 Definição de Critérios de Teste . . . . . . . . . . . . . . . . 203

7.2.2 Desenvolvimento de Ferramentas . . . . . . . . . . . . . . 203

7.2.3 Condução de Experimentos . . . . . . . . . . . . . . . . . . . 203

7.2.4 Teste de Componentes de Software . . . . . . . . . . . . . . . . . 204

7.2.5 Uso de Informações de Teste em Atividades de Depuração . . . . . . 204

7.2.6 Uso de Técnicas de Inteligência Artificial para Apoiar a Atividade de Teste . . . . . . . . . . . . . . . . 205

Referências Bibliográficas

A Descrição dos Operadores de Mutação

A.1 Descrição dos Operadores de Unidade . . . . . . . . . . . . . . . 225

A.2 Descrição dos Operadores de Integração . . . . . . . . . . . . . . . . . . . . . . . . . . . . . . . . . . . . . . . . . . . . .

A.3 Descrição dos Operadores de Classe . . . . . . . . . . . . . . . . . . . . . . 229

A.4 Descrição dos Operadores de Concorrência . . . . . . . . . . . . . . . . . . 231 


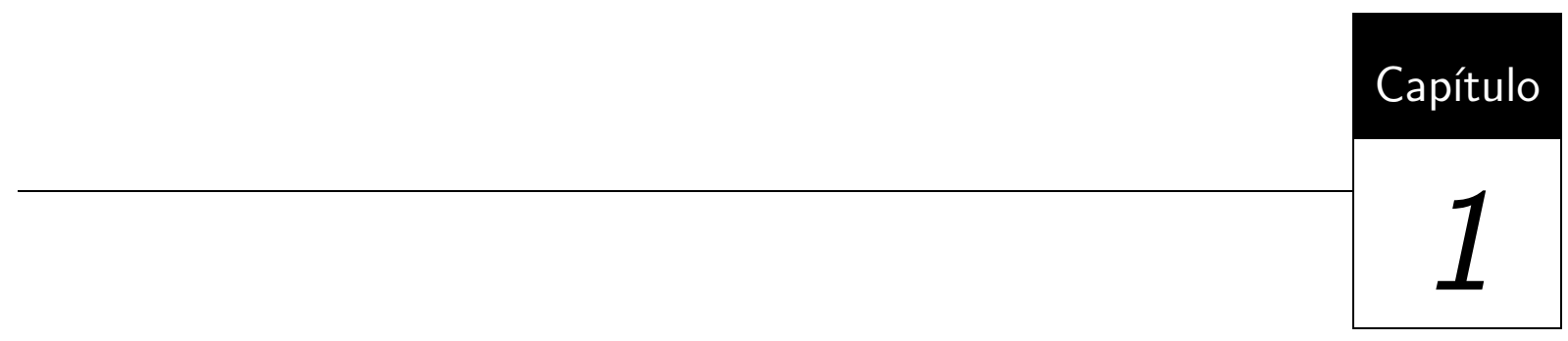

Introdução

$\mathrm{O}$ PROCESSO de desenvolvimento de software envolve uma série de atividades e mesmo com a evolução significativa da Engenharia de Software, com o estabelecimento de técnicas, métodos e ferramentas, os produtos de software desenvolvidos ainda podem conter defeitos. Assim sendo, atividades agregadas sob o nome de Garantia de Qualidade de Software têm sido introduzidas ao longo de todo o processo de desenvolvimento, entre elas atividades de Verificação, Validação e Teste (VV\&T), visando a reduzir a ocorrência de erros e os riscos associados. Dentre as técnicas de verificação e validação, a atividade de teste constitui um dos elementos para aprimorar a produtividade e fornecer evidências da confiabilidade e qualidade do produto de software desenvolvido, em complemento a outras atividades, como por exemplo o uso de revisões e de técnicas formais e rigorosas de especificação e de verificação (Maldonado, 1997; Maldonado et al., 1998).

O teste de produtos de software envolve basicamente quatro etapas: planejamento de testes, projeto de casos de teste, execução e avaliação dos resultados dos testes (Myers, 1979; Beizer, 1990; Maldonado, 1991; Pressman, 2001). Essas etapas devem ser desenvolvidas ao longo do próprio processo de desenvolvimento de software e concretizam-se em três fases de teste: de unidade, de integração e de sistema.

Considerada como sendo uma das atividades mais onerosas do processo de desenvolvimento, chegando a consumir 50\% dos custos (Harrold, 2000), a atividade de teste consiste em uma atividade dinâmica que visa a revelar defeitos. Além disso, Harrold destaca que o conjunto de informações obtido durante os testes é de fundamental importância para as atividades de depuração, manutenção e estimativa de confiabilidade (Harrold, 2000). 
Para fornecer uma maneira sistemática para a geração e avaliação de conjuntos de teste, técnicas e critérios têm sido desenvolvidos. As técnicas e critérios de teste fornecem ao testador uma abordagem sistemática e teoricamente fundamentada, além de constituírem um mecanismo que pode auxiliar a avaliar a qualidade da atividade de teste. As técnicas de teste são classificadas em funcional, estrutural e baseada em defeitos. Do ponto de vista comportamental do sistema, tem-se o teste baseado em máquinas de estados finitos, muito utilizado na área de protocolos de comunicação e no contexto do paradigma Orientado a Objetos. Cada uma das técnicas possui um conjunto de critérios de teste que podem ser utilizados tanto para a geração de conjunto de teste quanto para a avaliação da adequação desses conjuntos. Essas técnicas de teste devem ser vistas como complementares e a questão que se coloca é como utilizá-las de forma que as vantagens de cada uma sejam melhor exploradas.

Dada a diversidade de critérios que têm sido estabelecidos e reconhecido o caráter complementar das técnicas e critérios de teste, um ponto crucial que se coloca nessa perspectiva é a escolha e/ou a determinação de uma estratégia de teste, que em última análise passa pela escolha de critérios de teste, de forma que as vantagens de cada um desses critérios sejam combinadas objetivando uma atividade de teste de maior qualidade. Estudos teóricos e empíricos de critérios de teste são de extrema relevância para a formação desse conhecimento, fornecendo subsídios para o estabelecimento de estratégias de baixo custo e alta eficácia (Maldonado et al., 1998). Em particular, identificam-se algumas iniciativas no contexto de programas $\mathrm{OO}$ e no teste de componentes (Offutt e Irvine, 1995; Martins e Toyota, 1999; Yanagawa e Martins, 2000; Souter e Pollock, 2003).

Nos estudos teóricos procura-se avaliar os critérios de teste analisando suas características como custo de aplicação, eficácia em revelar defeitos e comparando os critérios entre si. Nos estudos empíricos os critérios de teste são aplicados em um grupo de programas selecionados e o resultado dessa aplicação é avaliado de modo que o custo e a eficácia de cada critério também possam ser avaliados.

Na prática, a aplicação de um critério de teste está fortemente condicionada à sua automatização. O desenvolvimento de ferramentas de teste é de fundamental importância uma vez que a atividade de teste é muito propensa a erros, além de improdutiva, se aplicada manualmente. Além disso, ferramentas de teste facilitam a condução de estudos empíricos que visam a avaliar e a comparar os diversos critérios de teste. Assim sendo, a disponibilidade de ferramentas de teste propicia maior qualidade e produtividade para a atividade de teste. Na literatura podem ser encontrados diversos esforços da comunidade científica nessa direção, tanto para o teste de programas procedimentais, como para o teste de programas OO (Doong e Frankl, 1994; Agrawal et al., 1998; Telcordia Technologies USA, 1998; BENDER \& Associates Inc., 1998; Quest Software, 2003; INTERNATIO- 
NAL SOFTWARE AUTOMATION (ISA), 1999a; Martins e Toyota, 1999; PARASOFT Corporation, 2000b; Corporation, 2002; PARASOFT Corporation, 2000a,c; Productivity through Sofware plc., 2000; RATIONAL Software Corporation, 2000a,b).

Pode-se observar que os critérios baseados em análise de fluxo de dados (Herman, 1976; Laski e Korel, 1983; Rapps e Weyuker, 1982, 1985; Ntafos, 1984; Ural e Yang, 1988) e o critério Análise de Mutantes (DeMillo et al., 1978; DeMillo, 1987; Budd, 1981), um dos critérios da técnica baseada em defeitos, introduzidos em meados da década de 70, têm sido investigados fortemente nessas últimas décadas por diversos pesquisadores fornecendo evidências que esses critérios, hoje investigados fundamentalmente no meio acadêmico, às vezes em cooperação com a indústria, podem, em médio prazo, constituir o estado da prática em ambientes de produção de software.

Em relação ao teste de mutação, além de se mostrar eficaz em revelar defeitos (Wong e Mathur, 1995a), o critério Análise de Mutantes, proposto inicialmente para o teste de unidade em programas procedimentais, tem se mostrado bastante flexível e já foi estendido para permitir a realização de teste de integração (Delamaro et al., 2001a), bem como para o teste de outras "entidades executáveis" em nível de especificação como por exemplo Máquinas de Estados Finitos (Fabbri et al., 1993, 1994), Redes de Petri (Fabbri et al., 1995; Simão, 2000), Statecharts (Fabbri, 1996; Sugeta, 1999), Estelle (Probert e Guo, 1991; Souza et al., 1999), SDL (Sugeta et al., 2004) e Especificações Algébricas (Woodward, 1993).

Offutt e Irvine (1995), em meados dos anos 90, comentaram que poucas eram as iniciativas que buscavam avaliar a adequação de técnicas e critérios de teste procedimentais no contexto de orientação a objetos. Os autores consideravam que antes que novos critérios de teste fossem desenvolvidos, uma avaliação fosse realizada, inclusive para identificar como os critérios de teste procedimentais já existentes poderiam ser adaptados para o teste de programas OO (Offutt e Irvine, 1995). Em consonância com essa perspectiva identificam-se vários trabalhos que exploram critérios de teste baseados em máquinas de estados finitos (Hoffman e Strooper, 1993; Turner e Robson, 1993a; Kung et al., 1996; McGregor, 1994; McDaniel e McGregor, 1994; Hoffman e Strooper, 1997; Chen et al., 1998; Binder, 1999; Chen et al., 2001), e também algumas extensões de critérios estruturais (Jorgensen e Erickson, 1994; Harrold e Rothermel, 1994; Kim e Wu, 1996; Binder, 1999; Sinha e Harrold, 1999; Souter e Pollock, 2003) que estão sendo exploradas no contexto de OO. Mais recentemente algumas iniciativas de estender critérios baseados em defeitos também são identificadas (Ghosh e Mathur, 2001; Jackson e Woodward, 2000; Sridhanan et al., 2000; Chevalley, 2001; Ma et al., 2002). Entretanto, ainda são poucas as iniciativas que visam a comparar a eficácia dessas técnicas e critérios em revelar defeitos em programas OO (Chen et al., 1999; Kim et al., 2000b, 2001). 
Conforme destacado por Harrold (2000), o teste de sistemas baseado em componentes de software, o qual inclui o teste de programas OO, o desenvolvimento de processos de teste efetivos e a demonstração da eficácia de critérios e estratégias de teste, constituem, atualmente, as principais direções para a área de teste de software. Para atingir tais objetivos é de fundamental importância o desenvolvimento de métodos e ferramentas de teste que dêem suporte à realização de estudos empíricos, bem como favoreçam a transferência tecnológica e a capacitação do parque tecnológico industrial (Harrold, 2000).

O teste de software $\mathrm{OO}$ e o teste de componentes devem lidar com novos problemas introduzidos pelas características das linguagens OO. Encapsulamento, herança, polimorfismo e acoplamento dinâmico, embora tragam benefícios para o projeto e codificação, oferecem novos desafios para as áreas de teste e de manutenção (McDaniel e McGregor, 1994). Atualmente, a maioria das organizações desenvolvedoras de software ainda estão no processo de transição para o paradigma $\mathrm{OO}$ e, à medida que mais e mais organizações adotarem tal paradigma maior será a demanda por técnicas, critérios e ferramentas que apóiem o teste de programas OO e de sistemas baseados em componentes (Kung et al., 1998; Harrold, 2000). No contexto de componentes, um projeto sendo desenvolvido pela Comunidade Européia, denominado CLARiFi - CLear And Reliable Information For Integration, visa a contribuir no desenvolvimento de um repositório de informações sobre componentes de modo a facilitar tanto o usuário de componentes a encontrar o componente desejado para desenvolver sua aplicação, bem como auxiliar o desenvolvedor de componentes a identificar quais as necessidades de seus usuários (Thomason et al., 2000; CLARiFi Project Team, 2000). Outra iniciativa relacionada ao desenvolvimento de software baseado em componentes é o projeto CBSEnet - Component Based Software Engineering Network) que visa a: i) criar um forum de discussão para a troca de informações entre pesquisadores e desenvolvedores trabalhando na área de CBSE; ii) sugerir como tecnologias de desenvolvimento baseado em componentes podem ser utilizadas para melhorar o processo de engenharia de software em diferentes domínios; e iii) propor linhas de pesquisa para o desenvolvimento de tecnologias de CBSE (CBSEnet Project Team, 2002). Tais iniciativas evidenciam a preocupação relacionada ao desenvolvimento baseado em componentes.

\subsection{Contexto e Motivação}

O teste de software, em conjunto com outras atividades de VV\&T, é de fundamental importância para a garantia da qualidade dos produtos de software desenvolvidos. Embora a orientação a objetos resolva alguns dos problemas do paradigma procedimen- 
tal, características como encapsulamento, herança, polimorfismo e acoplamento dinâmico introduzem novos desafios para a área de teste.

Diversas técnicas e critérios de teste vêm sendo propostos para apoiar a seleção de conjuntos de teste e dar indicações de quão bem testado está o produto de software. No contexto de orientação a objetos apesar de diversos trabalhos nessa direção, ainda são poucas as evidências sobre a eficácia das técnicas e critérios propostos. Assim, como destacado por Offutt e Irvine (1995), os critérios de teste utilizados no paradigma procedimental precisam ser avaliados no contexto da orientação a objetos e, quando necessário, passar por adaptações que permitam que os mesmos possam ser utilizados no teste de programas OO. Dessa forma, a experiência e o conhecimento já acumulado poderiam ser utilizados no contexto do paradigma $\mathrm{OO}$ e de desenvolvimento baseado em componentes.

Observa-se que uma grande quantidade de critérios de teste para validar os aspectos comportamentais de sistemas orientados a objetos foi desenvolvida (Hoffman e Strooper, 1993; Turner e Robson, 1993a; Kung et al., 1996; McGregor, 1994; McDaniel e McGregor, 1994; Hoffman e Strooper, 1997; Chen et al., 1998; Chen e Kao, 1999; Binder, 1999). Entretanto, como destaca Binder (Binder, 1999), o teste baseado em estados não detecta todos os tipos de defeitos, exigindo que critérios de teste complementares, tais como critérios de fluxo de controle e de dados também sejam desenvolvidos e aplicados para assegurar um teste de melhor qualidade.

O grupo de Engenharia de Software do ICMC/USP em colaboração com outros grupos de pesquisa na área de teste (DCA/FEEC/UNICAMP em Campinas e UNIVEM em Marília) vem desenvolvendo atividades de pesquisa concentradas no estudo de princípios, estratégias métodos e critérios de teste e validação de software, bem como na especificação e implementação de ferramentas de teste que apóiem a realização das atividades de teste e viabilizem a avaliação do aspecto complementar dos critérios de teste por meio de estudos empíricos. Dois critérios de teste bastante explorados pelo grupo são os critérios baseados em fluxo de dados e os critérios baseados em mutação. No contexto de fluxo de dados destaca-se o desenvolvimento da família de critérios Potenciais-Usos que pode ser utilizada tanto no teste de unidade (Maldonado, 1991) quanto no teste de integração (Vilela, 1998), com o suporte automatizado da ferramenta Poke-Tool (Chaim, 1991). No contexto do teste baseado em mutação, para o teste de programas procedimentais, destacam-se o desenvolvimento do critério Mutação de Interface (Delamaro et al., 2001a) destinado ao teste de integração e o desenvolvimento das ferramentas Proteum (Delamaro, 1993; Delamaro e Maldonado, 1996) e PROTEM/IM (Delamaro et al., 2000), que apóiam a aplicação dos critérios Análise de Mutantes e Mutação de Interface, respectivamente. No contexto do teste de especificações destaca-se o desenvolvimento dos critérios mutação para o teste de Máquinas de Estados Finitos (MEF) (Fabbri et al., 1994, 1999a), de 
Statecharts (Fabbri et al., 1997, 1999b) e de Redes de Petri (Fabbri et al., 1995; Simão e Maldonado, 2000), apoiados pelas ferramentas Proteum/FSM (Fabbri et al., 1999a), Proteum/ST (Fabbri et al., 1999b) e Proteum/PN (Fabbri et al., 1995; Simão e Maldonado, 2000; Simão et al., 2000), respectivamente e, mais recentemente, o desenvolvimento de critérios de teste baseados em mutação para Estelle (Probert e Guo, 1991; Souza et al., 1999) e SDL (Sugeta et al., 2004).

Entretanto, considerando o teste de programas, as ferramentas e critérios de teste desenvolvidos e utilizados pelo grupo apóiam a realização do teste de programas procedimentais, tem-se o interesse em avaliar e estender os recursos de teste existentes para o teste de programas $\mathrm{OO}$ e de componentes.

Assim sendo, a diversidade de critérios de teste existentes, a experiência prévia do grupo de Engenharia de Software do ICMC e a necessidade de se avaliar/desenvolver recursos de teste e de validação para programas OO e, também, para o teste de componentes motivaram a realização desta tese cujo objetivo é descrito a seguir.

\subsection{Objetivos da Tese}

O trabalho explorado nesta tese está em consonância com os demais trabalhos que vêm sendo desenvolvidos pelo grupo de Engenharia de Software do ICMC/USP e tem por objetivo avaliar a adequação de critérios de teste estrutural e baseados em defeitos, tradicionalmente utilizados no teste de programas procedimentais, para o teste de programas OO.

No caso dos critérios de teste estrutural, ênfase é dada ao teste intra-método, principalmente visando o desenvolvimento de recursos de teste que permitam utilizar tais critérios não somente no teste de programas, mas também para o teste de componentes de software. Além disso, critérios estruturais tradicionais como todos-nós, todas-arestas, todos-usos e todos-potenciais-usos são revisitados à luz do paradigma OO levando em consideração também aspectos relacionados ao fluxo de controle e de dados relacionados ao tratamento de exceções.

Em relação aos critérios de teste baseados em mutação, ênfase é dada ao teste intramétodo, inter-método e inter-classe, apresentando diferentes conjuntos de operadores de mutação que podem ser utilizados para o teste de programas OO durante as diferentes fases de teste.

Para apoiar a aplicação dos critérios de teste definidos, propõe-se um ambiente integrado de teste e validação, viabilizando a condução de estudos comparativos entre os critérios de teste baseados em fluxo de dados e baseados em mutação no contexto de programas OO. Os resultados obtidos e o ambiente de apoio podem ainda ser utilizados 
para promover a transferência tecnológica e a capacitação das empresas produtoras de software.

\subsection{Organização da Tese}

Neste capítulo foi discutida a importância da atividade de teste para assegurar a qualidade e a confiabilidade dos produtos de software desenvolvidos. Discutiu-se também a necessidade de se avaliar/desenvolver recursos de teste e de validação para programas OO. Foram apresentados o contexto, a motivação e os objetivos para a realização deste trabalho. Os próximos capítulos estão organizados da seguinte maneira:

- No Capítulo 2 é apresentada uma visão geral sobre teste de software OO. São introduzidos os conceitos básicos e a terminologia relacionadas ao paradigma OO, discutidos os principais problemas e direções na área de teste de programas OO. São também identificadas as fases de teste nesse contexto e é feita uma comparação com as fases de teste de programas procedimentais. Além disso, são descritos os principais trabalhos relacionados ao teste baseado em análise de fluxo de dados e baseados em mutação em programas OO, alguns estudos que foram realizados nesse contexto e as iniciativas de automatização desses critérios.

- No Capítulo 3 são caracterizadas as contribuições desta tese relacionadas aos critérios baseados em análise de fluxo de controle e de dados. Critérios baseados em análise de fluxo de controle e de dados são definidos e exemplificados. Duas propriedades dos critérios de teste são analisadas: a relação de inclusão e a complexidade. Com base na hierarquia determinada pela relação de inclusão, uma estratégia de teste incremental é definida.

- No Capítulo 4 são descritas as contribuições desta tese relacionadas aos critérios baseados em mutação. Os critérios de teste são definidos, uma análise de propriedades é apresentada e algumas estratégias de teste baseadas em mutação, definidas originalmente para o teste de programas procedimentais, são descritas. Uma técnica que utiliza informações históricas para auxiliar o testador na identificação de mutantes equivalentes é também descrita.

- No Capítulo 5 é discutida a importância da automatização da atividade de teste e apresentadas as contribuições desta tese no desenvolvimento de uma ferramenta de apoio ao teste baseado em fluxo de dados e na especificação da arquitetura de uma ferramenta para apoiar o teste de mutação. 
- No Capítulo 6, com o auxílio da ferramenta de teste desenvolvida, é apresentado um exemplo de aplicação de parte dos critérios de teste definidos, considerando dois conjuntos de programas e seguindo os passos determinados pela estratégia incremental.

- Finalmente, no Capítulo 7 são descritas as conclusões desta tese e as perspectivas de trabalho futuro.

- O Apêndice A traz a descrição dos operadores de mutação apresentados e discutidos no decorrer desta tese. 


\section{Revisão Bibliográfica}

T ESTE capítulo são apresentados alguns conceitos, terminologia e perspectivas re1 lacionadas ao teste de software Orientado a Objetos. Inicialmente, na Seção 2.1 é dada uma breve descrição das principais características da Orientação a Objetos. Em seguida, na Seção 2.2 são descritas as principais dificuldades relacionadas ao teste de programas OO. Na Seção 2.3 são descritas algumas das principais direções da área de teste de software. Na Seção 2.4 são caracterizadas as fases de teste para programas OO, contrapondo-as com as fases de teste de programas procedimentais. Na Seção 2.5 as principais estratégias, técnicas e critérios de teste definidos para o teste de programas OO e de componentes são descritas. É dada ênfase aos critérios de teste baseados em fluxo de dados e baseados em mutação devido à importância dos mesmos no contexto desta tese. Na Seção 2.7 são sintetizados alguns trabalhos relacionados à avaliação e comparação de critérios de teste OO. A importância da automatização da atividade de teste e as principais contribuições no contexto do teste de programas OO são discutidas na Seção 2.8. Finalmente, na Seção 2.9 são feitas as considerações finais sobre este capítulo.

\subsection{Terminologia e Conceitos Básicos de 00}

De acordo com o padrão IEEE número 610.12-1990 (IEEE, 1990), um defeito (fault) em um programa é um passo, processo ou definição de dados incorreto, como por exemplo, uma instrução ou comando incorreto. Um engano (mistake) é uma ação humana 
que produz um resultado incorreto, como por exemplo, uma ação incorreta tomada pelo programador. Um defeito pode levar um programa a produzir resultados diferentes do esperado, produzindo o que costuma-se chamar de falha (failure). Um erro (error) é uma diferença entre um valor corrente e o valor esperado, ou seja, qualquer estado intermediário ou resultado inesperado na execução de um programa constitui um erro. A literatura, porém, tem utilizado esses termos de diversas maneiras. Nesta tese procurou-se manter o significado desses termos. Entretanto, quando forem tratadas referências a trabalhos de outros autores, os termos originais serão mantidos, a não ser que possam causar dúvidas.

Independentemente da linguagem de programação utilizada no desenvolvimento de um produto de software, este pode ser liberado contendo defeitos não detectados durante a realização dos testes. Na programação estruturada, ênfase é dada ao desenvolvimento de procedimentos, implementados em blocos estruturados, e à comunicação entre procedimentos por passagem de dados. Na programação Orientada a Objetos (POO), dados e procedimentos passam a fazer parte de um só elemento básico, o objeto. A POO introduz uma abordagem na qual o programador visualiza seu programa em execução como uma coleção de objetos cooperantes que se comunicam por meio de troca mensagens. Cada um dos objetos é uma instância de uma classe e todas as classes formam uma hierarquia de classes unidas via relacionamento de herança. Esses e outros conceitos de OO são descritos brevemente a seguir.

Uma classe é uma entidade estática que engloba atributos (ou dados) e métodos (ou funções membro) que representam operações que podem ser realizadas sobre os dados. Um objeto é uma instância de uma classe criada em tempo de execução. Cada objeto tem uma cópia dos dados definidos na classe e encapsula estado e comportamento.

Ao invés da idéia procedimental de entrada e saída para procedimentos, a programação OO se preocupa com os objetos e seus relacionamentos. Os objetos interagem entre si e são ativados por meio de mensagens. Uma mensagem é uma solicitação para que um objeto execute um de seus métodos. O método solicitado pode alterar o estado interno do objeto e/ou enviar mensagens a outros objetos. Ao encerrar sua execução ele retorna o controle e, possivelmente, algum valor ao objeto que enviou a mensagem solicitando a operação.

A capacidade que um objeto tem de impedir que outros objetos tenham acesso aos seus dados é denominada de encapsulamento. O encapsulamento é uma técnica empregada para garantir a ocultação de informações na qual a interface e a implementação de uma classe são separadas sintaticamente. Com isso, somente os métodos pertencentes a um objeto podem ter acesso aos dados encapsulados. O encapsulamento encoraja a modularidade do programa e permite que decisões de projeto fiquem "escondidas" dentro da implementação de modo a restringir possíveis interdependências com outras classes, 
exceto por meio de sua interface. Com isso, mudanças na implementação de um método não deveriam afetar outras classes, a menos que a interface do método seja alterada.

Novas classes podem ser definidas em função de classes já existentes. Tal relacionamento entre classes é obtido por meio de herança. Com a utilização de herança, as classes são inseridas em uma hierarquia de especialização, de modo que uma classe mais especializada herda todas as propriedades da(s) classe(s) mais genérica(s) (classe(s) que está(ão) um nível acima na hierarquia). À classe mais genérica dá-se o nome de superclasse, classe pai ou classe-base e à classe mais especializada dá-se o nome de subclasse, classe filha ou classe derivada. Com o mecanismo de herança, uma subclasse pode estender ou restringir as características herdadas da superclasse.

Algumas linguagens de programação $\mathrm{OO}$, tais como $\mathrm{C}++$, permitem que uma subclasse herde características de mais de uma superclasse, caracterizando o que é chamado de herança múltipla. Entretanto, tal mecanismo pode trazer problemas quando duas superclasses oferecem atributos ou métodos com mesmo nome.

O termo polimorfismo representa a qualidade ou estado de um objeto ser capaz de assumir diferentes formas. Quando aplicado a linguagens de programação indica que uma mesma construção de linguagem pode assumir diferentes tipos ou manipular objetos de diferentes tipos. Por exemplo, o operador "+" nas linguagens C++ e Java pode ser utilizado para fazer a adição de dois valores inteiros ou em ponto-flutuante, bem como para concatenar duas strings. O mecanismo de polimorfismo permite tratar objetos semelhantes de uma maneira uniforme. Neste caso, é possível que se envie uma mesma mensagem para um conjunto de objetos e que cada objeto responda de maneira diferente em função da mensagem recebida.

Uma característica fortemente relacionada com herança e polimorfismo é o acoplamento dinâmico. Em programas procedimentais, sempre que uma nova funcionalidade deve ser acrescentada, a aplicação deve ser alterada e recompilada. Com o conceito de polimorfismo, é possível acrescentar novos métodos a classes já existentes sem a necessidade de recompilar a aplicação. Isto é possível utilizando-se a técnica de acoplamento dinâmico (dynamic binding), que permite que novos métodos sejam carregados e ligados (binding) à aplicação em tempo de execução. A Tabela 2.1 ilustra as principais diferenças entre os paradigmas $\mathrm{OO}$ e procedimental.

Outro termo utilizado no contexto de orientação a objetos é o de cluster. Cluster pode ser definido como um conjunto de classes que cooperam entre si na implementação de determinada(s) funcionalidade(s). As classes dentro de um cluster podem ser fortemente acopladas e trabalhar juntas para fornecer um comportamento unificado ou podem ser independentes e fornecer diferentes tipos de funções similares (Murphy et al., 1994). 
Tabela 2.1: Diferenças entre programação OO e procedimental.

\begin{tabular}{|c|c|}
\hline Programação Orientada a Objetos & Programação Estruturada \\
\hline \hline Métodos & Procedimentos e Funções \\
\hline Variáveis de Instâncias & Variáveis \\
\hline Mensagens & Chamadas a procedimentos e funções \\
\hline Classes & Tipos de dados definidos pelo usuário \\
\hline Herança & - \\
\hline Polimorfismo & - \\
\hline
\end{tabular}

Além dos clusters, outro termo que tem sido utilizado é o de componente de software. Embora possam existir componentes de rotinas em COBOL, por exemplo, foi com a orientação a objetos que o conceito de Desenvolvimento Baseado em Componentes (DBC) ganhou força e tem se tornado uma tendência de desenvolvimento. No contexto de componentes, utiliza-se muito a terminologia empregada em OO. Um componente de software pode ser definido como uma unidade de composição com interfaces bem definidas e especificadas e dependências de contexto explícitas (Szyperski, 1998). A idéia é que um componente de software pode ser desenvolvido independentemente e utilizado por terceiros na composição de um novo sistema.

A idéia de componentes está muito relacionada com o conceito de ocultação de informação ou encapsulamento. Em geral, quando se utiliza um componente de software, o desenvolvedor só tem acesso à sua especificação e à interface de acesso que deve ser utilizada para a obtenção de determinada funcionalidade. O código de um componente, em geral, não é disponibilizado. Com isso, mantendo-se a mesma interface de acesso, a implementação de determinada funcionalidade pode ser alterada sem causar maiores problemas aos projetos que utilizam determinado componente.

\subsection{Principais Problemas no Teste de Programas 00}

O paradigma de programação orientado a objetos possui um conjunto de construções poderosas, que apresentam risco de defeito (fault hazard) e problemas de teste. Isso é um resultado inevitável do encapsulamento de métodos e de atributos dentro de uma classe, da variedade de modos como um subsistema pode ser composto e da possibilidade de, em poucas linhas de código, dar um comportamento ao sistema que só será definido em tempo de execução (acoplamento dinâmico). Cada nível em uma hierarquia de herança dá um novo contexto para as características herdadas; o comportamento correto nos níveis mais elevados não é garantido nos níveis mais baixos. O acoplamento dinâmico e estruturas de herança complexas criam muitas oportunidades para enganos devido a associações incorretas ou uso incorreto desses recursos. 
Por exemplo, considere uma classe composta por herança múltipla, com seis superclasses, todas contribuindo na hierarquia de herança e muitos métodos polimórficos. $\mathrm{O}$ desenvolvedor deverá gastar tempo e esforço consideráveis para garantir que todos os métodos das superclasses funcionem adequadamente na subclasse e que não exista nenhuma interação indesejável entre os métodos. Além disso, polimorfismo e acoplamento dinâmico aumentam dramaticamente o número de caminhos que devem ser testados e o encapsulamento pode criar obstáculos que limitam a visibilidade do estado dos objetos.

A questão da reusabilidade também traz novos desafios para a atividade de teste. Componentes de software disponibilizados para reuso devem ser altamente confiáveis: teste extensivo é exigido quando se deseja obter um reuso efetivo. Entretanto, nem o reuso nem a composição de componentes testados previamente irão eliminar a necessidade do reteste, considerando o novo contexto no qual estes componentes serão reutilizados (Harrold et al., 1992; Harrold, 2000).

Embora a programação orientada a objetos possa reduzir a ocorrência de alguns tipos de defeitos cometidos na programação procedimental, ela aumenta a chance de ocorrência de outros. Tendo em vista que, em geral, métodos contêm somente algumas poucas linhas de código, defeitos de fluxo de controle são menos prováveis de ocorrer. O encapsulamento previne defeitos resultantes do acesso a dados armazenados em variáveis globais, que podem vir a ocorrer em linguagens procedimentais. Entretanto, não há motivos para supor que programadores OO estão menos propensos a cometer enganos. Enganos de codificação referentes à sintaxe ou grafia incorreta são tão comuns quanto antes. Além disso, algumas características das linguagens orientadas a objetos trazem novos riscos de defeitos (Binder, 1999). Defeitos na programação de interface são comuns em programas procedimentais. Programas OO têm, tipicamente, muitos métodos e, conseqüentemente, muitas interfaces, aumentando a ocorrência desses tipos de defeitos. Esses e outros problemas que podem ocorrer em programas OO são discutidos a seguir.

\subsubsection{Efeitos Colaterais do Paradigma 00}

Nesta seção, são apresentados os principais problemas que podem ocorrer no teste de programas OO, ou seja, o quanto características como encapsulamento, herança, polimorfismo e acoplamento dinâmico trazem problemas para a atividade de teste ou quais são os problemas que o uso dessas características pode causar.

\subsubsection{Encapsulamento}

Como definido anteriormente, o encapsulamento refere-se ao mecanismo de controle de acesso que determina a visibilidade de atributos e métodos dentro de uma classe. 
Com o controle de acesso previne-se dependências indesejadas entre uma classe cliente e uma classe servidora, por exemplo, tornando somente a interface da classe visível ao cliente, ocultando detalhes de implementação. O encapsulamento auxilia na ocultação de informação e na obtenção da modularidade do sistema sendo desenvolvido.

Embora o encapsulamento não contribua diretamente para a ocorrência de defeitos, ele pode apresentar-se como um obstáculo para a atividade de teste. O teste requer um relatório completo do estado concreto e abstrato de um objeto, bem como a possibilidade de alterar esse estado facilmente (Binder, 1999). As linguagens orientadas a objetos dificultam a atividade de se obter (get) ou atualizar (set) o estado de um objeto. No caso específico de $\mathrm{C}++$, as funções amigas (friend functions) podem ser utilizadas para solucionar esses problemas. Entretanto, no caso de linguagens que não possuem esse recurso, outras providências devem ser tomadas. Harrold (Harrold, 2000), comentando a respeito do teste de componentes de software, diz que uma solução seria a implementação de métodos get e set para todos os atributos de uma classe. Outra alternativa seria utilizar recursos de reflexão computacional, embora, como destacam Rosa e Martins (1998), algumas linguagens não permitem que as características de métodos privados sejam refletidas, somente a de métodos protegidos e públicos. Esse é o caso, por exemplo, da linguagem OpenC ++1.2 , utilizada pelas autoras (Rosa e Martins, 1998).

\subsubsection{Herança}

A herança é essencial à programação OO pois ela permite a reusabilidade via o compartilhamento de características presentes em uma classe já definida anteriormente.

Entretanto, como destacado por Binder (Binder, 1999), a herança enfraquece o encapsulamento e pode ser responsável pela criação de um risco de defeito similar ao uso de variáveis globais em programas procedimentais. Quando se está implementando uma classe que faz uso de herança, é de fundamental importância compreender os detalhes de implementação das classes ancestrais. Sem tomar esse cuidado é possível o desenvolvimento de classes que aparentemente funcionam corretamente, mas violam condições implícitas requeridas para garantir a correção das classes ancestrais. Grandes hierarquias de herança podem dificultar a compreensão, aumentar a chance de ocorrência de enganos e reduzir a testabilidade das classes.

Como comentado por Offutt e Irvine (1995), a utilização de herança pode levar a uma falsa conclusão de que subclasses que herdam características de superclasses não precisam ser testadas, reduzindo assim o esforço com os testes. Perry e Kaiser (1990) dizem que mesmo que um método seja herdado integralmente de uma superclasse, sem nenhuma modificação, ele deverá ser retestado no contexto da subclasse. Harrold et al. (1992) utilizaram os resultados de Perry e Kaiser (1990) e desenvolveram uma estratégia de 
teste, denominada Estratégia Incremental Hierárquica, baseada na hierarquia de herança das classes. A idéia é identificar quais métodos herdados necessitam de novos casos de teste para serem testados e quais métodos podem ser retestados aproveitando os casos de teste elaborados para o teste da superclasse.

Conforme destacado por Harrold et al. (1992), o uso da Estratégia Incremental Hierárquica reduz significativamente o esforço de teste. Muitos métodos que devem ser retestados reutilizam os casos de teste baseados em especificação que foram desenvolvidos para suas superclasses. A reutilização de conjuntos de testes da superclasse resulta em uma economia tanto no tempo para analisar a classe e determinar quais métodos devem ser testados, como no tempo gasto para executar os casos de teste. Com a estratégia proposta, o testador pode estimar quais os custos necessários para a realização dos teste e, com base nessa estimativa concentrar os esforços nos pontos considerados mais problemáticos ou com maior probabilidade de conter defeitos.

\section{Herança Múltipla}

A herança múltipla permite que uma subclasse herde características de duas ou mais superclasses as quais podem conter características comuns (atributos com mesmo nome e métodos com mesmo nome e mesmo conjunto de atributos). Perry e Kaiser destacam que, embora herança múltipla leve a pequenas mudanças sintáticas, ela pode levar a grandes mudanças semânticas (Perry e Kaiser, 1990). Alguns dos riscos de defeitos causados por herança múltipla são (Binder, 1999):

- Mudanças em qualquer uma das superclasses podem resultar em interações indesejadas na subclasse. Por exemplo, suponha que $Z$ seja uma subclasse das classes $X$ e $Y$ e que ambas as superclasses tenham um método $m$. Originalmente, $Z$ utilizava o método $m()$ da classe $X(X . m())$ mas foi alterada para passar a utilizar Y.m(). Com isso, $Z$ deve ser retestada e é pouco provável que o conjunto de teste que foi utilizado para testar Y.m() seja adequado ${ }^{1}$ para se testar Z.m(), pois quando o método $m()$ é utilizado no contexto da classe $Z$, este pode interagir com outros métodos e ser executado com outros valores que não foram previstos anteriormente.

- Herança repetida ocorre quando uma superclasse aparece mais de uma vez na hierarquia de herança. O teste na presença de herança repetida é ainda mais complicado que no caso de herança múltipla uma vez que existe um número de características

\footnotetext{
${ }^{1}$ Considere um critério de teste $C$ e um conjunto de teste $\mathcal{T}$. Se $\mathcal{T}$ é capaz de exercitar todos os requisitos de teste exigidos por $C, \mathcal{T}$ é adequado em relação a $C$, ou seja, diz-se nesse caso que $\mathcal{T}$ é $C$-adequado.
} 
que são renomeadas ou removidas e a possibilidade de defeitos aumenta. Por exemplo, suponha a existência de classes $B$ e $C$ derivadas da superclasse $A$ e uma classe $D$ derivada de $B$ e $C$. Essa estratégia pode levar a ocorrência de defeitos. Se métodos e atributos não forem explicitamente qualificados pelo nome da classe, pode ocorrer conflito de nomes resultando no comportamento inesperado de métodos virtuais ${ }^{2}$. Herança pública e privada, classes abstratas versus classes concretas e a visibilidade dos dados membros da superclasse constituem os riscos de defeitos associados com a herança múltipla.

\section{Classes Abstratas e Genéricas}

Uma classe abstrata é aquela que fornece somente uma interface sem nenhuma implementação, fornecendo um importante suporte para o reuso (Binder, 1999). O teste de uma classe abstrata só poderá ser realizado após esta ter sido especializada e uma classe concreta tenha sido obtida. Não é possível criar objetos ou instâncias de classes abstratas. Esse processo pode ser complicado se um método concreto utiliza um método abstrato para implementar sua funcionalidade.

Classe genéricas por sua vez não são necessariamente abstratas, mas também fornecem um importante suporte para o reuso uma vez que são a base para a ocorrência do acoplamento dinâmico. Uma classe genérica permite que sejam declarados atributos e parâmetros que podem ser instanciados com objetos de tipos específicos. Por exemplo, suponha uma classe genérica $A$ a partir da qual foram derivadas classes $B$ e $C$. Suponha também a existência de uma classe $D$ derivada a partir de $B$. Declarando-se um atributo ou parâmetro do tipo da classe genérica $A$, esse atributo ou parâmetro pode ser instanciado por qualquer um dos objetos criados a partir das classes $B, C$ ou $D$. Segundo Smith e Robson (1990), os principais problemas no teste de classes genéricas são:

1. Classes genéricas precisam ter o parâmetro genérico substituído por um parâmetro de um tipo específico para serem testadas. Com isso, surge o problema de escolher que tipo utilizar para o teste. Se for escolhido um tipo simples, pode ser que a classe genérica não seja testada corretamente. O uso de algum mecanismo de restrições que impeça que tipos inadequados sejam utilizados pode ser utilizado para reduzir a ocorrência de defeitos.

2. Da mesma forma que superclasses abstratas, se mudanças são feitas nas classes genéricas, as classes derivadas da classe genérica devem ser retestadas.

\footnotetext{
${ }^{2} \mathrm{Em} \mathrm{C}++$, métodos virtuais são aqueles métodos declarados na superclasse que precisam ser redefinidos nas subclasses. Para ter acesso aos objetos de diferentes classes usado a mesma instrução, os métodos da superclasse que serão reescritos nas subclasses devem ser declarados como virtuais.
} 


\subsubsection{Polimorfismo}

Polimorfismo é caracterizado pela possibilidade de um único nome (denominado nome polimórfico), ou seja, uma variável ou uma referência, denotar instâncias (objetos) de várias classes. Ele é usualmente restrito pela herança na qual essas várias classes devem pertencer a uma hierarquia de classes construída a partir de uma única superclasse ou de uma de suas subclasses. Considerando um esquema de herança de sub-tipo, todos os objetos denotados possuem, pelo menos, as propriedades da superclasse raiz da hierarquia. Assim sendo, um objeto pertencente a qualquer uma das subclasses poderia ser substituído em qualquer contexto no qual é requerido uma instância da superclasse sem causar qualquer erro de tipo em qualquer execução subseqüente do código. Observe que essa hierarquia de classes pode ser tão vasta quanto a totalidade das classes do sistema no caso de todas as classes derivarem de uma única superclasse comum, como ocorre em linguagens como Smalltalk, Eiffel e Java (Barbey e Strohmeier, 1994).

A seguir serão descritas alguma situações relatadas por Barbey e Strohmeier (1994) nas quais o uso do polimorfismo pode afetar a correção de um programa e causar problemas para o teste.

\section{Indecidibilidade no Acoplamento Dinâmico}

O polimorfismo traz indecidibilidade para o teste baseado em programa. Uma vez que nomes polimórficos podem denotar objetos de diferentes classes, é impossível, ao invocar um método por meio de um nome polimórfico, predizer em tempo de compilação qual o trecho de código que será executado, ou seja, se será executado o método original da superclasse ou o método refinado de uma possível subclasse. Tal decisão só ocorre em tempo de execução.

Embora o polimorfismo possa ser utilizado para produzir código elegante e extensível, alguns aspectos problemáticos podem ser detectados na sua utilização. Suponha a existência de um método $x()$ em uma superclasse que precisa ser testado. Posteriormente, o método $x()$ é sobrescrito. A correção do método $x$ na subclasse não é garantida pois as pré-condições e pós-condições na subclasse para a execução do método $x$ podem não ser as mesmas da superclasse (Binder, 1999).

Cada possibilidade de acoplamento de uma mensagem polimórfica é uma computação única. O fato de diversos acoplamentos polimórficos funcionarem corretamente não garante que todos o farão. Objetos polimórficos com acoplamento dinâmico podem facilmente resultar no envio de mensagens para a classe errada e pode ser difícil identificarem-se 
e executarem-se todas as combinações de acoplamento permitidas o que cria um risco de erro.

\section{Extensibilidade de Hierarquias}

Um problema similar ocorre quando se deseja testar um ou mais métodos com parâmetros polimórficos. O teste de um método consiste em verificar seu comportamento quando executado com diversos valores de parâmetros diferentes. Um bom conjunto de teste deveria garantir que todos os possíveis acoplamentos polimórficos sejam exercitados ao menos uma vez.

Entretanto, dada uma chamada polimórfica ou uma chamada a um método com um ou mais parâmetros polimórficos, é impossível desenvolver um conjunto de teste que garanta que o acoplamento em relação a todas as possíveis classes seja executado uma vez que a hierarquia de classes é livremente extensível.

Para resolver esse problema e o anterior, Barbey e Strohmeier (1994) sugere o uso de assertivas (assertions). As pré e pós-condições necessárias para executar cada método é especificada em termos de assertivas. Toda vez que um método é sobrescrito/refinado, as assertivas são também refinadas mas não podem ser relaxadas. Dessa forma, fica mais fácil identificar quando objetos polimórficos estão executando métodos de classes indevidas ou não esperadas.

\section{Containers Heterogêneos e Type Casting}

Containers heterogêneos são estruturas de dados que armazenam componentes que podem pertencer a várias classes diferentes, da mesma forma que nomes polimórficos.

Entretanto, alguns dos objetos armazenados podem não ter o mesmo conjunto de operações como aquelas pertencentes à superclasse raiz de uma hierarquia. Para permitir que tais objetos façam uso de todos os seus métodos é possível fazer a conversão (casting) do objeto contido na estrutura de dados heterogênea para qualquer classe da hierarquia. Isso pode levar a dois tipos comuns de falha:

1. um objeto pode estar sendo convertido para uma classe à qual ele não pertence, sendo, desse modo, incapaz de selecionar uma determinada característica ou invocar um método da classe em questão. Esse problema é conhecido com downcasting.

2. considerando um esquema de herança de subclasse, um objeto não convertido para o tipo de sua classe pode estar sendo usado para invocar um método que foi removido de sua classe, resultando em um erro em tempo de execução caso o método não exista em nenhuma outra classe da hierarquia, ou na invocação de um método indesejado. 
Esses dois tipos de falha, em geral, não são detectados durante a fase de compilação de modo que um cuidado especial deve ser tomado durante o desenvolvimento do conjunto de teste para evitar que esses tipos de falha passem despercebidas.

\subsubsection{Outros Problemas}

Além dos problemas apresentados acima, Binder (Binder, 1999) descreve ainda defeitos relacionados com seqüências de mensagens e estados dos objetos. O "empacotamento" de métodos dentro de uma classe é fundamental na OO; como resultado, mensagens devem ser executadas em alguma seqüencia, originando a questão: "Quais seqüências de envio de mensagens são corretas?".

Objetos são entidades criadas em tempo de execução, cada um podendo conter seu próprio conjunto de atributos em memória, caracterizando o seu estado. Cada nova configuração assumida por esse espaço de memória caracteriza um novo estado do objeto. Assim sendo, além do comportamento encapsulado por um objeto por meio de seus métodos e atributos, objetos também encapsulam estados.

Segundo McDaniel e McGregor (McDaniel e McGregor, 1994) existem a definição normal de estado e a definição de estados baseados em projeto. A definição normal de estado refere-se a todas as possíveis combinações de valores que os atributos de um objeto pode receber, caracterizando, em geral, um conjunto de estados infinito. Por outro lado, estados baseados em projeto referem-se ao conjunto de valores dos atributos que permitem claramente diferenciar e determinar o comportamento do objeto sendo observado. Por exemplo, para ilustrar ambos os conceitos, considere uma pilha de $n$ elementos. Na visão tradicional, que considera um estado em separado para cada atributo de dado, a pilha deveria ter $n$ estados. Assim sendo, para se testar $n$ possíveis estados seriam necessários $n$ casos de teste. Considerando agora uma representação de estados baseada em projeto, seria suficiente considerar os estados de pilha cheia, pilha vazia e, por exemplo, o estado pilha com mais de um elemento e não cheia. Com isso, o número de estados para representar uma pilha seria reduzido de $n$ para três (McDaniel e McGregor, 1994).

Examinando como a execução de um método pode alterar o estado de um objeto, quatro possibilidades são observadas (McDaniel e McGregor, 1994): 1) ele pode levar o objeto a um novo estado válido; 2) ele pode deixar o objeto no mesmo estado em que se encontra; 3) ele pode levar o objeto para um estado indefinido; ou 4) ele pode alterar o estado para um estado não apropriado.

As opções de número 3 e 4 caracterizam estados de erro. A opção 2 pode caracterizar um erro se o método executado deveria ter se comportado como na opção 1, e vice-versa. 


\subsection{Direções na Área de Teste}

Como comentado anteriormente, Harrold (2000) aponta as principais direções para a área de teste de software. A Figura 2.1 ilustra as direções que, segundo a autora, devem ser inevitavelmente exploradas nos próximos anos.

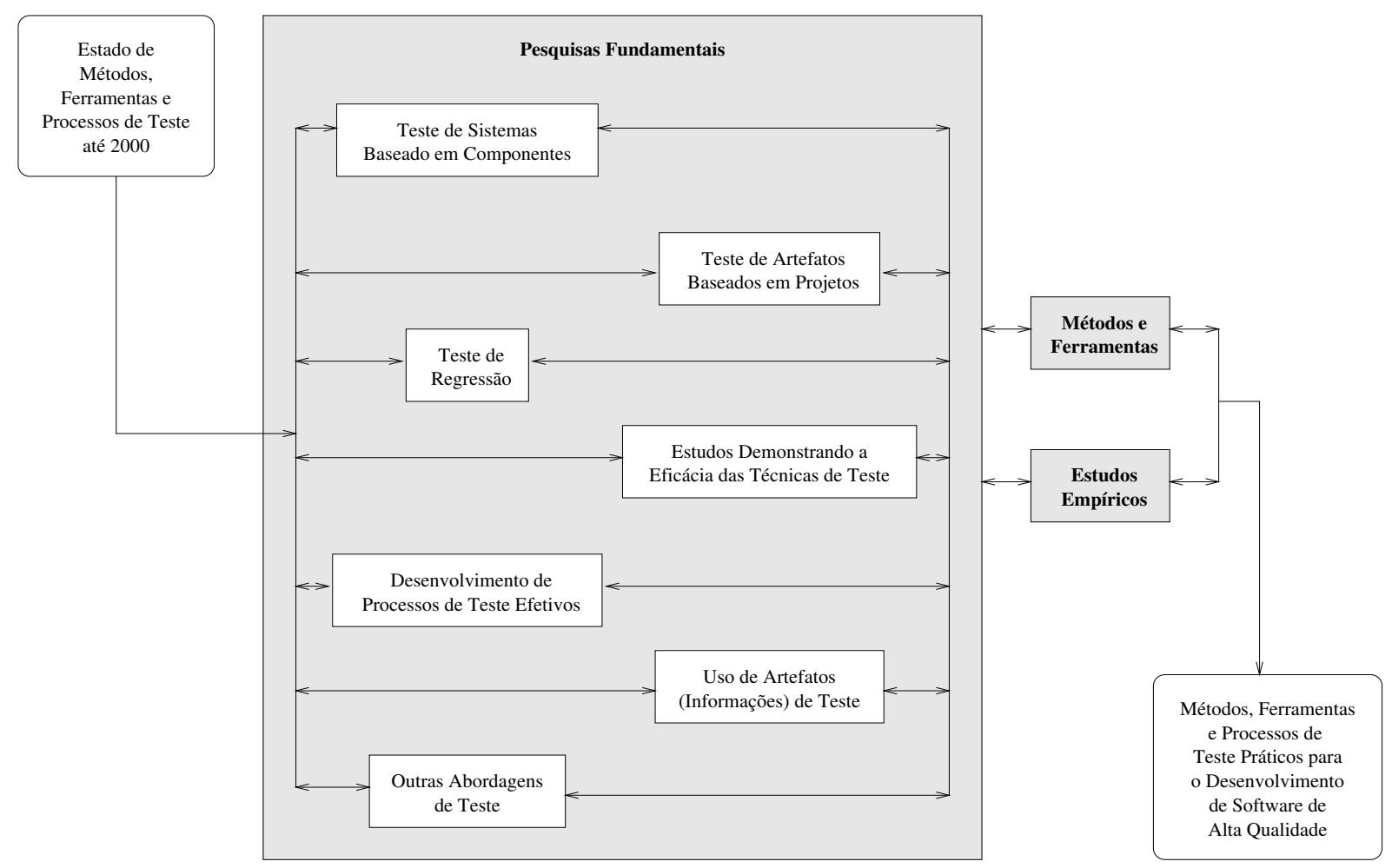

Figura 2.1: Direções de pesquisa na área de teste de software (Harrold, 2000).

Observa-se que dentre as principais direções para a área de teste de software destacamse a importância de estudos na área de teste de sistemas baseado em componentes, estudos demonstrando a eficácia das técnicas de teste e o desenvolvimento de processos de teste efetivos. Harrold (2000) comenta ainda que, é de fundamental importância o desenvolvimento de métodos e ferramentas de teste de modo que os resultados obtidos possam ser empregados na prática. Ferramentas de teste também são de fundamental importância para a condução de estudos empíricos visando a avaliar a eficácia dos critérios de teste e a definição de estratégias de teste efetivas e eficazes, facilitando a transferência tecnológica para a indústria.

\section{Teste de Sistemas Baseado em Componentes}

No que diz respeito ao teste de sistemas baseados em componentes, Harrold (2000) diz que o aumento no tamanho e na complexidade dos sistemas de software tem feito com que 
o foco dado ao desenvolvimento, principalmente no desenvolvimento de sistemas distribuídos, passasse a ser o de desenvolvimento baseado em componentes. Um sistema baseado em componentes é composto de módulos que encapsulam dados e funcionalidades e podem ser configurados, por meio de parâmetros, em tempo de execução. Dado o aumento no desenvolvimento de sistemas baseados em componentes é necessário o desenvolvimento de modos efetivos e eficientes de testá-los, os quais incluem o teste de sistemas OO, visto que a maioria dos componentes desenvolvidos fazem uso dessa tecnologia.

Pesquisas adicionais nessa área visam ao desenvolvimento de técnicas, critérios e ferramentas de teste que auxiliem os usuários a desenvolver e testar suas aplicações mais eficientemente (Vincenzi et al., 2003b). É necessário também entender e desenvolver critérios de teste que testem diversos aspectos do componente, incluindo segurança (security), segurança no funcionamento (dependability) e tolerância a falhas (safety), aspectos esses que são de fundamental importância com a explosão dos sistemas baseado em web (Harrold, 2000).

É necessário também identificarem-se quais os tipos de informações de teste que o usuário necessita para testar suas aplicações e desenvolver mecanismos que permitam introduzir essas informações dentro do componente. Binder (Binder, 1994a) denomina tal característica de componente autotestável (Built-in-Self Test).

Na Seção 2.6 são dadas mais informações sobre o teste de componentes e quais as técnicas, critérios e estratégias disponíveis.

\section{Estudos Demonstrando a Eficácia das Técnicas de Teste}

Harrold (2000) destaca que existem alguns trabalhos investigando a eficácia em revelar defeitos das estratégias de teste; entretanto, pesquisas adicionais ainda são necessárias. Um aspecto importante é a identificação de classes de defeitos e quais os critérios mais efetivos para cada uma dessas classes. Assim sendo, análises estatísticas ou empíricas são de fundamental importância para dar evidência tanto da eficácia de determinado critério em revelar certos tipos de defeitos como para a definição de estratégias de teste que combinem diversos critérios complementares e permitam a detecção da maioria dos defeitos com um baixo custo (Harrold, 2000). Na Seção 2.7 são descritos alguns estudos de casos avaliando a aplicação de estratégias de teste OO.

\section{Desenvolvimento de Processos de Teste Efetivos}

Um aspecto importante é o processo utilizado para planejar e implantar o processo de teste. Um processo de teste típico consiste na construção de um plano de teste durante a fase de análise e na implantação do plano de teste após a fase de implementação. 
Como destacado por Maldonado et al. (1998), tem-se observado que a própria atividade de projeto de casos de teste é bastante efetiva em evidenciar a presença de defeitos de software. Além disso, Binder (1994a) também destaca a necessidade de iniciar os testes o quanto antes no processo de desenvolvimento. Binder defende que é necessário projetar o software de modo que este apresente uma alta testabilidade ${ }^{3}$, tornando mais fácil a realização dos testes durante a fase de implementação (Binder, 1994a). Harrold (2000) destaca ainda que um processo de software que combine técnicas de análise estática com testes tem o potencial de melhorar a qualidade do software produzido e reduzir os custos na identificação e eliminação dos defeitos.

Tais considerações motivam a realização deste trabalho que, como mencionado anteriormente, visa a avaliar e a adaptar técnicas de teste baseadas em fluxo de dados e em mutação no teste de software $\mathrm{OO}$ e a desenvolver um ambiente de teste que permita a aplicação desses critérios, a realização de estudos empíricos a a transferência tecnológica para a indústria.

\subsection{Fases de Teste $\mathrm{OO}$}

Além da utilização de técnicas e critérios de teste, quando grandes programas são testados é necessário dividir a atividade de teste em várias fases. Com isso, o testador pode se concentrar em aspectos diferentes do software e em diferentes tipos de defeitos, e utilizar diferentes estratégias de seleção de dados de teste e medidas de cobertura em cada uma delas (Linnenkugel e Müllerburg, 1990).

Como descrito na literatura, a atividade de teste pode ser considerada como uma atividade incremental realizada em três fases: teste de unidade, teste de integração e testes de sistema (Pressman, 2001). Variações são identificadas no contexto de software OO, conforme discutido posteriormente nesta seção.

Inicialmente, os testes de unidade focalizam cada unidade objetivando garantir que os aspectos de implementação de cada uma estejam corretos. O objetivo é identificar defeitos de lógica e de implementação em cada unidade do software. Durante esta fase utilizase muito a técnica de teste estrutural que requer a execução de elementos específicos da estrutura de controle de cada unidade, com o objetivo de garantir uma completa cobertura e máxima detecção de defeitos. O teste de mutação também tem sido aplicado nesta fase.

Após cada unidade ter sido testada, inicia-se a fase de integração e, conseqüentemente, o teste de integração. Mas por que um programa construído a partir de unidades que individualmente trabalham corretamente - todas foram submetidas ao teste de unidade não trabalharia corretamente? A resposta é que o teste de unidade apresenta limitações e

\footnotetext{
${ }^{3}$ Testabilidade pode ser definida como a facilidade em se satisfazer uma meta particular estabelecida pelo critério de teste; por exemplo, exercitar todos os desvios condicionais de um programa.
} 
não pode garantir que cada unidade trabalhe adequadamente em todas as situações: por exemplo, uma unidade pode sofrer uma influência adversa, não prevista, de outra unidade; subfunções quando combinadas podem produzir resultados inesperados e estruturas de dados globais podem apresentar problemas (Delamaro, 1997). Além disso, deve-se ressaltar que os tipos de erro geralmente revelados com o teste de integração elevam em muito o custo da atividade de teste se forem detectados somente nos estágios mais avançados, principalmente se a correção do erro forçar modificações em unidades previamente testadas. Desse modo, a realização de testes de integração é de fundamental importância para assegurar uma melhor qualidade do software sendo construído, e reduzir os custos associados. Segundo Pressman (Pressman, 2001), as técnicas de projeto de casos de teste funcional são as mais utilizadas durante esta fase. Iniciativas de extensões de critérios utilizados no teste de unidade para o teste de integração são identificadas na literatura, tais como a extensão de critérios baseados em fluxo de dados e de critérios baseados em mutação (Haley e Zweben, 1984; Linnenkugel e Müllerburg, 1990; Harrold e Soffa, 1991; Jin e Offut, 1995; Vilela, 1998; Delamaro et al., 2001a).

Como destacado por Jorgensen e Erickson (Jorgensen e Erickson, 1994) e por Binder (Binder, 1999), o software orientado a objetos é composto de classes as quais encapsulam uma série de métodos, em geral de baixa complexidade, que cooperam entre si na implementação de dada funcionalidade. Com isso, devido ao grande número de métodos e de conexões existentes, mais ênfase deve ser dada ao teste de integração.

Depois que o software foi integrado, e o mesmo funciona como um todo, são realizados os testes de sistema. O objetivo é assegurar que o software e os demais elementos que compõem o sistema (por exemplo, hardware e banco de dados), combinam-se adequadamente e se a função/desempenho global desejada é obtida. A técnica de teste funcional é que tem sido mais utilizada nessa fase de teste (Pressman, 2001).

A Figura 2.2, adaptada de Binder (1999), ilustra as três fases de teste mencionadas acima bem como os componentes utilizados em cada uma das fases tanto para programas procedimentais como para programas OO.

Segundo o padrão IEEE 610.12-1990 ((IEEE, 1990)), uma unidade é um componente de software que não pode ser subdividido. Assim sendo, considerando que teste é uma atividade dinâmica, em programas procedimentais, uma unidade $F$ refere-se a uma subrotina ou um procedimento que é a menor parte funcional de um programa que pode ser executada. Observa-se que, durante os testes de unidade é necessária a implementação de drivers e stubs. O driver é uma unidade que coordena o teste de $F$, sendo responsável por ler os dados de teste fornecidos pelo testador, repassar esses dados na forma de parâmetros para $F$, coletar os resultados relevantes produzidos por $F$, e apresentá-los para o testador. Um stub é uma unidade que substitui, na hora do teste, uma unidade 
usada (chamada) por F. Na maior parte dos casos, um stub é uma unidade que simula o comportamento da unidade chamada por $F$ com o mínimo de computação ou manipulação de dados.

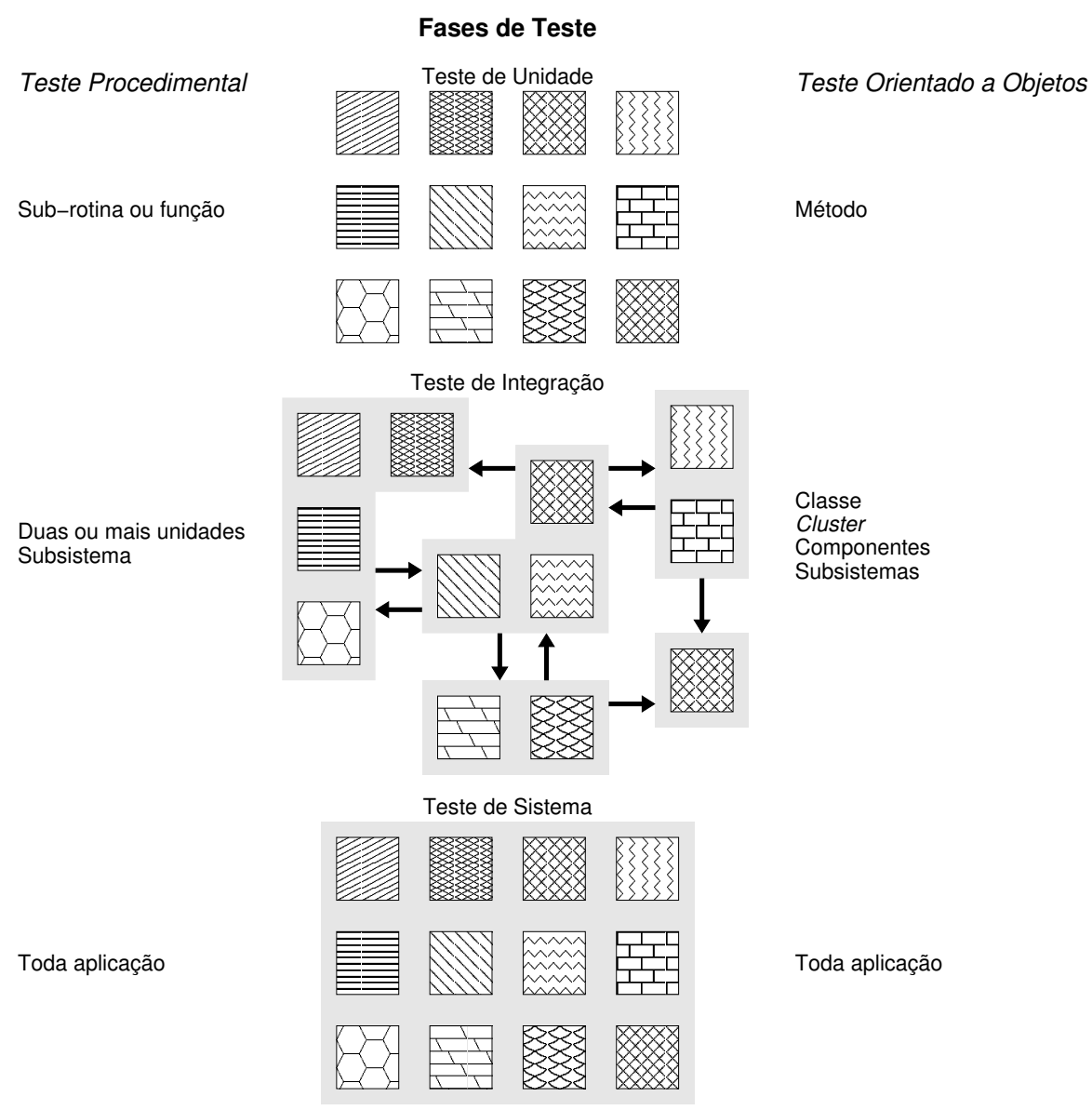

Figura 2.2: Relacionamento entre teste de unidade, de integração e de sistema: programas procedimentais e OO (Binder, 1999).

Dadas essas definições pode se considerar que em programas OO, a menor unidade a ser testada é um método sendo que a classe à qual o método pertence pode ser vista como o driver do método. Sem a existência da classe não é possível executar um método. No paradigma procedimental, o teste de unidade também é chamado de intraprocedimental e no paradigma orientado a objetos intra-método (Harrold e Rothermel, 1994).

Por definição, uma classe engloba um conjunto de atributos e métodos que manipulam esses atributos. Assim sendo, considerando uma única classe já é possível pensar-se em teste de integração. Métodos da mesma classe podem interagir entre si para desempenhar funções específicas caracterizando uma integração entre métodos que deve ser testada: teste inter-método (Harrold e Rothermel, 1994). No paradigma procedimental essa fase de teste também pode ser chamada de teste interprocedimental. 
Harrold e Rothermel (Harrold e Rothermel, 1994) definem ainda outros dois tipos de teste para programas $\mathrm{OO}$ : teste intra-classe e teste inter-classe. No teste intraclasse são testadas interações entre métodos públicos fazendo chamada a esses métodos em diferentes seqüências. O objetivo é identificar possíveis seqüências de ativação de métodos inválidas que levem o objeto a um estado inconsistente. Segundo os autores, como o usuário pode invocar seqüências de métodos públicos em uma ordem indeterminada, o teste intra-classe aumenta a confiança de que diferentes seqüências de chamadas interagem adequadamente. No teste inter-classe o mesmo conceito de invocação de métodos públicos em diferentes seqüências é utilizado; entretanto, esses métodos públicos não necessitam estar na mesma classe.

Finalmente, após realizados os testes acima, o sistema todo é integrado e podem ser realizados os testes de sistema que, por ser baseado em critérios funcionais, não apresenta diferença fundamentais entre o teste procedimental e OO.

Pequenas variações quanto à divisão das fases de teste para programas OO são identificadas na literatura. Por exemplo, Colanzi (1999) caracteriza a fase do Teste de Classe, que tem por objetivos descobrir defeitos de integração entre os métodos dentro do escopo da classe em teste, e a fase do Teste de Integração para software OO que tem o objetivo de encontrar defeitos na integração de classes do sistema. Assim, segundo Colanzi (1999), o teste $\mathrm{OO}$ é organizado em quatro fases:

- Teste de unidade: testa os métodos individualmente;

- Teste de classe: testa a interação entre métodos de uma classe;

- Teste de integração: testa a interação entre classes do sistema; e

- Teste de sistema: testa a funcionalidade do sistema como um todo.

Considerando-se o método como a menor unidade, o teste de classe, proposto por Colanzi (1999), pode ser visto como parte do teste de integração, juntamente com o teste intra-classe e inter-classe.

Alguns autores entendem que a classe é a menor unidade no paradigma OO (Perry e Kaiser, 1990; Arnold e Fuson, 1994; McDaniel e McGregor, 1994; Binder, 1999). Nessa direção o teste de unidade poderia envolver o teste intra-método, inter-método e intraclasse e, o teste de integração corresponderia ao teste inter-classe. Nesse contexto, o teste de classe proposto por Colanzi seria enquadrado como teste de unidade.

Na Tabela 2.2 são sintetizados os tipos de teste que podem ser aplicados em cada uma das fases tanto em programas procedimentais quanto em programas $\mathrm{OO}$ considerando o método ou a classe como sendo a menor unidade. 
Tabela 2.2: Relação entre fases de teste de programas procedimentais e OO.

\begin{tabular}{|c|c|c|}
\hline \multicolumn{3}{|c|}{ Menor Unidade: Método } \\
\hline Fase & Teste Procedimental & Teste Orientado a Objetos \\
\hline Unidade & Intraprocedimental & Intra-método \\
\hline Integração & Interprocedimental & Inter-método, Intra-classe e Inter-classe \\
\hline Sistema & Toda Aplicação & Toda Aplicação \\
\hline \multicolumn{3}{|c|}{ Menor Unidade: Classe } \\
\hline Fase & Teste Procedimental & Teste Orientado a Objetos \\
\hline Unidade & Intraprocedimental & Intra-método, Inter-método e Intra-classe \\
\hline Integração & Interprocedimental & Inter-classe \\
\hline Sistema & Toda Aplicação & Toda Aplicação \\
\hline
\end{tabular}

\subsection{Estratégias, Técnicas e Critérios de Teste 00}

Na literatura, podem ser encontrados trabalhos que visam a assegurar que a atividade de teste seja aplicada em todas as fases de desenvolvimento do software (Binder, 1994a; Poston, 1994; McGregor e Korson, 1994; Colanzi, 1999; Duncan et al., 2000): da fase de análise até a fase de implementação. Por exemplo, Colanzi (1999) definiu um processo de desenvolvimento de software baseado no método Fusion (Coleman et al., 1994) que utiliza a notação $U M L$ (Object Management Group, 2003). Além disso, a autora propõe uma abordagem de teste de software $\mathrm{OO}$ que permite o estabelecimento de requisitos de teste baseados em especificações $U M L$. Visando a garantir a qualidade do software, ao fim de cada fase do processo a autora propõe uma série de diretrizes para checagens dos modelos gerados durante o processo e pela abordagem de teste (Colanzi, 1999).

Howden (Howden, 1987b) define que o teste pode ser classificado de duas maneiras: teste baseado em especificação e teste baseado em programa, dependendo se utilizase a especificação funcional do software para derivar os requisitos de teste ou o próprio código do programa, respectivamente. No contexto de OO encontra-se uma série de trabalhos relacionados com o teste baseado em especificação (Hoffman e Strooper, 1993; Turner e Robson, 1993a; Kung et al., 1996; McGregor, 1994; McDaniel e McGregor, 1994; Offutt e Irvine, 1995; Hoffman e Strooper, 1997; Chen et al., 1998; Binder, 1999). Basicamente, esses trabalhos utilizam diagramas que modelam o comportamento dos objetos para derivar os requisitos de teste. Referente ao teste baseado em programa, embora em menor número, algumas iniciativas também são encontradas (Harrold e Rothermel, 1994; Chen et al., 1998; Chen e Kao, 1999; Binder, 1999; Sinha e Harrold, 1999; Jackson e Woodward, 2000; Kim et al., 1999b; Bieman et al., 2001; Ma et al., 2002; Souter e Pollock, 2003).

A seguir é dada uma descrição mais detalhada a respeito dos diversos critérios e estratégias de teste desenvolvidas para o teste de programas OO. Inicialmente são descritos 
brevemente os critérios funcionais e baseados em estados e posteriormente são descritos os critérios estruturais e baseados em mutação que podem ser utilizados nesse contexto. Algumas estratégias e critérios utilizados no teste de componentes de software também são descritos.

No contexto desta tese, ênfase é dada ao teste baseado em programa devido à carência de critérios de teste desenvolvidos com essa finalidade. Além disso, como comenta Binder (1999), certos tipos de defeitos só são detectados com o uso de critérios de fluxo de controle e de dados, que garantam a cobertura intra-método. Nesse sentido, a idéia desta tese é investigar a adequação de critérios baseados em análise de fluxo de controle e de dados no teste intra-método de programas $\mathrm{OO}$ e de componentes. Além disso, também será explorada a adequação dos critérios de mutação nesse contexto, abrangendo as fases do teste de unidade e de integração para programas OO (teste intra e inter-método).

\subsubsection{Teste Funcional}

O teste funcional ou caixa preta (teste baseado em especificação) tem esse nome pelo fato de tratar o software como uma caixa cujo conteúdo é desconhecido e só é possível visualizar o lado externo. Desse modo, o testador utiliza essencialmente a especificação de requisitos do programa para derivar os casos de teste que serão empregados sem se importar com os detalhes de implementação (Beizer, 1990). Assim sendo, uma especificação correta e de acordo com os requisitos do usuário é de fundamental importância para apoiar a aplicação dos critérios relacionados a essa técnica.

Exemplos de critérios de teste funcional são (Pressman, 2001): Particionamento de Equivalência, Análise do Valor Limite, Grafo de Causa-efeito, dentre outros.

Teste estatístico de software (statistical software testing) também pode ser visto como teste funcional uma vez que o mesmo também leva em conta a especificação do software para gerar o conjunto de teste. Exemplos de tais critérios pode ser encontrados em (Thevenod-Fosse e Waeselynck, 1993; Whittaker e Thomason, 1994; Whittaker, 1997; Banks et al., 1998). A idéia desses critérios é a de exercitar um programa com valores aleatórios selecionados do domínio de entrada utilizando-se uma função de distribuição. Assim sendo, a eficácia desses critérios está condicionada à capacidade de se derivar uma função de distribuição que maximize a probabilidade de uma entrada que revele falha ser selecionada. Basicamente, como definido por Thevenod-Fosse e Waeselynck (1993), os conjuntos de teste estatísticos são definidos por dois parâmetros: (1) o perfil de teste, ou a distribuição de entrada a partir da qual os dados de teste são selecionados aleatoriamente; e (2) o número de dados de teste a serem gerados. 
Um problema com a técnica funcional é a dificuldade de quantificar a atividade de teste, visto que não se pode garantir que partes essenciais ou críticas do programa sejam executadas. Outro problema é que o teste caixa preta está sujeito às inconsistências decorrentes da especificação, pois é ela a base a partir da qual são derivados os casos de teste. Como, em geral, a especificação é feita de forma descritiva e informal, os requisitos derivados da especificação também são, de certa forma, descritivos e informais, dificultando a automatização dos critérios funcionais.

Destaca-se que, como os critérios dessa técnica baseiam-se exclusivamente na especificação do software para derivar os requisitos de teste, esses critérios podem ser aplicados indistintamente a programas procedimentais e a programas OO (Offutt e Irvine, 1995; Hoffman e Strooper, 1993; Turner e Robson, 1993a; Kung et al., 1996; McGregor, 1994; McDaniel e McGregor, 1994; Hoffman e Strooper, 1997).

Visando a avaliar a adequação de um critério de teste funcional, utilizado no teste procedimental, para revelar defeitos em programas OO, Offutt e Irvine (1995) propõem a utilização do Método de Partição-Categoria (Category-Partition Method). Segundo os autores, existe muita preocupação no desenvolvimento de novas técnicas e critérios para o teste de programas $\mathrm{OO}$ sem que se tenha investigado a eficácia das técnicas e critérios tradicionais nesse contexto. Offutt e Irvine comentam que diversos autores acham que utilizar somente técnicas de teste tradicionais é insuficiente para testar programas OO mas, segundo Offutt e Irvine, somente um autor dá alguma evidência desse fato e suas evidências ainda não são conclusivas. Nesse contexto eles propõem o uso de um critério de teste baseado em especificação (que, teoricamente é aplicável tanto para programas procedimentais quanto OO, indistintamente) no teste de programas OO.

O Método de Partição-Categoria oferece um procedimento que é utilizado pelo testador para produzir casos de teste a partir da especificação. O trabalho do testador é definir categorias que representem as principais características do domínio de entrada da função sendo testada e particionar cada categoria em classes de equivalência de entradas chamadas choices. Por definição, as choices dentro de uma categoria devem ser disjuntas e, quando unidas, devem cobrir todo o domínio de entrada de dada categoria.

Offutt e Irvine (1995) conduziram um estudo piloto para avaliar a aplicação do critério no contexto de programas $\mathrm{OO}$ e observam que não existem evidências de que as técnicas e critérios de teste tradicionais, destinadas ao teste de programas procedimentais, sejam ineficazes para o teste de programas OO. Os resultados obtidos por Offutt e Irvine (1995) indicam que a combinação de Método de Partição-Categoria com uma ferramenta para detectar defeitos de alocação e desalocação de memória pode ser uma estratégia de teste eficaz para o teste de programas $\mathrm{C}++$. 


\subsubsection{Teste Baseado em Estados}

Os critérios de teste dessa técnica visam a modelar o comportamento do sistema ou unidade a ser testada como uma máquina de estados finitos (MEF). Com base na MEF derivada, métodos de geração de seqüências de teste podem ser utilizados de modo a avaliar se o comportamento esperado da MEF é obtido.

Um dos métodos de geração de seqüencias de teste baseado em máquinas de estados finitos mais conhecido é o método $W$ que, para ser aplicado, exige que a MEF em questão satisfaça determinadas propriedades, tais como (Chow, 1978): deve ser completamente especificada, determinística, minimal e uma máquina de Mealy. Além do método $W$, podem ser encontrados na literatura outros critérios, tais como: DS (Gönenç, 1970), UIO (Sabnani e Dahbura, 1988) e Wp (Fujiwara et al., 1991). Além desses, critérios baseados em mutação também têm sido investigados para a geração de conjuntos de casos de teste para MEFs (Fabbri et al., 1993, 1994).

Dada a própria natureza dos objetos de englobarem estado e comportamento, os critérios baseados em máquinas de estados finitos são bastante utilizados no contexto de orientação a objetos para representar o aspecto comportamental dos objetos (Hoffman e Strooper, 1993; Turner e Robson, 1993a; Kung et al., 1996; McGregor, 1994; McDaniel e McGregor, 1994; Hoffman e Strooper, 1997; Binder, 1994b, 1995, 1996, 1999) e no contexto de teste de componentes de software (Beydeda e Gruhn, 2001).

Segundo Binder (1995), o grande desafio do teste de software OO é projetar conjuntos de teste que exercitem combinações de seqüências de mensagens e interações de estados dando confiança de que o software funciona corretamente. Em alguns casos, casos de teste derivados baseado em seqüência de mensagens ou estados são suficientes. Em um de seus trabalhos Binder (1996) define a noção de modalidade de classes, caracterizando as diferenças de comportamento da classe, que é utilizada para indicar qual a melhor estratégia que deve ser utilizada para selecionar casos de teste.

Sistemas OO podem ser vistos como um conjunto de entidades que cooperam entre si para desempenhar alguma tarefa. Cada entidade é responsável por seu estado. O comportamento é resultante da seqüência de mensagens e respostas que uma dada classe aceita ou produz. O comportamento do sistema é resultante da interação do comportamento individual de cada classe. Assim sendo, para desenvolver um sistema OO confiável é preciso garantir que:

- Cada componente comporta-se corretamente;

- O comportamento coletivo dos componentes esteja correto; e

- Nenhum comportamento incorreto será produzido. 
Binder afirma que, embora os métodos de análise e projeto $\mathrm{OO}$ auxiliem na prevenção de muitos tipos de defeitos, o teste permanece necessário. Um modelo de teste que focalize a atenção do testador nos pontos mais prováveis de ocorrerem defeitos e que facilite a geração de casos de teste é necessário. Os sistemas orientados a objetos são bem adequados ao teste baseado em estados pelas seguintes razões (Binder, 1994b, 1999):

1. Embora o número de seqüências de mensagens e valores para os atributos seja infinito para o propósito prático, algumas dessas ativações podem ser proibidas pela especificação ou podem causar falhas na implementação. Uma máquina de estados finitos pode então ser utilizada para fornecer um modo compacto e previsível (predictable) do comportamento da classe.

2. O funcionamento correto de um sistema OO está distribuído no conjunto de classes, clusters e subsistemas que o implementam. Com isso, erros de comportamento são comuns devido à complexa estrutura que compõe o sistema. As máquinas de estados finitos podem ser utilizadas em qualquer escopo: classe, cluster, subsistema ou sistema, permitindo que o teste baseado em estados seja aplicado em qualquer um desses níveis. O nível de detalhe da máquina de estados deve decrescer à medida que elas são desenvolvidas para escopos maiores; entretanto, o mesmo relacionamento e notação são aplicados.

3. Um modelo de software usado para teste deve auxiliar em revelar defeitos. O teste baseado em estados é um método direto para desenvolver conjuntos de testes que podem revelar defeitos de comportamento individual (classes) e coletivo (sistema integrado).

Além dos critérios de teste definidos por Binder (Binder, 1995, 1996), outras estratégias de teste baseadas em especificação foram desenvolvidas. Por exemplo, Hoffman e Strooper (1993) conduziram um estudo de caso para o teste de classes. Na abordagem apresentada pelos autores, um driver de teste e um oráculo são desenvolvidos para cada classe sendo testada. O driver de teste é baseado em um testgraph. Um testgraph é baseado em uma máquina de estados finitos e pode ser representado por um grafo dirigido que modela uma pequena parte dos estados e transições da classe em teste. Segundo os autores, o espaço de estados de uma classe contém todos os estados possíveis de serem alcançados para a classe em questão; o testgraph contém somente os estados que serão alcançados pela classe no contexto no qual esta está sendo utilizada (Hoffman e Strooper, 1993). Casos de teste são então gerados percorrendo-se o testgraph a partir do nó raiz, visando a cobrir todos os nós, arcos e caminhos do testgraph. Segundo os autores, da mesma forma que no teste estrutural, a cobertura de caminhos pode ser difícil de ser obtida - impossível no caso de testgraphs cíclicos. 
Turner e Robson (1993a) descrevem um método de teste baseado em estados para testar interações das características dos objetos e seus estados. As características dos objetos são usualmente implementadas como métodos ou operações. Essa abordagem leva em consideração a ordem aleatória na qual os métodos podem ser invocados. O estado de um objeto é definido como uma combinação dos valores dos atributos de um objeto. Tendo em vista que o número de todas as possíveis combinações é muito grande, dois conceitos são introduzidos para reduzir a complexidade: valores de estado específico e valores de estado geral.

Um valor de estado específico corresponde ao valor de um atributo que tem um significado especial para a aplicação em questão. Por exemplo, a quantidade em estoque de determinado produto. Se essa quantidade estiver abaixo de determinado valor, um evento de atualização do estoque poderia ser disparado automaticamente. Outro exemplo é o valor "nulo" de um apontador para uma lista ligada, indicando que a lista está vazia. Observa-se que um único atributo pode ter mais de um valor específico. Por exemplo, um atributo que denota o topo de uma pilha pode assumir os valores "cheia" e "vazia" como seus valores específicos. Já os valores de estado geral de um atributo incluem todos os valores que não estão especificados. Usando esses conceitos, os estados de um objeto são identificados de acordo com sua especificação ou com o projeto da classe. Estados inválidos ou situações de exceção também são identificadas (Turner e Robson, 1993a).

Kung et al. (1996) mostram que certos tipos de defeitos relacionados com o comportamento dos estados dos objetos não podem ser detectados por métodos de teste convencionais, tais como, análise de fluxo de dados e de controle. Os autores descrevem um método de teste baseado no estado dos objetos que considera o modelo de estado dos objetos, uma ferramenta de engenharia reversa e uma ferramenta para a geração de casos de teste. O modelo de estado dos objetos é uma agregação de máquinas de estados organizadas hierarquicamente, concorrentemente e que se comunicam visando o teste de estado de sistemas OO. Uma máquina de estados pode ser classificada como diagrama de estado de objeto atômico (AOSD - atomic object state diagram) ou como um diagrama de estado de objeto composto (COSD - composite object state diagram).

Os passos necessários para conduzir o teste baseado em estados podem ser sumarizados em (Kung et al., 1996):

1. Selecionar a classe a ser testada;

2. Gerar os $A O S D$ s para a classe em questão. Observa-se que os COSDs são simples agregações de $A O S D$ se e $C O S D$ s;

3. Gerar casos de teste baseados em estados a partir dos AOSDs e COSDs; 
4. Executar os casos de teste;

5. Analisar os resultados dos testes para identificar possíveis erros; e

6. Conduzir uma análise de erros baseado em estados para identificar as possíveis causas dos erros que foram detectados.

Kung et al. (1996) discutem ainda alguns problemas relacionados com a aplicação do método, como por exemplo, o problema de manter a clareza dos diagramas à medida que o número de estados e a complexidade do grafo aumenta. Outros pontos destacados pelos autores são como estender a técnica para que esta possa ser utilizada no teste de sistemas de tempo real $\mathrm{OO}$ e como estender a ferramenta de engenharia reversa para lidar com ponteiros.

Destaca-se que o trabalho de Kung et al. (1996) também não pode ser considerado exclusivamente baseado em especificação pois também pode fazer uso do código durante a engenharia reversa para a construção dos $A O S D$ s.

Observa-se que todos esses trabalhos de teste baseado em estados, em geral, seguem a mesma abordagem que se resume em modelar os estados dos objetos utilizando alguma representação similar às máquinas de estados finitos e utilizar a teoria das MEFs para derivar conjuntos de teste. Entretanto, como destacado por Binder (Binder, 1999), o teste baseado em estados não é capaz de detectar todos os tipos de defeitos, exigindo que critérios de teste baseado em programa sejam utilizados, visando a maximizar a detecção de defeitos.

\subsubsection{Teste Baseado em Análise de Fluxo de Dados}

A técnica estrutural de teste de programas apresenta uma série de limitações e desvantagens decorrentes das limitações inerentes às atividades de teste de programa enquanto estratégia de validação, tais como a determinação de caminhos e associações não executáveis (Howden, 1987a; Frankl, 1987; Ntafos, 1988; Rapps e Weyuker, 1985; Maldonado, 1991). Esses aspectos introduzem sérias limitações na automatização do processo de validação de software (Maldonado, 1991). Independentemente dessas desvantagens, essa técnica é vista como complementar à técnica funcional (Pressman, 2001) e informações obtidas pela aplicação desses critérios têm sido consideradas relevantes para as atividades de manutenção, depuração e confiabilidade de software (Ostrand e Weyuker, 1988; Hartmann e Robson, 1990; Pressman, 2001; Veevers e Marshall, 1994; Varadan, 1995; Harrold, 2000).

Dentre os critérios de fluxo de dados, destacam-se os critérios de Rapps e Weyuker (Rapps e Weyuker, 1982, 1985), introduzidos nos anos 80. Para derivar os requisitos 
de teste exigidos por esses critérios é necessário adicionar ao grafo de programa informações sobre fluxo de dados, caracterizando o Grafo Def-Uso (Def-Use Graph) definido por Rapps e Weyuker (Rapps e Weyuker, 1982, 1985). Nesse grafo são exploradas as associações entre a definição e o uso das variáveis determinando os caminhos a serem exercitados. Quando a variável é usada em uma computação, diz-se que seu uso é computacional (c-uso); quando usada em uma condição, seu uso é predicativo (p-uso). Alguns critérios desta classe são: todas-definições (todas-def), todos-usos, todos-du-caminhos e todos-p-usos.

No final dos anos 80 e início dos anos 90, Maldonado introduziu a família de critérios Potenciais-Usos e a correspondente família de critérios Executáveis, obtida pela eliminação dos caminhos e associações não executáveis (Maldonado et al., 1988; Maldonado, 1991). Esses são critérios de fluxo de dados e baseiam-se nas associações entre uma definição de uma variável e os seus possíveis subseqüentes usos para a derivação de casos de teste. De modo semelhante aos demais critérios de fluxo de dados, os Potenciais-Usos podem utilizar o Grafo Def-Uso como base para o estabelecimento dos requisitos de teste. Na verdade, basta estender o grafo de programa para que cada nó do grafo passe a conter somente informações a respeito das definições que ocorrem em cada um.

Rapps e Weyuker $(1982,1985)$ mostraram que seus critérios de fluxo de dados formam uma hierarquia de critérios, de acordo com a relação de inclusão. O mesmo foi feito por Maldonado (1991), incluindo nessa hierarquia a família de critérios Potenciais Usos. A relação de inclusão estabelece uma ordem parcial entre os critérios, caracterizando uma hierarquia entre eles. Dados dois critérios $C$ e $C^{\prime}$, diz-se que $C$ inclui $C^{\prime}$ se para qualquer programa $P$, todo conjunto de teste $C$-adequado é também $C^{\prime}$-adequado. $\mathrm{O}$ critério $C$ inclui estritamente o critério $C^{\prime}$, denotado por $C \Rightarrow C^{\prime}$, se $C$ inclui $C^{\prime}$ e $C^{\prime}$ não inclui $C$. Quando nem $C$ inclui $C^{\prime}$ nem $C^{\prime}$ inclui $C$ diz-se que os critérios $C$ e $C^{\prime}$ são incomparáveis (Rapps e Weyuker, 1985).

A Figura 2.3(a) mostra a hierarquia formada pelos critérios de Rapps e Weyuker (1982, 1985) e Maldonado (1991). Observa-se que algumas restrições são impostas para que se possa mostrar a inclusão. Entretanto, nem sempre essas restrições correspondem à realidade. No caso da família de critérios de Rapps e Weyuker $(1982,1985)$, a análise de inclusão se aplica para programas $P$ que satisfaçam as seguinte propriedades:

NSUP - No-Syntactic-Undefined-P-Use Property: Para cada p-uso de uma variável $x$ em uma aresta $(i, j)$, em $P$, existe algum caminho do nó de entrada para a aresta $(i, j)$, o qual contém uma definição global ${ }^{4}$ de $x$.

\footnotetext{
${ }^{4}$ Um nó $i$ possui uma definição global de uma variável $x$ se ocorre uma definição de $x$ no nó $i$ e existe um caminho livre de definição de $i$ para algum nó $j \neq i$ ou alguma aresta que contém um c-uso ou um p-uso, respectivamente, da variável $x$.
} 
NSL - No-Straight-Line Property: $P$ contém ao menos um comando condicional ou de repetição, ou seja:

- Pelo menos um nó no grafo de fluxo de controle de $P$ tem mais de um sucessor;

- Pelo menos uma variável tem um p-uso em $P$.

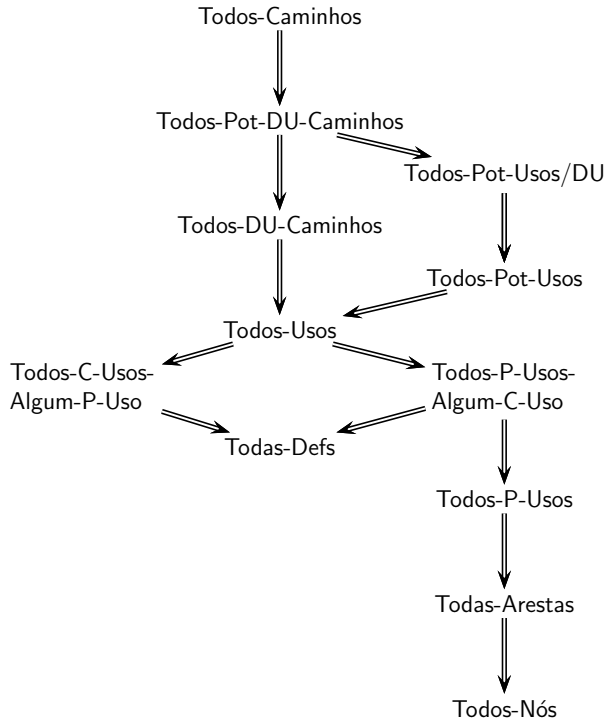

(a) Caminhos executáveis

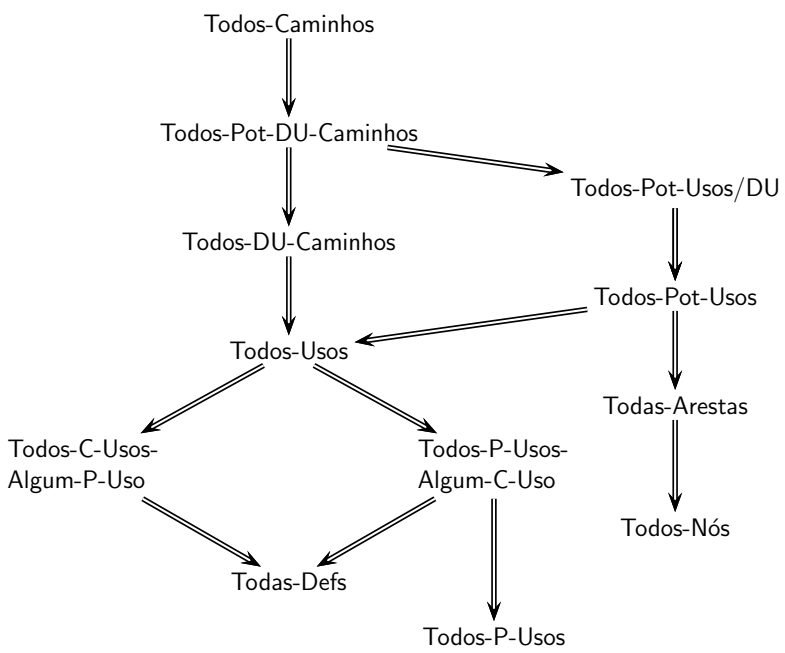

(b) Caminhos não executáveis

Figura 2.3: Hierarquia dos critérios de Rapps e Weyuker (1982, 1985) e PotenciaisUsos (Maldonado, 1991).

Horgan e London (1990) mostram que se o programa em teste não atende à restrição de que cada comando de decisão faz referência a pelo menos uma variável - o que é comum, por exemplo, na linguagem C - então a situação mostrada na Figura 2.3(a) nem sempre é verdadeira e o critério todos-p-usos, por exemplo, deixa de incluir o critério todasarestas. Frankl e Weyuker (1988) observam que, na verdade, na presença de caminhos não executáveis, nenhum dos critérios de Rapps e Weyuker $(1982,1985)$ inclue o critério todas-arestas, sendo esta uma propriedade esperada de um bom critério de teste.

Já os critérios Potenciais Usos são menos restritivos, exigindo apenas a propriedade AT-Least-oneDefinition-in-the-Entry-Node (LDEN): definição de pelo menos uma variável no nó de entrada. Observa-se que a propriedade LDEN é verificável e facilmente satisfeita pela maioria dos programas desenvolvidos, ao passo que a propriedade NSUP não o é. Desse modo, as observações feitas por Horgan e London (1990) em relação aos critérios de Rapps e Weyuker não se aplicam aos critérios Potenciais Usos. Alguns dos critérios Potenciais Usos são os únicos critérios baseados em análise de fluxo de dados que satisfazem, mesmo na presença de caminhos não executáveis, as propriedades mínimas esperadas de um critério de teste $C$, a saber (Maldonado, 1991): 
1. incluir o critério todas-arestas, ou seja, um conjunto de casos de teste que exercite os elementos requeridos pelo critério $C$ deve exercitar todos os desvios de execução do programa;

2. requerer, do ponto de vista de fluxo de dados, ao menos um uso de todo resultado computacional; isto equivale ao critério $C$ incluir o critério todas-def; e

3. requerer um conjunto de teste finito.

Além disso, nenhum outro critério baseado em análise de fluxo de dados os inclui. A Figura 2.3(b) mostra as alterações na hierarquia de critérios de teste na presença de caminhos não executáveis. Observa-se que alguns dos critérios Potenciais Usos "preenchem o espaço" ("bridge the gap") entre os critérios todas-arestas e todos-caminhos mesmo na presença de caminhos não executáveis, o que não ocorre para os demais critérios baseados em fluxo de dados.

Embora seja a relação mais utilizada na comparação entre critérios de teste, a relação de inclusão não é única. Visto que, segundo Frankl e Weyuker (1993a), o fato de um critério $C_{1}$ incluir um critério $C_{2}$ não garante que $C_{1}$ é melhor que $C_{2}$ em revelar defeitos levou as autoras a proporem algumas outras relações para a comparação entre critérios de teste de modo que, se um determinado critério $C_{1}$ satisfaz uma dada relação com respeito a um critério $C_{2}$, seja possível afirmar que $C_{1}$ é melhor que $C_{2}$ em revelar a presença de defeitos. Duas formas de seleção de casos de teste foram consideradas:

- $\operatorname{Sel}_{1}$ - seleção aleatória de casos de teste a partir do domínio de entrada até que o critério seja satisfeito;

- $\operatorname{Sel}_{2}(n)$ - seleção aleatória de $n$ casos de teste a partir de cada subdomínio.

As autoras definiram cinco novas relações que relacionam a capacidade em revelar defeitos dos critérios de teste de acordo com três medidas probabilísticas $\left(M_{1}, M_{2}\right.$ e $\left.M_{3}\right)$.

Considere um programa $P$, uma especificação $S$ e um critério $C$. Seja $S D c(P, S)=$ $\left\{D_{1}, \ldots, D_{k}\right\}$ um multi-conjunto de subdomínios do domínio de entrada de $(P, S)$ derivados de acordo com o critério $C$. A medida $M_{1}$, definida abaixo, corresponde ao limite inferior da probabilidade de que o critério $C$ irá revelar ao menos um defeito, considerando $\mathrm{Sel}_{1}$ ou $\mathrm{Sel}_{2}$.

$$
M_{1}(C, P, S)=\max _{1 \leq j \leq k}\left(\frac{m_{i}}{d_{i}}\right)
$$


onde:

- $d_{i}=\left|D_{i}\right|$, ou seja, $d_{i}$ corresponde ao número de entradas do subdomínio $D_{i}$; e

- $m_{i}$ é o número de entradas de $D_{i}$ que causam falhas.

A medida $M_{2}$, definida abaixo, fornece a probabilidade exata de que um conjunto de teste escolhido por meio de $\mathrm{Sel}_{2}(1)$ irá revelar pelo menos um defeito.

$$
M_{2}(C, P, S)=1-\prod_{i=1}^{k}\left(1-\frac{m_{i}}{d_{i}}\right)
$$

A medida $M_{3}$ é uma generalização da medida $M_{2}$ que leva em consideração o número $n$ de casos de teste selecionados em cada subdomínio. A medida $M_{2}$ é precisa somente quando $k=1$, ou seja, todo o domínio de entrada é tratado como um único subdomínio. Entretanto, para $k>1$, não seria prático assumir que todos os subdomínios apresentam o mesmo número de casos de teste e, nesse caso, a medida $M_{3}$ se torna mais adequada.

$$
M_{3}(C, P, S, n)=1-\prod_{i=1}^{k}\left(1-\frac{m_{i}}{d_{i}}\right)^{n}
$$

onde:

$$
n=\frac{\left|S D c_{1}(P, S)\right|}{\left|S D c_{2}(P, S)\right|}
$$

Os resultados obtidos estão mostrados na Tabela 2.3. Por exemplo, sempre que um determinado critério $C_{1}$ particiona um critério $C_{2}$, de acordo com a medida probabilística $M_{1}$, é garantido que $C_{1}$ revela mais defeitos que $C_{2}$.

Tabela 2.3: Relações definidas por Frankl e Weyuker (1993a) e suas implicações quanto à efetividade em revelar erros.

\begin{tabular}{|l|c|c|c|}
\hline Relação & $M_{1}\left(C_{1}\right) \geq M_{1}\left(C_{2}\right) ?$ & $M_{2}\left(C_{1}\right) \geq M_{2}\left(C_{2}\right) ?$ & $M_{3}\left(C_{1}\right) \geq M_{3}\left(C_{2}\right) ?$ \\
\hline \hline$C_{1}$ restringe $C_{2}$ & nem sempre & nem sempre & nem sempre \\
\hline$C_{1}$ cobre $C_{2}$ & nem sempre & nem sempre & nem sempre \\
\hline$C_{1}$ particiona $C_{2}$ & sempre & nem sempre & nem sempre \\
\hline$C_{1}$ cobre propriamente $C_{2}$ & nem sempre & sempre & nem sempre \\
\hline$C_{1}$ particiona propriamente $C_{2}$ & sempre & sempre & nem sempre \\
\hline
\end{tabular}

Salienta-se, entretanto, que as próprias autoras consideram difícil a aplicação de tais relações na avaliação teórica de critérios mais elaborados, apontando que outros trabalhos 
analíticos e experimentais devem ser conduzidos até que se possam transpor para o estado da prática os resultados obtidos (Frankl e Weyuker, 1993b).

O trabalho conduzido por Zhu (1996) contesta os resultados obtidos por Frankl e Weyuker (1993a) de que a relação de inclusão não reflete a capacidade em revelar defeitos dos critérios. Zhu (1996) apresenta dois cenários de teste: um cenário em que os casos de teste são construídos com base no critério de adequação utilizado, e outro em que os casos de teste são gerados sem que se tenha conhecimento sobre qual critério está sendo considerado. De acordo com Zhu (1996), os resultados obtidos por Frankl e Weyuker (1993a) são válidos para o primeiro cenário de teste. No entanto, considerando-se o segundo cenário, Zhu (1996) mostrou que a relação de inclusão reflete também a capacidade em revelar defeitos dos critérios.

Mais recentemente, Frankl e Weyuker (2000) estenderam os resultados obtidos anteriormente (Frankl e Weyuker, 1993a) por meio da definição de medidas de eficácia relacionadas ao risco de software ${ }^{5}$ do programa em teste. Duas métricas foram introduzidas, relacionando o risco detectado com a redução nos riscos proporcionada pela utilização de dado critério de teste. Com base nessas métricas, os critérios de teste foram comparados analiticamente considerando o aspecto de eficácia. Demonstrou-se que, se um critério $C_{1}$ cobre propriamente um critério $C_{2}$ para um dado programa $P$ e uma especificação $S$, e se os casos de teste são selecionados a partir de cada subdomínio de acordo com uma distribuição normal, então garante-se que $C_{1}$ é, no mínimo, tão bom quanto $C_{2}$ segundo as métricas de risco definidas (Frankl e Weyuker, 2000). Conforme ressaltado pelas autoras, tais resultados podem ser úteis na escolha do critério mais apropriado para o teste de um programa quando se tem como objetivo a minimização dos riscos (Frankl e Weyuker, 2000).

Observa-se que os critérios de fluxo de dados citados nesta seção (Howden, 1987a; Frankl, 1987; Ntafos, 1988; Rapps e Weyuker, 1985; Maldonado, 1991) foram inicialmente propostos para o teste de unidade de programas procedimentais. Extensões dos mesmos foram propostas tanto para o teste de integração (Harrold e Soffa, 1989, 1991; Vilela, 1998) e também para o teste de programas OO (Harrold e Rothermel, 1994; Chen e Kao, 1999; Sinha e Harrold, 1999; Boujarwah et al., 2000; Martena et al., 2002; Souter e Pollock, 2003). O que diferencia esses critérios é o modelo de fluxo de dados no qual esses se baseiam. O modelo de fluxo de dados é que define precisamente o que caracteriza a definição e uso de variáveis em cada contexto.

\footnotetext{
${ }^{5}$ Risco de Software, segundo Hall (1998), é uma medida de probabilidade das perdas ocasionadas por resultado insatisfatório, que afete o projeto de software, processo de software ou o produto de software.
} 


\section{Modelos de Fluxo de Dados}

Considerando linguagens procedimentais, diferentes modelos de fluxo de dados têm sido definidos, os quais levam em consideração diferentes tipos de variáveis, tais como variáveis agregadas (vetores), variáveis estruturadas (registros) e variáveis tipo ponteiro. As primeiras versões das ferramentas de fluxo de dados não consideravam os fluxos que envolviam a derreferenciação de ponteiros e o uso de campos de registros (Frankl et al., 1985; Chaim, 1991). Entretanto, defeitos relacionadas ao uso incorreto de ponteiros e de campos de registro são muito comuns (Dundan e Robson, 1996).

Outras ferramentas utilizam um modelo de fluxo de dados que não distinguem as variáveis derreferenciadas das variáveis agregadas (Horgan e London, 1991). Essas ferramentas consideram todos os endereços de memória possíveis de serem associados a uma variável derreferenciada como um único objeto de memória, ou seja, expressões do tipo $* p, * * p$, $p[i]$, and $*(p+1)$ referem-se todas ao mesmo objeto de memória (Horgan e London, 1991). Assim sendo, uma atribuição (ou referência) a qualquer elemento do objeto de memória significa uma definição (uso) de todo o objeto. Além disso, os campos de uma variável agregada são considerados, cada um, uma variável independente, de modo que uma atribuição (ou referência) a um determinado campo de uma variável agregada significa uma definição (uso) do campo. Embora simples de ser implementada, essa abordagem pode resultar em uma medida de cobertura inflacionada pois não há garantia de que os fluxos de dados das associações consideradas como exercitadas tenham realmente ocorrido em tempo de execução ou de que aquelas que realmente ocorreram foram identificadas por associações exercitadas (Chaim, 2001).

Visando a desenvolver um modelo de fluxo de dados mais preciso, Ostrand e Weyuker (1991) propuseram uma abordagem que requer o monitoramento constante das posições de memória. Nesse modelo, Ostrand e Weyuker (1991) consideram associações de fluxo de dados de posições de memória, de tal forma que somente existe uma associação de fluxo de dados se a mesma posição de memória recebe um valor e este valor, inalterado, é subseqüentemente usado. A grande vantagem desta abordagem é que ela é capaz de capturar precisamente as associações de fluxo de dados mas apresenta como efeito colateral o alto custo no monitoramento de posições de memória em tempo de execução.

Vilela et al. (1997) propuseram o uso da abordagem conservadora no teste de fluxo de dados com ponteiros e campos de registro. Essa abordagem foi inicialmente definida por Maldonado (1991) para tratar variáveis agregadas, parâmetros passados por referência e variáveis tipo ponteiro. Ela parte do princípio de que é razoável superestimar o número de requisitos de teste para aumentar a sua eficácia.

$\mathrm{Na}$ análise de fluxo de dados relativos a ponteiros e a campos de registro, a abordagem conservadora é similar à proposta por Horgan e London (1991) no sentido de que as 
variáveis derreferenciadas são tratadas da mesma forma que as variáveis agregadas. Assim sendo, segundo essa abordagem, qualquer atribuição (ou referência) a uma posição de memória endereçada utilizado expressões envolvendo ponteiros (e.g. $(* p=1)$ onde $p$ é um ponteiro) aponta para o mesmo objeto comum de memória. As definições de variáveis derreferenciadas dão origem a associações de fluxo de dados da mesma maneira que a definição de variáveis escalares, porém, diferentemente destas últimas, não bloqueiam definições anteriores, o que implica num aumento no número de requisitos de teste exigidos pelo critério de fluxo de dados. Por outro lado, a abordagem conservadora não requer o monitoramento de posições de memória em tempo de execução e minimiza a probabilidade de que fluxo de dados que ocorrem em tempo de execução deixem de ser exercitados pelo conjunto de teste adequado visto que ela requer as associações adicionais que podem ocorrer em tempo de execução (Chaim, 2001).

Chaim et al. (2002) também utilizaram a abordagem conservadora na definição de modelos de fluxo de dados com dois níveis de precisão no que diz respeito à identificação de associações de fluxo de dados envolvendo variáveis derreferenciadas e variáveis agregadas (Chaim et al., 2002):

- Nível 0 - não são levadas em consideração associações de fluxo de dados envolvendo derreferenciação de ponteiros ou campos de registros. Assim sendo, um vetor é tratado como uma variável simples. Entretanto, a abordagem conservadora estabelece que as atribuições a elementos de vetores são definições por referência (def-ref), as quais dão origem a novas definições mas não bloqueiam a geração de associações de fluxo de dados devido a definições prévias.

- Nível 1 - implementa a abordagem conservadora para tratar fluxo de dados relativos a derreferenciação de ponteiros e campos de registro. De acordo com esse modelo, uma variável derreferenciada $* p$ é definida por uma operação de derreferenciação sobre uma expressão envolvendo $p$. Além disso, nesse modelo, cada campo de uma variável agregada (registro) é considerado como uma variável independente. As variáveis derreferenciadas são tratadas da mesma forma que os vetores na abordagem conservadora, ou seja, qualquer atribuição a uma variável derreferenciada implica uma def-ref. Além disso, diferentemente da abordagem de Horgan e London (1991), os resultados da aplicação do operador de derreferenciação uma vez (e.g., *p) ou duas vezes $(\mathrm{eg}, * * p)$ sobre um ponteiro (e.g., $p$ ) resultam em variáveis derreferenciadas distintas.

Observa-se que a maioria desses modelos foram desenvolvidos considerando a linguagem $\mathrm{C}$ que é conhecida pelo uso intensivo de ponteiros e variáveis agregadas. Entretanto, os conceitos apresentados podem ser facilmente estendidos para outras linguagens, in- 
cluindo as chamadas orientadas a objetos. Posteriormente, na Seção 3.2.3.1 será mostrada uma possível extensão do modelo proposto por Horgan e London (1991) para o teste de fluxo de dados intra-método de programas Java.

A seguir são descritos alguns trabalhos relacionados à definição de critérios de teste destinados ao teste de fluxo de dados em programas OO. Observa-se que as definições de tais critérios são abstratas e não estabelecem como os conceitos de fluxo de dados (e.g., definição, uso e associação definição-uso) são implementados para uma linguagem particular. Portanto, fica a cargo do desenvolvedor de ferramentas de teste selecionar um ou mais modelos de fluxo de dados para apoiar o teste na linguagem alvo de sua ferramenta.

Harrold e Rothermel (1994) estenderam o teste de fluxo de dados para o teste de classes. Os autores comentam que os critérios de fluxo de dados destinados ao teste de programas procedimentais (Rapps e Weyuker, 1985; Frankl e Weyuker, 1988; Harrold e Soffa, 1989) podem ser utilizados tanto para o teste de métodos individuais quanto para o teste de métodos que interagem entre si dentro de uma mesma classe. Entretanto, esses critérios não consideram interações de fluxo de dados quando os usuários de uma classe invocam seqüência de métodos em uma ordem arbitrária.

Para viabilizar o teste de fluxo de dados nos níveis intra-método, inter-método e intraclasse, Harrold e Rothermel (1994) propuseram as seguintes representações de programa: grafo de chamadas de classe (class call graph), grafo de fluxo de controle de classe ( $C C F G$ - class control flow graph) e o framed CCFG. Com base nessas representações, os três níveis de teste foram considerados:

- Teste Intra-Método testa os métodos individualmente. Esse nível é equivalente ao teste de unidade de programas procedimentais.

- Teste Inter-Método testa os métodos públicos em conjunto com outros métodos dentro de uma mesma classe. Esse nível de teste é equivalente ao teste de integração de programas procedimentais.

- Teste Intra-Classe testa a interação entre métodos públicos quando eles são chamados em diferentes seqüências. Como os usuários de uma classe podem invocar seqüências de métodos em uma ordem indeterminada, o teste intra-classe serve para aumentar a confiança de que essas diferentes seqüências de invocação não colocam a classe em um estado inconsistente. Entretanto, os autores destacam que, como o conjunto de todas as possíveis seqüências de invocação é infinito, somente um subconjunto dessas seqüências pode ser testado. 
Com base nesses níveis de teste, Harrold e Rothermel (Harrold e Rothermel, 1994) definiram pares definições e uso que permitem avaliar relações de fluxo de dados em programas OO. Seja $C$ uma classe sendo testada. Se $d$ representa um comando contendo uma definição e $u$ um comando contendo um uso de uma variável, seguem-se as seguintes definições:

- Pares Def-Uso Intra-Método (Intra-Method def-use pairs) Seja $M$ um método de $C$. Se $d$ e $u$ estão em $M$ e existe um programa $P$ que chama $M$ tal que, $(d, u)$ é um par def-uso exercitado durante uma simples invocação de $M$, então $(d, u)$ é uma par def-uso intra-método.

- Pares Def-Uso Inter-Método (Inter-Method def-use pairs) Seja $M_{0}$ um método público de $C$ e seja $\left\{M_{1}, M_{2}, \ldots, M_{n}\right\}$ o conjunto de métodos que são chamados, direta ou indiretamente, quando $M_{0}$ é invocado. Suponha que $d$ está em $M_{i}$ e que $u$ está em $M_{j}$, sendo que tanto $M_{i}$ quanto $M_{j}$ estão em $\left\{M_{1}, M_{2}, \ldots, M_{n}\right\}$. Se existe um programa $P$ que chama $M_{0}$ tal que, em $P,(d, u)$ é um par def-uso exercitado durante uma simples invocação de $M_{0}$ por $P$, e $M_{i} \neq M_{j}$ e $M_{i}$ e $M_{j}$ são invocações separadas do mesmo método, então $(d, u)$ é um par def-uso inter-método.

- Pares Def-Uso Intra-Class (Intra-Class def-use pairs) Seja $M_{0}$ um método público de $C$ e seja $\left\{M_{1}, M_{2}, \ldots, M_{n}\right\}$ o conjunto de métodos que são chamados, direta ou indiretamente, quando $M_{0}$ é invocado. Seja $N_{0}$ um método público de $C$ e seja $\left\{N_{1}, N_{2}, \ldots, N_{n}\right\}$ o conjunto de métodos que são chamados, direta ou indiretamente, quando $N_{0}$ é invocado. Suponha que $d$ está em alguns dos métodos em $\left\{M_{1}, M_{2}, \ldots, M_{n}\right\}$ e $u$ em alguns dos métodos em $\left\{N_{1}, N_{2}, \ldots, N_{n}\right\}$. Se existe um programa $P$ que chama $M_{0}$ e $N_{0}$, tal que, $(d, u)$ é um par def-uso e que a chamada a $M_{0}$ é feita após $d$ ter sido executado e $M_{0}$ encerra sua execução antes que $u$ seja executado, então $(d, u)$ é uma par def-uso intra-classe.

Informalmente, o teste intra-método permite testar pares def-uso dentro de um único método. Pares def-uso inter-método ocorrem quando métodos dentro do contexto de uma invocação interagem e a definição de uma variável dentro dos limites de um método alcança um uso dentro dos limites de outro método chamado direta ou indiretamente por um método público. Finalmente, pares def-uso intra-classe ocorrem quando seqüências de métodos públicos são invocados. Assim sendo, o CCFG é o modelo base para representar o fluxo de dados de uma classe, facilitando a geração de requisitos de teste intra-método, inter-método e intra-classe. Para a identificação dos requisitos de teste inter-classe, algum tipo de análise é requerido para identificar o tipo de interação entre as classes, o que não foi considerado pela técnica da forma como foi proposta. 
Algumas das limitações da técnica proposta por Harrold e Rothermel (1994) incluem: 1) não identificar alguns pares definição-uso intra-método, inter-método e intra-classe resultantes de aliases específicos; e 2) não manipular características específicas de OO tais como polimorfismo e acoplamento dinâmico. Posteriormente, Rothermel et al. (2000) propuseram uma extensão na construção do CCFG incluindo um "nó polimórfico específico" nos pontos de chamada que conecta o conjunto de métodos polimórficos que poderiam ser invocados daquele ponto, conjunto este obtido a partir de análise estática da hierarquia de classes. Como ressalta Clarke e Malloy (2001), mesmo essa abordagem ainda requer algum refinamento uma vez que o número de métodos polimórficos identificado pode ser grande, tornando a construção do grafo impraticável.

Sinha e Harrold (1999) desenvolveram uma família de seis critérios de teste destinados especificamente ao teste do comportamento de construções relacionadas ao tratamento de exceções da linguagem Java. A definição dos critérios foi baseada em uma representação de programa conhecida como grafo de fluxo de programa interprocedural (ICFG) (Sinha e Harrold, 1998), a partir da qual os requisitos de teste são derivados. Exceções em Java podem ser classificadas como sendo síncronas ou assíncronas. Uma exceção síncrona ocorre em um ponto particular do programa e é causada durante a avaliação de uma expressão, da execução de um comando ou pela execução explícita de um comando throw. Uma exceção assíncrona pode ocorrer de forma arbitrária, em qualquer ponto do programa. A principal limitação na construção do ICFG é que o mesmo não representa exceções assíncronas e nem aquelas que podem ser geradas implicitamente, ou seja, o algoritmo para a construção do ICFG realiza uma inferência de tipo localmente em cada método para determinar tipos de exceções que possam ser geradas explicitamente por meio de um comando throw. A Figura 2.4 ilustra qual a relação de inclusão entre os seis critérios de teste definidos por Sinha e Harrold (1999), bem como a relação dos mesmos com outros critérios de fluxo de dados conhecidos (Rapps e Weyuker, 1985).

Chen e Kao (1999) desenvolveram uma estratégia de teste baseada em fluxo de objetos (object-flow based testing strategy) que utiliza dois critérios de cobertura baseados em fluxo de objetos todas-ligações (all-bindings) e todos-pares-du (all-du-pairs). O critério todas-ligações leva em consideração as características de herança e polimorfismo para garantir que todas as possíveis ligações a todos os possíveis objetos sejam exercitadas por algum caso de teste. Já o critério todos-pares-du é aplicado para monitorar o comportamento de cada objeto durante o seu tempo de vida rastreando os objetos dos pontos onde são definidos até os pontos onde são referenciados. Os requisitos de teste são derivados a partir de uma representação de programa denominada grafo de fluxo de controle de objetos (object control-flow graph - OCFG). 


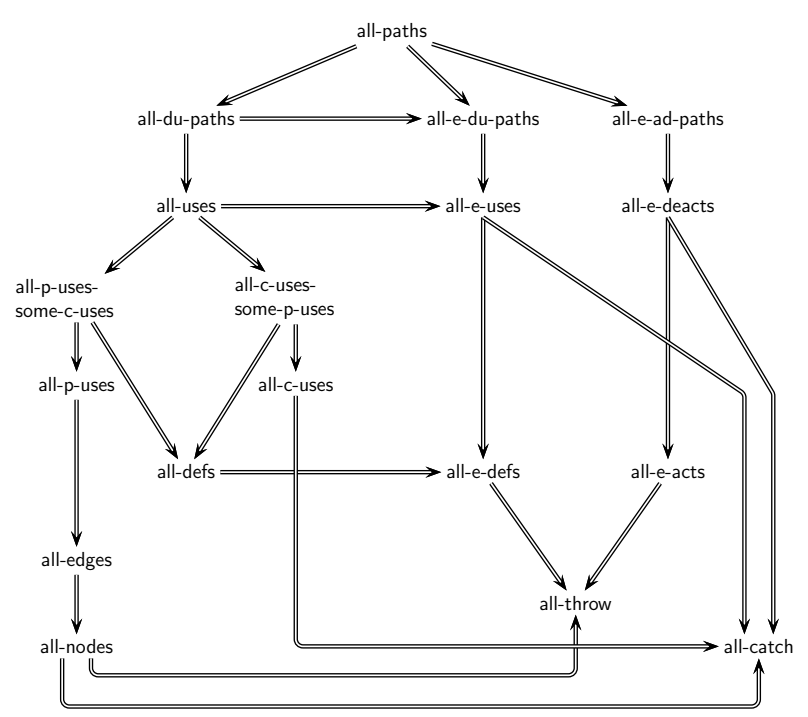

Figura 2.4: Hierarquia da relação de inclusão entre os critérios de Fluxo de Dados (esquerda) e os Critérios de Exceção (direita) (Sinha e Harrold, 1999).

Recentemente, Souter e Pollock (2000) estabeleceram o conceito de associações definiçãouso contextuais (contextual def-use associations) as quais exigem que um contexto específico deve existir para que determinada associação definição-uso seja considerada coberta. Com isso, as associações de fluxo de dados obtidas a partir dos critérios descritos acima seriam classificadas como sendo livres de contexto (context-free) uma vez que as mesmas podem ser cobertas sem considerar um contexto específico. O argumento utilizado pelas autoras é que o contexto no qual um par definição-uso ocorre não fornece o contexto no qual um objeto é usado. Por exemplo, pares definição-uso de variáveis de instância não são tipicamente associados com um objeto encapsulado ou não fornecem nenhum contexto em termos da seqüência de chamadas que um objeto sendo invocado executou até que a definição e o uso de suas variáveis de instância fossem alcançadas. Para derivar associações definição-uso contextuais (cdus), Souter e Pollock (2000) utilizam uma representação de programa conhecidas como grafo de pontos de escape anotado (Annotated Point-to Escape graph - APE) que fornece uma representação de programa baseada em objetos que modela a manipulação dos objetos e os relacionamentos de agregação que ocorrem entre eles. Para permitir a construção de cdus, informações adicionais sobre a localização e o tipo de manipulação (definição (store) ou uso (load)) sendo realizada no objeto também é incluída no grafo. Segundo as autoras, o teste baseado em associações definição-uso contextuais pode melhorar a cobertura dos testes uma vez que múltiplas associações definição-uso contextuais únicas podem ser geradas para uma mesma associação definição-uso livre de contexto. Ao todo, quatro níveis de contexto foram propostos, identificados por cdu-0, cdu-1, cdu-2 e cdu-3, Quanto maior o nível de contexto maior o 
conjunto de associações definição-uso contextuais requeridas e, conseqüentemente, maior os requisitos computacionais exigidos para calculá-las.

Entretanto, Clarke e Malloy (2001) ressaltam que a abordagem proposta não considera associações definição-uso contextuais envolvendo variáveis de tipo primitivo. Além disso, conforme destacado por Souter e Pollock (2000, 2003), em programas que contenham longas cadeias de chamadas e métodos com múltiplas chamadas para o mesmo método é possível atingir um número de anotações exponencial com tamanho exponencial, considerando um APE com anotações precisas. A solução adotada pelas autoras foi então limitar o tamanho das anotações de modo que a construção do APE tivesse uma complexidade da ordem de $O\left(n^{4}\right)$, sendo $n$ o número de nós do APE e mesmo assim, na condução de alguns experimentos com programas da ordem de 7500 a 9700 LOC, a quantidade de memória requerida para computar o conjunto de associações definição-uso contextuais cdu-2 e cdu-3 não foi suficiente.

No Capítulo 3 são apresentadas as contribuições desta tese no que se refere ao teste estrutural de programas $\mathrm{OO}$ no teste intra-método e quais as principais diferenças em relação aos trabalhos descritos acima.

\subsubsection{Teste Baseado em Mutação ${ }^{6}$}

A técnica de teste baseada em defeitos utiliza informações sobre os enganos mais freqüentes cometidos no processo de desenvolvimento de software e sobre os tipos específicos de defeitos que se desejam revelar (DeMillo, 1987). Dois critérios típicos que se concentram em defeitos são os critérios Semeadura de Erros (Error Seeding) (Budd, 1981) e Análise de Mutantes (Mutation Analysis) (DeMillo et al., 1978).

O critério Análise de Mutantes surgiu na década de 70 na Yale University e Georgia Institute of Technology, possuindo um forte relacionamento com um método clássico para detecção de defeitos lógicos em circuitos digitais - o modelo de teste de falha única (Friedman, 1975). Um dos primeiros artigos que descrevem o teste de mutantes foi publicado em 1978 (DeMillo et al., 1978). A Análise de Mutantes é um critério que utiliza um conjunto de programas ligeiramente modificados (mutantes) obtidos a partir de determinado programa $P$, para avaliar o quanto um conjunto de teste $T$ é adequado para o teste de $P$. O objetivo é encontrar um conjunto de teste $T$ capaz de revelar as diferenças de comportamento existentes entre $P$ e seus mutantes (DeMillo et al., 1978). Quando o mutante apresenta um comportamento diferente de $P$ diz-se que o mutante "morre". Do contrário, se para todo o conjunto de teste $T$ o comportamento do mutante for o mesmo do que o de $P$ então é dito que o mutante está "vivo" e deve ser analisado para verificar

\footnotetext{
${ }^{6}$ Esta seção foi parcialmente extraída de Barbosa et al. (2000).
} 
se ele é equivalente a $P$ ou se o conjunto de teste $T$ é que precisa ser melhorado para que seja possível matar o mutante vivo.

Para gerar os programas mutantes são utilizados os chamados operadores de mutação. Entende-se por operador de mutação as regras que definem as alterações que devem ser aplicadas no programa original $P$. A aplicação de um operador de mutação gera, na maioria das vezes, mais que um mutante, visto que $P$ pode conter várias entidades que estão no domínio de um operador e, desse modo, o operador é aplicado a cada uma dessas entidades, uma de cada vez. Na verdade, os operadores de mutação representam uma implementação de um modelo de defeitos e ao utilizá-los avalia-se se $P$ contém ou não os tipos de defeitos modelados por eles. No caso do critério da Análise de Mutantes os operadores modelam defeitos típicos relacionados ao teste de unidade.

Destaca-se que um dos maiores problemas para a utilização do critério diz respeito ao alto custo computacional exigido na execução do grande número de mutantes gerados. Além disso, tem-se o problema da análise dos mutantes vivos quanto à sua equivalência ou não em relação ao programa original o que, em geral, é uma questão indecidível.

Na tentativa de solucionar o problema de custo, algumas abordagens, derivadas da Análise de Mutantes, vêm sendo propostas, tais como, Mutação Aleatória (Randomly Selected X\% Mutation) (Acree et al., 1979), a Mutação Restrita (Constrained Mutation) (Mathur, 1991), a Mutação Seletiva (Selective Mutation) (Offutt et al., 1993) e a determinação de Conjuntos Essenciais de Operadores de Mutação (Offutt et al., 1996a; Wong et al., 1997; Barbosa et al., 2001).

Entende-se por conjunto essencial de operadores de mutação aquele formado por um subconjunto do total de operadores de mutação, capaz de modelar a maioria dos defeitos que se objetiva revelar durante a atividade de teste. Ainda, a utilização desse conjunto deve proporcionar sensível redução de custo, em termos do número de mutantes gerados, preservando alto escore de mutação em relação ao conjunto completo de operadores (Barbosa et al., 2001).

No contexto da linguagem C, por exemplo, Barbosa et al. (2001) propuseram o procedimento Essencial para a determinação de um conjunto essencial de operadores de mutação. Para a aplicação e validação desse procedimento dois experimentos foram conduzidos. No primeiro, utilizou-se um grupo de 27 programas $\mathrm{C}$ os quais compõem um editor de texto simplificado; no segundo, 5 programas C utilitários do UNIX foram utilizados. De um modo geral, ambos os conjuntos essenciais obtidos apresentaram um alto grau de adequação em relação ao critério Análise de Mutantes, com escores de mutação acima de 0,995, proporcionando, em média, reduções de custo superiores a 65\% (Barbosa et al., 2001).

Independentemente da abordagem utilizada para a redução no número de mutantes, a idéia básica é determinar um subconjunto de mutantes de modo que se um conjunto 
de teste $\mathcal{T}$ é capaz de distinguir tais mutantes então $\mathcal{T}$ também será capaz de distinguir o conjunto completo de mutantes. Entretanto, mesmo utilizando-se tais abordagens, o esforço na determinação dos mutantes equivalentes ainda é requerido.

Em relação à atividade de determinar mutantes equivalentes, algumas iniciativas também são identificadas. Por se tratar de um problema indecidível determinar se dois programas são equivalentes, diferentes técnicas e heurísticas têm sido desenvolvidas e investigadas tanto para a detecção automática de mutantes equivalentes, considerando classes específicas de programas, quanto na definição de diretrizes que facilitem tal atividade, como por exemplo, o uso de Análise de Dependência (Harman et al., 2000), Particionamento Amorfo (Amorphous Slicing) (Hierons et al., 1999), Restrições (DeMillo e Offutt, 1991), Técnicas de Otimização de Compiladores (Offutt e Craft, 1994; Offutt e Pan, 1996, 1997) e Técnicas de Inteligência Artificial (Vincenzi et al., 2002), esta última descrita mais detalhadamente na Seção 4.4.2.2 do Capítulo 4.

Da mesma forma que os critérios de fluxo de dados, o teste de mutação também foi proposto inicialmente para o teste de unidade de programas procedimentais. Entretanto, já existem extensões desse critério tanto para o teste de integração quanto para o teste de especificações. Delamaro et al. (2001a) definiram o critério Mutação de Interface que aplica o conceito de mutação no teste de integração. Para a aplicação do critério foi desenvolvido um novo conjunto de operadores de mutação que corresponde a um modelo de defeitos relacionado ao teste de integração.

A flexibilidade de extensão do critério vem do fato de que para se aplicar o teste de mutação é necessária a existência de um modelo que seja executável e que aceite uma entrada e produza uma saída que possa ser comparada com a saída do mutante. Além disso, é necessária a definição de um conjunto de operadores de mutação responsável pela representação do modelo de defeitos correspondente à entidade executável em questão. Tal flexibilidade motiva investigar a aplicação do teste de mutação em programas OO.

Atualmente, vários pesquisadores têm trabalhado na definição de operadores de mutação para programas OO. Dentre eles destacam-se os trabalhos de Kim et al. (1999a, 2000a) que definem um conjunto de operadores de mutação de classes que não exploram todas as características de um programa OO; de Bieman et al. (2001) que definem um conjunto de operadores de mutação específico para o teste de determinadas classes da Java API; e de Ma et al. (2002) os quais propuseram um conjunto de operadores de mutação de classe para Java que incluem os operadores propostos por Kim et al. (1999a, 2000a).

Outros pesquisadores têm também explorado o teste de mutação no contexto de sistemas distribuídos que se comunicam via CORBA (Ghosh e Mathur, 2001; Sridhanan et al., 2000). Ainda, Delamaro et al. (2001b) definiram um conjunto de operadores de mutação que modelam defeitos típicos encontrados em programas concorrentes em Java. 
Em geral, os operadores de mutação são projetados tendo por base a experiência no uso de dada linguagem, bem como os enganos mais comuns cometidos durante a utilização da mesma. No trabalho de Kim et al. (1999a, 2000a) foi proposto o uso de uma técnica chamada Hazard and Operability Studies - (HAZOP) para se chegar ao conjunto de 13 operadores de mutação de classe para programas Java ilustrado na Tabela 2.4. Embora a técnica HAZOP não difira substancialmente da abordagem usual, ela tenta sistematizar e tornar mais rigorosa a forma como os operadores de mutação são gerados. Primeiramente a técnica identifica na gramática de Java as construções que serão alvo de mutações e, com base em algumas palavras chaves (Guide Words), tais como NO/NONE, MORE, LESS, AS WELL AS, PART OF, REVERSE, OTHER THAN, NARROWING, WIDENING e EQUIVALENT, os operadores de mutação são definidos (Kim et al., 1999b,c). A idéia é que essas palavras chaves guiem a construção dos operadores de mutação. À medida que mais palavras chaves vão sendo aplicadas nas diversas partes que compõem um determinado comando os operadores de mutação vão sendo definidos. Esse processo é repetido considerando cada um dos comandos aos quais se deseja aplicar mutações (Kim et al., 1999b,c).

Como destacado por Kim et al. (1999a, 2000a), o conjunto de operadores de mutação de classes não é fechado, no sentido de que existem novos operadores que podem ser definidos para explorar outras características específicas da linguagem Java, tais como controle de acesso, tratamento de exceções e concorrência.

Chevalley (2001), baseado em sua experiência em programação OO, estendeu o conjunto de operadores de Kim et al. (2000a) com a definição de três operadores de mutação de classe adicionais. Tais operadores são apresentados na Tabela 2.5.

Bieman et al. (2001) definiram alguns operadores de mutação mais específicos, voltados para o teste de coleções (Collection ou List), iterações (Iterator) ou entrada de dados (InputStream), visando, principalmente, a alterar o estado dos objetos durante a execução do programa. A idéia é utilizar a semântica definida pelas interfaces ou classes abstratas para realizar mutações nos programas em Java. Por exemplo, um atributo do tipo Collection deverá conter uma referência para algum objeto que implemente a interface Collection. Em Java, toda classe que implemente a interface Collection obrigatoriamente tem que implementar os métodos clear(), remove() e add(); assim sendo, uma vez que se tenha uma referência a um objeto do tipo Collection qualquer um desses métodos pode ser invocado caracterizando a mutação. Em atributos de tipo simples ou de tipos diferentes dos mencionados acima, somente operadores chamados default são aplicados. No caso de tipo simples (e.g., int e float) operadores de incremento, decremento e atribuição de constantes são utilizados. No caso de tipo referência, operadores que atribuem valores 
nulos aos atributos são utilizados e outros operadores que testam igualdade, trocam a referência com outro objeto de tipo compatível, dentre outros.

Tabela 2.4: Operadores de Mutação de Classe - Class Mutation (Kim et al., 2000a).

\begin{tabular}{|c|c|c|}
\hline $\begin{array}{l}\text { Operadores de Mutação de } \\
\text { Classe }\end{array}$ & Descrição & $\begin{array}{l}\text { Característica de OO Relacio- } \\
\text { nada }\end{array}$ \\
\hline $\begin{array}{l}\text { CRT (Compatible Reference } \\
\text { Type replacement) }\end{array}$ & $\begin{array}{l}\text { Substitui um tipo referência por tipos com- } \\
\text { patíveis }\end{array}$ & $\begin{array}{l}\text { Tipos polimórficos, sobrecarga de } \\
\text { métodos, tratamento de exceção }\end{array}$ \\
\hline $\begin{array}{l}\text { ICE (Instance Creation Ex- } \\
\text { pression changes) }\end{array}$ & $\begin{array}{l}\text { Troca uma expressão de criação de instân- } \\
\text { cia por outra de mesmo tipo ou de tipo com- } \\
\text { patível }\end{array}$ & $\begin{array}{l}\text { Inicialização/creação de objetos, ti- } \\
\text { pos de objetos em tempo de execu- } \\
\text { ção, estado inicial de um objeto }\end{array}$ \\
\hline $\begin{array}{lll}\text { POC } & \text { (Parameter } & \text { Order } \\
\text { Change) } & & \end{array}$ & $\begin{array}{l}\text { Troca a ordem dos parâmetros nas declara- } \\
\text { ções dos métodos }\end{array}$ & Sobrecarga de método \\
\hline $\begin{array}{l}\text { VMR (oVerloading Method } \\
\text { Removal) }\end{array}$ & $\begin{array}{l}\text { Remove a declaração de um método sobre- } \\
\text { carregado }\end{array}$ & Sobrecarga de método \\
\hline $\begin{array}{lll}\text { AOC } & \text { (Argument } & \text { Order } \\
\text { Change) } & & \\
\end{array}$ & $\begin{array}{l}\text { Troca a ordem dos argumentos nas expres- } \\
\text { sões de invocação dos métodos }\end{array}$ & Sobrecarga de método \\
\hline $\begin{array}{l}\text { AND (Argument Number De- } \\
\text { crease) }\end{array}$ & $\begin{array}{l}\text { Decrementa o número de argumentos em } \\
\text { uma unidade }\end{array}$ & Sobrecarga de método \\
\hline $\begin{array}{l}\text { HFR (Hiding Field variable } \\
\text { Removal) }\end{array}$ & $\begin{array}{l}\text { Remove a declaração de um atributo que } \\
\text { oculta o atributo da superclasse }\end{array}$ & Ocultamento de atributo (herança) \\
\hline $\begin{array}{l}\text { HFA (Hiding Field variable } \\
\text { Addition) }\end{array}$ & $\begin{array}{l}\text { Adiciona a declaração de um atributo de } \\
\text { mesmo nome e tipo da superclasse }\end{array}$ & Ocultamento de atributo (herança) \\
\hline $\begin{array}{l}\text { OMR (Overriding Method Re- } \\
\text { moval) }\end{array}$ & $\begin{array}{l}\text { Remove a declaração de um método sobres- } \\
\text { crito }\end{array}$ & $\begin{array}{l}\text { Ocultamento/sobrescrita de método } \\
\text { (herança) }\end{array}$ \\
\hline $\begin{array}{lll}\text { AMC } & \text { (Access } & \text { Modifier } \\
\text { Change) } & & \\
\end{array}$ & $\begin{array}{l}\text { Substitui um modificador de acesso por ou- } \\
\text { tros modificadores }\end{array}$ & $\begin{array}{l}\text { Controle de acesso (ocultamento de } \\
\text { informação) }\end{array}$ \\
\hline SMC (Static Modifier Change) & Adiciona ou remove o modificador static & $\begin{array}{l}\text { Estado estático/dinâmico de um ob- } \\
\text { jeto }\end{array}$ \\
\hline $\begin{array}{l}\text { EHR (Exception Handler Re- } \\
\text { moval) }\end{array}$ & Remove tratador de exceção um a um & Tratamento de exceção \\
\hline $\begin{array}{l}\text { EHC (Exception Handling } \\
\text { Change) }\end{array}$ & $\begin{array}{l}\text { Troca um comando tratador de exceção por } \\
\text { um comando de propagação de exceção e } \\
\text { vice-versa }\end{array}$ & Tratamento de exceção \\
\hline
\end{tabular}

Tabela 2.5: Operadores de Mutação de Classe adicionais de Chevalley (2001).

\begin{tabular}{|l|l|l|}
\hline $\begin{array}{l}\text { Operadores de Mutação de } \\
\text { Classe }\end{array}$ & Descrição & $\begin{array}{l}\text { Característica de OO Relacio- } \\
\text { nada }\end{array}$ \\
\hline \hline MNC (Method Name Change) & $\begin{array}{l}\text { Troca a chamada de um método pela cha- } \\
\text { mada de outro método compatível }\end{array}$ & Invocação de método incorreto \\
\hline $\begin{array}{l}\text { RAC (Reference Assignment } \\
\text { and Content assignment repla- } \\
\text { cement) }\end{array}$ & $\begin{array}{l}\text { Substitui uma atribuição por referência por } \\
\text { uma atribuição a uma referência "clonada" }\end{array}$ & Atribuição por valor ou por referência \\
\hline $\begin{array}{l}\text { RCC (Reference Comparison } \\
\text { and Content comparison repla- } \\
\text { cement) }\end{array}$ & $\begin{array}{l}\text { Troca uma comparação de referências por } \\
\text { uma comparação de conteúdo e vice-versa }\end{array}$ & $\begin{array}{l}\text { Comparação incorreta entre referên- } \\
\text { cia a um objeto e seu estado }\end{array}$ \\
\hline
\end{tabular}

Especificamente em relação aos trabalhos de Kim et al. (1999a, 2000a) e Chevalley (2001), Ma et al. (2002) alegam que o modelo de defeitos utilizado no desenvolvimento daqueles operadores não é geral, resultando em operadores de mutação específicos para uma aplicação (application-specific) ou específicos para um programador (programmerspecific). Observa-se que o mesmo ocorre com os operadores definidos por Bieman et al. (2001). 
Ma et al. (2002) consideram os conjuntos de operadores de mutação de classe definidos por Kim et al. (1999a, 2000a) e por Chevalley (2001) muito seletivos, os quais deixam de considerar diversos tipos de defeitos que podem ocorrer em programas Java. Nesse sentido, Ma et al. (2002), baseados em alguns modelos de defeitos para programas OO (Kim et al., 1999a, 2000a; Offutt et al., 2001; Chevalley, 2001), definiram um conjunto mais abrangente de operadores de mutação os quais incluem os operadores definidos por Kim et al. (2000a, 2001). O conjunto completo de 24 operadores de mutação definidos por Ma et al. (2002) é apresentado na Tabela 2.6. Operadores que apresentam o mesmo nome indicam que os mesmos foram reaproveitados de trabalhos anteriores, por exemplo, o operador AMC foi reaproveitado do trabalho de Kim et al. (2000a, 2001). A terceira coluna da Tabela 2.6 relaciona os operadores definidos por Kim et al. (2000a, 2001) (operadores precedidos por "K-") e Chevalley (2001) (operadores precedidos por "C-") que são incluídos pelos operadores de Ma et al. (2002). O símbolo ${ }^{*}$ indica que existe alguma diferença na implementação daquele operador em relação ao implementado por Ma et al. (2002). Por exemplo, o operador C-MNC corresponde aos operadores EAM e EMM do conjunto definido por Ma et al. (2002). A Tabela 2.7 relaciona quais tipos de defeitos são detectados por quais operadores de mutação. Observa-se que todas os defeitos são cobertos por pelo menos um operador de mutação e alguns operadores de mutação são capazes de detectar mais de um tipo de defeito.

Ma et al. (2002) definiram ainda alguns modelos analíticos na tentativa de estimar o número de mutantes gerados pelo conjunto de operadores de mutação de classe mas admitem que os modelos propostos devem ser avaliados empiricamente para sem aceitos. Além disso, embora exista uma série de operadores de mutação específicos para o teste inter-classe de programas Java ainda são poucos os estudos empíricos realizados evidenciando os aspectos de custo, eficácia e dificuldade de satisfação entre eles. Dentre esses estudos podem ser citados os realizados por Kim et al. (2001) e Bybro (2003). Um dos motivos pelos quais ainda são poucos os estudos empíricos relacionados ao teste de mutação em programas $\mathrm{OO}$ pode ser a falta de uma ferramenta de teste que implemente todo o conjunto de operadores de mutação inter-classe uma vez que as que existem descritas na literatura são protótipos que implementam apenas parte desses operadores (Chevalley, 2001; Ma et al., 2002; Alexander et al., 2002; Bybro, 2003).

Especificamente relacionado ao aspecto de concorrência de programas Java, um conjunto de operadores de mutação foi desenvolvido (Delamaro et al., 2001b). Tal conjunto de operadores está descrito mais detalhadamente na Seção 4.3.4 do Capítulo 4.

Conforme destacado por Harrold (Harrold, 2000), é cada vez maior o número de sistemas desenvolvidos utilizando componentes, principalmente com o aumento dos sistemas baseados em web. Assim sendo, Harrold destaca que o teste de sistemas baseados em 
componentes é uma das principais direções de pesquisa a ser investigada nos próximos anos. A seguir, são discutidos alguns aspectos relacionados ao teste de componentes de software e descritas algumas das estratégias e critérios de teste que podem ser utilizados nesse contexto.

Tabela 2.6: Operadores de Mutação para o teste Inter-Classe (Ma et al., 2002).

\begin{tabular}{|c|c|c|}
\hline Operadores & Descrição & $\begin{array}{l}\text { Operadores } \\
\text { Incluídos }\end{array}$ \\
\hline AMC (Access modifier change) & $\begin{array}{l}\text { Substitui um modificador de acesso por outros } \\
\text { modificadores }\end{array}$ & K-AMC \\
\hline IHD (Hiding variable deletion) & $\begin{array}{l}\text { Remove a declaração de um atributo que oculta } \\
\text { o atributo da superclasse }\end{array}$ & K-HFR \\
\hline IHI (Hiding variable insertion) & $\begin{array}{l}\text { Adiciona a declaração de um atributo de mesmo } \\
\text { nome e tipo da superclasse }\end{array}$ & K-HFA \\
\hline IOD (Overriding method deletion) & Remove a declaração de um método sobrescrito & K-OMR \\
\hline IOP (Overridden method calling position change) & $\begin{array}{l}\text { Move a chamada ao método sobrescrito para o } \\
\text { primeiro e último comando do método e sobe e } \\
\text { desce um comando }\end{array}$ & \\
\hline IOR (Overridden method rename) & Renomeia o método sobrescrito na superclasse & \\
\hline ISK (super keyword deletion) & Remove palavra reservada super & \\
\hline $\begin{array}{l}\text { IPC (Explicit call of a parent's constructor dele- } \\
\text { tion }\end{array}$ & $\begin{array}{l}\text { Remove chamada explícita ao construtor da su- } \\
\text { perclasse }\end{array}$ & \\
\hline PNC (new method call with child class type) & $\begin{array}{l}\text { Troca uma expressão de criação de instância por } \\
\text { outra de mesmo tipo ou de tipo compatível }\end{array}$ & K-ICE \\
\hline $\begin{array}{l}\text { PMD (Instance variable declaration with parent } \\
\text { class type) }\end{array}$ & $\begin{array}{l}\text { Troca a declaração de tipo de um objeto pela de- } \\
\text { claração de tipo da superclasse }\end{array}$ & $\mathrm{K}-\mathrm{CRT}^{*}$ \\
\hline $\begin{array}{l}\text { PPD (Parameter variable declaration with child } \\
\text { class type) }\end{array}$ & $\begin{array}{l}\text { Idêntico ao PMD mas troca os tipos dos parâme- } \\
\text { tros e não nas declarações }\end{array}$ & $\mathrm{K}-\mathrm{CRT}^{*}$ \\
\hline $\begin{array}{l}\text { PRV (Reference assignment with other compati- } \\
\text { ble type) }\end{array}$ & $\begin{array}{l}\text { Troca atribuição de referência a um objeto por } \\
\text { referência a um objeto de uma subclasse }\end{array}$ & \\
\hline OMR (Overloading method contents change) & Troca o corpo de métodos de mesmo nome & \\
\hline OMD (Overloading method deletion) & $\begin{array}{l}\text { Remove a declaração de um método sobrecarre- } \\
\text { gado }\end{array}$ & K-VMR \\
\hline OAO (Argument order change) & $\begin{array}{l}\text { Troca a ordem dos argumentos nas expressões de } \\
\text { invocação dos métodos }\end{array}$ & $\mathrm{K}-\mathrm{AOC}$ \\
\hline OAN (Argument number change) & $\begin{array}{l}\text { Decrementa o número de argumentos em uma } \\
\text { unidade }\end{array}$ & K-AND \\
\hline JTD (this keyword deletion) & Remove palavra reservada this & \\
\hline JSC (static modifier change) & Adiciona ou remove o modificador static & K-SMC \\
\hline JID (Member variable initialization deletion) & $\begin{array}{l}\text { Remove a inicialização de atributos para usar va- } \\
\text { lor padrão }\end{array}$ & \\
\hline JDC (Java-supported default constructor create) & $\begin{array}{l}\text { Força a criação do construtor padrão removendo } \\
\text { o construtor padrão existente }\end{array}$ & \\
\hline $\begin{array}{l}\text { EOA (Reference assignment and content assign- } \\
\text { ment replacement) }\end{array}$ & $\begin{array}{l}\text { Substitui uma atribuição por referência por uma } \\
\text { atribuição a uma referência "clonada" }\end{array}$ & C-RAC \\
\hline $\begin{array}{l}\text { EOC (Reference comparison and content compa- } \\
\text { rison replacement) }\end{array}$ & $\begin{array}{l}\text { Troca uma comparação de referências por uma } \\
\text { comparação de conteúdo e vice-versa }\end{array}$ & C-RCC \\
\hline EAM (Accessor method change) & $\begin{array}{l}\text { Troca nome de método de acesso }(g e t) \text { por outro } \\
\text { nome de método de acesso de tipo compatível }\end{array}$ & $\mathrm{C}-\mathrm{MNC}^{*}$ \\
\hline EMM (Modifier method change) & $\begin{array}{l}\text { Troca nome de método de atualização }(\text { set }) \text { por } \\
\text { outro nome de método de atualização de tipo } \\
\text { compatível }\end{array}$ & $\mathrm{C}-\mathrm{MNC}^{*}$ \\
\hline
\end{tabular}


Tabela 2.7: Relação entre falhas e operadores (Ma et al., 2002).

\begin{tabular}{|l|l|}
\hline Falhas & Operadores de Mutação de Classe \\
\hline \hline Anomalia na visibilidade do estado & IOP \\
\hline Inconsistência na definição do estado (devido ao ocultamento de variável) & IHD, IHI \\
\hline Anomalia na definição do estado (devido a sobrecarga) & IOD \\
\hline Definição indireta de estado inconsistente & IOD \\
\hline Comportamento de construção anômala & IOR, IPC, PNC \\
\hline Construção incompleta & JID, JDC \\
\hline Uso de tipo inconsistente & PID, PNC, PPD, PRV \\
\hline Uso incorreto de sobrecarga de método & OMD, OAO, OAN \\
\hline Uso incorreto de modificador de acesso & AMC \\
\hline Uso incorreto do modificador static & JSC \\
\hline Implementação de métodos sobrecarregados incorreta & OMR \\
\hline Uso incorreto da palavra reservada super & ISK \\
\hline Uso incorreto da palavra reservada this & JTD \\
\hline Defeitos provenientes de enganos de programação comuns & EOA, EOC, EAM, EMM \\
\hline
\end{tabular}

\subsection{Teste de Componentes de Software}

Como definido por Szyperski (1998), um componente de software é uma unidade de composição com especificações contratuais de interfaces e explicita dependência de contexto. Um componente de software pode ser desenvolvido independentemente e ser utilizado por terceiros para composição. Componentes de software existem em diferentes formas. Em geral, um componente de software pode ser tão simples como uma única classe ou tão sofisticado como um JavaBean, Enterprise JavaBean (Matena e Stearns, 2001) ou objetos COM (Microsoft, 2002). Pode ser observado que componentes de software herdam muito das características do paradigma OO, mas a noção de componentes transcende a noção de objetos. Reuso em OO, em geral, representa reuso de bibliotecas de classes considerando uma linguagem de programação específica. Componentes de software podem ser reutilizados sem conhecimento da linguagem de programação ou ambiente no qual foram desenvolvidos, caracterizando uma forma mais genérica de reuso (Gimenes et al., 2000; Werner e Braga, 2000). Assim sendo, o desenvolvimento de sistemas baseados em componentes, os quais, em geral, fazem uso extensivo das características OO, tem motivado uma reavaliação das estratégias de teste quanto à adequação nesse novo contexto.

Conforme será descrito nesta seção, o teste de componentes e de sistemas baseados em componentes envolve uma série de questões. Como destacam Harrold et al. (1999), é possível analisar a questão do teste de sistemas baseados em componentes de duas perspectivas: a perspectiva do cliente e a perspectiva do desenvolvedor. 


\section{Perspectiva do Cliente}

Os clientes são aqueles que desenvolvem sistemas integrando em suas aplicações componentes desenvolvidos independentemente. Para auxiliá-los, existem diversas iniciativas de se adaptarem técnicas de análise e teste destinadas a programas tradicionais na análise, teste e manutenção de sistemas baseados em componentes. Entretanto, existem algumas questões que dificultam a adaptação de tais técnicas.

Primeiro, o código fonte dos componentes em geral não é disponibilizado para os seus clientes. Técnicas e critérios de teste baseados na implementação, tais como critérios baseados em análise de fluxo de dados e critérios baseados em mutação necessitam do código fonte para derivar os requisitos de teste. Quando o código fonte do componente não está disponível para o cliente, as técnicas de teste tradicionais não podem ser aplicadas no teste de sistemas baseados em componentes ou pelo menos requerer-se-á um esquema alternativo estabelecido entre as partes interessadas.

Segundo, em sistemas baseados em componentes, mesmo se o código fonte estiver disponível, os componentes e a aplicação do cliente podem ter sido implementadas em diferentes linguagens de programação. Desse modo, uma ferramenta de análise ou de teste que seja baseada em uma linguagem de implementação específica irá falhar durante os testes.

Terceiro, um componente de software freqüentemente oferece mais funcionalidades do que a aplicação do cliente necessita. Com isso, sem a identificação da parte da funcionalidade que é utilizada pela aplicação, uma ferramenta de teste irá fornecer relatórios imprecisos. Por exemplo, critérios de teste estruturais avaliam o quanto determinado conjunto de teste é adequado em cobrir os requisitos de teste exigidos pelo critério (elementos estruturais do programa). Quando se deseja avaliar a adequação de um determinado conjunto de teste em relação a um sistema baseado em componentes, os elementos estruturais que compreendem a parte não utilizada do componente devem ser excluídos na avaliação. Caso contrário, uma ferramenta de teste irá produzir relatórios indicando baixa cobertura para o conjunto de teste mesmo se tal conjunto teste exaustivamente a parte do código sendo utilizada (Rosenblum, 1997).

\section{Perspectiva do Desenvolvedor}

O desenvolvedor implementa e testa o componente de software independentemente da aplicação que fará uso de tal componente. Ao contrário do cliente, o desenvolvedor tem acesso ao código fonte. Desse modo, testar o componente para o desenvolvedor é similar ao teste de unidade/integração tradicional. Entretanto, critérios tradicionais, tais como cobertura de comandos e de desvios condicionais, podem não ser suficientes para o teste 
de componentes devido à baixa capacidade de detecção de defeitos desses critérios (Ural e Yang, 1988). Corrigir um defeito em um componente depois que esse já está no mercado, em geral, envolve um custo de correção muitas vezes maior do que se o mesmo defeito fosse descoberto durante o teste de integração de um sistema não baseado em componentes, porque um componente pode estar sendo utilizado por muitas aplicações.

O desenvolvedor do componente deve ter mecanismos para resolver duas questões: primeiro, o desenvolvedor dos componentes deve testar efetivamente os componentes como uma unidade de software independente. Testar adequada e efetivamente componentes de software independentemente do contexto de seus usos aumenta a confiança do cliente na qualidade do componente e reduz os custos dos testes do componente por parte de seus clientes. Rosenblum (1997) descreve uma abordagem para o teste de unidade para componentes de software que é dependente do contexto da aplicação e, portanto, mais relevante para o cliente do que para o desenvolvedor. Outra abordagem, desenvolvida por Harrold et al. (1999) separa a análise e o teste da aplicação do cliente da análise e do teste do componente de software.

A seguir são descritos alguns critérios de teste funcional e algumas estratégias que podem ser utilizadas no teste de componentes. Em seguida, são discutidas algumas alternativas que tentam viabilizar o uso de critérios estruturais no teste de componentes.

\section{Estratégias e Critérios de Teste para Componentes de Software}

Como pode ser observado, critérios funcionais (Beizer, 1990), incluindo o teste estatístico de software (Banks et al., 1998), são aplicados diretamente no teste de programas procedimentais, $\mathrm{OO}$ e componentes de software visto que derivam os seus requisitos de teste somente com base na especificação do programa/componente. Por exemplo, o Método Partição-Categoria (Offutt e Irvine, 1995), classificado como pertencente à técnica funcional (Seção 2.5.1) fornece um conjunto de diretrizes para identificar, a partir da especificação, diferentes categorias relacionadas com o domínio de entrada do programa em teste, bem como funcionalidades específicas que podem estar relacionadas com cada categoria. Teste estatístico de software, nos quais as entradas são amostradas com base numa função de distribuição de probabilidade que representa diferentes perfis de uso do programa, pode também estar baseado na especificação e ser utilizado no teste de componentes (Banks et al., 1998). Entretanto, como mencionado na Seção 2.5.1, o maior problema com os critérios da técnica funcional é que por serem baseados na especificação eles não são capazes de garantir que partes essenciais ou críticas da implementação tenham sido cobertas pelo conjunto de teste.

Uma vez que os critérios da técnica estrutural, conforme descrito na Seção 2.5.3, e os critérios baseados em defeitos, conforme descrito na Seção 2.5.4, em geral, requerem a 
disponibilidade do código fonte para serem aplicados, critérios alternativos, os quais não apresentam tal restrição, vêm sendo propostos. Tais critérios são baseados em reflexão computacional (Edwards, 2001a), polimorfismo (Soundarajan e Tyler, 2001), metadados (metadata) (Edwards, 2001b) e metaconteúdo (metacontent) (Orso et al., 2001), teste baseado em estados (Beydeda e Gruhn, 2001) e autoteste (built-in testing) (Wang et al., 1999; Edwards, 2001a).

Reflexão computacional permite acesso à estrutura interna de um programa e inspeção do seu comportamento, sendo utilizada na área de teste para automatizar a execução dos testes, criando instâncias de classes e invocando métodos em diferentes seqüências. No teste de componentes, a reflexão computacional é usada para "carregar" uma determinada classe em uma ferramenta de teste que identifica os métodos e seus respectivos parâmetros, viabilizando a execução dos mesmos. Com isso, a reflexão viabiliza o desenvolvimento de casos de teste inspecionando o que é necessário para invocar os métodos de cada uma das classes (Edwards, 2001b). Rosa e Martins (1998) propõem o uso de uma arquitetura reflexiva para validar o comportamento de programas OO.

Outra solução, similar a um empacotador (wrapper), é proposta por Soundarajan e Tyler (2001) usando polimorfismo. Dada a especificação formal de um componente, contendo as pré e pós-condições que devem ser satisfeitas na invocação de cada método, métodos polimórficos são criados de modo que, antes da invocação do método real (o que é implementado pelo componente), a versão polimórfica do método checa se a pré-condição é satisfeita, coleta informações usadas na invocação do método (valor dos parâmetros, por exemplo), e verifica se as pós-condições foram satisfeitas. A desvantagem dessa abordagem é que ela requer uma especificação formal do componente e não garante a cobertura de código. Além disso, para viabilizar a sua utilização, é necessário o desenvolvimento de um gerador automático de empacotadores uma vez que alterações na especificação do componente (as pré ou pós-condições, por exemplo) podem requerer que os métodos polimórficos sejam gerados/avaliados novamente.

Metadados são também utilizados pelos modelos de desenvolvimento de componentes para fornecer informações genéricas sobre o componente, tais como o nome de suas classes, o nome de seus métodos, bem como informações para o teste (Orso et al., 2001; Edwards, 2001b). Pelo uso de metadados aspectos estáticos e dinâmicos do componente podem ser consultados pelo cliente para a realização de diversas tarefas. O problema com essa abordagem é que ainda não há um consenso sobre o conjunto de informações que deve ser disponibilizado e nem na forma como disponibilizá-lo. Além do mais, essa abordagem requer um trabalho adicional por parte do desenvolvedor do componente.

Outras estratégias propõem uma abordagem integrada para a geração de dados de teste para o teste de componentes de software. Elas combinam informações funcionais e 
estruturais obtidas a partir de uma especificação formal ou semi-formal do componente. A idéia é construir um grafo def-use (Rapps e Weyuker, 1985) do componente com base na sua especificação de modo que critérios de teste de fluxo de dados e de controle possam ser utilizados para a geração de dados de teste. O problema é que como as informações estruturais são derivadas da especificação, satisfazer tais critérios não garante a cobertura do código do componente, mas sim de sua especificação. Além disso, uma especificação formal ou semi-formal do componente tem que estar disponível (Edwards, 2000; Beydeda e Gruhn, 2001).

O conceito de componentes auto-testáveis também vem sendo explorado. A idéia é disponibilizar componentes de software com capacidades de teste embutidas e que possam ser habilitadas ou desabilitadas, dependendo se o componente encontra-se em operação normal ou em manutenção, por exemplo (Edwards, 2001b; Wang et al., 1999; Martins e Toyota, 1999). Edwards (2001b) discute como diferentes tipos de informações podem ser embutidas em componentes de software por meio de um empacotador de metadados reflexivo (reflexive metadata wrapper). Ele sugere que informações como a especificação do componente, sua documentação, histórico de verificação, serviços de checagem de violação de pré e pós-condições, serviços de auto-teste, dentre outras, podem ser embutidas utilizando-se tal mecanismo. O problema com essa abordagem, embora muito útil, é depender da boa vontade do desenvolvedor do componente, pois é dele que depende a coleta e inclusão de tais informações. Além disso, quais informações realmente deveriam ser fornecidas e como deveriam ser fornecidas ainda não foram padronizadas, tornando mais difícil o trabalho de se desenvolver ferramentas de teste que necessitam de tais informações.

Como pode ser observado pelos trabalhos descritos acima, todas as abordagens propostas tentam minimizar o problema do teste de componentes do lado dos clientes, quando o código fonte do componente não se encontra disponível. Isso implica que, exceto se o componente for dotado de auto-teste ou metadados que permitam a coleta de informações de seu estado interno, nenhuma informação sobre cobertura de características estruturais do componente pode ser obtida por parte do cliente. Como será descrito mais detalhadamente no Capítulo 3, no caso de componentes Java, tais como JavaBeans, esse problema pode ser superado realizando os testes diretamente no arquivo .class, ao invés de depender do código fonte Java. O arquivo .class é uma representação binária independente de plataforma que contém informações de alto nível sobre uma classe, tais como seu nome, o nome de sua super classe, informações sobre métodos, variáveis e constantes utilizadas, além do bytecode de cada um de seus métodos.

Instruções de bytecode lembram instruções em linguagem assembly, mas armazenam informações de alto nível sobre um programa de modo que é possível extrair informações de fluxo de controle e de dados a partir delas (Vincenzi et al., 2003a). Trabalhando dire- 
tamente com bytecode Java, tanto o desenvolvedor do componente quando seus clientes podem utilizar a mesma representação e os mesmos critérios para testar componentes Java. Além disso, o cliente será capaz de avaliar qual a porcentagem do componente foi coberta por sua massa de teste, ou seja, ele será capaz de avaliar a qualidade de seu conjunto de teste funcional em relação a critérios de teste estruturais.

Chambers et al. (1999) e Zhao (2000) descrevem duas abordagens diferentes para realizar análise de dependência em bytecode Java. Os critérios de fluxo de dados definidos nesta tese (Capítulo 3) utilizam uma técnica de análise similar à desenvolvida por Zhao (2000). No trabalho de Zhao (2000), a análise de dependência de fluxo de controle e de dados é também realizada diretamente no bytecode. A principal diferença entre abordagem utilizada por Zhao (2000) e a descrita no próximo capítulo está no modelo de fluxo de dados utilizado para identificar os conjuntos de variáveis que são definidas e usadas. O modelo de fluxo de dados proposto por Zhao (2000) considera somente o conjunto de variáveis locais (aquelas definidas dentro de um método) na identificação das dependências de fluxo de dados e o modelo proposto na Seção 3.2.3 do Capítulo 3 considera não somente as variáveis locais, mas também os atributos de instância e de classe, e variáveis agregadas. Assim sendo, acredita-se que o modelo de fluxo de dados proposto represente mais precisamente as interações de fluxo de dados intra-método que possam ocorrer em um programa Java.

Dada a diversidade de critérios que têm sido estabelecidos (Harrold e Rothermel, 1994; Sinha e Harrold, 1999; Chen e Kao, 1999; Souter e Pollock, 2003; Kim et al., 1999a, 2000a; Bieman et al., 2001; Chevalley, 2001; Ma et al., 2002; Soundarajan e Tyler, 2001; Edwards, 2001b; Orso et al., 2001; Beydeda e Gruhn, 2001; Wang et al., 1999; Edwards, 2001a) e reconhecido o caráter complementar das técnicas e critérios de teste (Mathur e Wong, 1994; Wong, 1993; Souza, 1996; Chen et al., 1998; Chen e Kao, 1999; Sinha e Harrold, 1999; Vincenzi et al., 2001), um ponto crucial que se coloca nessa perspectiva é a escolha e/ou a determinação de uma estratégia de teste, que em última análise passa pela escolha de critérios de teste, de forma que as vantagens de cada um desses critérios sejam combinadas objetivando uma atividade de teste de maior qualidade. Estudos teóricos e empíricos de critérios de teste são de extrema relevância para a formação desse conhecimento, fornecendo subsídios para o estabelecimento de estratégias de baixo custo e alta eficácia (Maldonado et al., 1998). A seguir são apresentados alguns desses estudos realizados no contexto de programas OO.

\subsection{Avaliação e Comparação entre Critérios de Teste 00}

Conforme destacado por Harrold (Harrold, 2000), a realização de estudos comparando critérios de teste, procurando estabelecer uma relação entre quais tipos de defeitos cada um 
dos critérios de teste é capaz de revelar, é de fundamental importância para se acumular conhecimento sobre os diversos critérios de teste que irá auxiliar na definição de estratégias adequadas a cada tipo ou tipos de defeitos que se deseja revelar.

Entretanto, embora esse conhecimento seja de fundamental importância, ainda são poucos os trabalhos nessa direção no contexto de programas OO. Das iniciativas encontradas, somente alguns estudos de caso são apresentados visando a ilustrar a aplicação de determinada técnica ou critério de teste e poucas evidências são dadas a respeito da eficácia das técnicas em revelar defeitos (Arnold e Fuson, 1994; Murphy et al., 1994; Offutt e Irvine, 1995; Chang et al., 1998; Chen et al., 1999; Chen e Kao, 1999; Yanagawa e Martins, 2000; Martena et al., 2002). A seguir, alguns desses trabalhos são descritos sucintamente.

Visando a avaliar a adequação de um critério de teste funcional, utilizado no teste procedimental, para revelar defeitos em programas OO, Offutt e Irvine (1995) propõem a utilização do Método de Partição-Categoria (Category-Partition Method). Segundo os autores, existe muita preocupação no desenvolvimento de novas técnicas e critérios para o teste de programas $\mathrm{OO}$ sem que se tenha investigado a eficácia das técnicas e critérios tradicionais nesse contexto. Offutt e Irvine (1995) comentam que diversos autores (Fiedler, 1989; Smith e Robson, 1990; Turner e Robson, 1993b) acham que utilizar somente técnicas de teste tradicionais é insuficiente para testar programas OO. Entretanto, os resultados apresentados não são conclusivos. Nesse contexto, Offutt e Irvine (1995) propõem o uso de um critério de teste baseado em especificação (que, teoricamente é aplicável tanto para programas procedimentais quanto OO, indistintamente) no teste de programas OO e apresenta um estudo piloto visando a avaliar a aplicação do critério nesse contexto. Dois programas foram utilizados: um sistema de arquivos simplificado denominado MiStix e um programa para a validação de datas.

Aplicando-se o Método de Partição-Categoria, 106 casos de teste foram desenvolvidos para o programa MiStix e 31 casos de teste foram desenvolvidos para o programa de validação de datas.

Para avaliar a capacidade de revelar defeitos desses conjuntos de teste, 23 tipos de defeitos relacionados com programas OO foram utilizados. Os defeitos considerados foram divididos em cinco categorias: gerenciamento de memória, funções implícitas, inicialização, herança e encapsulamento.

Dos 23 tipos diferentes de defeitos, 19 puderam ser aplicados no programa MiStix, produzindo-se 60 programas com defeitos. Os outros 4 tipos de defeitos restantes, todos relacionados com herança, foram aplicados no programa de validação de datas resultando em 15 programas com defeitos. Assim sendo, 75 versões de programas com defeitos foram produzidas. A Tabela 2.8 mostra os resultados que foram obtidos. 
Tabela 2.8: Resultados da aplicação do método de Partição-Categoria.

\begin{tabular}{|l|c|c|}
\hline & Número de Defeitos & Porcentagem de Defeitos \\
\hline \hline Detectados & 55 & $73,3 \%$ \\
\hline Não Detectados & 20 & $26,7 \%$ \\
\hline
\end{tabular}

Um erro era considerado revelado quando fazia o programa ter um comportamento anormal ou quando a saída produzida pelo programa incorreto era diferente da produzida pelo programa original. Observa-se que $73 \%$ dos defeitos foram detectados pelo método. Os autores ressaltam que os 20 defeitos que não foram detectados eram todos defeitos de gerenciamento de memória os quais, em geral, causam memory leaks e não afetam a saída do programa. Uma análise de alocação e desalocação de memória é necessária para a detecção desse tipo de erro.

Em suma, Offutt e Irvine (1995) observam que não existem evidências conclusivas de que as técnicas e critérios de teste tradicionais, destinadas ao teste de programas procedimentais, sejam ineficazes para o teste de programas OO. Os resultados obtidos por Offutt e Irvine (1995) indicam que a combinação do Método de Partição-Categoria com uma ferramenta para detectar defeitos de alocação e desalocação de memória pode ser uma estratégia de teste efetiva para o teste de programas $\mathrm{C}++$.

Chen et al. (1999) descrevem outro estudo de caso comparando a eficácia de estratégias de teste tradicionais e do teste baseado em estados em detectar defeitos em programas OO. Ao todo cinco critérios de teste foram utilizados: um funcional (não especificado no artigo), dois estruturais (todos-nós e todas-arestas) e dois baseados em estados (todos-estados e todas-transições). Para cada um desses critérios, conjuntos de casos de teste adequados foram gerados em relação a três programas diferentes, implementados em $\mathrm{C}++$, os quais tinham um tamanho variando de $5.6 \mathrm{k}$ a $21.3 \mathrm{k}$ LOC. Todos os programas continham um número conhecido de defeitos, os quais foram classificados em três diferentes categorias, de acordo com a relevância dos mesmos no contexto da OO. Defeitos do Tipo I são aqueles fortemente relacionadas com as características de herança e polimorfismo; defeitos do Tipo II são aqueles relacionadas com o gerenciamento de objetos; e os defeitos do Tipo III são aqueles que não estão relacionadas com características OO. Os resultados obtidos demonstraram que a maioria dos defeitos do Tipo I e II não foram detectados pelos critérios utilizados, o que sugere que técnicas de teste tradicionais não seriam adequadas para detectar defeitos relacionados com características OO e que o teste baseado em estados foi duas vezes mais eficaz em detectar defeitos $\mathrm{OO}$ do que os critérios estruturais. Mesmo assim, este critério também não seria suficiente para revelar todos os tipos de 
defeitos, dando evidências de que é necessária a combinação de diferentes critérios para alcançar um teste de melhor qualidade.

A partir dos resultados obtidos por Chen et al. (1999), Chen e Kao (1999) propuseram dois critérios de teste baseados em fluxo de objetos denominados todas-ligações e todospares-du, descritos na Seção 2.5.3, e conduziram dois estudos de caso utilizando os mesmos três programas do estudo anterior e a mesma classificação de defeitos. O objetivo foi comparar os critérios baseados em fluxo de objetos com dois critérios estruturais (todos-nós e todos-arcos) e dois critérios baseados em estado (todos-estados e todas-transições). No primeiro estudo de caso as três estratégias de teste foram comparadas e os resultados obtidos demonstraram que os critérios estruturais foram capazes de detectar $22 \%$ dos defeitos relacionados com características OO, os critérios baseados em estados detectaram $44 \%$ dos defeitos e os critérios baseados em fluxo de objetos detectaram $88 \%$ dos defeitos relacionados com características OO. O segundo estudo de caso visou ao desenvolvimento de uma estratégia de teste integrada, utilizando as três técnicas de teste. As técnicas foram aplicadas na seguinte ordem, após a realização dos testes funcionais: todos-nós, todosarcos, todos-pares-du, todas-ligações, todos-estados e todas-transições. Utilizando-se tal estratégia observou-se que a detecção dos defeitos relacionados com características OO foi de 100\%, 95\% e 97\% considerando cada um dos três programas utilizados, respectivamente. No que se refere à redução de custo, Chen e Kao (1999) sugerem que o uso de uma estratégia de teste de melhor qualidade, incluindo critérios de diferentes técnicas de teste, contribui para uma redução significativa, por volta de $80 \%$, nos custos com manutenção.

No Capítulo 6 são descritos os experimentos realizados com base nos critérios de teste definidos nesta tese visando a avaliar os aspectos de custo, eficácia e dificuldade de satisfação dos mesmos.

\subsection{Automatização da Atividade de Teste}

Na prática, a aplicação de um critério de teste está fortemente condicionada à sua automatização. O desenvolvimento de ferramentas de teste é de fundamental importância uma vez que a atividade de teste é muito propensa a erros, além de improdutiva, se aplicada manualmente. Além disso, ferramentas de teste facilitam a condução de estudos empíricos que visam a avaliar e a comparar os diversos critérios de teste. Assim sendo, a disponibilidade de ferramentas de teste propicia maior qualidade e produtividade para a atividade de teste. A seguir é apresentada a descrição, parcialmente extraída de (Domingues, 2002), de uma série de ferramentas comerciais e não comerciais que se encontram disponíveis para o teste de programas OO e algumas também destinadas ao teste de componentes, principalmente para o teste de programas escritos em $\mathrm{C}++$ e Java. 
Essas ferramentas foram obtidas por meio de pesquisa na World Wide Web e a descrição apresentada é baseada na documentação existente de cada uma, bem como na execução das mesmas utilizando versões de demonstração quando essas encontravam-se disponíveis.

A ferramenta de teste PiSCES Coverage Tracker for Java é uma das primeiras ferramentas de teste desenvolvidas para o teste de applets Java. PiSCES é uma ferramenta de medida de cobertura (comandos e decisões) que identifica quais partes do código fonte já foram exercitadas durante os testes e quais ainda precisam ser exercitadas. Embora tenha sido projetada para o teste de applets Java, a ferramenta requer a disponibilidade do código fonte para derivar os requisitos de teste a serem cobertos (Binns e McGraw, 1996).

Outra iniciativa no desenvolvimento de um conjunto de ferramentas de teste foi iniciado pela Sun Microsystems em meados dos anos 90 (Sun Microsystems, 1996). SunTest (Java Testing Tools from Sun) incluía uma ferramenta de capture-replay, denominada JavaStar, destinada ao teste de programas com interface gráfica; uma ferramenta de medida de cobertura de código (comandos e decisões), denominada JavaScope; uma ferramenta para a geração de drivers para o teste de métodos, denominada JavaSpec; uma ferramenta para o teste de carga, denominada JavaLoad; uma ferramenta destinada a análise estática de threads, denominada JavaLoom; e uma ferramenta para checar a portabilidade de programas Java, denominada JavaPureCheck. Infelizmente, em 1999 a Sun tomou uma decisão estratégica de descontinuar o desenvolvimento desse conjunto de ferramentas de teste.

A $x$ Suds da Telcordia Technologies (Agrawal et al., 1998; Telcordia Technologies USA, 1998) é um conjunto de sete ferramentas ( $\mathcal{x}$ ATAC, ${ }_{\mathcal{X}}$ Regress, $\mathcal{x}$ Vue, ${ }_{\mathcal{X}}$ Slice, ${ }_{\mathcal{X}}$ Prof, ${ }_{\mathcal{X}}$ Find e a $\mathcal{X}$ Diff) destinadas ao entendimento, à análise e ao teste de software para códigos $\mathrm{C} / \mathrm{C}++$. O grupo de Engenharia de Software do ICMC/USP possui uma licença desta ferramenta de modo que a mesma pode ser utilizada para a condução de estudos empíricos envolvendo programas escritos nessas linguagens. Dentre as sete ferramentas, a que realiza a análise de cobertura é a xATAC. Tal ferramenta mede o quanto a aplicação está sendo exercitada pelo conjunto de teste, identificando códigos que não estão suficientemente testados e determinando a cobertura da aplicação com os casos de teste. Essas medidas são usadas para indicar o progresso durante o teste do software e servem de critério de aceitação para subseqüentes estágios do desenvolvimento e da atividade de teste. Para o teste de programas C, a $\mathcal{X}$ ATAC apóia a aplicação dos critérios de fluxo de controle (todosnós e todos-arcos) e de fluxo de dados (todos-c-usos, todos-p-usos e todos-usos). Para o teste de programas $\mathrm{C}++$, somente os critérios de fluxo de controle estão disponíveis.

JProbe Suite (Quest Software, 2003) é um conjunto de três ferramentas composto por: JProbe Profiler and Memory Debugger ajuda a eliminar gargalos de execução causados por 
algoritmos ineficientes em códigos Java e aponta as causas de perdas de memória nessas aplicações rastreando quais objetos seguram referências para outros; JProbe Threadalyzer monitora interações entre threads e avisa o testador quando essa interação representar perigo. Essa ferramenta identifica potenciais perigos de concorrências e deadlocks; JProbe Coverage localiza códigos não testados e mede quanto do código está sendo exercitado, permitindo ao testador estimar qual a confiança dos testes executados.

Panorama $C / C++$ (INTERNATIONAL SOFTWARE AUTOMATION (ISA), 1999a) e Panorama for Java (INTERNATIONAL SOFTWARE AUTOMATION (ISA), 1999b) é um conjunto de cinco ferramentas composto por: 1) OO-Test; 2) OO-SQA; 3) OOAnalyser; 4) OO-Browser; e 5) OO-Diagrammer. Essas ferramentas são úteis no teste de software, garantia de qualidade e reengenharia e ainda suportam as etapas do projeto de software, codificação e documentação. OO-Test executa a análise de cobertura de arcos, análise das freqüências dos arcos executados, análise da eficiência dos casos de teste e minimização do conjunto de teste.

TCAT/Java (Research, 1999) e JCover (MAN MACHINE SYSTEMS, 2002) são duas ferramentas de teste que implementam os critérios de cobertura de comandos e decisões para o teste de programas e applets Java. Tais ferramentas também exigem o código fonte para conduzir a atividade de teste.

Parasoft CodeWizard (PARASOFT Corporation, 2000b) é uma ferramenta de execução de padrões de código para ajudar desenvolvedores prevenir erros e padronizar códigos de $\mathrm{C} / \mathrm{C}++$ automaticamente. Padronização de códigos são regras para uma determinada linguagem que, se seguidas, irão reduzir significativamente os enganos cometidos pelos desenvolvedores. Essa ferramenta executa automaticamente mais de 120 padrões de codificação que, em geral, não são executados por compiladores.

Parasoft $\mathrm{C}++$ Test (PARASOFT Corporation, 2000a) é uma ferramenta de teste de unidade para códigos $\mathrm{C} / \mathrm{C}++$ que executa os seguintes tipos de teste: 1) Teste funcional; 2) Teste estrutural (cobertura de comandos e decisões); e 3) Teste de regressão. Essa ferramenta permite aos desenvolvedores testar em suas classes imediatamente após elas terem sido escritas e compiladas por meio da automatização da criação de driver e de quaisquer stubs necessários, no qual o testador pode personalizar os seus respectivos valores de retorno, ou ainda entrar com seus próprios stubs. Essa ferramenta automatiza o teste funcional com a geração automática dos casos de teste e documentação dos resultados esperados, os quais são comparados com os resultados reais. Além disso, o testador pode incluir seus próprios casos de teste e obter relatório personalizados. No teste estrutural, essa ferramenta gera e executa automaticamente casos de teste projetados para testar à classe especificada. Qualquer problema encontrado é assinalado e apresentado em uma estrutura gráfica. Esses casos de teste são automaticamente salvos de forma que eles 
possam ser usados facilmente no teste de regressão para se ter certeza que modificações nas aplicações não introduzirão novos defeitos.

Parasoft Insure ++ (PARASOFT Corporation, 2000c) é uma ferramenta de detecção de defeitos em tempo de execução para códigos $\mathrm{C} / \mathrm{C}++$ que acelera as tarefas de depuração. Pela visualização e execução de um programa e manipulação simultânea de dados, essa ferramenta ajuda desenvolvedores a entenderem como o código funciona. Esta ferramenta provê um completo diagnóstico de cada problema, incluindo a descrição do erro, a linha do código fonte que contém o erro e informações da pilha de execução. Os relatórios de defeitos providos pela ferramenta ajudam desenvolvedores a encontrarem defeitos mais facilmente que no teste manual. Apesar de não modificar o código fonte, essa ferramenta provê informações completas para correção dos defeitos.

ProLint Advanced Graphical Lint (Productivity through Sofware plc., 2000) verifica os módulos de uma aplicação com o objetivo de encontrar defeitos e inconsistências para mais de 600 tipos de problemas proporcionando uma maior confiabilidade e portabilidade de códigos $\mathrm{C} / \mathrm{C}++$.

Rational PureCoverage (RATIONAL Software Corporation, 2000a) é uma ferramenta de análise de cobertura (comandos e decisões) para códigos $\mathrm{C}++$ e Java que aponta as áreas do código que foram ou não exercitadas durante os testes. Ela expõe o código não testado em todas as partes da aplicação. Essa ferramenta possui diversas opções de apresentação que auxiliam ao testador na compreensão de quais partes do código foram ou não testadas utilizando informação de cobertura de código em arquivos, módulos e linhas de código, permitindo ainda ao testador escolher o nível de cobertura de código por módulos e então focalizar as partes da aplicação que mais lhe interessam.

Rational Purify (RATIONAL Software Corporation, 2000b) é uma ferramenta de detecção de defeitos em tempo de execução para códigos $\mathrm{C} / \mathrm{C}++$ que ajuda o testador a encontrar a raiz do problema em qualquer parte da aplicação. Como a Rational PureCoverage, essa ferramenta permite ao testador escolher o nível de checagem por módulos.

JUnit é um framework de teste que vem sendo muito utilizado e viabiliza a documentação e execução automática de casos de teste. O framework JUnit é de código aberto e pode ser utilizado para escrever e executar de forma automática um conjunto de teste fornecendo relatórios sobre quais casos de teste não se comportaram de acordo com o que foi especificado. A idéia básica é implementar algumas classes específicas que armazenam informações sobre os dados de entrada e a respectiva saída esperada para cada caso de teste. Após a execução de um caso de teste, a saída obtida é comparada com a saída esperada e quaisquer discrepâncias são reportadas. O principal problema do JUnit é que ele não fornece informação a respeito da cobertura obtida pelos casos de teste. JUnit 
pode ser utilizado mesmo que somente o bytecode e a especificação do programa estejam disponíveis (Beck e Gamma, 2002).

Uma outra ferramenta, denominada Component Test Bench (CTB), pode ser utilizada no teste de componentes de software (Bundell et al., 2000). A ferramenta fornece um padrão genérico que permite ao desenvolvedor do componente especificar o conjunto de teste utilizado no teste de um dado componente. O conjunto de teste é armazenado em um arquivo XML (eXtensible Markup Language) e executados utilizando uma ferramenta que compõe o CTB, denominada IRTB (Instrumented runtime system), ou eles podem ser executados invocando-se a execução de uma máquina virtual Java ou ainda compilando e executando programas em $\mathrm{C}$ ou $\mathrm{C}++$. Caso o conjunto de teste seja disponibilizado juntamente com o componente, o cliente poderá repetir os testes e verificar se o componente comporta-se como esperado no contexto do sistema baseado em componentes. A ferramenta não fornece medidas de cobertura de código e é utilizada somente para a realização dos teste de conformidade, ou seja, avaliar se o componente comporta-se como esperado.

Uma abordagem similar é utilizada pela Parasoft JTest (Corporation, 2002) que é uma ferramenta de teste de classes para códigos Java que executa os seguintes tipos de teste: 1) Análise estática; 2) Teste funcional; 3) Teste estrutural (cobertura de comandos e decisões); e 4) Teste de regressão. Essa ferramenta pode executar todos esses tipos de teste em uma simples classe ou em um conjunto de classes. No teste funcional, a ferramenta gera automaticamente um conjunto essencial de casos de teste, estrategicamente projetado para alcançar uma cobertura tão completa quanto possível. O testador pode aumentar esse conjunto de casos de teste com seus próprios casos de teste. Em seguida, a ferramenta executa automaticamente todos esses casos de teste e mostra os seus respectivos resultados em uma representação de árvore. O testador pode ainda visualizar esses resultados e validá-los e, quando a ferramenta executar testes subseqüentes nessa classe, a ferramenta será capaz de notificar ao testador quando ocorrerem erros nos testes de regressão e funcional. A principal diferença entre JTest e CTB é que JTest utiliza o framework JUnit para armazenar e executar os casos de teste automaticamente, enquanto CTB armazena os casos de teste em arquivos XML. JTest não detecta somente erros, como também pode prevenir erros e assegurar que defeitos não serão adicionados no código quando ele é modificado de maneira automatizada, reexecutando os casos de teste documentados com o JUnit. A análise estática previne enganos padronizando códigos e, por conseqüência, reduz a possibilidade de defeitos serem inseridos no código.

Glass JAR Toolkit (GJTK) é uma ferramenta de teste de cobertura que opera diretamente no bytecode Java e não requer o código fonte para aplicar critérios de teste de fluxo de controle (cobertura de comandos e decisões) em bytecodes Java. Ela pode ser utilizada 
para arquivos .class diretamente ou arquivos .class empacotados em arquivos .jar (Edge, 2002).

Para apoiar o teste de mutação em programas OO, algumas ferramentas também vêm sendo desenvolvidas. Alexander et al. (2002) propuseram a arquitetura de uma ferramenta, denominada Object Mutation Engine - OME, que implementa um subconjunto dos operadores de mutação propostos por Bieman et al. (2001) no teste de classes Java.

Tanto Chevalley (2001) quanto Ma et al. (2002) desenvolveram também ferramentas de teste baseadas em mutação para apoiar a aplicação dos conjuntos de operadores de mutação que ambos desenvolveram/estenderam. A característica comum entre essas ferramentas é que elas utilizam o conceito de reflexão computacional para implementar as mutações. Ambas as ferramentas utilizam OpenJava (Tatsubori et al., 2000), que é um sistema reflexivo em tempo de compilação, o qual utiliza macros (meta-programas) para manipular meta-objetos que representam entidades lógicas de um programa, facilitando a realização das mutações.

Recentemente, Bybro (2003) desenvolveu uma ferramenta de teste, denominada $M u$ tation Testing System, que implementa parte do conjunto de operadores de mutação proposto por Ma et al. (2002), descrito na Seção 2.5.4. A ferramenta utiliza o framework JUnit para documentar e executar de forma automática os casos de teste, determinando o número de mutantes mortos e qual o escore de mutação obtido.

A Tabela 2.9 apresenta comparações das atividades apoiadas por essas ferramentas de teste para programas OO, tais como: 1) análise estática; 2) fases do teste; 3) critérios de teste; 4) linguagem suportada, 4) exigência do código fonte, 5) atividade de depuração; e 6) teste de regressão.

Analisando-se a Tabela 2.9 observa-se que o framework JUnit (Beck e Gamma, 2002) é uma das ferramentas que pode ser utilizada tanto para o programas quanto para o teste de componentes de software desenvolvidos em Java, mas tal ferramenta suporta apenas a realização de testes funcionais, não fornecendo informação sobre a cobertura de código obtida por determinado conjunto de teste. Outra ferramenta que também apóia somente o teste funcional é a CTB (Bundell et al., 2000).

Considerando as ferramentas que permitem a avaliação de cobertura de código por meio de critérios estruturais, observa-se que das ferramentas analisadas todas apóiam somente o teste de fluxo de controle (cobertura de comandos e decisão) em programas OO. Nenhuma delas apóia a aplicação de algum critério de fluxo de dados seja para o teste de unidade, integração ou sistema. Além disso, exceto pela ferramenta GlassJAR (Edge, 2002) e as que apóiam o teste funcional, todas as demais necessitam do código fonte para a aplicação dos critérios, dificultando a utilização das mesmas no teste estrutural 
de componentes de software por parte dos clientes, os quais, em geral, não têm acesso ao código fonte.

Tabela 2.9: Características apresentadas pelas ferramentas de teste OO.

\begin{tabular}{|c|c|c|c|c|c|c|c|c|c|c|c|}
\hline Ferramentas de teste de software & 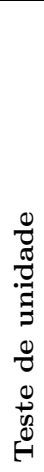 & 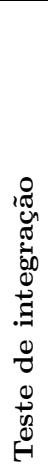 & 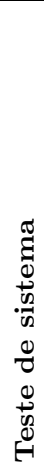 & 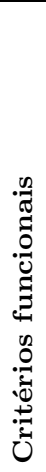 & 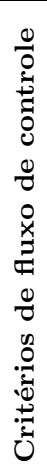 & 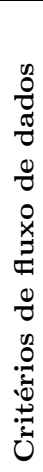 & 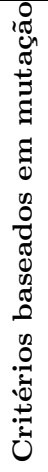 & 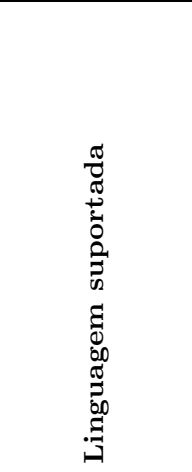 & 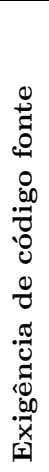 & 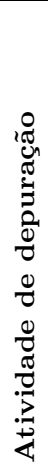 & $\begin{array}{c}0 \\
10 \\
0 \\
0 \\
0 \\
0 \\
0 \\
0 \\
0 \\
0 \\
0 \\
0 \\
0 \\
0 \\
0 \\
0\end{array}$ \\
\hline PiSCES & $\checkmark$ & & & & $\checkmark$ & & & Java & 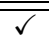 & & \\
\hline SunTest & $\checkmark$ & & $\checkmark$ & & $\checkmark$ & & & Java & $\checkmark$ & & \\
\hline$x$ Suds Toolsuite & $\checkmark$ & & $\checkmark$ & & $\checkmark$ & & & $\mathrm{C} / \mathrm{C}++$ & $\checkmark$ & $\checkmark$ & $\checkmark$ \\
\hline JProbe Developer Suite & $\checkmark$ & & $\checkmark$ & & $\checkmark$ & & & Java & $\checkmark$ & $\checkmark$ & \\
\hline Panorama $\mathrm{C} / \mathrm{C}++$ & $\checkmark$ & & & & $\checkmark$ & & & $\mathrm{C} / \mathrm{C}++$ & $\checkmark$ & & \\
\hline Panorama for Java & $\checkmark$ & & & & $\checkmark$ & & & Java & $\checkmark$ & & \\
\hline TCAT/Java & $\checkmark$ & & & & $\checkmark$ & & & Java & $\checkmark$ & & \\
\hline JCover & $\checkmark$ & & & & $\checkmark$ & & & Java & $\checkmark$ & & \\
\hline Parasoft CodeWizard & & & & & & & & $\mathrm{C} / \mathrm{C}++$ & $\checkmark$ & & \\
\hline Parasoft $\mathrm{C}++$ Test & $\checkmark$ & & $\checkmark$ & $\checkmark$ & $\checkmark$ & & & $\mathrm{C} / \mathrm{C}++$ & $\checkmark$ & & $\checkmark$ \\
\hline Parasoft Insure ++ & & & & & & & & $\mathrm{C} / \mathrm{C}++$ & $\checkmark$ & $\checkmark$ & \\
\hline ProLint & & & & & & & & $\mathrm{C} / \mathrm{C}++$ & $\checkmark$ & & \\
\hline Rational PureCoverage & $\checkmark$ & & $\checkmark$ & & $\checkmark$ & & & $\mathrm{C}++/$ Java & $\checkmark$ & & \\
\hline Rational Purify & & & $\checkmark$ & & & & & $\mathrm{C} / \mathrm{C}++$ & $\checkmark$ & $\checkmark$ & \\
\hline JUnit & $\checkmark$ & & & $\checkmark$ & & & & Java & & & \\
\hline$C T B$ & $\checkmark$ & & $\checkmark$ & $\checkmark$ & & & & Java/C/C++ & & & \\
\hline Parasoft JTest & $\checkmark$ & & $\checkmark$ & $\checkmark$ & $\checkmark$ & & & Java & $\checkmark$ & & $\checkmark$ \\
\hline Glass JAR Toolkit & $\checkmark$ & & $\checkmark$ & $\checkmark$ & $\checkmark$ & & & Java & & & \\
\hline Object Mutation Engine & & $\checkmark$ & & & & & $\checkmark$ & Java & $\checkmark$ & & \\
\hline Ferramenta de Chevalley (2001) & & $\checkmark$ & & & & & $\checkmark$ & Java & $\checkmark$ & & \\
\hline Ferramenta de $\mathrm{Ma}$ et al. (2002) & & $\checkmark$ & & & & & $\checkmark$ & Java & $\checkmark$ & & \\
\hline Mutation Testing System & & $\checkmark$ & & & & & $\checkmark$ & Java & $\checkmark$ & & \\
\hline
\end{tabular}

Considerando as ferramentas que apóiam o teste de mutação, observa-se que todas dão suporte ao teste de integração inter-classe. Embora o teste de integração seja de grande importância no contexto de programas OO, considera-se que ainda assim, os testes de unidade devam ser realizados visando, principalmente, a eliminar os defeitos de lógica e de programação antes das unidades individuais serem integradas.

Com base nas considerações relacionadas ao teste estrutural, no Capítulo 3 é apresentado um conjunto de critérios de teste que viabiliza a realização do teste de fluxo de controle e de dados intra-método em programas OO. Tais critérios derivam os requisitos de testes diretamente a partir de bytecodes Java, podendo ser utilizados tanto no teste de programas quando de componentes desenvolvidos em Java. Para apoiar a aplicação desses critérios e suprir parte das deficiências apresentada pelas ferramentas existentes, 
destinadas ao teste estrutural de programas, uma ferramenta, denominada JaBUTi (Java Bytecode Understanding and Testing), foi desenvolvida. Os aspectos de implementação dessa ferramenta são descritos na Seção 5.2 do Capítulo 5.

No que se refere ao teste de mutação, no Capítulo 4 são revisitados os conjuntos de operadores de mutação descritos anteriormente, considerando também operadores de mutação destinados ao teste de unidade (Agrawal et al., 1989) e de integração (Delamaro et al., 2001a) tradicionalmente utilizados no teste de programas procedimentais. A arquitetura de uma ferramenta de teste que visa a apoiar a aplicação do teste de mutação considerando as diferentes fases de teste é descrita na Seção 5.3 do Capítulo 5.

\subsection{Considerações Finais}

Neste capítulo descreveu-se o estado da arte no que se refere ao teste de programas OO e de componentes de software. Foram discutidos os principais problemas relacionados ao teste de programas $\mathrm{OO}$ e quais as principais direções na área de teste de software, ressaltando-se a importância do desenvolvimento de critérios de teste para programas OO e de componentes, o desenvolvimento de ferramentas de teste e a realização de estudos comparativos visando a avaliar os diferentes critérios estabelecidos culminando no desenvolvimento de estratégias de teste de baixo custo e alta eficácia.

As fases de teste para programas $\mathrm{OO}$ e quais as diferenças em relação ao teste de programas procedimentais foram caracterizadas. Estratégias, técnicas e critérios de teste

foram descritas considerando o teste de programas OO e de componentes. Ênfase foi dada aos critérios estruturais e baseados em mutação por serem estes o foco principal desta tese. Considerando o teste de componentes observou-se que, em geral, o teste estrutural não é utilizado quando o código fonte não está disponível.

No que se refere à realização de estudos empíricos, observou-se que ainda são poucas as contribuições nesse contexto. A importância da automatização da atividade de teste também foi discutida e foram identificadas uma série de ferramentas de teste para programas OO que apóiam diferentes critérios de teste. Observou-se que existe uma carência de ferramentas que apóiem o teste de critérios baseados em análise de fluxo de dados em programas $\mathrm{OO}$ e que poucas são as ferramentas de teste que oferecem suporte ao teste de componentes de software, principalmente do ponto de vista do cliente. Nenhuma das ferramentas avaliadas apóia a aplicação de critérios de fluxo de dados em componentes de software.

Assim sendo, a revisão apresentada neste capítulo motiva o desenvolvimento desta tese que visa a definir critérios de fluxo de dados intra-método os quais possam ser aplicados tanto no teste de programas OO quando de componentes, bem como a definição de critérios 
de teste baseados em mutação que cubram as diferentes fases de teste. A automatização desses critérios também é contemplada, dando subsídios para a realização de estudos comparativos que viabilize a definição de estratégias de teste de baixo custo e eficazes. 


\section{Teste de Fluxo de Dados OO}

$\mathrm{N}$ ESTE capítulo apresentam-se as contribuições desta tese no que se refere ao estabelecimento de critérios de teste estruturais para o teste de programas OO. O objetivo principal é definir/adaptar critérios estruturais tradicionais, tais como os critérios de fluxo de controle todos-nós e todos-arcos, e os critérios de fluxo de dados todos-usos e todospotenciais-usos, para o teste de unidade (intra-método) de programas OO. Para avaliar a aplicabilidade dos critérios de teste definidos escolheu-se a linguagem Java devido à grande gama de aplicações e componentes que vêm sendo desenvolvidos utilizando tal linguagem. Mais precisamente, a idéia é viabilizar o teste estrutural de programas Java a partir do bytecode Java, permitindo, com isso, também o teste estrutural de componentes para os quais os códigos fonte nem sempre encontram-se disponíveis. Uma vez escolhida a linguagem alvo, como mencionado na Seção 2.5.3, o modelo de fluxo de dados subjacente é definido, caracterizando as instruções de bytecode responsáveis pela definição e/ou o uso de variáveis. De posse de modelo de fluxo de dados, um modelo de representação de programa é construído, considerando os mecanismos de tratamento de exceção, em geral presentes nas linguagens OO. A partir do modelo de representação de programa definido, quatro critérios de fluxo de controle e quatro critérios de fluxo de dados são definidos, viabilizando o teste estrutural intra-método de programas OO e componentes. É feita uma análise das propriedades de inclusão e de complexidade dos critérios de teste definidos visando a avaliar, respectivamente, a dificuldade de satisfação e o número máximo de casos de teste requeridos para satisfazer os critérios no pior caso. Um exemplo ilustrando 
a aplicação dos critérios de teste é apresentado e uma estratégia incremental de aplicação dos critérios é proposta.

\subsection{Motivação}

Conforme observado no capítulo anterior, diversos autores consideram que estratégias de teste tradicionais não são eficazes em detectar defeitos em programas OO e a grande maioria dos trabalhos desenvolvidos relacionados ao teste de programas OO focam no teste baseado em estados, visando a avaliar se os objetos comportam-se adequadamente. Entretanto, como mencionado por Binder (1999) e observado por Souter e Pollock (2003), o teste baseado em estados também não é capaz de detectar todos os tipos de defeitos em programas OO. É necessário que outros critérios de teste, tais como critérios de fluxo de controle, critérios de fluxo de dados e critérios de fluxo de objetos (Souter e Pollock, 2003) sejam utilizados em conjunto para que uma máxima detecção de defeitos seja alcançada.

Além disso, considerando o teste de componentes de software, observa-se que a grande maioria dos critérios de teste atualmente propostos para validar o comportamento de um dado componente por parte do cliente são critérios de teste funcionais, não garantindo que partes essenciais ou críticas do código dos componentes tenham sido cobertas pelo conjunto de teste. Assim sendo, existe a necessidade de desenvolver mecanismos que permitam ao cliente a realização de teste estrutural mesmo em componentes para os quais o código fonte nem sempre encontra-se disponível.

Tais considerações motivaram a investigar a aplicação de critérios de teste estruturais (baseados em análise de fluxo de controle e fluxo de dados) no teste de programas OO e de componentes de software. A solução adotada, instanciada para bytecode, viabiliza a realização de teste estruturais intra-método em programas OO e componentes de software. A seguir são descritas a terminologia e os conceitos básicos necessários para o estabelecimento desses critérios.

\subsection{Terminologia e Conceitos Básicos}

O modelo de representação de programas mais conhecido para o estabelecimento de critérios de fluxo de controle (McCabe, 1976; Roper, 1994) é o grafo de fluxo de controle (GFC), a partir do qual os requisitos de teste são derivados. Já os critérios de fluxo de dados (Herman, 1976; Rapps e Weyuker, 1985; Maldonado, 1991) utilizam o grafo de fluxo de dados def-uso, que é uma extensão do GFC contendo informações sobre o conjunto de variáveis definidas e utilizadas em cada nó e cada aresta do GFC. Nesta tese, o grafo de 
fluxo de dados def-uso $(\mathcal{D U} \mathcal{G})$ é o modelo a partir do qual requisitos de teste de fluxo de controle e de dados são derivados.

De acordo com a metodologia adotada, antes de se construir o grafo $\mathcal{D U \mathcal { G }}$, constrói-se o que é chamado de grafo de fluxo de dados de instrução (data-flow instruction graph - $\mathcal{I G}$ ) de cada método. Informalmente, um $\mathcal{I} \mathcal{G}$ é um grafo no qual cada nó contém uma única instrução de bytecode e as arestas conectam instruções que podem ser executadas em sequiência. O $\mathcal{I} \mathcal{G}$ também contém informação sobre os tipos de acesso (definição ou uso) que cada instrução de bytecode faz. Posteriormente, o grafo $\mathcal{D U \mathcal { G }}$ é obtido aplicando-se um algoritmo de redução no $\mathcal{I} \mathcal{G}$. Tal algoritmo combina diversos nós de um $\mathcal{I} \mathcal{G}$ em um único nó em um grafo $\mathcal{D U G}$ identificando blocos de instruções de bytecode que, em condições normais, sempre são executadas em seqüência. A construção dos grafos $\mathcal{I} \mathcal{G}$ e $\mathcal{D} \mathcal{U} \mathcal{G}$ exige que seja realizada uma análise estática em instruções de bytecode. Uma breve descrição de bytecode Java é apresentada na Seção 3.2.1. Nas Seções 3.2.2 e 3.2.3 descreve-se como um $\mathcal{I} \mathcal{G}$ é construído e como informações de fluxo de dados são coletadas, respectivamente. Na Seção 3.2.4 é apresentado o algoritmo que gera um grafo $\mathcal{D U} \mathcal{G}$ a partir de um $\mathcal{I} \mathcal{G}$.

\subsubsection{Bytecode Java}

Nesta seção é apresentada uma revisão sucinta sobre bytecode Java. Para uma revisão completa sobre o assunto, incluindo a especificação da Máquina Virtual Java e o conjunto completo de instruções aceitos pela mesma sugere-se o livro de Lindholm e Yellin (1999).

Uma das principais razões da popularidade da linguagem Java é a independência de plataforma fornecida pelo seu ambiente de execução: a Máquina Virtual Java (Java Virtual Machine - JVM). O chamado arquivo .class é uma representação binária portátil que contém dados relacionados a uma dada classe, tais como o nome da classe, de sua superclasse, informações sobre atributos e constantes definidas na classe, bem como as instruções de bytecode de cada um de seus métodos.

Instruções de bytecode são similares às instruções de uma linguagem de montagem mas que retêm informações de alto-nível sobre o programa, como por exemplo, o acesso aos atributos da classe a partir dos nomes pelos quais esses foram definidos. Uma instrução de bytecode é representada por um opcode de um byte seguido por valores de operando, caso algum seja requerido pela instrução. Cada opcode tem associado a ele um mnemônico que é mais significativo do que o opcode. As instruções são tipadas e uma letra, a primeira do mnemônico, indica qual o tipo de dado manipulado pela instrução. A convenção utiliza a letra i para representar instruções que manipulam valores tipo int, I para valores tipo long, s para short, b para byte, c para char, f para float, d para double, e a para valores tipo reference (objetos e vetores). Por exemplo, a instrução que insere no topo da 
pilha de execução da JVM um inteiro de um byte tem opcode 16, mnemônico bipush, e requer um operando (um valor inteiro de um byte). A instrução bipush 9 insere no topo da pilha de execução da JVM o valor 9.

A JVM tem uma pilha de execução (stack frame) na qual um novo registro de ativação (frame) é inserido para a invocação de cada método ${ }^{1}$. Tal registro é composto por, além do endereço de retorno da chamada, um vetor de variáveis locais, o qual contém todos os parâmetros e variáveis locais utilizadas pelo método; e por uma pilha de operandos, onde são executadas as instruções de bytecode. Por exemplo, considerando o comando "a $=\mathrm{b}+\mathrm{c}$ ", parte do vetor de variáveis locais e parte da pilha de operandos são ilustrados na Figura 3.1.

\begin{tabular}{|c|c|}
\hline Posição & Variável \\
\hline \hline$\cdots$ & $\cdots$ \\
\hline 2 & $a$ \\
\hline 3 & $b$ \\
\hline 4 & $c$ \\
\hline$\cdots$ & $\cdots$ \\
\hline
\end{tabular}

(a) Vetor de Variáveis Locais

\begin{tabular}{|l|l|l|}
\hline $\begin{array}{c}\text { Instrução de } \\
\text { Bytecode }\end{array}$ & $\begin{array}{l}\text { Pilha de Operandos após } \\
\text { a Execução da Instrução }\end{array}$ & \multicolumn{1}{c|}{ Comentário } \\
\hline \hline 12: iload_3 & $\begin{array}{l}\text { Valor de } b \\
\ldots\end{array}$ & Empilha a variável local 3 (b) \\
\hline 13: iload_4 & $\begin{array}{l}\text { Valor de } c \\
\text { Valor de } b\end{array}$ & Empilha a variável local 4 (c) \\
& $\ldots$ & \\
\hline 14: iadd & $\begin{array}{l}\text { Valor de } b+c \\
\ldots\end{array}$ & $\begin{array}{l}\text { Soma os dois valores e empilha } \\
\text { o resultado no topo da pilha }\end{array}$ \\
\hline 15: istore_2 & $\cdots$ & $\begin{array}{l}\text { Desempilha e armazena } \\
\text { na variável local 2 (a) }\end{array}$ \\
& $\cdots$ & Opena \\
\hline
\end{tabular}

(b) Simulação da Pilha de Operandos

Figura 3.1: Exemplo de execução de instruções de bytecode.

Considerando o exemplo apresentado acima, as variáveis $a, b$ e $c$ correspondem às variáveis locais de números 2,3 e 4, respectivamente. As instruções de bytecode iload_3 e iload_4 empilham na pilha de operandos os valores armazenados nas variáveis $b$ e $c$. A instrução iadd desempilha os dois valores, executa a operação de adição e empilha o resultado na pilha de operandos. Finalmente, a instrução istore_2 desempilha o valor do topo da pilha de operandos e armazena-o na variável local 2 (variável $a$ ).

\subsubsection{Construindo o Grafo de Instruções - IG}

A idéia do grafo $\mathcal{I G}$ é abstrair o fluxo de controle e o fluxo de dados entre as instruções de bytecode individualmente. Utilizando tal representação é possível extrair diversas informações de cada método, em particular, a configuração do vetor de variáveis locais e a pilha de operandos quando cada uma das instruções é executada. Tais configurações são essenciais para se computar as informações de fluxo de dados intra-método.

Algumas características de bytecode Java precisam ser manipuladas cuidadosamente durante a realização da análise de fluxo de controle. Em particular:

\footnotetext{
${ }^{1}$ Para ser mais preciso, cada linha de execução (thread) possui sua pilha de execução.
} 
- O uso de chamadas de subrotinas intra-método (intra-method subroutine calls). A JVM tem as instruções jsr, jsr_w e ret que permitem que um trecho de código do método seja "chamado" a partir de diferentes pontos dentro do mesmo método. Tal recurso é utilizado, principalmente, para implementar a execução de blocos finally em Java, que é parte dos comandos de tratamento de exceção.

- Tratadores de exceção (exception handlers). Cada trecho de código inserido dentro de um bloco catch em Java é um tratador de exceção. A execução desse trecho de código não é realizada por meio do fluxo de controle normal do programa, mas quando ocorre uma exceção.

Observa-se que para lidar com o mecanismo de tratamento de exceção de Java, o modelo de representação de programa utilizado $(\mathcal{I} \mathcal{G}$ ou $\mathcal{D U \mathcal { G }}$ no caso desta tese) deve, de alguma forma, espelhar a ocorrência dos desvios de fluxo de execução após a ocorrência de uma exceção. Para isso, optou-se por utilizar dois tipos diferentes de arestas na construção do $\mathcal{I} \mathcal{G}$ : arestas regulares (regular edges) representando o fluxo de controle "normal", ou seja, quando nenhuma exceção é lançada (thrown); e arestas de exceção (exception edges) representando o desvio de fluxo de controle quando ocorre uma exceção.

Formalmente, o grafo $\mathcal{I} \mathcal{G}$ de um método $m$ é definido como um grafo dirigido $\mathcal{I} \mathcal{G}(m)=$ $(N I, E I$, si, TI) onde:

- $N I$ representa o conjunto não vazio de nós de um grafo $\mathcal{I} \mathcal{G}: N I=\left\{n_{i} \mid n_{i}\right.$ corresponde a uma instrução de bytecode $i$, para toda instrução de bytecode alcançável ${ }^{2} i$ de $m$ \}. Como cada nó corresponde a uma única instrução bytecode, usa-se daqui por diante $n_{i}$ para referenciar indistintamente o nó do grafo $\mathcal{I} \mathcal{G}$ ou a instrução a ele correspondente;

- si $\in N I$ é o nó de entrada, ou seja, ele corresponde ao nó que contém a primeira instrução do método $m$. Seja $x$ um nó de um grafo dirigido qualquer, $I N(x)$ corresponde ao número de arestas que chegam a $x$ e $O U T(x)$ corresponde ao número de arestas que partem de $x$. Tem-se que $I N\left(s_{i}\right)=0$;

- $T I \subseteq N I$ é o conjunto (possivelmente vazio) de nós de saída, ou seja, $T I=\left\{n_{i} \in\right.$ $\left.N I \mid O U T\left(n_{i}\right)=0\right\}$

- $E I=E I_{r} \cup E I_{e}$ é o conjunto completo de arestas de $\mathcal{I} \mathcal{G}$.

onde:

\footnotetext{
${ }^{2}$ Observa-se que caso o compilador gere instruções de bytecode não alcançáveis, tais instruções não são representadas no grafo $\mathcal{I} \mathcal{G}$.
} 
- $E I_{r}$ e $E I_{e}$ correspondem a dois subconjuntos disjuntos de arestas regulares e de exceção, respectivamente;

* $E I_{e}$ é o conjunto de arestas de exceção definido como $E_{e}=\left\{\left(n_{i}, n_{j}\right) \mid\right.$ a instrução em $n_{i}$ está no escopo do tratador de exceção ${ }^{3}$ com início na instrução correspondente ao nó $\left.n_{j}\right\}$;

* $E I_{r}$ é o conjunto de arestas regulares definido como $E I_{r}=\left\{\left(n_{i}, n_{j}\right) \mid\right.$ a instrução em $n_{j}$ pode ser executada imediatamente após a instrução em $n_{i}$ e $\left.\left(n_{i}, n_{j}\right) \notin E I_{e}\right\}$;

Considere o código fonte em Java apresentado na Figura 3.2(a). A classe Vet contém um método Vet.average() que calcula e retorna a média dos números armazenados em um vetor de inteiros. As instruções de bytecode que representam o método Vet.average() são apresentadas na Figura 3.2(b). Cada instrução de bytecode é precedida de um contador de programa (pc) que identifica unicamente cada instrução em um dado método. No exemplo, a primeira instrução de bytecode, aload_0, é indicada pelo pc 0 e a última, freturn, pelo pc 101.

A Figura 3.2(c) ilustra a tabela de exceção do método Vet.average(). A tabela de exceção indica, para cada segmento de instruções de bytecode (colunas from e to), o início (coluna target) de cada tratador de exceção válido, bem como o tipo de exceção que é tratada pelo mesmo (coluna type). Por exemplo, do pc 12 ao pc 54 o tratador de exceção válido começa no pc 60 e é responsável por tratar qualquer exceção da classe java.lang. Exception ou qualquer uma de suas subclasses. Um tratador de exceção que esteja registrado como sendo do tipo 〈Class all〉 é responsável por tratar quaisquer exceções que sejam geradas dentro de seu escopo de atuação.

As instruções de bytecode podem ser relacionadas com linhas do código fonte pois o arquivo .class armazena informações que permitem mapear cada instrução de bytecode para a linha de código fonte que lhe deu origem. Com isso, se o código fonte estiver disponível, as análises realizadas no bytecode podem ser mapeadas de volta para o código fonte. A tabelas de números de linha (line number table), ilustrada na Figura 3.2(d), fornece tal correspondência. Por exemplo, o comando localizado na linha número 06 do código fonte corresponde às instruções de bytecode do pc 0 para o pc 2, inclusive. As instruções de bytecode do pc 5 ao 7 , inclusive, correspondem ao comando da linha 07 no código fonte, e assim por diante.

\footnotetext{
${ }^{3}$ Um tratador de exceção $j$ é responsável por tratar exceções geradas pelas instruções de bytecode localizadas entre um determinado intervalo de offsets $\left[o_{j_{m}} . . o_{j_{n}}\right]$. Diz-se que uma instrução de bytecode $i$ localizada no offset $o_{i}$ está no escopo de um tratador de exceção $j$ se e somente se $o_{i} \in\left[o_{j_{m}} . . o_{j_{n}}\right]$.
} 
$/^{*} 01^{*} /$ public class Vet \{

$/{ }^{*} 02^{*} /$ int $v[]$;

$/{ }^{*} 03^{*} /$ float out;

$/ * 04^{*} /$

$/{ }^{*} 05^{\star} /$ float average(int[] in) \{

$/{ }^{*} 06^{*} / \quad \mathrm{v}=\mathrm{in}$;

$/{ }^{*} 07^{*} / \quad$ out $=0.0 \mathrm{f}$;

${ }^{*} 08^{*} / \quad$ int $\mathrm{i}=0$

$/{ }^{*} 09^{*} / \quad$ try \{

$/^{*} 11^{*} / \quad$ while $(i<v$. length $)\{$
$/^{*} 12^{*} / \quad$ out $+=v[i]$

${ }^{*} 13^{*} / \quad \mathrm{i}++$;

$|* 14 *|<$

${ }^{*} 15^{\star} / \quad$ out $=$ out $/ \mathrm{i}$;

${ }^{*} 16^{*} /$ \} catch (Exception e) \{

${ }^{*} 17^{*} / \quad$ out $=0.0 \mathrm{f}$;

$/ * 18 * / \quad \mathrm{i}=0$;

$\left.{ }^{*} 19^{*} / \quad\right\}$ finally \{

$/ 20 * / \quad v=$ null;

$|* 21 *| \quad\}$

$/ * 22^{*} / \quad$ print((float) i);

$/{ }^{*} 23 *$ return out;

$\left.\left|{ }^{*} 24^{*}\right|\right\}$

$/{ }^{*} 25^{\star} /$

$/{ }^{*} 26^{\star} /$ public void print(float n) \{

${ }^{*} 27^{*} / \quad$ System.out.print $\left(\mathrm{n}+{ }^{*} \mid \mathrm{n} "\right)$;

$|* 28 *|\}$

$\left.{ }^{*} 29^{*} /\right\}$

(a) Código Fonte Vet.java from to target type

$125460<$ Class java.lang.Exception>

$1257 \quad 74<$ Class all>

$\begin{array}{llll}60 & 71 \quad 74<\text { Class all> }\end{array}$

$7479 \quad 74<$ Class all>

(c) Tabela de Exceção

Line 6: $p c=0$

Line 7: $p c=5$

Line 8: $p c=10$

Line 11: $p c=12$

Line 12: $p c=15$

Line 13: $p c=31$

Line 11: $p c=34$

Line 15: $p c=43$

Line 16: $p c=54$

Line 17: $p c=60$

Line 18: $p c=66$

Line 19: $p c=68$

Line 20: $\mathrm{pc}=74$

Line 22: $p c=91$

Line 23: $p c=97$

(d) Tabela de Números de Linha

0 aload_0 49 i2f

1 aload_1 50 fdiv

2 putfield \#2 <Field int[] v> 51 putfield \#3 <Field float out>

5 aload_0 54 jsr 82

6 fconst_0 57 goto 91

7 putfield $\# 3<$ Field float out> 60 astore 3

10 iconst_0 61 aload_0

11 istore_2 62 fconst_0

12 goto $34 \quad 63$ putfield $\# 3<$ Field float out>

15 aload_0 66 iconst_0

16 dup 67 istore 2

17 getfield \#3<Field float out> 68 jsr 82

20 aload_0 71 goto 91

21 getfield \#2 <Field int[] v> 74 astore 4

24 iload_2 76 jsr 82

25 iaload 79 aload 4

26 i2f 81 athrow

27 fadd 82 astore 5

28 putfield \#3 <Field float out $>84$ aload_0

31 iinc $21 \quad 85$ aconst_null

34 iload_2 86 putfield \#2 <Field int[] v>

35 aload $0 \quad 89$ ret 5

36 getfield \#2 <Field int[] v> 91 aload_0

39 arraylength 92 iload_2

40 if icmplt 15

43 aload_0 94 invokevirtual \#5 $<$ Method void print(float)>

44 aload_0 97 aload_0

45 getfield \#3<Field float out> 98 getfield \#3 <Field float out> 48 iload_2

101 freturn

(b) Instruções de Bytecode de Vet.average()

\author{
ption>
}

def=\{L@0, L@1, L@0.v, L@0.out $\}$

uso $=\{\mathrm{L} @ 0\}$

uso= $=$ L @1 1

$\operatorname{def}=\{L @ 0 . v\}$

$\therefore$

$\dddot{j}$

def $=\{$ L@0.out $\}$

$\dddot{1}$

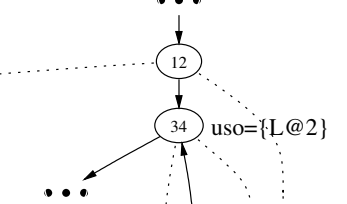

uso= $\because$ L @ 0$\}$

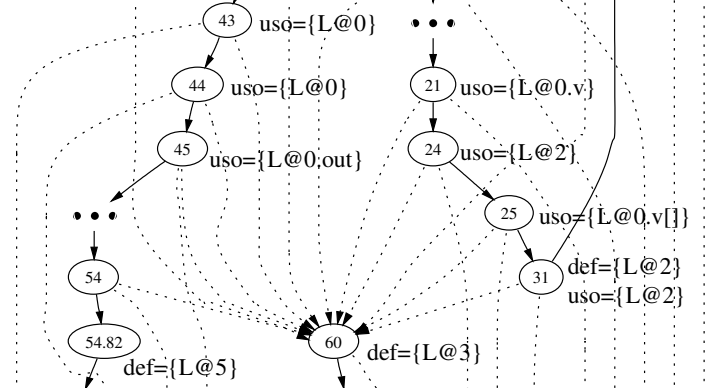

$\therefore$ def $=\{L @ 5\} \quad$ T $\because \ddots$

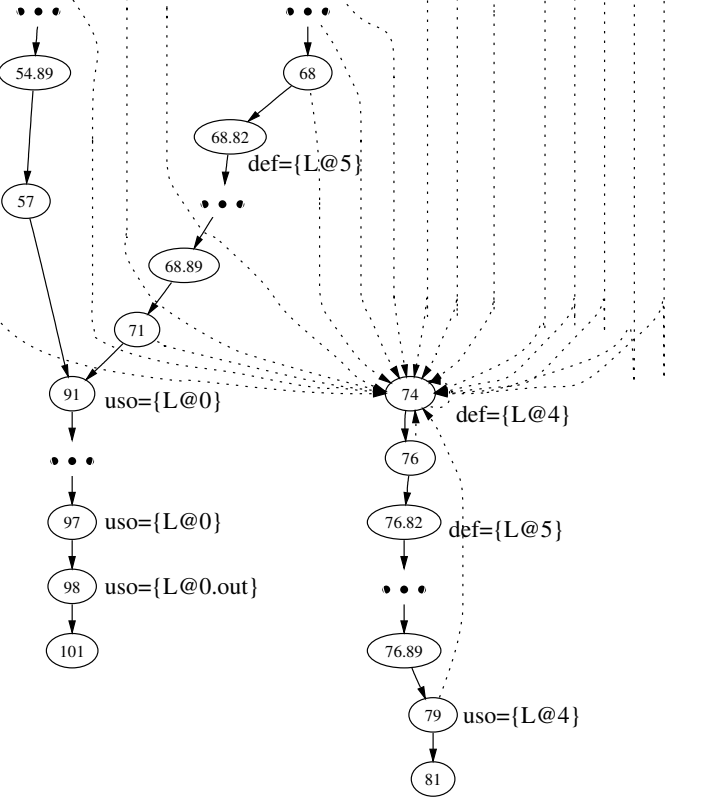

(e) Grafo de Fluxo de Dados de Instruções de Vet.average()

Figura 3.2: Ilustração de um $\mathcal{I} \mathcal{G}$ para o método Vet.average().

Para a construção do grafo $\mathcal{I} \mathcal{G}$, as instruções de bytecode de um dado método são lidas e um interpretador é responsável por analisar a semântica de cada instrução, identificando 
o conjunto de nós e arestas do $\mathcal{I} \mathcal{G}$. Inicialmente, um nó no $\mathcal{I} \mathcal{G}$ é criado para cada instrução de bytecode, e tais nós são conectados por arestas regulares, considerando a existência de transferência de controle entre cada instrução, e por arestas de exceção, considerando a tabela de exceção. A partir do conjunto completo de instruções de bytecode, apresentadas na Tabela 3.1 (Seção 3.2.3), as instruções destacadas em negrito pertencentes às Classes 0 e 1 (primeira e segunda linhas) estão relacionadas com o fluxo de controle em bytecode Java. A Figura 3.2(e) ilustra o $\mathcal{I} \mathcal{G}$ resultante do método Vet.average() apresentado na Figura 3.2(b). Os nós do $\mathcal{I} \mathcal{G}$ são numerados de acordo com o número do contador de programa (pc) de suas respectivas instruções de bytecode. Na Seção 3.2.3 é descrito como são gerados os conjuntos def(i) e uso $(i)$, correspondentes aos conjuntos de variáveis definidas e usadas em cada nó $i$ do grafo $\mathcal{I} \mathcal{G}$, respectivamente. Observe que no nível de instruções de bytecode pode ser difícil distinguir entre usos predicativos ( $p$-uso) e usos computacionais (c-uso). Mais detalhes a respeito de como os conjuntos de p-usos são computados são dados no final da Seção 3.2.4.

Uma vez que cada instrução de bytecode corresponde a um único nó em $\mathcal{I} \mathcal{G}$, o número de nós e arestas é relativamente grande, mesmo para métodos com poucas linhas de código fonte. No caso do $\mathcal{I} \mathcal{G}$ apresentado na Figura 3.2(e), alguns nós foram omitidos para reduzir o tamanho do $\mathcal{I} \mathcal{G}$ e melhorar a sua legibilidade. Reticências (“•••") foram utilizadas para representar os nós que foram omitidos.

As arestas regulares são representadas por linhas contínuas e as arestas de exceção por linhas pontilhadas. Observe que existe um grande número de arestas de exceção conectando os nós que se encontram no domínio de cada tratador de exceção com o primeiro nó correspondente ao tratador de exceção propriamente dito. Por exemplo, de acordo com a tabela de exceção apresentada na Figura 3.2(c), o tratador de exceção localizado no pc 60 é responsável por tratar de todas as exceções da classe java.lang.Exception que forem lançadas por qualquer uma das instruções do pc 12 ao pc 54. Desse modo, existem arestas de exceção conectando todos os nós neste intervalo ao nó 60 . O mesmo se aplica aos outros tratadores de exceção. Uma observação importante que precisa ser feita é que como todas as instruções de bytecode podem lançar todos os tipos de exceção, esta abordagem, embora simples de ser implementada, pode resultar em um $\mathcal{I} \mathcal{G}$ com arestas de exceção "falsas" (ou espúrias). Uma abordagem mais precisa iria requerer um esforço computacional adicional e iria criar um modelo de fluxo de controle mais complexo. Cada instrução de bytecode poderia ter um conjunto de tratadores de exceção diferentes, o que impediria que as mesmas pudessem ser agrupadas em um único bloco durante a construção do grafo $\mathcal{D U \mathcal { G }}$, como será descrito na Seção 3.2.4. Observa-se que com a realização de estudos empíricos pretende-se avaliar se a abordagem adotada gera um grande número de 
arestas de exceção espúrias, dificultando a realização dos testes, ou o número de requisitos espúrios não chega a ser tão significativo e a abordagem pode ser mantida.

Um cuidado especial na construção do $\mathcal{I} \mathcal{G}$ é necessário para lidar com chamadas de subrotina intra-método, usadas, por exemplo, para implementar blocos finally em Java. Cada instrução jsr desvia a execução do método para um trecho de código dentro do mesmo método (subrotina). Após a execução dessa subrotina, a execução continua a partir de um ponto diferente do método, dependendo de qual instrução jsr invocou a subrotina. No exemplo apresentado, existem três instruções do tipo jsr localizadas nos nós 54, 68, e 76. Todas elas representam um desvio para o pc 82, que corresponde à primeira instrução do bloco finally. Tal bloco finally vai do pc 82 ao pc 89 . Observe que no pc 89 existe uma instrução ret que retorna a execução para uma das instruções localizadas em pc 57, 71 ou 79, dependendo qual instrução jsr invocou a subrotina. Para evitar uma interpretação incorreta a respeito de qual instrução jsr causou a invocação de um bloco finally, e qual será a próxima instrução a ser executada após a execução da subrotina, o conjunto de nós correspondentes ao bloco finally é replicado para cada instrução jsr, e rótulos diferentes são utilizados para identificar os nós replicados. No exemplo sendo utilizado, os nós do pc 82 ao 89 são replicados três vezes e os rótulos desses nós são precedidos por "54.", "68.", e "76.", como pode ser observado na Figura 3.2(e). A Figura 3.3(a) ilustra o problema se os nós que correspondem ao bloco finally não fossem replicados.

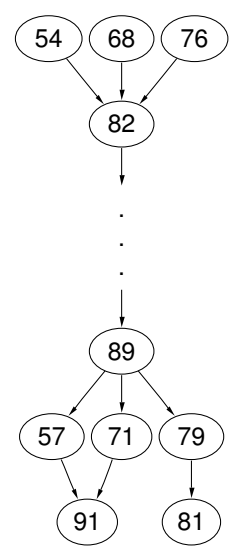

(a)

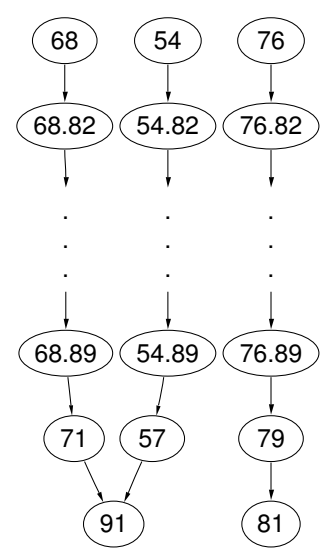

(b)

Figura 3.3: Diferentes abordagens para lidar com blocos finally: (a) Único nó de finally (b) Múltiplos nós de finally.

Observe que uma vez que existem três arestas chegando ao nó 82 e três arestas saindo do nó 89, isso poderia levar à falsa impressão de que a partir de qualquer aresta chegando podem existir três possibilidades de caminhos a serem seguidos quando na verdade existe apenas um. A replicação dos nós correspondentes à subrotina evita tal problema, como 
pode ser observado na Figura 3.3(b). Acredita-se que esta abordagem seja mais precisa e represente com mais exatidão o fluxo de controle do método. Como desvantagem, esta solução pode aumentar o número de nós no grafo, especialmente na presença de chamadas a subrotinas aninhadas.

\subsubsection{Incluindo Informações de Fluxo de Dados no $\mathcal{I G}$}

Uma vez que o grafo de instruções representando o fluxo de controle de determinado método tenha sido computado é necessário incluir no mesmo informações de fluxo de dados. Entretanto, para que informações de fluxo de dados sejam computadas faz-se necessária a definição do modelo de fluxo de dados que indique quais instruções de bytecode são responsáveis pela definição e uso de variáveis e como variáveis de referência e vetores devem ser considerados. O primeiro passo na definição do modelo de fluxo de dados foi a classificação do conjunto de instruções de bytecode, obtidas de Lindholm e Yellin (1999), em diferentes classes, de acordo com a relação que as mesmas tenham com o fluxo de dados no nível de bytecode.

\subsubsection{Modelo de Fluxo de Dados para Bytecode Java}

A Tabela 3.1 ilustra as 11 classes de instruções que foram definidas para auxiliar na definição do modelo de fluxo de dados.

A divisão do conjunto de instruções nessas diferentes classes teve como base os tipos de definição e uso de variáveis que se desejava identificar. Em Java e em bytecode Java, as variáveis podem ser classificadas como sendo de dois tipos: básicos ou de referência. Atributos também podem ser dos tipos básicos ou de referência e classificados como atributos de instância ou de classe, dependendo se eles são únicos para cada objeto de determinada classe ou se são compartilhados entre todos os objetos de determinada classe (atributos estáticos), respectivamente. As variáveis locais definidas dentro de cada método podem ser de tipo básico ou de referência e as variáveis agregadas (vetores) são sempre do tipo referência. Visto que a grande maioria dos modelos de fluxo de dados propostos na literatura foram definidos considerando o teste de programas $\mathrm{C}$, para lidar com variáveis agregadas decidiu-se utilizar, em um primeiro momento, a abordagem proposta por Horgan e London (1991), a qual considera uma variável agregada unidimensional como sendo uma única localização de memória de tal modo que quando ocorre uma definição (uso) de qualquer um de seus elementos considera-se que a variável agregada em si é que está sendo definida (usada) e não o elemento particular. Além disso, conforme comentado na Seção 2.5.3 do Capítulo 2, as definições de variáveis nesse modelo são bloqueantes, ou seja, redefinições bloqueiam definições prévias em relação a mesma variável. Posterior- 
mente, outras abordagens, tais como a abordagem conservadora proposta por Maldonado (1991) no qual a definição de um tipo agregado não é bloqueante, devem ser consideradas e investigadas no contexto de programas $\mathrm{OO}$, verificando se os resultados obtidos no teste de programas procedimentais se mantêm.

Tabela 3.1: Diferentes classes de instruções de bytecode.

\begin{tabular}{|c|c|c|}
\hline Classe & Instrução de Bytecode & Implicações no Fluxo de Dados \\
\hline 0 & $\begin{array}{l}\text { athrow, goto, goto_w, if_acmpeq, if_acmpne, } \\
\text { if_icmpeq, if_icmpge, if_icmpgt, if_icmple, } \\
\text { if_icmplt, if_icmpne, ifeq, ifge, ifgt, ifle, iflt, } \\
\text { ifne, ifnonnull, ifnull, lookupswitch, tableswitch, } \\
\text { areturn, dreturn, freturn, ireturn, Ireturn, return, } \\
\text { ret, monitorenter, monitorexit, pop, pop2, break- } \\
\text { point, impdep1, impdep2, nop, checkcast, wide, } \\
\text { swap }\end{array}$ & $\begin{array}{l}\text { Essas instruções não têm implicações no fluxo } \\
\text { de dados do método. }\end{array}$ \\
\hline 1 & $\begin{array}{l}\text { invokeinterface, invokespecial, invokestatic, } \\
\text { invokevirtual, jsr, jsr_w, dadd, ddiv, dmul, dneg, } \\
\text { drem, dsub, fadd, fdiv, fmul, fneg, frem, fsub, iadd, } \\
\text { iand, idiv, imul, ineg, ior, irem, ishl, ishr, isub, } \\
\text { iushr, ixor, ladd, land, Idiv, Imul, Ineg, lor, Irem, } \\
\text { Ishl, Ishr, Isub, lushr, Ixor, arraylength, instanceof, } \\
\text { aconst_null, bipush, dconst, fconst, iconst, lconst, } \\
\text { sipush, Idc, Idc_w, Idc2_w, d2f, d2i, d2I, f2d, } \\
\text { f2i, f2l, i2b, i2c, i2d, i2f, i2l, i2s, I2d, I2f, I2i, } \\
\text { new, multianewarray, anewarray, newarray, dcmpg, } \\
\text { dcmpl, fcmpg, fcmpl, Icmp }\end{array}$ & $\begin{array}{l}\text { Essas instruções não têm implicações no fluxo } \\
\text { de dados do método. Além disso, elas deixam no } \\
\text { topo da pilha de execução um elemento desconhe- } \\
\text { cido. Acesso a tais elementos não irão caracteri- } \\
\text { zar definição ou uso de nenhuma variável. Por } \\
\text { exemplo, a instrução new empilha a referência a } \\
\text { um novo objeto no topo da pilha de execução e } \\
\text { qualquer uso futuro de tal referência, tal como o } \\
\text { acesso de um de seus atributos, não é considerado } \\
\text { um uso ou definição desse objeto. }\end{array}$ \\
\hline 2 & $\begin{array}{l}\text { aaload, baload, caload, daload, faload, iaload, la- } \\
\text { load, saload }\end{array}$ & $\begin{array}{l}\text { Carregam no topo da pilha de execução um ele- } \\
\text { mento de um vetor caracterizando um uso do ve- } \\
\text { tor. }\end{array}$ \\
\hline 3 & $\begin{array}{l}\text { aastore, bastore, castore, dastore, fastore, iastore, } \\
\text { lastore, sastore }\end{array}$ & $\begin{array}{l}\text { Armazenam o valor do topo da pilha de execu- } \\
\text { ção em um elemento do vetor caracterizando uma } \\
\text { definição do vetor. }\end{array}$ \\
\hline 4 & putfield & $\begin{array}{l}\text { Armazena o valor do topo da pilha de execução } \\
\text { em um atributo de instância caracterizando a de- } \\
\text { finição de tal atributo. }\end{array}$ \\
\hline 5 & putstatic & $\begin{array}{l}\text { Armazena o valor do topo da pilha de execução } \\
\text { em um atributo de classe caracterizando a defi- } \\
\text { nição de tal atributo. }\end{array}$ \\
\hline 6 & dup, dup2, dup_x1, dup $\_2$, dup2_x1, dup2_×2 & $\begin{array}{l}\text { Essas instruções duplicam o valor do topo da pilha } \\
\text { de execução e não têm implicações no fluxo de } \\
\text { dados do método. }\end{array}$ \\
\hline 7 & aload, dload, fload, iload, lload & $\begin{array}{l}\text { Carregam no topo da pilha de execução o valor } \\
\text { armazenado em uma variável local caracterizando } \\
\text { um uso de tal variável. }\end{array}$ \\
\hline 8 & astore, dstore, fstore, istore, Istore & $\begin{array}{l}\text { Armazenam o valor do topo da pilha de execução } \\
\text { em uma variável local caracterizando uma defi- } \\
\text { nição de tal variável. }\end{array}$ \\
\hline 9 & getfield & $\begin{array}{l}\text { Carrega no topo da pilha de execução o valor ar- } \\
\text { mazenado em um atributo de instância caracteri- } \\
\text { zando um uso de tal atributo. }\end{array}$ \\
\hline 10 & getstatic & $\begin{array}{l}\text { Carrega no topo da pilha de execução o valor } \\
\text { armazenado em um atributo de classe caracteri- } \\
\text { zando um uso de tal atributo. }\end{array}$ \\
\hline 11 & iinc & $\begin{array}{l}\text { Incrementa o valor armazenado em uma dada va- } \\
\text { riável local caracterizando um uso e uma defini- } \\
\text { ção de tal variável. }\end{array}$ \\
\hline
\end{tabular}

Desse modo, no modelo de fluxo de dados apresentado a seguir, aplicam-se as seguintes suposições na identificação da definição e uso de variáveis: 
1. Variáveis agregadas são consideradas como sendo uma única posição de memória. A definição/uso de qualquer elemento da variável agregada a[] é considerada como sendo uma definição/uso de $a[]$. Assim sendo, em um comando do tipo " $a[i]=a[j]+1 "$ existe uma definição e um uso da variável agregada $a[]$.

2. Se uma variável agregada $a[][]$ é declarada, o acesso aos seus elementos caracterizam uma definição ou uso de $a[][]$, dependendo do tipo de acesso. Assim sendo, comandos de atribuição do tipo " $a[0][0]=10$ " ou " $a[0]=$ newint $[10]$ " caracterizam uma definição de $a[][]$ e $a[]$, respectivamente, ao passo que no comando "a[0][0] = a[2][3]" existe um uso e uma definição da variável $a[][]$.

3. Toda vez que um atributo de instância é usado (definido) existe um uso da variável de referência que permite o acesso ao atributo e um uso (definição) do atributo em si. Por exemplo, considere $r e f \_1$ e ref_2 duas variáveis de referência para objetos da classe $C$ a qual contém dois atributos de instância $x$ e $y$ do tipo inteiro (int), no comando "ref_1.x = ref_2.y" existem usos das variáveis de referência $r e f \_1$ e $r e f \_2$, um uso do atributo de instância $r e f \_2 . y$, e uma definição do atributo de instância ref_1.x. Uma vez que os atributos de instância são válidos no escopo de toda a classe, cada atributo de instância usado em um dado método, e que não tenha sido definido no método, é considerado como tendo sido definido no primeiro nó do grafo $\mathcal{I} \mathcal{G}$ do método em questão.

4. Atributos de classe (atributos estáticos) podem ser considerados como variáveis globais e o acesso aos mesmos é feito sem a necessidade de uma variável de instância. Considerando uma classe $C$ com os atributos estáticos $w$ and $z$, ambos do tipo int, no comando "C.z=C.w+10" existe um uso do atributo C.w e uma definição do atributo C.z. Mesmo que o acesso ao atributo estático seja feito por meio de uma variável de instância ref_1 do tipo da classe $C$, tal como "ref_1.w = 10", no nível de bytecode, tal variável de referência é automaticamente convertida no nome da classe; não é caracterizado um uso da variável de referência nesse caso. Uma vez que os atributos de classe são válidos no escopo de toda a classe, cada atributo de classe usado em um dado método, e que não tenha sido definido no método, é considerado como tendo sido definido no primeiro nó do grafo $\mathcal{I} \mathcal{G}$ do método em questão.

5. Na invocação de um método, tal como $r e f \_1 . f o o\left(e \_1, e \_2, \ldots, e \_n\right)$, considerase que ocorre um uso da variável de instância ref_1. As regras para a identificação de definição e uso nas expressões $e_{-} 1, e \_2, \ldots, e \_n$ são as mesmas descritas nos itens de 1 a 4 . 
Ainda no caso de métodos de instância, uma definição para a variável que representa o objeto corrente this é associada ao primeiro nó do $\mathcal{I} \mathcal{G}$. O mesmo ocorre para as variáveis locais que correspondem aos parâmetros formais do método sendo invocado. Para métodos de classe, somente as variáveis locais correspondentes aos parâmetros formais são consideradas definidas no nó de entrada de $\mathcal{I} \mathcal{G}$ já que nenhuma variável de instância é requerida para invocar um método de classe.

Baseada nas suposições definidas pelo modelo de fluxo de dados apresentado acima e nas diferentes classes de instruções de bytecode, o $\mathcal{I G}$ de um dado método é percorrido e a cada nó do grafo é associado um conjunto def $(i)$ que representa o conjunto de variáveis definidas naquele nó e um conjunto uso $(i)$ que representa o conjunto de variáveis usadas naquele nó. Antes de explicar como esses conjuntos são criados é importante destacar como esses diferentes tipos de variáveis são tratadas no nível de bytecode. Parâmetros formais e variáveis declaradas dentro do método são tratadas como variáveis locais e são associadas ao vetor de variáveis locais pela JVM da seguinte forma: se for um método de instância, a variável local zero, referenciada aqui como $L @ 0$, recebe o valor da referência para o objeto corrente (this), ou seja, o objeto usado para a invocação do método. Os parâmetros formais, caso existam, são associados às variáveis locais um $(L @ 1)$, dois $(L @ 2)$, e assim por diante, dependendo do tipo e do número de parâmetros. Finalmente, as variáveis declaradas dentro do método são associadas às demais variáveis locais, também dependendo do tipo e do número de variáveis. Por exemplo, considerando o código fonte do método Vet.average(), observa-se que se trata de um método de instância o qual aceita um parâmetro in e possui uma variável local $i$. Nesse caso, $L @ 0$ corresponde à referência para o objeto corrente. O parâmetro formal in corresponde à variável local $L @ 1$, e a variável $i$ corresponde à variável local $L @ 2$. Três outras variáveis locais ( $L @ 3, L @ 4$ e $L @ 5)$ são usadas pelo compilador para implementar o mecanismo de tratamento de exceção. Esse método ainda faz acesso a dois atributos de instância: $v$ e out. Como são atributos de instância, eles necessitam de uma referência a um objeto da classe Vet para que o acesso seja possível. Quando nenhuma referência explícita é utilizada precedendo o atributo, a referência ao objeto corrente é utilizada. Desse modo, $v$ e out são referenciados no código em bytecode como L@0.v e L@0.out.

Para analisar o $\mathcal{I G}$ foi implementado um simulador o qual interpreta as instruções de bytecode e identifica o tipo e origem dos dados manipulados pelas mesmas. Por exemplo, suponha que a instrução iload_2 seja a próxima instrução a ser executada. Tal instrução, quando interpretada pela JVM, coloca no topo da pilha de execução um valor inteiro armazenado na variável $L @ 2$. O simulador, ao invés de empilhar o valor inteiro, coloca no topo da pilha uma indicação na forma "<tipo $>$ - < origem_dado>" que será utilizada quando a próxima instrução for interpretada. < tipo > corresponde ao tipo de dado sendo 
manipulado e <origem_dado $>$ representa a partir de onde o dado é obtido. No exemplo sendo utilizado, a instrução iload_2 coloca no topo a indicação "int - L@2", uma vez que a variável $L @ 2$ é a origem do dado tipo inteiro que seria depositado no topo da pilha. Além disso, uma instrução de carga (load) caracteriza um uso da variável $L @ 2$ de modo que tal variável é então adicionada ao conjunto de variáveis usadas no nó corrente do $\mathcal{I} \mathcal{G}$. Diferentes indicações são utilizadas para representar diferentes tipos de locais de armazenamento. Na segunda coluna da Figura 3.4(b) existem três tipos de indicações diferentes que são colocadas no topo da pilhas de execução à medida que as instruções de bytecode ilustradas na primeira coluna são executadas. Para atributos de classe a indicação é na forma "<tipo $>$ - S@ $<$ nome_classe $>$. $<$ nome_atributo $>$ ", onde $<$ tipo $>$ é o tipo do atributo de classe, $<$ nome_classe $>$ é o nome da classe da qual o atributo pertence, e $<$ nome_atributo $>$ é o nome do atributo de classe.

Considerando o $\mathcal{I G}$ apresentado na Figura 3.2(e), observa-se que as definições de $L @ 0$, $L @ 1, L @ 0 . v$, e $L @ 0 . o u t$ estão associadas ao nó 0. Além disso, o nó 0 também contém uma instrução de bytecode da Classe 7 (aload_0), a qual indica um uso da variável $L @ 0$. Observe que a instrução de bytecode localizada em pc 0 é uma das instruções de bytecode que correspondem ao comando " $v=i n$ " localizado na linha 6 do código fonte da Figura 3.2(a). O uso existe pois, antes de inicializar o atributo $v$, o que é realizado pela instrução localizada em pc 2, a referência ao objeto corrente, armazenada na variável local $L @ 0$, tem que ser carregada no topo da pilha de execução, caracterizando um uso de tal variável local.

No nó 2, a instrução putfield, pertencente à Classe 4, indica a definição de um atributo de instância, o atributo de instância $v$ do exemplo, referenciado como $L @ 0 . v$. Assim sendo, o conjunto de variáveis definidas do nó 2 passa a conter o elemento $L @ 0 . v$. Finalmente, a instrução no nó 25, iaload, pertencente à Classe 2, indica um uso de um elemento de um vetor de inteiros; com isso, o conjunto de variáveis usadas no nó 25 passa a conter o elemento $L @ 0 . v[]$.

Um ponto importante a ser observado é que, quando uma determinada instrução de bytecode está sendo analisada, a pilha de execução pode assumir mais de uma configuração, dependendo do caminho seguido até que a instrução sendo analisada seja alcançada. A restrição que se faz é que o tamanho da pilha de operandos seja sempre o mesmo, porém seu conteúdo pode ser distinto (respeitando algumas restrições de tipo). Visto que é possível alcançar determinado nó a partir de diferentes seqüências de instruções, cada possível combinação de configurações da pilha de execução precisa ser considerada para se obter o conjunto completo de variáveis definidas e usadas em cada nó do $\mathcal{I} \mathcal{G}$. Isso é realizado percorrendo-se o grafo $\mathcal{I} \mathcal{G}$ utilizando um algoritmo similar ao implementado pela JVM, descrito na Seção 4.9.2 do livro The Java Virtual Machine Specification (Lindholm e Yel- 
lin, 1999), para fazer a verificação do bytecode antes deste ser executado. Tal algoritmo permite que as diferentes configurações possíveis de serem alcançadas sejam computadas e o conjunto completo de variáveis definidas e usadas de cada nó seja encontrado.

Como um exemplo de tal situação, considere o trecho de instruções de bytecode apresentado na Figura 3.4(b). Esse conjunto de instruções corresponde ao trecho de código fonte mostrado na Figura 3.4(a). A Figura 3.4(c) mostra o $\mathcal{I G}$ com informações de fluxo de dados correspondente.

$$
\begin{aligned}
& r=\text { newFoo }() \\
& s=\text { newFoo( }) \\
& (r . x==0 ? r: s) . x=20
\end{aligned}
$$

\begin{tabular}{|c|c|}
\hline Instruções de Bytecode & Configuração da Pilha de Operandos \\
\hline 16 aload_1 & Foo - L@1 \\
\hline 17 getfield $\# 4<$ Field int $x>$ & int - L@1.x \\
\hline 20 ifne 27 & $\cdots$ \\
\hline 23 aload_1 & Foo - L@1 \\
\hline 24 goto 28 & Foo - L@1 \\
\hline 27 aload_2 & $\begin{array}{l}\text { Foo - L@2 } \\
\ldots\end{array}$ \\
\hline 28 bipush 20 & $\begin{array}{l}\text { int - DC } \\
\text { Foo - L@1 or } \\
\text { Foo - L@2 }\end{array}$ \\
\hline 30 putfield $\# 4<$ Field int $x>$ & $\begin{array}{l}\text { int - L@1.x or } \\
\text { int - L@2.x } \\
\ldots\end{array}$ \\
\hline
\end{tabular}

(a) Trecho de Código Fonte Java

(b) Instruções de bytecode

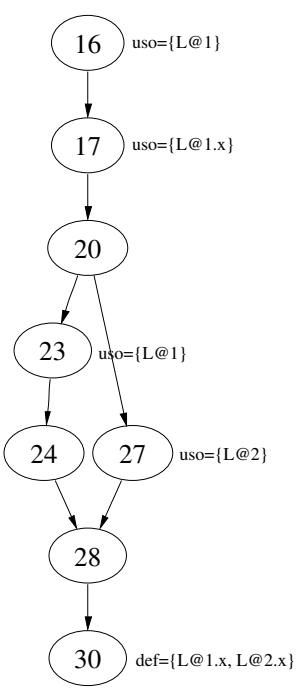

(c) $\mathcal{I G}$ correspondente

Figura 3.4: Diferentes configurações da pilha de operandos.

Observe que a instrução de bytecode no nó 30 pode ser alcançada a partir de dois caminhos diferentes: $\{16,17,20,23,24,28,30\}$ ou $\{16,17,20,27,28,30\}$. Cada um desses caminhos insere indicações diferentes no topo da pilha de operandos. O primeiro carrega no topo da pilha uma indicação para a variável local $L @ 1$ enquanto o outro carrega a indicação para a variável $L @ 2$. Quando a instrução de bytecode localizada no pc 30 é executada, a qual armazena o valor no topo da pilha em um atributo de um objeto, duas possíveis combinações podem ocorrer, a definição de $L @ 1 . x$, ou a definição de $L @ 2 . x$. Assim sendo, o conjunto completo de variáveis definidas no nó 30 do $\mathcal{I} \mathcal{G}$ contém ambos elementos: $L @ 1 . x$ e $L @ 2 . x$.

Uma vez que o conjunto completo de variáveis definidas e usadas em cada nó do $\mathcal{I} \mathcal{G}$ tenham sido identificados, tal $\mathcal{I} \mathcal{G}$ pode ser reduzido, originando o grafo de fluxo de dados $(\mathcal{D U} \mathcal{G})$. O algoritmo utilizado para realizar tal redução é descrito na próxima seção. 


\subsubsection{Construindo o Grafo de Fluxo de Dados $(\mathcal{D U G})$}

O grafo de fluxo de dados de instruções oferece um modo prático de se percorrer o conjunto de instruções de um dado método, identificando-se o conjunto de variáveis definidas e usadas pelas mesmas. Entretanto, uma vez que um nó em $\mathcal{I} \mathcal{G}$ é criado para cada instrução de bytecode de um método $m$, o número de nós e arestas pode ser demasiadamente grande. Assim sendo, uma vez coletadas todas as informações necessárias a respeito do conjunto de instruções de um dado método, o conceito de bloco de instruções é utilizado para reduzir o número de nós e arestas de um grafo $\mathcal{I} \mathcal{G}$ tanto quanto possível.

Um bloco de instruções é definido como um conjunto de instruções que são, "normalmente", executadas em seqüência. Quando a primeira instrução do bloco é executada todas as demais instruções também o são; desvios de execução somente ocorrem para o início de um bloco. A palavra "normalmente" foi utilizada acima para indicar o fluxo de controle determinado pelos comandos do programa, ou seja, sem considerar que possíveis interrupções possam impedir a execução do bloco de comandos como um todo.

O grafo de fluxo de dados $\mathcal{D U G}$ representa o modelo base que é utilizado para se derivar requisitos de teste de fluxo de controle e de dados intra-método para o teste de programas e componentes Java. Um grafo $\mathcal{D U \mathcal { G }}$ de um dado método $m$ é definido com um grafo dirigido $\mathcal{D U}(m)=(N, E, s, T)$ no qual cada nó $n \in N$ representa um bloco de instruções:

- $N$ representa o conjunto de nós de um grafo $\mathcal{D U \mathcal { G } : ~} N=\{n \mid n$ corresponde a bloco de instruções de bytecode de $m\}$, ou seja, $N$ é um conjunto não vazio de nós, representando todos os blocos de instruções de bytecode de $m ; I_{n}$ é a n-upla ordenada de instruções agrupadas no nó $n$;

- $s \in N \mid I N(s)=0$ é o nó de entrada de $m$;

- $T \subseteq N$ é o conjunto (possivelmente vazio) de nós de saída, ou seja, $T=\{n \in$ $N \mid O U T(n)=0\}$;

- $E=E_{r} \cup E_{e}$ é o conjunto completo de arestas de $\mathcal{D U \mathcal { G }}$. Seja $\mathcal{I} \mathcal{G}(m)=(N I, E I$, si, $T I)$, tem-se:

- $E_{e}$ é o conjunto de arestas de exceção definido como $E_{e}=\left\{\left(n_{i}, n_{j}\right) \mid\right.$ existe em $\mathcal{I G}(m)$ uma aresta de exceção do último elemento de $I_{n_{i}}$ para o primeiro elemento de $\left.I_{n_{j}}\right\}$ 
- $E_{r}$ é o conjunto de arestas regulares definido como $E_{r}=\left\{\left(n_{i}, n_{j}\right) \mid\right.$ existe em $\mathcal{I} \mathcal{G}(m)$ uma aresta regular do último elemento de $I_{n_{i}}$ para o primeiro elemento de $\left.I_{n_{j}}\right\}$;

A cada nó $i \in N$ de um grafo $\mathcal{D} \mathcal{U G}$ três conjuntos (não necessariamente disjuntos) são associados: o conjunto def(i) de variáveis definidas no bloco $i$, o conjunto uso $(i)$ de variáveis usadas no bloco $i$ mas que foram definidas em outro bloco, e o conjunto usol $(i)$ de variáveis usadas em $i$ e que foram definidas anteriormente no próprio nó $i$, ou seja, usol $(i)$ é o conjunto de variáveis usadas localmente em um nó $i$ do grafo $\mathcal{D} \mathcal{U} \mathcal{G}$. Por exemplo, a Figura 3.5 ilustra como os conjuntos de variáveis definidas e usadas de um grafo $\mathcal{I} \mathcal{G}$ são mapeados para os conjuntos def(i), uso $(i)$ e usol $(i)$ de um grafo $\mathcal{D U \mathcal { G }}$. O código fonte de um método simples dummy e o seu respectivo bytecode são mostradas nas Figuras 3.5(a) e (b), respectivamente. A Figura 3.5(c) traz a correspondência entre as linhas de código fonte e os pcs do bytecode. O grafo $\mathcal{I} \mathcal{G}$ correspondente ao conjunto de instruções de bytecode da Figura 3.5(b) é apresentado na Figura 3.5(d), com seus respectivos conjuntos de variáveis definidas $(\operatorname{def}(i))$ e usadas $(u s o(i))$ em cada nó. Considerando o primeiro nó do grafo $\mathcal{D U G}$ da Figura 3.5(e), o qual corresponde ao bloco de instruções que envolve os nós de "0" a "5" do grafo $\mathcal{I} \mathcal{G}$, tem-se que esse conjunto de instruções define as variáveis $L @ 0, L @ 1$ e $L @ 2$; portanto, o conjunto $\operatorname{def}(i)$ associado ao primeiro nó do grafo $\mathcal{D} \mathcal{U} \mathcal{G}$ contém essas variáveis. Já o conjunto de usos uso(i) é vazio por não existir uso global associado a esse nó e o conjunto usol $(i)$ contém as variáveis $L @ 1$ e $L @ 2$ por serem essas variáveis usadas por instruções que pertencem ao mesmo bloco, caracterizando um uso denominado local. Uma definição mais precisa de uso local e global é dada mais adiante nesta seção.

O algoritmo utilizado para reduzir um grafo de fluxo de dados de instruções $\mathcal{I} \mathcal{G}$ em um grafo de fluxo de dados $\mathcal{D} \mathcal{U} \mathcal{G}$ - isto é, para computar a seqüência $I_{n}$ de instruções que compõem o nó $n$ do grafo $\mathcal{D U \mathcal { G }}$ - é apresentado na Figura 3.6.

Na linha 14 do algoritmo é tomada a decisão se a instrução corrente $x$ sendo analisada será a última instrução do bloco de instruções corrente ou não. Ela será a última instrução se uma das seguintes condições for satisfeita:

- $x$ é uma instrução de tipo jump, goto, ret ou invoke;

- $x$ tiver mais de um sucessor regular, conforme ilustrado na Figura 3.7(a);

- o único sucessor regular de $x$ tem mais de um sucessor (regular ou de exceção), como ilustrado na Figura 3.7(b);

- o único sucessor regular de $x$ não tem o mesmo conjunto de sucessores de exceção de $x$, conforme ilustrado na Figura 3.7(c). 
Como mencionado anteriormente, dois pontos que merecem ser destacados são: primeiro, quando existem chamadas a subrotinas intra-método o conjunto de nós que correspondem às instruções da subrotina são expandidos (no grafo $\mathcal{I} \mathcal{G}$ ) para cada ponto de chamada à subrotina. Como conseqüência, na redução de acordo com o algoritmo apresentado, os blocos de instruções que representam a subrotina podem aparecer mais de uma vez no grafo $\mathcal{D} \mathcal{U G}$ dentro de nós com rótulos diferentes.
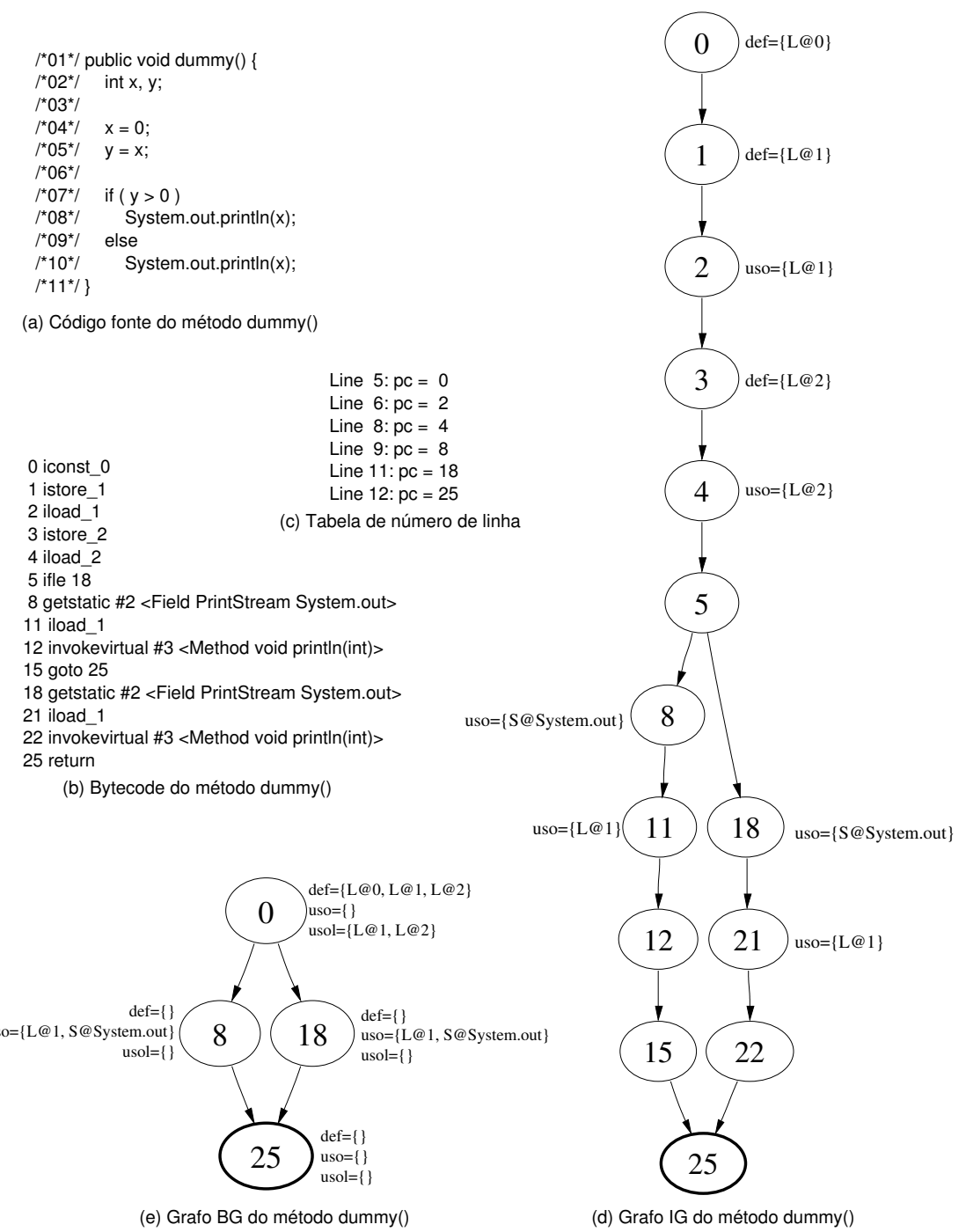

Figura 3.5: Como são gerados os conjuntos def(i), uso(i) e usol(i) no grafo $\mathcal{D U \mathcal { G }}$.

Segundo, uma vez que nem todas as instruções de bytecode dentro de um bloco podem gerar todos os tipos de exceções que podem ser tratadas, o grafo $\mathcal{D} \mathcal{U} \mathcal{G}$ pode ter arestas de exceção "falsas" (ou espúrias). Além disso, a execução de um dado bloco pode ser interrompida em qualquer ponto quando ocorrer uma exceção, ou seja, na presença de uma exceção o bloco pode perder a sua característica de "atomicidade" como mencionado acima. Por outro lado, essa abordagem simplifica não somente a construção do grafo 
$\mathcal{D U \mathcal { G }}$, mas também a sua interpretação, uma vez que o número de nós e arestas é reduzido. Uma abordagem alternativa para a construção do grafo de fluxo de controle considerando construções de tratamento de exceção é proposta por Sinha e Harrold (1998) de modo que o grafo gerado não apresente arestas falsas ou espúrias. Entretanto, a abordagem proposta considera somente as exceções que são geradas explicitamente pelo programa, ou seja, aquelas lançadas explicitamente por comandos throw (Sinha e Harrold, 1998).

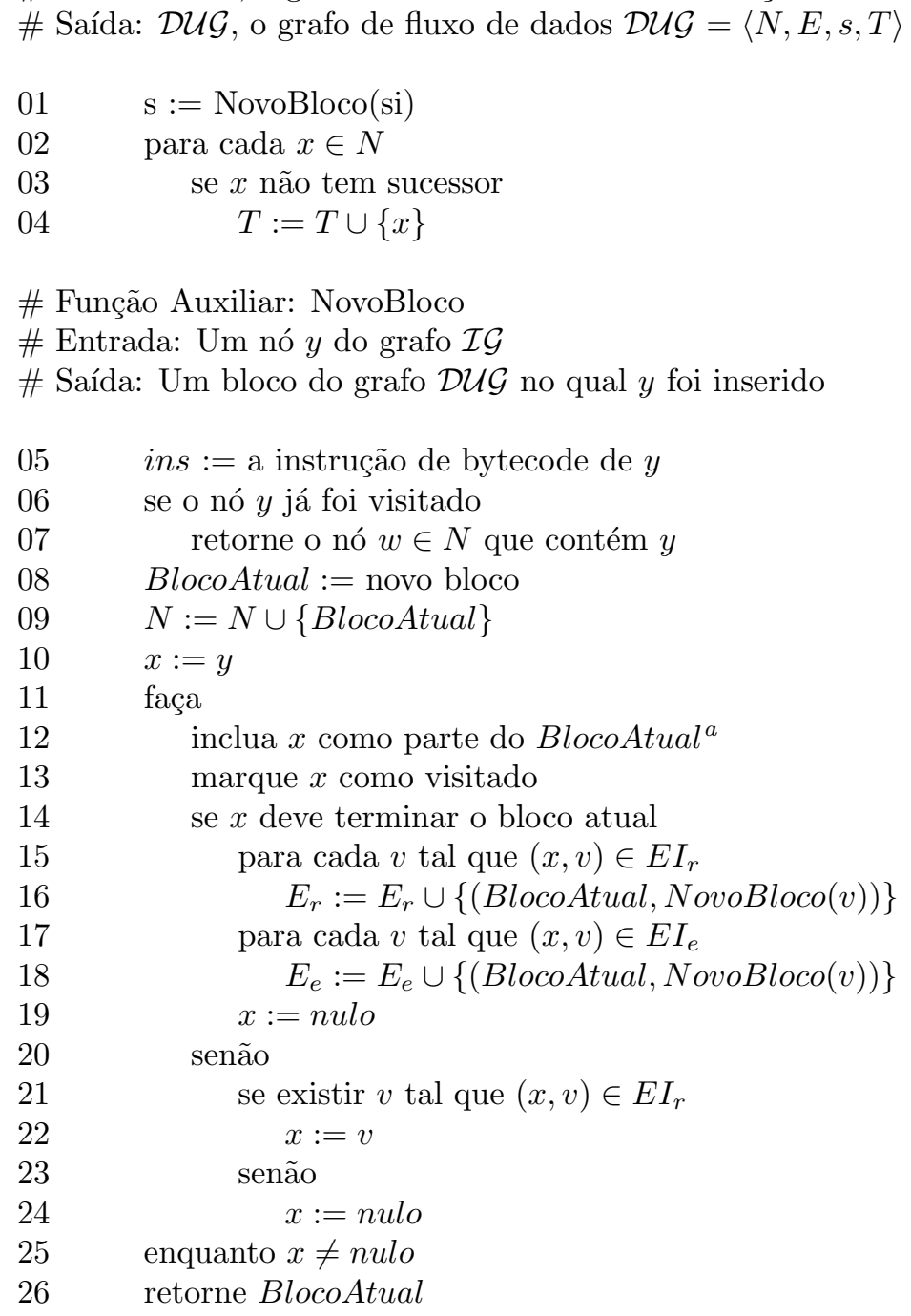

${ }^{a}$ Observe que incluir um nó de $\mathcal{I} \mathcal{G}$ como parte de um bloco em $\mathcal{D U} \mathcal{G}$ significa não somente incluir a instrução de bytecode em si como parte do bloco, mas também os conjuntos de variáveis definidas e usadas pela instrução são unidos ao conjunto de variáveis definidas e usadas do bloco, respectivamente. Associações entre variáveis definidas e usadas dentro do mesmo bloco não são consideradas.

Figura 3.6: Algoritmo para gerar o grafo $\mathcal{D U \mathcal { G }}$ a partir de um grafo $\mathcal{I} \mathcal{G}$. 
Após o grafo $\mathcal{D U \mathcal { G }}$ ter sido construído, uma análise simples é realizada para eliminar nós desnecessários, ou seja, nós contendo uma única instrução de desvio goto. Esses nós podem ser eliminados conectando-se diretamente as arestas que chegam nele como sendo as arestas chegando em seu sucessor. A Figura 3.8 ilustra o grafo $\mathcal{D} \mathcal{U} \mathcal{G}$ obtido após a aplicação do algoritmo de redução no grafo $\mathcal{I} \mathcal{G}$ apresentado na Figura 3.2(e).

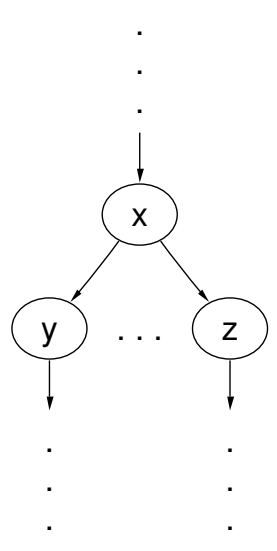

(a)

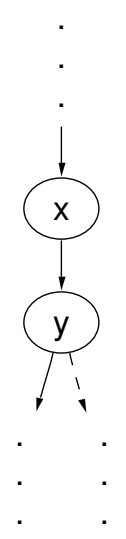

(b)

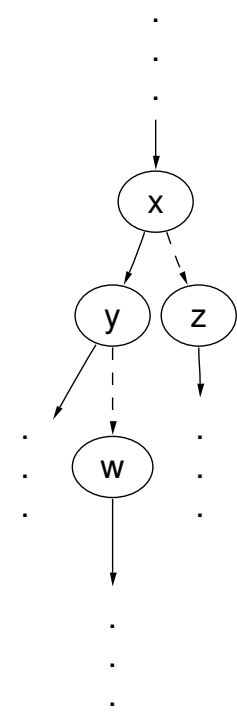

(c)

Figura 3.7: Situações que levam uma instrução de bytecode a encerrar um bloco de instruções.

O rótulo de um dado nó no grafo $\mathcal{D U \mathcal { G }}$ é o número do contador de programa da primeira instrução de bytecode desse nó. Os rótulos dos nós replicados, ou seja, os nós que correspondem a uma subrotina, são precedidos do rótulo do nó que causou a invocação da subrotina. Observe que uma vez que o nó 68 do grafo $\mathcal{I G}$ passou a fazer parte do bloco (nó) 60 do grafo $\mathcal{D U} \mathcal{G}$, o nó 68.82 do grafo $\mathcal{I} \mathcal{G}$ corresponde ao nó 60.82 do grafo $\mathcal{D} \mathcal{U}$. Todos os outros nós do grafo $\mathcal{I} \mathcal{G}$ que correspondiam ao bloco finally, ou seja, nós 84, 85, 86 e 89 do grafo $\mathcal{I} \mathcal{G}$, fazem parte do nó $x x .82$ do grafo $\mathcal{D U} \mathcal{G}$, onde $x x$ é um dos rótulo que precedem os nós replicados.

Na construção do grafo $\mathcal{D U G}$ a mesma representação para arestas regulares e de exceção é mantida. Linhas contínuas representam as arestas regulares e as linhas pontilhadas as arestas de exceção (Figura 3.8). Além disso, três diferentes tipos de nós são utilizados no grafo $\mathcal{D U G}$ : nós de saída são representados por círculos em negrito (como os nós 79 e 97 da Figura 3.8); nós de chamada são representados por círculos desenhados com linhas duplas (com o nó 91 da Figura 3.8); e os demais nós são representados por círculos desenhados com linhas simples (todos os demais nós da Figura 3.8). Os nós de chamada 
estão sendo distinguidos dos demais nós pois pretende-se estender os critérios de teste intra-método para o teste inter-método. Desse modo, os nós de chamada serão úteis para identificar os pontos de comunicação entre os métodos, facilitando a construção do grafo de fluxo de controle e de dados para o teste de integração. As informações sobre as variáveis definidas e usadas em cada nó do grafo $\mathcal{D U G}$ é facilmente computada, bastando para isso realizar a união dos conjuntos de variáveis definidas e usadas em cada um dos nós do grafo $\mathcal{I} \mathcal{G}$ que compõem um único nó do grafo $\mathcal{D} \mathcal{U} \mathcal{G}$. Observa-se que, como ilustrado na Figura 3.5, o conjunto usol( $i$ ) é também criado contendo os usos locais, ou seja, usol $(i)$ contém toda variável $x$ que foi definida e posteriormente usada dentro do mesmo bloco de instruções.

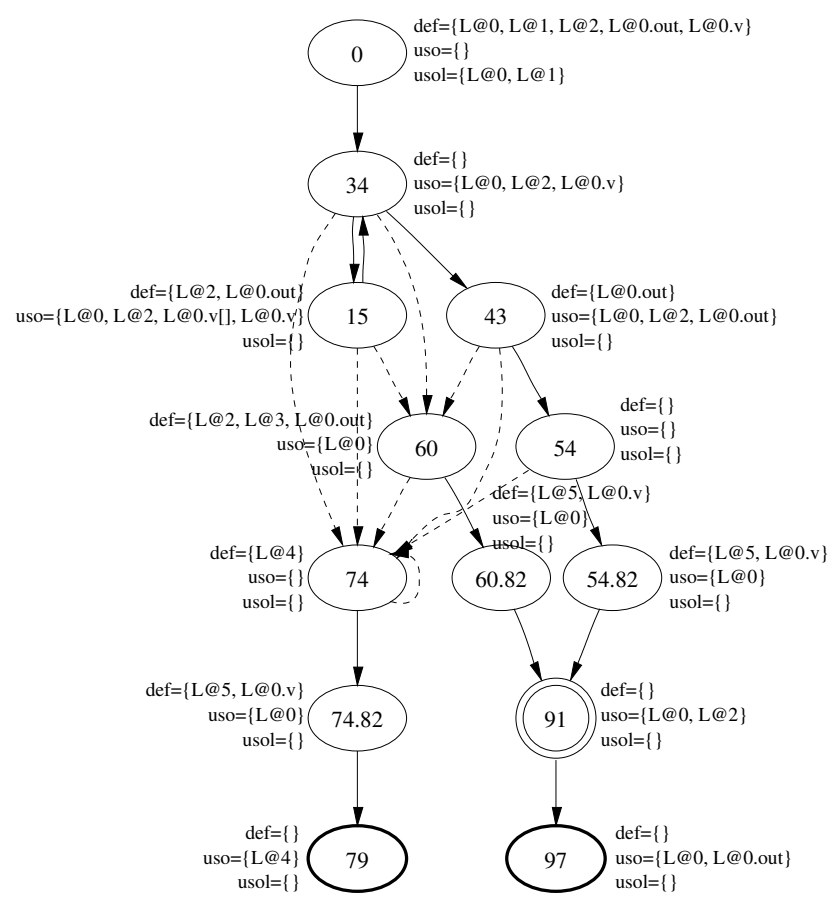

Figura 3.8: Grafo $\mathcal{D U G}$ do método Vet.average().

Uma vez que o grafo $\mathcal{D U \mathcal { G }}$ de cada método tenha sido obtido, critérios de teste podem ser definidos para derivar diferentes requisitos de teste que podem ser utilizados tanto para avaliar a qualidade de um determinado conjunto de teste, quanto para a própria geração de dados de teste. Na definição dos critérios de teste estruturais, apresentados na próxima seção, optou-se por separar os requisitos de teste em dois conjuntos disjuntos: os que podem ser cobertos durante a execução normal do programa, denominados independentes de exceção, e os que para serem cobertos exigem, obrigatoriamente, que uma exceção tenha sido gerada, denominados dependentes de exceção. Assim sendo, as seguintes definições são requeridas. 
Seja $O U T_{r}(i)$ o número de arestas regulares que partem de um nó $i$, ou seja, $O U T_{r}(i)=$ $\left|\left\{(i, j) \mid(i, j) \in E_{r}\right\}\right|$. O conjunto de nós predicativos $N_{\text {pred }}=\left\{n \in N \mid O U T_{r}(n)>1\right\}$, ou seja, $N_{\text {pred }}$ é o conjunto de todos os nós $n$ de um grafo $\mathcal{D U \mathcal { G }}$ para os quais existe mais de uma aresta regular saindo. Os demais nós $N-N_{\text {pred }}$ são ditos nós computacionais.

Um caminho $\pi$ é uma seqüência finita de nós $\left(n_{1}, n_{2}, \ldots, n_{k}\right), k \geq 2$, tal que existe uma aresta $\left.\left(n_{i}, n_{i+1}\right) \in E\right\}$ para $i=1,2, \ldots, k-1$. Um caminho é um caminho simples se todos os nós que compõem esse caminho, exceto possivelmente o primeiro e o último, são distintos; se todos os nós são distintos diz-se que esse caminho é um caminho livre de laço. Um caminho completo é um caminho onde o primeiro nó é o nó de entrada $\left(n_{1}=s\right)$ e o último nó é um nó de saída $\left(n_{k} \in T\right)$ do grafo $\mathcal{D} \mathcal{U G}$.

Um caminho livre de exceção (exception free path) é um caminho $\pi \mid \forall\left(n_{i}, n_{j}\right) \in$ $\pi \Rightarrow\left(n_{i}, n_{j}\right)$ é alcançável por meio de um caminho que não contém arestas de exceção.

Dado um nó $i$, diz-se que $i$ pertence a um caminho $\pi=\left(n_{1}, n_{2}, \ldots, n_{k}\right), k \geq 2$, denotado por $i \in \pi$, se $i=n_{j}$ para algum $j, 1 \leq j \leq k$. Similarmente, diz-se que uma aresta $\left(i_{1}, i_{2}\right)$ pertence a $\pi$, denotado por $\left(i_{1}, i_{2}\right) \in \pi$, se $i_{1}=n_{j}$ e $i_{2}=n_{j+1}$ para algum $j, 1 \leq j \leq k-1$.

Com base no conceito de caminho livre de exceção, os requisitos de teste que podem ser derivados do grafo $\mathcal{D} \mathcal{U G}$, tais como nós, arestas, caminhos e associações definição-uso, podem ser subdivididos em dois conjuntos disjuntos, considerando os requisitos de teste independentes de exceção e os requisitos de teste dependentes de exceção. A seguir, tais conjuntos de requisitos são definidos rigorosamente.

Seja $N$ o conjunto de nós de um grafo $\mathcal{D U \mathcal { G }} . \quad N_{e d} \subseteq N$ é o subconjunto de nós dependentes de exceção definido como $N_{e d}=\{n \in N \mid \nexists$ um caminho livre de exceção $\pi$ tal que $n \in \pi\}$, ou seja, $N_{e d}$ é o subconjunto completo de nós que só podem ser alcançados após a ocorrência de uma exceção. O conjunto de nós independentes de exceção $N_{e i}$ é definido como: $N_{e i}=N-N_{e d}$, ou seja, $N_{e i}$ é o subconjunto formado por todos os nós que podem ser alcançados sem que uma exceção seja lançada. Observe que esses subconjuntos são disjuntos, ou seja, $N_{e i} \cap N_{e d}=\emptyset$, e juntos representam o conjunto completo de nós de um grafo $\mathcal{D} \mathcal{U G}$, ou seja, $N_{e i} \cup N_{e d}=N$.

Seja $E$ o conjunto de arestas de um grafo $\mathcal{D U \mathcal { G }}$. $E_{\text {ed }} \subseteq E$ é o subconjunto de arestas dependentes de exceção definido como $E_{e d}=\{e \in E \mid \nexists$ um caminho livre de exceção $\pi$ tal que $e \in \pi\}$, ou seja, $E_{\text {ed }}$ é o subconjunto completo de arestas que só podem ser alcançadas após a ocorrência de uma exceção. O conjunto de arestas independentes de exceção $E_{e i}$ é definido como: $E_{e i}=E-E_{e d}$, ou seja, $E_{e i}$ é o subconjunto formado por todas as arestas que podem ser alcançadas sem que uma exceção seja lançada. Observe que $E_{e d} \supseteq E_{e}$ e que $E_{e i}=E_{r}-E_{e d}$. Isso implica que algumas arestas regulares podem passar a fazer parte do conjunto de arestas dependentes de exceção, tornando $E_{e i}$ um subconjunto de $E_{r}$ e $E_{e d}$ um super conjunto de $E_{e}$. Isso ocorre quando uma aresta regular só puder ser 
alcançada após uma exceção ter sido gerada. Além disso, observe que esses subconjuntos são disjuntos, ou seja, $E_{e i} \cap E_{e d}=\emptyset$, e juntos representam o conjunto completo de arestas de um grafo $\mathcal{D} \mathcal{U} \mathcal{G}$, ou seja, $E_{e i} \cup E_{e d}=E$.

Conforme mencionado na Seção 2.5.3, as ocorrências de variáveis em um programa podem ser uma definição de variável, um uso de variável, ou uma indefinição. Usualmente, os diferentes tipos de ocorrências de variáveis são definidos por um modelo de fluxo de dados.

De acordo com o modelo de fluxo de dados apresentado na Seção 3.2.3.1, uma definição de variável ocorre quando um valor é armazenado em uma posição de memória. A ocorrência de uma variável é um uso quando a referência a esta variável não a estiver definindo. Se o uso ocorrer num nó computacional caracteriza-se um uso computacional, ou simplesmente c-uso. Quando o uso ocorrer num nó predicativo diz-se que se tem um uso predicativo, ou simplesmente $p$-uso. Os usos predicativos são associados às arestas regulares saindo do nó. Uma variável está indefinida quando, ou não se tem acesso ao seu valor, ou sua localização deixa de estar definida na memória.

Um caminho $c=\left(i, n 1, \ldots, n_{m}, j\right), m \geq 0$ que não contenha definição de uma variável $x$ no nós $n 1, \ldots, n_{m}$ é chamado de caminho livre de definição com respeito a $x$ do nó $i$ ao nó $j$ e do nó $i$ ao arco $\left(n_{m}, j\right)$.

Um c-uso da variável $x$ em um nó $j$ é um c-uso global se não existir uma definição de $x$ no nó $j$ precedendo esse $c$-uso; caso contrário é um c-uso local.

Um ponto que merece ser destacado é que, devido à estrutura orientada a pilha da JVM, pode ser difícil distinguir entre p-uso e c-uso quando instruções de bytecode estão sendo analisadas. Todas as instruções de bytecode relacionadas com a transferência de fluxo de controle somente checam o valor atual do topo da pilha de operandos para decidir qual a próxima instrução a ser executada. Desse modo, identificar quais variáveis são usadas em um predicado e quais são usadas em uma computação pode ser computacionalmente caro uma vez que seria necessário identificar todas as variáveis que, de alguma forma, influenciam o valor corrente colocado no topo da pilha de operandos.

$\mathrm{Na}$ implementação dos critérios de fluxo de dados (descritos detalhadamente na Seção 3.3.2) consideram-se todas as variáveis usadas em um nó predicativo $i \in N_{\text {pred }}$ como sendo $p$-usos associados às arestas regulares e são criadas associações p-usos dessas variáveis com todas as arestas regulares saindo de $i$, ou seja, $(i, j) \in E_{r}$. Nesse caso, somente associações $p$-uso são criadas uma vez que as associações $c$-uso são cobertas pelas associações $p$-uso. Essa decisão de implementação simplifica o algoritmo para a identificação de associações p-uso e c-uso, embora associações definição-uso adicionais sejam requeridas. Observa-se que não são criadas associações p-usos relacionadas com as arestas de exceção. 
Desse modo, considerando um determinado nó $i$ de um grafo $\mathcal{D} \mathcal{U G}$, três conjuntos podem ser derivados:

$$
\begin{aligned}
\operatorname{def}(i) & =\{\text { variáveis com definição no nó } i\} \\
\text { c-uso }(i) & =\left\{\begin{array}{l}
\text { variáveis com uso global no nó } i, \text { se } i \text { é nó computacional } \\
\emptyset, \text { caso contrário ( } i \text { é predicativo })
\end{array}\right. \\
\operatorname{p-uso}(i) & =\left\{\begin{array}{l}
\text { variáveis com uso (global ou local) no nó } i, \text { se } i \text { é nó predicativo } \\
\emptyset, \text { caso contrário ( } i \text { é computacional) }
\end{array}\right.
\end{aligned}
$$

A partir dos conjuntos c-uso e $p$-uso, dois outros conjuntos são definidos: $d c u(x, i)=$ \{nós $j$ de um grafo $\mathcal{D U G}$ tal que $x \in c$-uso $(j)$ e existe um caminho livre de definição em relação a $x$ do nó $i$ para o nó $j\}$ e $d p u(x, i)=\{\operatorname{arestas}(j, k)$ de um grafo $\mathcal{D} \mathcal{U} \mathcal{G}$ tal que $x \in p$-uso $(j)$ e existe um caminho livre de definição em relação a $x$ do nó $i$ para a aresta $(j, k)\}$.

Uma associação definição-c-uso é uma tripla $(i, j, x)$ onde $i$ é um nó que contém uma definição de $x$ e $j \in d c u(x, i)$. Uma associação definição-p-uso é uma tripla $(i,(j, k), x)$ onde $i$ é um nó que contém uma definição de $x$ e $(j, k) \in d p u(x, i)$. Uma associação é uma associação definição-c-uso ou uma associação definição-p-uso.

Para dar um exemplo de c-uso, considere o $\mathcal{D} \mathcal{U G}$ da Figura 3.8. No nó 0 o conjunto de variáveis definidas contém a variável $L @ 0 . v$, a qual representa a variável de instância $v$ no código fonte correspondente. No nó 15 ocorre um uso de $L @ 0 . v$ para se computar o somatório dos elementos do vetor, determinando um par c-uso em relação a $L @ 0 . v$ do nó 0 para o nó 15 , uma vez que existe ao menos um caminho livre de definição em relação a $L @ 0 . v$ do nó 0 ao nó 15 . Por outro lado, no nó 0 há uma definição de $L @ 2$, que corresponde a variável local $i$ do código fonte. Tal variável é utilizada no predicado localizado no nó 34 para verificar se o último elemento do vetor $v$ já foi alcançado. Assim sendo, existem os pares p-uso em relação à variável $L @ 2$ do nó 0 para as arestas $(34,15)$ e $(34,43)$.

Para permitir que o conjunto de associações possa ser subdividido em dois subconjuntos disjuntos, considerando o fato de existir ou não um caminho livre de definição que também seja livre de exceção que cubra dada associação, os seguintes subconjuntos, derivados de $d c u(x, i)$ e $d p u(x, i)$, são definidos:

- $d c u_{e d}(x, i)=\{$ nós $j$ de um grafo $\mathcal{D U G}$ tal que $x \in c$-uso $(j)$ e não existe um caminho livre de definição que seja livre de exceção em relação a $x$ do nó $i$ para o nó $j\}$;

- $d c u_{e i}(x, i)=d c u(x, i)-d c u_{e d}(x, i)$; 
- $d p u_{e d}(x, i)=\{\operatorname{arestas}(j, k)$ de um grafo $\mathcal{D U G}$ tal que $x \in p$-uso $(j)$ e não existe um caminho livre de definição que seja livre de exceção em relação a $x$ do nó $i$ para a $\operatorname{aresta}(j, k)\}$;

- $d p u_{e i}(x, i)=d p u(x, i)-d p u_{e d}(x, i)$.

Com isso, define-se uma associação definição-c-uso independente de exceção como sendo uma tripla $(i, j, x)$ onde $i$ é um nó que contém uma definição de $x$ e $j \in$ $d c u_{e i}(x, i)$ e associação definição-c-uso dependente de exceção é uma tripla $(i, j, x)$ onde $i$ é um nó que contém uma definição de $x$ e $j \in d c u_{e d}(x, i)$. Analogamente, uma associação definição-p-uso independente de exceção é uma tripla $(i,(j, k), x)$ onde $i$ é um nó que contém uma definição de $x$ e $(j, k) \in d p u_{e i}(x, i)$ e uma associação definiçãop-uso dependente de exceção é uma tripla $(i,(j, k), x)$ onde $i$ é um nó que contém uma definição de $x$ e $(j, k) \in d p u_{e d}(x, i)$.

Da forma como foram definidos os critérios de fluxo de dados de Rapps e Weyuker (1985), um elemento (associação, caminho, etc.) será requerido somente se houver a ocorrência explícita de um uso de variável, aspecto este que determina as principais limitações desses critérios como será visto posteriormente na Seção 3.4.

Com a introdução do conceito potencial-uso são definidos vários critérios, denominados critérios Potenciais-Usos (Maldonado, 1991), cujos elementos são requeridos independentemente da ocorrência explícita de uma referência - um uso - a uma determinada definição; se um uso dessa definição pode existir, ou seja, existir um caminho livre de definição até um certo nó ou aresta - um potencial-uso - a potencial-associação entre a definição e o potencial-uso é caracterizada, e eventualmente requerida. Na realidade, pode-se dizer que, com a introdução do conceito potencial-uso, procura-se explorar todos os possíveis efeitos a partir de uma mudança de estado do programa em teste, decorrente de definição de variáveis em um determinado nó $i$. Da mesma forma como os demais critérios baseados na análise de fluxo de dados, os critérios Potenciais-Usos podem utilizar o grafo def-uso como base para o estabelecimento dos requisitos de teste. Na verdade, basta ter a extensão do grafo de programa associando a cada nó do grafo informações a respeito das definições que ocorrem nesses nós, denominado de grafo def (Maldonado, 1991).

Com base nesse conceito têm-se então as seguintes definições: $\operatorname{defg}(i)=\{$ variáveis $v \mid v$ é definida no nó $i\} ; p d c u(x, i)=\{$ nós $j$ de um grafo $\mathcal{D U \mathcal { G }}$ tal que existe um caminho livre de definição em relação a $x$ do nó $i$ para o nó $j$, e $\left.j \notin N_{\text {pred }}\right\}$ e $p d p u(x, i)=\{\operatorname{arestas}(j, k)$ de $\mathcal{D} \mathcal{U G}$ tal que existe um caminho livre de definição em relação a $x$ do nó $i$ para a aresta $(j, k)\}$.

Uma associação potencial-definição-c-uso é uma tripla $(i, j, x)$ onde $x \in \operatorname{def} g(i)$ e $j \in p d c u(x, i)$. Uma associação potencial-definição-p-uso é uma tripla $(i,(j, k), x)$ 
onde $x \in \operatorname{def} g(i)$ e $(j, k) \in p d p u(x, i)$. Uma potencial associação é uma associação potencial-definição-c-uso ou uma associação potencial-definição-p-uso. Observe que toda associação é uma potencial associação.

Similarmente, para subdividir o conjunto potenciais-associações os seguintes subconjuntos, derivados de $p d c u(x, i)$ e $p d p u(x, i)$, são definidos:

- $p_{d c u_{e d}}(x, i)=\{$ nós $j$ de um grafo $\mathcal{D U \mathcal { G }}$ tal que não existe um caminho livre de definição que seja livre de exceção em relação a $x$ do nó $i$ para o nó $j\}$;

- $p d c u_{e i}(x, i)=p d c u(x, i)-p d c u_{e d}(x, i)$;

- $p d p u_{e d}(x, i)=\{\operatorname{arestas}(j, k)$ de um grafo $\mathcal{D U \mathcal { G }}$ tal que não existe um caminho livre de definição que seja livre de exceção em relação a $x$ do nó $i$ para a aresta $(j, k)\}$;

- $p d p u_{p}(x, i)=p d p u(x, i)-p d p u_{e d}(x, i)$.

Uma associação potencial-definição-c-uso independente de exceção é uma tripla $(i, j, x)$ onde $x \in \operatorname{def} g(i)$ e $j \in p d c u_{e i}(x, i)$ e associação potencial-definição-c-uso dependente de exceção é uma tripla $(i, j, x)$ onde $x \in \operatorname{defg}(i)$ e $j \in \operatorname{pdcu}_{e d}(x, i)$. Uma associação potencial-definição-p-uso independente de exceção é uma tripla $(i,(j, k), x)$ onde $x \in \operatorname{def} g(i)$ e $(j, k) \in p d p u_{e i}(x, i)$ e uma associação potencialdefinição-p-uso dependente de exceção é uma tripla $(i,(j, k), x)$ onde $x \in \operatorname{def} g(i) \mathrm{e}$ $(j, k) \in p d p u_{e d}(x, i)$.

Um caminho completo é executável (feasible) se existe um conjunto de valores, que possa ser atribuído às variáveis de entrada do programa, que causa a execução desse caminho; caso contrário, diz-se que ele é não-executável (infeasible) (Frankl, 1987). Um caminho é executável se ele for um subcaminho de um caminho completo executável, isto é, se ele for incluído pelo caminho completo executável. Uma associação/potencialassociação é executável se existir um caminho completo executável que cubra essa associação; caso contrário é não executável.

Com base nas definições apresentadas acima, na próxima seção oito critérios de teste estruturais para o teste intra-método de programas OO são definidos.

\subsection{Definição dos Critérios}

Nesta seção são dadas as definições dos critérios de teste estruturais, os quais podem ser utilizados para derivar requisitos de testes intra-métodos para programas OO. Após a definição de cada critério é dado um exemplo do conjunto de requisitos de teste gerado 
pelo mesmo. Os exemplos de requisitos apresentados são derivados a partir do grafo $\mathcal{D U G}$ da Figura 3.8. Posteriormente, na Seção 6.3, um exemplo mais detalhado considerando uma estratégia incremental de aplicação dos critérios é também apresentado.

\subsubsection{Critérios de Fluxo de Controle}

O grafo $\mathcal{D U G}$ pode ser considerado como uma representação abstrata de um dado método de uma classe. Critérios de fluxo de controle podem e têm sido definidos com base em tal representação de programa. Os critérios de teste são de fundamental importância pois fornecem um mecanismo para sistematizar a seleção de casos de teste e a avaliação da qualidade de conjuntos de teste já definidos. Considerando o teste de fluxo de controle intra-métodos, decidiu-se por utilizar dois critérios de teste bastante conhecidos: os critérios todos-nós (all-nodes) e todas-arestas (all-edges) (Myers, 1979). Tais critérios são revisitados no contexto do teste de programas OO considerando os aspectos relacionados ao tratamento de exceção discutidos acima.

Seja $\mathcal{T}$ um conjunto de teste para um programa $P(\mathcal{D U G}$ é o correspondente grafo de fluxo de controle de $P$ ), e seja $\Pi$ o conjunto de caminhos executados por $\mathcal{T}$. Diz-se que um nó $i$ está incluído em $\Pi$ se $\Pi$ contém um caminho $\left(n_{1}, \ldots, n_{m}\right)$ tal que $i=n_{j}$ para algum $j, 1 \leq j \leq m$. Similarmente, uma aresta $\left(i_{1}, i_{2}\right)$ é incluída em $\Pi$ se $\Pi$ contém um caminho $\left(n_{1}, \ldots, n_{m}\right)$ tal que $i_{1}=n_{j}$ e $i_{2}=n_{j+1}$ para algum $j, 1 \leq j \leq m-1$. Um caminho $\left(i_{1}, \ldots, i_{k}\right)$ está incluído em $\Pi$ se $\Pi$ contém um caminho $\left(n_{1}, \ldots, n_{m}\right)$ e $i_{1}=n_{j}, i_{2}=n_{j+1}, \ldots, i_{k}=n_{j_{k}-1}$, para algum $j, 1 \leq j \leq m-k+1$.

\section{- critério todos-nós (Todos-Nós)}

- П satisfaz o critério todos-nós se cada nó $n \in N$ de um grafo $\mathcal{D U G}$ está incluído em П. Em outras palavras este critério garante que todos as instruções (comandos) de um dado método tenham sido executadas ao menos uma vez por algum caso de teste de $\mathcal{T}$.

Para considerar os comandos relacionados ao tratamento de exceção de forma individual, tal critério foi subdividido, resultando em dois conjuntos disjuntos de requisitos de modo que o testador possa se concentrar em diferentes aspectos do programa separadamente:

\section{- todos-nós-independentes-de-exceção (Todos-Nós ${ }_{e i}$ )}

* П satisfaz o critério todos-nós-independentes-de-exceção se cada nó $n_{e i} \in$ $N_{e i}$ está incluído em П. Em outras palavras, este critério requer que cada nó de um grafo $\mathcal{D U G}$ que é alcançável por meio de pelo menos um caminho 
livre de exceção seja executado ao menos uma vez por algum caso de teste de $\mathcal{T}$.

\section{- todos-nós-dependentes-de-exceção (Todos-Nós ${ }_{e d}$ )}

* П satisfaz o critério todos-nós-dependentes-de-exceção se cada nó $n_{e d} \in N_{e d}$ está incluído em П. Em outras palavras, este critério requer que cada nó de um grafo $\mathcal{D U G}$ que não é alcançável por meio de um caminho livre de exceção seja executado ao menos uma vez por por algum caso de teste de $\mathcal{T}$.

\section{- critério todas-arestas (Todas-Arestas)}

- П satisfaz o critério todas-arestas se cada aresta $e \in E$ de um grafo $\mathcal{D U \mathcal { G }}$ está incluída em $\Pi$. Em outras palavras, este critério requer que requer que cada aresta de um grafo $\mathcal{D U \mathcal { G }}$ seja exercitada ao menos uma vez por algum caso de teste de $\mathcal{T}$.

Para considerar os desvios no fluxo de execução relacionados ao tratamento de exceção, este critério foi subdividido de modo que dois subconjuntos disjuntos de requisitos de teste possa ser obtido:

\section{- todas-arestas-independentes-de-exceção (Todas-Arestas ${ }_{e i}$ )}

* II satisfaz o critério todas-arestas-independentes-de-exceção se cada aresta $e_{e i} \in E_{e i}$ está incluída em $\Pi$. Em outras palavras, este critério requer que cada aresta de um grafo $\mathcal{D U G}$ alcançável a partir de um caminho livre de exceção seja executada ao menos uma vez por algum caso de teste de $\mathcal{T}$.

- todas-arestas-dependentes-de-exceção (Todas-Arestas ${ }_{e d}$ )

* П satisfaz o critério todas-arestas-dependentes-de-exceção se cada aresta $e_{e d} \in E_{e d}$ está incluída em П. Em outras palavras, este critério requer que cada aresta de um grafo $\mathcal{D U \mathcal { G }}$ não alcançável a partir de um caminho livre de exceção seja executada ao menos uma vez por algum caso de teste de $\mathcal{T}$.

Para ilustrar o conjunto de requisitos de teste que pode ser derivado a partir dos critérios de fluxo de controle definidos acima, considere o $\mathcal{D U} \mathcal{G}$ apresentado na Figura 3.8. A Tabela 3.2 apresenta o conjunto completo de requisitos de teste obtido.

\subsubsection{Critérios de Fluxo de Dados}

Em relação aos critérios de fluxo de dados, também optou-se pela utilização de dois critérios conhecidos: o critério todos-usos (all-uses) (Rapps e Weyuker, 1985), que inclui 
os critérios todos-c-usos e todos-p-usos; e o critério todos-potenciais-usos (all-potentialuses) o qual inclui o critério todos-usos (Maldonado, 1991).

Tabela 3.2: Conjunto de requisitos de teste estruturais derivados pelos critérios de fluxo de controle para o método Vet.average().

\begin{tabular}{|c|c|c|}
\hline \multicolumn{2}{|c|}{ Critério } & Requisitos de Teste \\
\hline \multirow{2}{*}{ Todos-Nós } & Todos-Nós ${ }_{e i}$ & $\{0,15,34,43,54,54.82,91,97\}$ \\
\hline & Todos-Nós ${ }_{e d}$ & $\{60,60.82,74,74.82,79\}$ \\
\hline \multirow[b]{2}{*}{ Todas-Arestas } & Todas-Arestas $_{e i}$ & $\begin{array}{l}\{(0,34),(15,34),(34,15),(34,43),(43,54),(54,54.82), \\
(54.82,91),(91,97)\}\end{array}$ \\
\hline & Todas-Arestas $_{e d}$ & 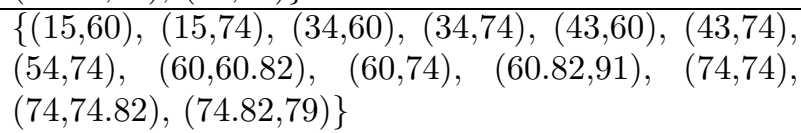 \\
\hline
\end{tabular}

\section{- critérios todos-usos (Todos-Usos)}

- П satisfaz o critério todos-usos se para todo nó $i \in N$ e para todo $x \in \operatorname{def}(i)$, $\Pi$ inclui um caminho livre de definição em relação a $x$ do nó $i$ para todos os elementos de $d c u(x, i)$ e para todos os elementos de $d p u(x, i)$. Em outras palavras, este critério requer que toda associação definição-uso $(i, j, x) \mid j \in d c u(x, i)$ e toda associação definição-uso $(i,(j, k), x) \mid(j, k) \in d p u(x, i)$ seja exercitada ao menos uma vez por algum caso de teste de $\mathcal{T}$.

Da mesma forma como foi feito com os critérios todos-nós e todas-arestas, o conjunto de requisitos de teste do critério todos-usos também é subdividido em dois subconjunto disjuntos, conforme definido pelos critérios abaixo:

\section{- todos-usos-independentes-de-exceção (Todos-Usos ${ }_{e i}$ )}

* П satisfaz o critério todos-usos-independentes-de-exceção se para todo nó $i \in N$ e para todo $x \in \operatorname{def}(i)$, $\Pi$ inclui um caminho livre de definição em relação a $x$ do nó $i$ para todos os elementos de $d c u_{e i}(x, i)$ e para todos os elementos de $d p u_{e i}(x, i)$. Em outras palavras, este critério requer que toda associação definição-uso independente de exceção $(i, j, x) \mid j \in d c u_{e i}(x, i) \mathrm{e}$ toda associação definição-uso independente de exceção $(i,(j, k), x) \mid(j, k) \in$ $d p u_{e i}(x, i)$ seja exercitada ao menos uma vez por algum caso de teste de $\mathcal{T}$.

\section{- todos-usos-dependentes-de-exceção (Todos-Usos ${ }_{e d}$ )}

* ПI satisfaz o critério todos-usos-dependentes-de-exceção se para todo nó $i \in N$ e para todo $x \in \operatorname{def}(i), \Pi$ inclui um caminho livre de definição em relação a $x$ do nó $i$ para todos os elementos de $d c u_{e d}(x, i)$ e para todos 
os elementos de $d p u_{e d}(x, i)$. Em outras palavras, este critério requer que toda associação definição-uso dependente de exceção $(i, j, x) \mid j \in d c u_{e d}(x, i)$ e toda associação definição-uso dependente de exceção $(i,(j, k), x) \mid(j, k) \in$ $d p u_{e d}(x, i)$ seja exercitada ao menos uma vez por algum caso de teste de $\mathcal{T}$.

\section{- critérios todos-potenciais-usos (Todos-Pot-Usos)}

- П satisfaz o critério todos-potenciais-usos se para todo nó $i \in N$ e para todo $x \in \operatorname{def} g(i)$, $\Pi$ inclui um caminho livre de definição em relação a $x$ do nó $i$ para todos os elementos de $p d c u(x, i)$ e para todos os elementos de $p d p u(x, i)$. Em outras palavras, este critério requer que toda potencialassociação definição-uso $(i, j, x) \mid j \in p d c u(x, i)$ e toda potencial-associação definição-uso $(i,(j, k), x) \mid(j, k) \in p d p u(x, i)$ seja exercitada ao menos uma vez por algum caso de teste de $\mathcal{T}$.

\section{- todos-potenciais-usos-independentes-de-exceção (Todos-Pot-Usos ${ }_{e i}$ )}

* П satisfaz o critério todos-potenciais-usos-independentes-de-exceção se para todo nó $i \in N$ e para todo $x \in \operatorname{def} g(i)$, $\Pi$ inclui um caminho livre de definição em relação a $x$ do nó $i$ para todos os elementos de $p d c u_{e i}(x, i)$ e para todos os elementos de $p d p u_{e i}(x, i)$. Em outras palavras, este critério requer que toda potencial-associação definição-uso independente de exceção $(i, j, x) \mid j \in p d c u_{e i}(x, i)$ e toda potencial-associação definição-uso independente de exceção $(i,(j, k), x) \mid(j, k) \in p d p u_{e i}(x, i)$ seja exercitada ao menos uma vez por algum caso de teste de $\mathcal{T}$.

\section{- todos-potenciais-usos-independentes-de-exceção (Todos-Pot-Usos ${ }_{e d}$ )}

* II satisfaz o critério todos-potenciais-usos-independentes-de-exceção se para todo nó $i \in N$ e para todo $x \in \operatorname{def} g(i)$, $\Pi$ inclui um caminho livre de definição em relação a $x$ do nó $i$ para todos os elementos de $p d c u_{e d}(x, i)$ e para todos os elementos de $p d p u_{e d}(x, i)$. Em outras palavras, este critério requer que toda potencial-associação definição-uso dependente de exceção $(i, j, x) \mid j \in p d c u_{e d}(x, i)$ e toda potencial-associação definição-uso dependente de exceção $(i,(j, k), x) \mid(j, k) \in p d p u_{e d}(x, i)$ seja exercitada ao menos uma vez por algum caso de teste de $\mathcal{T}$.

A título de ilustração, as Tabelas 3.3 e 3.4 apresentam os conjuntos completos de de requisitos teste que seriam obtidos pela aplicação dos critério Todos-Usos e Todos-Pot-Usos no $\mathcal{D U \mathcal { G }}$ do método Vet.average (Figura 3.8), respectivamente. 
Tabela 3.3: Conjunto de requisitos de teste estruturais derivados pelo critério todos-usos para o método Vet.average().

\begin{tabular}{|c|c|c|c|c|}
\hline \multicolumn{2}{|c|}{ Critério } & \multicolumn{3}{|c|}{ Requisitos de Teste } \\
\hline \multirow{10}{*}{ Todos-Usos } & & $\overline{\langle\langle 0,15, L @ 0\rangle}$ & $\overline{\langle\langle 0,(34,15), L @ 0\rangle}$ & $\overline{\langle\langle 0,(34,43), L @ 0\rangle}$ \\
\hline & & $\langle 0,43, L @ 0\rangle$ & $\langle 0,54.82, L @ 0\rangle$ & $\langle 0,91, L @ 0\rangle$ \\
\hline & & $\langle 0,97, L @ 0\rangle$ & $\langle 0,43, L @ 0$. out $\rangle$ & $\langle 15,43, L @ 0$. out $\rangle$ \\
\hline & Todos-Usos $_{e i}$ & $\langle 43,97, L @ 0$. out $\rangle$ & $\langle 0,15, L @ 0 . v\rangle$ & $\langle 0,(34,15), L @ 0 . v\rangle$ \\
\hline & & $\langle 0,(34,43), L @ 0 . v\rangle$ & $\langle 0,15, L @ 0 . v[]\rangle$ & $\langle 0,15, L @ 2\rangle$ \\
\hline & & $\langle 15,(34,15), L @ 2\rangle$ & $\langle 0,(34,15), L @ 2\rangle$ & $\langle 15,(34,43), L @ 2\rangle$ \\
\hline & & $\langle 0,(34,43), L @ 2\rangle$ & $\langle 0,43, L @ 2\rangle$ & $\langle 15,43, L @ 2\rangle$ \\
\hline & & $\langle 0,91, L @ 2\rangle$ & $\langle 15,91, L @ 2\rangle$ & \\
\hline & Todos-Usos ed & $\langle 0,60, L @ 0\rangle$ & $\langle 0,60.82, L @ 0\rangle$ & $\langle 0,74.82, L @ 0\rangle$ \\
\hline & & $\langle 60,97, L @ 0$. out $\rangle$ & $\langle 60,91, L @ 2\rangle$ & $\langle 74,79, L @ 4$ \\
\hline
\end{tabular}

\subsection{Análise de Propriedades}

Em geral, pode-se dizer que as propriedades mínimas que devem ser satisfeitas por um critério de teste $C$ são: 1) garantir, do ponto de vista de fluxo de controle, a cobertura de todos os desvios condicionais; 2) requerer, do ponto de vista de fluxo de dados, ao menos um uso de todo resultado computacional; e 3) requerer um conjunto de teste finito (Maldonado, 1991).

Conforme discutido no Capítulo 1, as vantagens e desvantagens de critérios de teste de software podem ser avaliadas por meio de estudos teóricos e empíricos sob três aspectos: custo, eficácia e dificuldade de satisfação (strength). O fator custo reflete o esforço necessário para que o critério seja utilizado; em geral medido pelo número de casos de teste necessários para satisfazer o critério no pior caso. A eficácia refere-se à capacidade que um critério possui de detectar defeitos. O fator strength refere-se à probabilidade de satisfazer-se um critério tendo sido satisfeito um outro critério (Mathur e Wong, 1994).

A seguir, é apresentada uma análise de inclusão e de complexidade dos critérios de teste definidos na Seção 3.3, visando a avaliar a dificuldade de satisfação e o custo dos mesmos, respectivamente.

\subsubsection{Análise de Inclusão}

Como definida na Seção 2.5.3 do Capítulo 2, a análise de inclusão é uma propriedade dos critérios de teste utilizada para avaliá-los do ponto de vista teórico. Como resultado da análise de inclusão obtém-se uma ordem parcial entre os critérios de teste, caracterizando uma hierarquia entre eles. Dados dois critérios $C$ e $C^{\prime}$, diz-se que $C$ inclui $C^{\prime}$ se, para qualquer programa $P$, todo conjunto de teste $C$-adequado é também $C^{\prime}$-adequado. $\mathrm{O}$ critério $C$ inclui estritamente o critério $C^{\prime}$, denotado por $C \Rightarrow C^{\prime}$, se $C$ inclui $C^{\prime}$ e $C^{\prime}$ 
não inclui $C$. Quando nem $C$ inclui $C^{\prime}$ nem $C^{\prime}$ inclui $C$ diz-se que os critérios $C$ e $C^{\prime}$ são incomparáveis (Rapps e Weyuker, 1985).

Tabela 3.4: Conjunto de requisitos de teste estruturais derivados pelo critério todospotenciais-usos para o método Vet.average().

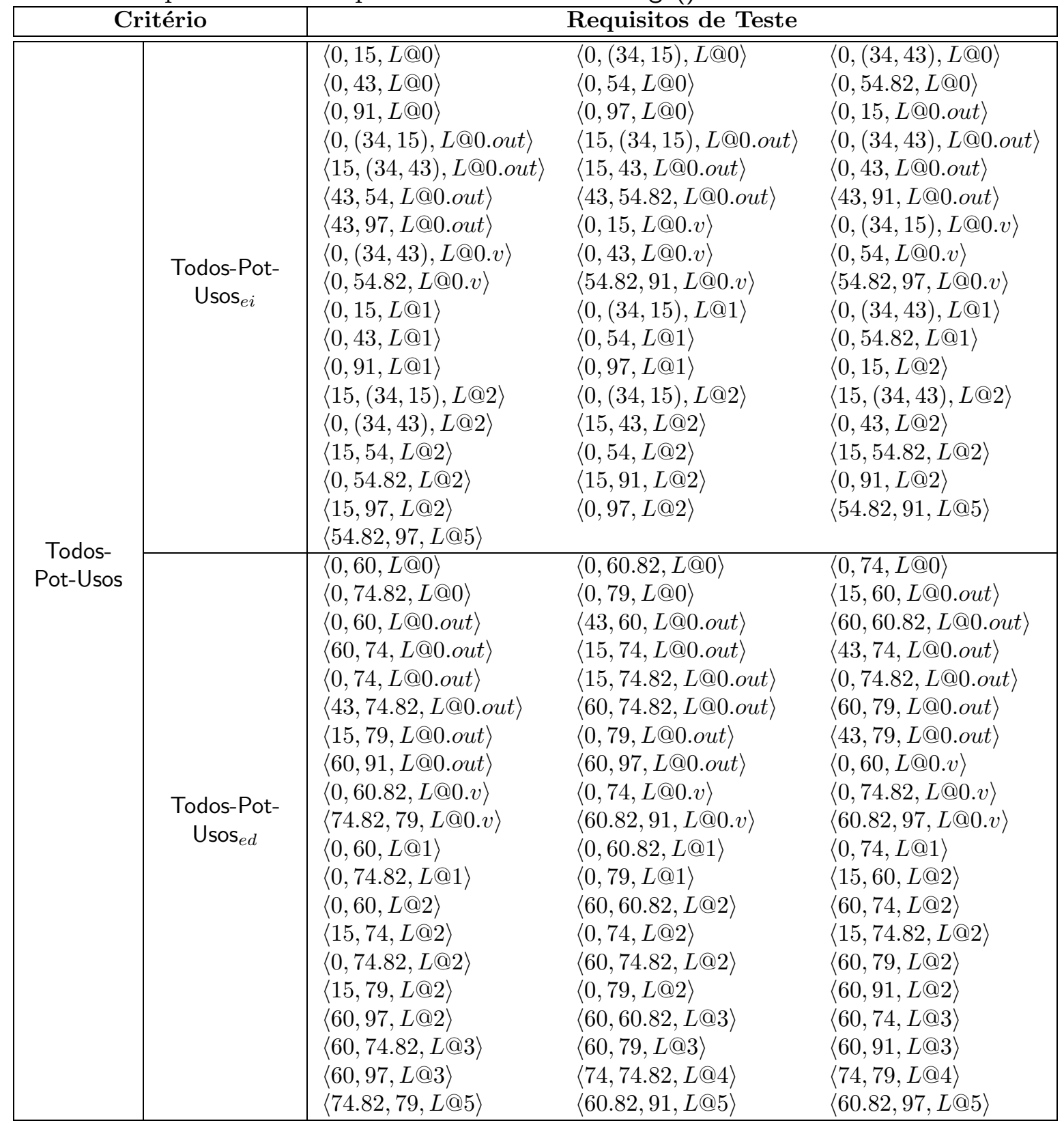

Considerando os critérios de teste definidos na Seção 3.3, a Figura 3.9 ilustra qual seria a relação de inclusão "desejável" entre eles (Figura 3.9(a)) e qual a relação efetivamente obtida (Figura 3.9(b)). O fato dos critérios Todos-Pot-Usos e Todos-Usos deixarem de incluir estritamente o critério Todas-Arestas tem a ver com o fato dos critérios de teste Todos-Pot-Usos ${ }_{e d}$ e Todos-Usos ${ }_{e d}$ deixarem de incluir estritamente o critério Todas- 
Arestas $_{e d}$. Posteriormente, demonstra-se que uma simples alteração no modelo de fluxo de dados, apresentado na Seção 3.2.3.1, faz com que a relação de inclusão estrita entre os critérios seja como ilustrado na Figura 3.9(a), desde que algumas propriedades sejam mantidas.

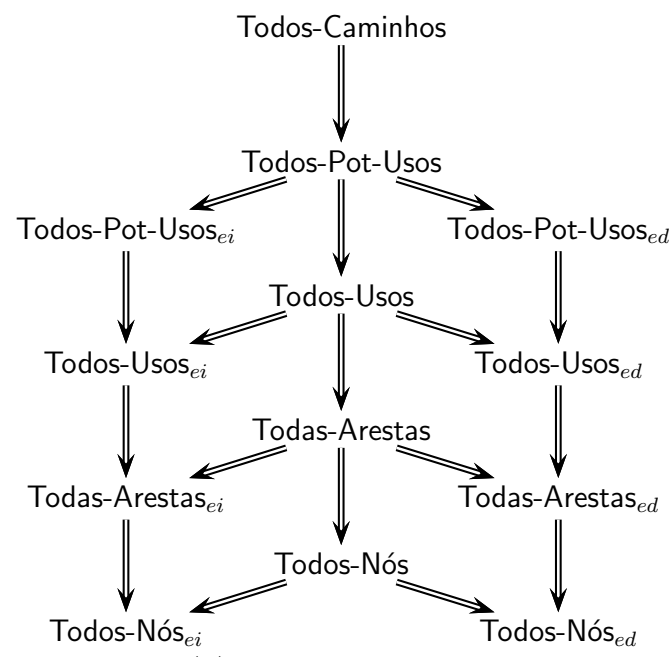

(a) Relação Esperada

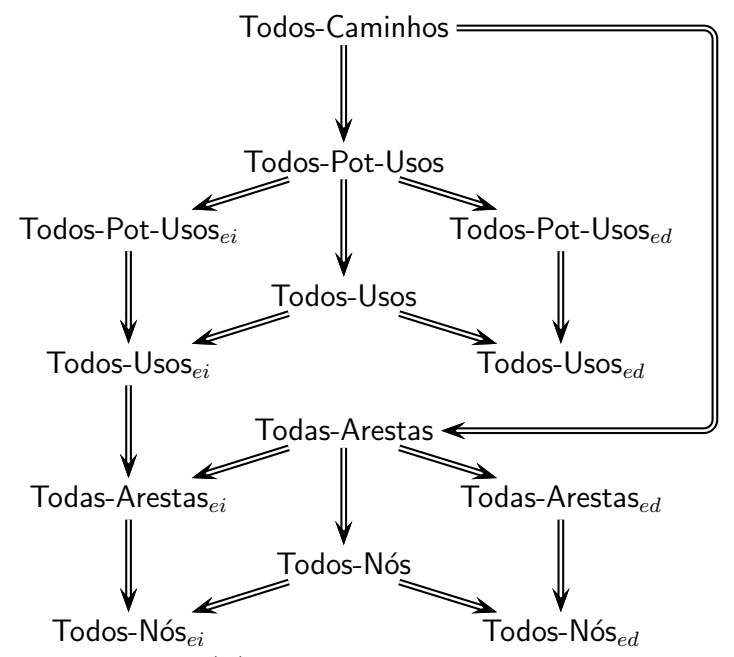

(b) Relação Obtida

Figura 3.9: Hierarquia entre os critérios estruturais intra-método.

Teorema 1 : Os critérios definidos na Seção 3.3 são parcialmente ordenados pela relação de inclusão estrita conforme ilustrado na Figura 3.9(b). Com base em uma extensão no modelo de fluxo de dados é possível ordenar os critérios pela relação de inclusão estrita conforme ilustrado na Figura 3.9(a).

Prova: Seja $\mathcal{T}$ um conjunto de teste para um programa $P(\mathcal{D U} \mathcal{G}$ é o correspondente grafo de fluxo de controle de $P$ ), e seja $\Pi$ o conjunto de caminhos executados por $\mathcal{T}$. Observa-se que as provas são válidas assumindo-se que os programas satisfaçam as propriedades NSL e/ou NSUP. Inicialmente são apresentadas as provas de inclusão estrita entre os critérios independentes de exceção. Nos contra-exemplos são utilizados os grafos $\mathcal{D U G}$ da Figura 3.10, adaptados de (Rapps e Weyuker, 1985).

- Todas-Arestas ${ }_{e i} \Rightarrow$ Todos-Nós $_{e i}$

Suponha que $\mathcal{T}$ é Todas-Arestas ${ }_{e i}$-adequado para $P$. Isso implica que, $\forall\left(n_{1}, n_{2}\right) \in E_{e i}$ existe um caminho $\left(n_{1}, \ldots, n_{m}\right)$ tal que $n_{1}=n_{j}$ e $n_{2}=n_{j+1}$ para algum $j, 1 \leq$ $j \leq m-1$. Se $\mathcal{T}$ não é Todos-Nós ${ }_{e i}$-adequado implica que existe pelo menos um nó $n_{e i} \in N_{e i} \mid n_{e i} \nsubseteq \Pi$. Entretanto, como $P$ satisfaz a propriedade NSL, todo nó $n_{e i} \in N_{e i}$ é a origem ou o fim de uma aresta regular, ou seja, existe uma aresta 
$\left(n_{1}, n_{e i}\right) \in E_{e i}$ ou uma aresta $\left(n_{e i}, n_{2}\right) \in E_{e i}$. Portanto, se $\mathcal{T}$ é Todas-Arestas $i_{e i}$ adequado, $\mathcal{T}$ é também Todos-Nós ${ }_{e i}$-adequado.

Para provar que Todos-Nós ${ }_{e i}$ não inclui Todas-Arestas ${ }_{e i}$, denotado por (Todos-Nós $_{e i}$ $\not \Rightarrow$ Todas-Arestas $_{e i}$ ), basta considerar o grafo $\mathcal{D U G}$ apresentado na Figura 3.10(a). $\{(1,2,3)\}$ satisfaz o critério Todos-Nós ${ }_{e i}$ mas não satisfaz o critério Todas-Arestas ${ }_{e i}$ pois a aresta $(1,3)$ não é coberta.

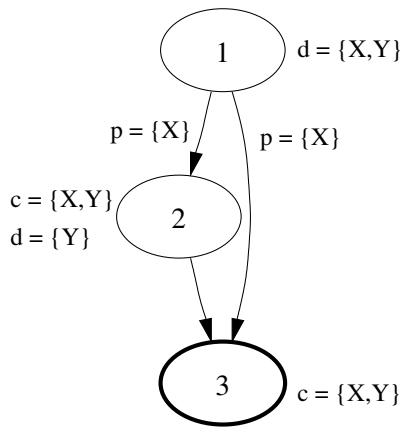

(a)

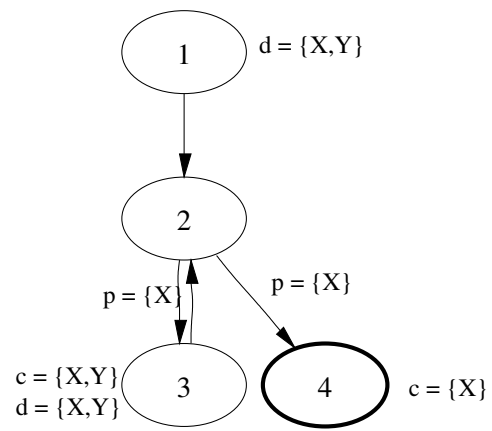

(b)

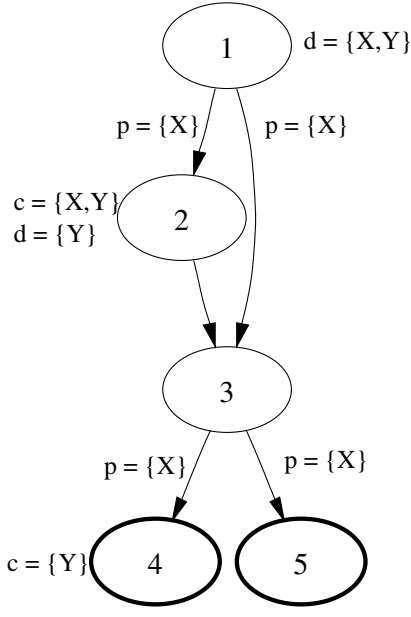

(c)

Figura 3.10: $\mathcal{D} \mathcal{U} \mathcal{G}_{\mathrm{S}}$ utilizados para fornecer contra-exemplos nas provas das relações de inclusão estrita entre os critérios primários (Rapps e Weyuker, 1985).

\section{- Todos-Usos $_{e i} \Rightarrow$ Todas-Arestas $_{e i}$}

Suponha que $\mathcal{T}$ é Todos-Usos ${ }_{e i}$-adequado para $P$. Seja $(i, j) \in E_{e i}$ um arco independente de exceção de $P$. Como $P$ satisfaz as propriedades NSL e NSUP, existe pelo menos um caminho completo $\pi=\left(I, n_{1}, n_{2}, \ldots, n_{k}, i, j, \ldots, F\right)$ do nó de entrada $I$ para o nó de saída $F$ tal que o arco $(i, j)$ está incluído em $\pi$. A partir desta declaração resta mostrar, para completar a prova, que existe pelo menos um caminho livre de definição que seja livre de exceção de algum nó $n_{d}$ para a aresta $(i, j)$ com relação a alguma variável $v$ definida em $n_{d}$ e com p-uso em $(i, j)$. Conseqüentemente, o conjunto $\Pi$ deveria cobrir a associação $\left(n_{d},(i, j), v\right)$, i.e., $\Pi$ deveria incluir pelo menos um caminho livre de definição de $n_{d}$ para a aresta $(i, j)$ com relação à $v$; desta forma $\Pi$ incluiria a aresta $(i, j)$.

i. Uma vez que o programa $P$ satisfaz a propriedade NSUP, o nó $I$ possui pelo menos a definição de alguma variável $v$ com p-uso em $(i, j)$. Se os nós $n_{1}, n_{2}, \ldots, n k$ não tiverem redefinições da variável $v$, definida no nó $I$, tem-se que o caminho 
$\left(I, n_{1}, n_{2}, \ldots, n_{k}, i, j\right)$ é um caminho livre de definição do nó $I$ para a aresta $(i, j)$, por definição. Se algum nó $n_{d}, 1 \leq d \leq k$, possuir redefinição de $v$, então o caminho $\left(n_{d}, n_{d+1}, \ldots, n_{k}, i, j\right)$ é um caminho livre de definição com relação a $v$ do nó $n_{d}$ para a aresta $(i, j)$.

Para provar que Todas-Arestas ${ }_{e i} \not \nRightarrow$ Todos-Usos $_{e i}$ basta considerar o grafo $\mathcal{D U} \mathcal{G}$ apresentado na Figura 3.10(b). $\{(1,2,3,2,4)\}$ satisfaz o critério Todas-Arestas ${ }_{e i}$ mas não satisfaz o critério Todos-Usos ${ }_{e i}$ porque ele não inclui um caminho livre de definição com respeito a $X$ de sua definição no nó 1 para o seu p-uso na aresta $(2,4)$.

- Todos-Pot-Usos ${ }_{e i} \Rightarrow$ Todas-Arestas $_{e i}$

Suponha que $\mathcal{T}$ é Todos-Pot-Usos ${ }_{e i}$-adequado para $P$. Seja $(i, j) \in E_{e i}$ um arco independente de exceção de $P$. Como $P$ satisfaz a propriedade NSL, existe pelo menos um caminho completo $\pi=\left(I, n_{1}, n_{2}, \ldots, n_{k}, i, j, \ldots, F\right)$ do nó de entrada $I$ para o nó de saída $F$ tal que o arco $(i, j)$ está incluído em $\pi$. A partir desta declaração resta mostrar, para completar a prova, que existe pelo menos um caminho livre de definição que seja livre de exceção de algum nó $n_{d}$ para a aresta $(i, j)$ com relação a alguma variável $v$ definida em $n_{d}$. Conseqüentemente, o conjunto $\Pi$ deveria cobrir a associação $\left(n_{d},(i, j), v\right)$, i.e., $\Pi$ deveria incluir pelo menos um caminho livre de definição de $n_{d}$ para a aresta $(i, j)$ com relação a $v$; desta forma $\Pi$ incluiria a aresta $(i, j)$.

i. Se o nó $i$ tiver a definição de uma variável $v$ então a aresta $(i, j)$ é um caminho livre de definição do nó $i$ para a aresta $(i, j)$;

ii. Uma vez que o programa $P$ satisfaz a propriedade LDEN, o nó $I$ possui pelo menos a definição de alguma variável $v$. Se os nós $n_{1}, n_{2}, \ldots, n k$ não tiverem redefinições da variável $v$, definida no nó $I$, tem-se que o caminho $\left(I, n_{1}, n_{2}, \ldots, n_{k}, i, j\right)$ é um caminho livre de definição do nó $I$ para a aresta $(i, j)$, por definição. Se algum nó $n_{d}, 1 \leq d \leq k$, possuir redefinição de $v$, então o caminho $\left(n_{d}, n_{d+1}, \ldots, n_{k}, i, j\right)$ é um caminho livre de definição com relação a $v$ do nó $n_{d}$ para a aresta $(i, j)$.

Para provar que Todas-Arestas ${ }_{e i} \not \nRightarrow$ Todos-Pot-Usos $_{e i}$ basta considerar o grafo $\mathcal{D U G}$ apresentado na Figura 3.10(b). $\{(1,2,3,2,4)\}$ satisfaz o critério Todas-Arestas ${ }_{e i}$ mas não satisfaz o critério Todos-Pot-Usos ${ }_{e i}$ pois a associação $\langle 1,4, X\rangle$ não é coberta.

- Todos-Pot-Usos ${ }_{e i} \Rightarrow$ Todos-Usos $_{e i}$

Seja $C_{p u}$ o conjunto de todas potenciais-associações requeridas pelo critério TodosPot-Usos $_{e i}$ para $P$. Suponha que $\mathcal{T}$ é Todos-Pot-Usos ${ }_{e i}$-adequado para $P$, ou seja, 
$\mathcal{T}$ cobre todas as potenciais associações de $C_{p u}$. Seja $C_{u}$ o conjunto de todas as associações requeridas pelo critério Todos-Usos ${ }_{e i}$ para $P$. Como por definição toda associação é uma potencial-associação $C_{p u} \supseteq C_{u}$ de modo que $\mathcal{T}$ é também TodosUsos $_{e i}$-adequado por definição.

Para provar que Todos-Usos Ti $_{\text {in }} \nRightarrow$ Todos-Pot-Usos $_{e i}$ basta considerar o $\mathcal{D} \mathcal{U} \mathcal{G}$ apresentado na Figura 3.10(c). $\{(1,2,3,4),(1,3,4),(1,3,5)\}$ satisfaz o critério Todos-Usos ${ }_{e i}$ mas não satisfaz o critério Todos-Pot-Usos ${ }_{e i}$. A potencial-associação $\langle 2,(3,5), Y\rangle$ não é coberta.

Com as provas acima, demonstra-se que o lado esquerdo da hierarquia apresentada na Figura 3.9(b) é verdadeira. A seguir as mesmas demonstrações são feitas em relação aos critérios dependentes de exceção. Nas demonstrações, o grafo $\mathcal{D U \mathcal { G }}$ da Figura 3.11(a) é utilizado quando contra-exemplos são necessários para mostrar que a relação de inclusão não existe ou não é estrita.

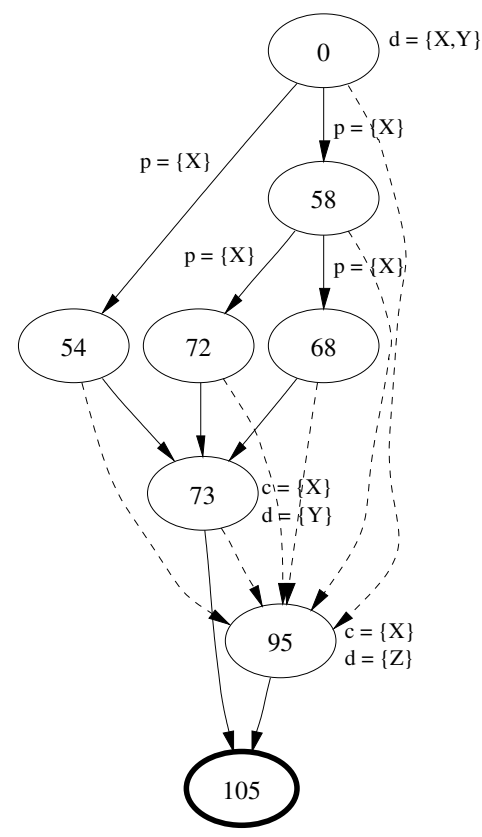

(a)

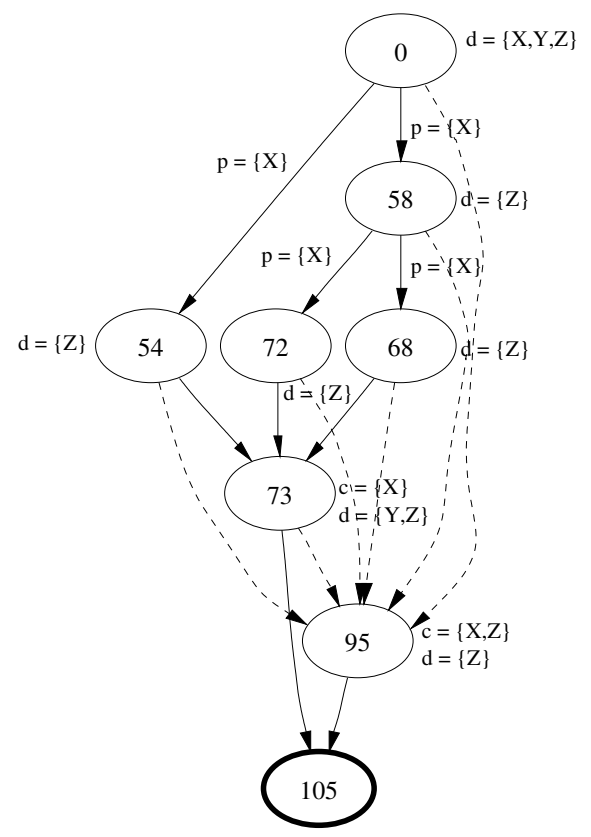

(b)

Figura 3.11: $\mathcal{D} \mathcal{U} \mathcal{G}_{\mathrm{s}}$ utilizados para fornecer contra-exemplos nas provas das relações de inclusão estrita entre os critérios dependentes de exceção.

A Tabela 3.5 apresenta o conjunto de requisitos de teste exigidos para cada um dos critérios de teste estruturais, considerando o grafo $\mathcal{D U \mathcal { G }}$ da Figura 3.11(a).

Seja $\mathcal{T}$ um conjunto de teste para um programa $P(\mathcal{D U} \mathcal{G}$ é o correspondente grafo de fluxo de controle de $P$ ), e seja $\Pi$ o conjunto de caminhos executados por $\mathcal{T}$. 
- Todas-Arestas ${ }_{e d} \Rightarrow$ Todos-Nós $_{e d}$

Suponha que $\mathcal{T}$ é Todas-Arestas $e^{-}$-adequado para $P$. Isso implica que, $\forall\left(n_{1}, n_{2}\right) \in$ $E_{e d}$ existe um caminho $\left(n_{1}, \ldots, n_{m}\right)$ que não é livre de exceção tal que $n_{1}=n_{j}$ e $n_{2}=n_{j+1}$ para algum $j, 1 \leq j \leq m-1$. Se $\mathcal{T}$ não é Todos-Nós ${ }_{e d}$-adequado implica que existe pelo menos um nó $n_{e d} \in N_{e d} \mid n_{e d} \nsubseteq \Pi$. Entretanto, por definição, um nó dependente de exceção é aquele que não pode ser alcançado por um caminho livre de exceção, ou seja, todo nó dependente de exceção $n_{e d} \in N_{e d}$ é a origem ou destino de uma aresta dependente de exceção. Desse modo, existe uma aresta dependente de exceção $\left(n_{1}, n_{e d}\right) \in E_{e d}$ ou uma aresta dependente de exceção $\left(n_{e d}, n_{2}\right) \in E_{e d}$. Portanto, se $\mathcal{T}$ é Todas-Arestas ${ }_{e d}-$ adequado, $\mathcal{T}$ é também Todos-Nós $_{e d}$-adequado.

Para provar que Todos-Nós ${ }_{e d} \nRightarrow$ Todas-Arestas $_{e d}$, basta considerar o $\mathcal{D U} \mathcal{G}$ apresentado na Figura 3.11(a). $\{(0,95,105)\}$ satisfaz o critério Todos-Nós ed $_{\text {mas não satisfaz }}$ o critério Todas-Arestas ${ }_{e d}$. As arestas de exceção $(54,95),(58,95),(68,95),(72,95)$, $(73,95)$ e $(95,105)$ não são cobertas.

Observa-se que como Todas-Arestas ${ }_{e i} \Rightarrow$ Todos-Nós $_{e i}$ e Todas-Arestas Tod $_{e} \Rightarrow$ TodosNós $_{e d}$, isso implica que Todas-Arestas $\Rightarrow$ Todos-Nós uma vez que o conjunto de requisitos de teste do critério Todas-Arestas é a união dos requisitos dos critérios Todas-Arestas $_{e i}$ e Todas-Arestas $e d$, da mesma forma que Todos-Nós é a união dos requisitos de Todos-Nós ${ }_{e i}$ e Todos-Nós ${ }_{e d}$.

Tabela 3.5: Conjunto de requisitos de teste derivados a partir do grafo $\mathcal{D U} \mathcal{G}$ da Figura 3.11(a)

\begin{tabular}{|c|c|}
\hline Critério & Conjunto de Requisitos \\
\hline Todos-Nós ${ }_{e i}$ & $0,54,58,68,72,73,105$ \\
\hline Todos-Nós $e_{d}$ & 95 \\
\hline Todas-Arestas $_{e i}$ & $(0,54),(0,58),(54,73),(58,68),(58,72),(68,73),(72,73),(73,105)$ \\
\hline Todas-Arestas $_{e d}$ & $(0,95),(54,95),(58,95),(68,95),(72,95),(73,95),(95,105)$ \\
\hline Todos-Usos $_{e i}$ & $\langle 0,(0,54), X\rangle,\langle 0,(0,58), X\rangle,\langle 0,(58,68), X\rangle,\langle 0,(58,72), X\rangle,\langle 0,73, X\rangle$ \\
\hline Todos-Usos $e_{e d}$ & $\langle 0,95, X\rangle$ \\
\hline Todos-Pot-Usos $_{e i}$ & $\begin{array}{lcccr}0,(0,54), X\rangle, & \langle 0,(0,58), X\rangle, & \langle 0,105, X\rangle, & \langle 0,54, X\rangle, & \langle 0,(58,68), X\rangle, \\
\langle 0,(58,72), X\rangle, \quad\langle 0,68, X\rangle, & \langle 0,72, X\rangle, & \langle 0,73, X\rangle, & \langle 0,(0,54), Y\rangle, \\
\langle 0,(0,58), Y\rangle, & \langle 0,54, Y\rangle, \quad\langle 0,(58,68), Y\rangle, & \langle 0,(58,72), Y\rangle, & \langle 0,68, Y\rangle, \\
\langle 0,72, Y\rangle,\langle 0,73, Y\rangle,\langle 73,105, Y\rangle & & \end{array}$ \\
\hline Todos-Pot-Usos $e d$ & $\langle 0,95, X\rangle,\langle 0,95, Y\rangle,\langle 73,95, Y\rangle,\langle 95,105, Z\rangle$ \\
\hline
\end{tabular}

- Todos-Pot-Usos ${ }_{e d} \Rightarrow$ Todos-Usos $_{e d}$

Seja $C_{p u}$ o conjunto de todas potenciais-associações requeridas pelo critério TodosPot-Usos ed $_{\text {para }} P$. Suponha que $\mathcal{T}$ é Todos-Pot-Usos ${ }_{e d}$-adequado para $P$, ou seja, $\mathcal{T}$ cobre todas as potenciais associações de $C_{p u}$. Seja $C_{u}$ o conjunto de todas as 
associações requeridas pelo critério Todos-Usos $e d$ para $P$. Como, por definição, toda associação é uma potencial-associação $C_{p u} \supseteq C_{u}$ de modo que $\mathcal{T}$ é também TodosUsos $_{e d}$-adequado.

Para provar que Todos-Usos ed $_{2} \nRightarrow$ Todos-Pot-Usos $_{e d}$ basta considerar o DUG apresentado na Figura 3.11(a). $\{(0,95,105)\}$ satisfaz o critério Todos-Usos ed $_{\text {mas não }}$ satisfaz o critério Todos-Pot-Usos ${ }_{e d}$. A potencial-associação dependente de exceção $\langle 73,95, Y\rangle$ não é coberta.

De forma análoga aos critérios Todas-Arestas e Todos-Nós, observa-se que como Todos-Pot-Usos $_{e i} \Rightarrow$ Todos-Usos $_{e i}$ e Todos-Pot-Usos Tod $_{e d} \Rightarrow$ Todos-Usos $_{e d}$, isso implica que Todos-Pot-Usos $\Rightarrow$ Todos-Usos.

- Todos-Usos $_{e d} \nRightarrow$ Todas-Arestas $_{e d}$

Para provar que o critério Todos-Usos ${ }_{e d}$ não inclui Todas-Arestas ${ }_{e d}$ basta considerar o grafo $\mathcal{D U G}$ apresentado na Figura 3.11(a). $\{(0,95,105)\}$ satisfaz o critério TodosUsos $_{e d}$ mas não satisfaz o critério Todas-Arestas ${ }_{e d}$. As arestas dependentes de exceção $(54,95),(58,95),(68,95),(72,95)$ e $(73,95)$ não são cobertas.

\section{- Todos-Pot-Usos ${ }_{e d} \nRightarrow$ Todas-Arestas $_{e d}$}

Para provar que o critério Todos-Pot-Usos ${ }_{e d}$ não inclui Todas-Arestas ${ }_{e d}$ basta considerar o grafo $\mathcal{D U G}$ apresentado na Figura 3.11(a). $\{(0,95,105),(0,54,73,95,105)\}$ satisfaz o critério Todos-Pot-Usos ${ }_{e d}$ mas não satisfaz o critério Todas-Arestas ${ }_{e d}$. As arestas dependentes de exceção $(54,95),(58,95),(68,95)$ e $(72,95)$ não são cobertas.

\section{- Todos-Usos ${ }_{e i} \nRightarrow$ Todas-Arestas}

Para provar que o critério Todos-Usos ${ }_{e i}$ não inclui Todas-Arestas ${ }_{e d}$ basta considerar o grafo $\mathcal{D U \mathcal { G }}$ apresentado na Figura 3.11(a). \{(0,54,73,105), $(0,58,72,73,105)$, $(0,58,68,73,105)\}$ satisfaz o critério Todos-Usos ${ }_{e i}$ mas não satisfaz o critério TodasArestas $_{e d}$. Nenhuma das arestas dependentes de exceção são cobertas.

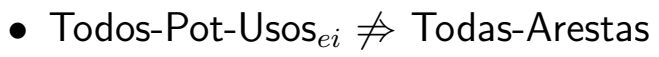

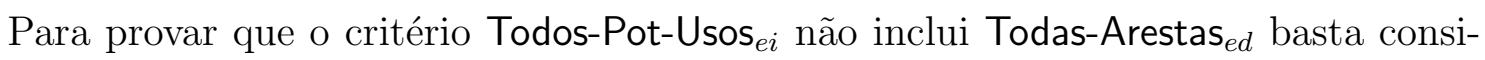
derar o grafo $\mathcal{D U \mathcal { G }}$ apresentado na Figura 3.11(a). $\{(0,54,73,105),(0,58,72,73,105)$, $(0,58,68,73,105)\}$ satisfaz o critério Todos-Pot-Usos $e_{e i}$ mas não satisfaz o critério Todas-Arestas $_{e d}$. Nenhuma das arestas dependentes de exceção são cobertas.

Com as definições apresentadas em relação aos critérios dependentes de exceção provase que a relação de inclusão entre os critérios se mantém como mostrado na Figura 3.9(b). 
Observa-se que o fato dos critérios Todos-Usos ${ }_{e d}$ e Todos-Pot-Usos ${ }_{e d}$ não incluírem o critério Todas-Arestas $_{e d}$ está relacionado com a forma como foi definido o modelo de fluxo de dados.

Para resolver esse problema uma simples extensão do modelo de fluxo de dados é suficiente para que a relação de inclusão se mantenha também para os critérios dependentes de exceção. Basta considerar que todo nó no escopo de um tratador de exceção, ao lançar uma exceção, define a variável que será posteriormente usada pelo tratador de exceção. Considerando a Figura 3.11(a), seria necessário considerar que todos os nós no escopo do tratador de exceção definissem a variável $Z$ e que no nó 95 houvesse um uso de $Z$, como mostrado no grafo $\mathcal{D U G}$ da Figura 3.11(b). Isso forçaria que os critérios Todos-Usos ${ }_{e d}$ e Todos-Pot-Usos ${ }_{e d}$ requeressem associações c-uso de cada nó no escopo de um tratador de exceção para o nó responsável pelo tratamento de exceção, ou seja, pelo menos uma associação envolvendo cada aresta dependente de exceção seria exigida fazendo com que a relação de inclusão se mantivesse. A Tabela 3.6 ilustra o conjunto de requisitos resultante, considerando o grafo $\mathcal{D U \mathcal { G }}$ da Figura 3.11(b). Se tal extensão for considerada no modelo de fluxo de dados, a relação de inclusão entre os critérios de teste passaria a ser como mostrado na Figura 3.9(a).

Tabela 3.6: Conjunto de requisitos de teste derivados a partir do grafo $\mathcal{D} \mathcal{U G}$ da Figura 3.11(b)

\begin{tabular}{|c|c|}
\hline Critério & Conjunto de Requisitos \\
\hline Todos-Nós ${ }_{e i}$ & $\overline{00,54,58,68,72,73,105}$ \\
\hline Todos-Nós ${ }_{e d}$ & 95 \\
\hline Todas-Arestas $_{e i}$ & $(0,54),(0,58),(54,73),(58,68),(58,72),(68,73),(72,73),(73,105)$ \\
\hline Todas-Arestas $_{e d}$ & $(0,95),(54,95),(58,95),(68,95),(72,95),(73,95),(95,105)$ \\
\hline Todos-Usos $_{e i}$ & $\langle 0,(0,54), X\rangle,\langle 0,(0,58), X\rangle,\langle 0,(58,68), X\rangle,\langle 0,(58,72), X\rangle,\langle 0,73, X\rangle$ \\
\hline Todos-Usos $_{e d}$ & $\begin{array}{l}\langle 0,95, X\rangle \\
\langle 73,95, Z\rangle\end{array}$ \\
\hline Todos-Pot-Usos $_{e i}$ & $\begin{array}{lllll}\langle 0,(0,54), X\rangle, & \langle 0,(0,58), X\rangle, & \langle 0,105, X\rangle, & \langle 0,54, X\rangle, & \langle 0,(58,68), X\rangle \\
\langle 0,(58,72), X\rangle, \quad\langle 0,68, X\rangle, \quad\langle 0,72, X\rangle, & \langle 0,73, X\rangle, & \langle 0,(0,54), Y\rangle, \\
\langle 0,(0,58), Y\rangle, \quad\langle 0,54, Y\rangle, \quad\langle 0,(58,68), Y\rangle, & \langle 0,(58,72), Y\rangle, \quad\langle 0,68, Y\rangle, \\
\langle 0,72, Y\rangle,\langle 0,73, Y\rangle,\langle 73,105, Y\rangle,\langle 0,(0,54), Z\rangle,\langle 0,(0,58), Z\rangle,\langle 54,73, Z\rangle, & \\
\langle 58,(58,68), Z\rangle,\langle 58,(58,72), Z\rangle,\langle 68,73, Z\rangle, & \langle 72,73, Z\rangle,\langle 73,105, Z\rangle\end{array}$ \\
\hline Todos-Pot-Usos & $\begin{array}{llll}\langle 0,95, X\rangle,\langle 0,95, Y\rangle,\langle 73,95, Y\rangle,\langle 95,105, Z\rangle, & \langle 0,95, Z\rangle, & \langle 54,95, Z\rangle, \\
\langle 58,95, Z\rangle,\langle 68,95, Z\rangle,\langle 72,95, Z\rangle,\langle 73,95, Z\rangle,\langle 95,105, Z\rangle & \end{array}$ \\
\hline
\end{tabular}

Um ponto importante a ser destacado é que, para o critérios Todos-Usos (TodosUsos $_{e i} /$ Todos-Usos $_{e d}$ ) continuar incluindo o critério Todas-Arestas (Todas-Arestas ${ }_{e i} /$ TodasArestas $_{e d}$ ) a propriedade NSUP deve ser respeitada. Já o critério Todos-Pot-Usos (TodosPot-Usos ${ }_{e i}$ (Todos-Pot-Usos ${ }_{e d}$ ) exige somente a propriedade LDEN para manter a relação de inclusão em relação ao critério Todas-Arestas (Todas-Arestas $e_{e i} /$ Todas-Arestas $_{e d}$ ).

Como já citado, uma das desvantagens do teste estrutural é a existência de caminhos não executáveis. Existe também o problema de caminhos ausentes, ou seja, quando uma 
certa funcionalidade deixa de ser implementada no programa, não existe um caminho que corresponda àquela funcionalidade e, como conseqüência, nenhum caso de teste será requerido para exercitá-la. Mesmo assim, esses critérios estabelecem de forma rigorosa os requisitos de teste a serem exercitados, em termos de caminhos, associações definição-uso, ou outras estruturas do programa, fornecendo medidas objetivas sobre a adequação de um conjunto de teste para o teste de um dado programa $P$. Esse rigor na definição dos requisitos favorece a automatização desses critérios. Na Seção 5.2 do Capítulo 5 é descrita a arquitetura de uma ferramenta de teste que apóia a aplicação dos critérios estruturais propostos nesta tese.

\subsubsection{Análise de Complexidade}

A complexidade de um critério de teste $C$ é definida como o número máximo de casos de teste requerido pelo critério no pior caso, ou seja, dado um programa qualquer $P$, se existir um conjunto de teste $\mathcal{T}$ que seja $C$-adequado para $P$, então existe um conjunto de teste $\mathcal{T}_{1}$ tal que a cardinalidade de $\mathcal{T}_{1}$ é menor ou igual à complexidade do critério $C$ (Maldonado, 1991).

Conforme ressaltado por Maldonado (1991), o primeiro passo na determinação da complexidade de um critério consiste em identificar qual estrutura de fluxo de controle, considerando um fluxo de dados qualquer, maximiza o número de elementos requeridos pelo critério. Desse modo, para determinar a complexidade dos critérios Potenciais Usos, Maldonado (1991) identificou o grafo de controle ilustrado na Figura 3.12 como sendo o que maximiza o número de elementos requeridos pelos critérios Potenciais Usos, ou seja, potenciais-du-caminhos e potenciais associações. Com base nesse grafo, Maldonado (1991) demonstra que $((11 / 2) t+9) 2^{t}-10 t-9$ potenciais-du-caminhos seriam requeridos o que iria exigir, no pior caso, $2^{t}$ casos de teste para serem cobertos, sendo $t$ o número de comandos de decisão, ou seja, a complexidade do critério todos-potenciais-du-caminhos é da ordem de $2^{t}$.

Sendo todos-potenciais-du-caminhos o critério mais forte da família de critérios Potenciais Usos (vide Figura 2.3 na Seção 2.5.3 do Capítulo 3), isso quer dizer que, no pior caso, $2^{t}$ é o limitante superior de todos os critérios incluídos pelo todos-potenciais-du-caminhos, como por exemplo, os critérios todos-potenciais-usos e todos-usos.

No contexto desta tese, observa-se que o grafo apresentado na Figura 3.12 corresponde a um grafo $\mathcal{D U G}$ o qual não possui requisitos dependentes de exceção de modo que podese considerar que, no pior caso, o limitante superior para o critério Todos-Pot-Usos ${ }_{e i}$ é também exponencial da ordem de $2^{t}$ e, conseqüentemente, para os demais critérios independentes de exceção que são incluídos pelo critério Todos-Pot-Usos ${ }_{e i}$. 
Sendo os critérios independentes de exceção de ordem exponencial, pode-se concluir que, quando combinados com os respectivos critérios dependentes de exceção, vão resultar em critérios que demandam, no pior caso, um número exponencial de casos de teste para serem satisfeitos. Resta agora a realização de um estudo analítico mais detalhado para dizer se essa complexidade é superior a $2^{t}$.

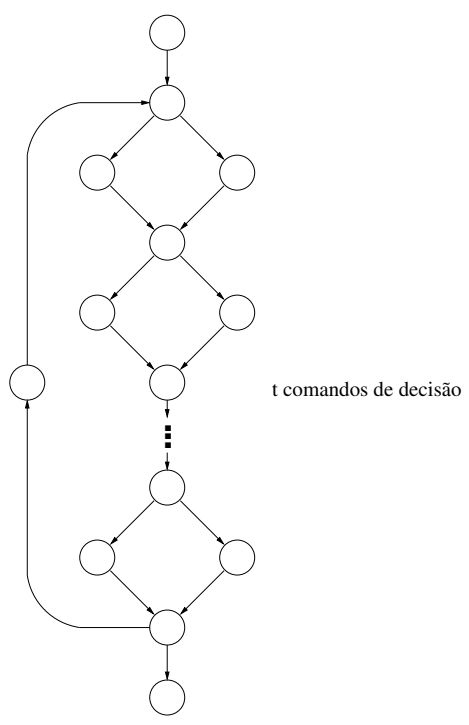

Figura 3.12: Estrutura de controle que maximiza o número de potenciais-ducaminhos (Maldonado, 1991).

É importante observar que, embora teoricamente os critérios de teste de fluxo de dados apresentem uma complexidade exponencial, na prática tem-se observado que a complexidade dos mesmos pode ser vista como linear em relação aos número de comandos de decisão $t$, resultados esses relatados por Weyuker (1990) e Maldonado (1991) e que devem ser investigados posteriormente no contexto de programas OO. A título de ilustração, no Capítulo 6 são apresentados alguns dados referentes ao número de requisitos de teste gerados pelos critérios de teste estruturais definidos, considerando dois grupos distintos de programas.

\subsection{Estratégia de Teste Incremental}

Visando a atingir uma alta cobertura dos requisitos de teste é possível utilizar um conjunto de teste gerado em diversas fases, considerando uma estratégia incremental de aplicação dos critérios de teste. Com isso, o testador pode se concentrar em diferentes aspectos do programa sendo testado e gerenciar mais facilmente os recursos de tempo e custo em função da qualidade dos testes desejada. 
A estratégia definida abaixo é fundamentada na relação de inclusão entre os critérios de teste. O objetivo é aplicar um critério de teste menos rigoroso e de menor custo e, caso nenhum defeito seja revelado, considerar a aplicação de critérios mais rigorosos visando a evoluir o conjunto de teste e aumentar a confiança de que o software se comporta de acordo com o especificado. Na definição da estratégia, os seguintes conjuntos de teste são considerados:

- $\mathcal{T}_{f}$ correspondente a um teste inicial, em geral desenvolvido com base em algum critério de teste funcional;

- $\mathcal{T}_{n}$ correspondente a um conjunto de teste adequado ao critério Todos-Nós (TodosNós ${ }_{e i} /$ Todos-Nós $_{e d}$ );

- $\mathcal{T}_{a}$ correspondente a um conjunto de teste adequado ao critério Todas-Arestas (TodasArestas $_{e i} /$ Todas-Arestas $_{e d}$ );

- $\mathcal{T}_{u}$ correspondente a um conjunto de teste adequado ao critério Todos-Usos (TodosUsos $_{e i} /$ Todos-Usos $\left._{e d}\right)$; e

- $\mathcal{T}_{p u}$ correspondente a um conjunto de teste adequado ao critério Todos-Pot-Usos (Todos-Pot-Usos ${ }_{e i} /$ Todos-Pot-Usos $_{e d}$ ).

Os nove passos necessários para a aplicação da estratégia incremental são descritos na Tabela 3.7.

Tabela 3.7: Seqüência de passos da estratégia incremental.

\begin{tabular}{|c|c|}
\hline Passo & Descrição \\
\hline Passo 1 & $\begin{array}{l}\text { Elaborar um conjunto de teste funcional }\left(\mathcal{T}_{f}\right) \text {, utilizando um critério funcional tal } \\
\text { como, análise do valor limite, particionamento em classes de equivalência, error- } \\
\text { guessing, ou uma combinação deles (Linkman et al., 2003), considerando a especifi- } \\
\text { cação das classes sendo testadas (CST). }\end{array}$ \\
\hline Passo 2 & Avaliar a cobertura de $\mathcal{T}_{f}$ em relação aos critérios de teste estruturais. \\
\hline Passo 3 & $\begin{array}{l}\text { Evoluir } \mathcal{T}_{f} \text { até obter um conjunto de teste }\left(\mathcal{T}_{n}\right) \text {, adequado ao critério Todos-Nós } \\
\text { (Todos-Nós }{ }_{e i} / \text { Todos-Nós }{ }_{e d} \text { ) para as CST. }\end{array}$ \\
\hline Passo 4 & Avaliar a cobertura de $\mathcal{T}_{n}$ em relação aos demais critérios de teste estruturais. \\
\hline Passo 5 & $\begin{array}{l}\text { Evoluir } \mathcal{T}_{n} \text { até obter um conjunto de teste }\left(\mathcal{T}_{a}\right) \text {, adequado ao critério Todas-Arestas } \\
\left(\text { Todas-Arestas }_{e i} / \text { Todas-Arestas }_{e d} \text { ) para as CST. }\right.\end{array}$ \\
\hline Passo 6 & Avaliar a cobertura de $\mathcal{T}_{a}$ em relação aos demais critérios de teste estruturais. \\
\hline Passo 7 & $\begin{array}{l}\text { Evoluir } \mathcal{T}_{a} \text { até obter um conjunto de teste }\left(\mathcal{T}_{u}\right) \text {, adequado ao critério Todos-Usos } \\
\left(\text { Todos-Usos }{ }_{e i} / \text { Todos-Usos }\right. \\
\text { (Tod }) \text { para as CST. }\end{array}$ \\
\hline Passo 8 & Avaliar a cobertura de $\mathcal{T}_{u}$ em relação aos demais critérios de teste estruturais. \\
\hline Passo 9 & $\begin{array}{l}\text { Evoluir } \mathcal{T}_{u} \text { até obter um conjunto de teste }\left(\mathcal{T}_{p}\right) \text {, adequado ao critério Todos-Pot-Usos } \\
\text { (Todos-Pot-Usos }{ }_{e i} / \text { Todos-Pot-Usos } e d \text { ) para as CST. }\end{array}$ \\
\hline
\end{tabular}


Observa-se que a estratégia considera, inicialmente, o desenvolvimento de um conjunto de teste funcional. Tal conjunto de teste pode ser gerado por meio de algum algoritmo de geração aleatório, com base em algum critério de teste funcional, ou até mesmo com base no conhecimento do testador sobre o programa sendo testado. Esses casos de teste servem como um bom ponto de partida para a avaliação de cobertura. Se os resultados obtidos não satisfizerem os objetivos pré-estabelecidos, casos de teste adicionais podem ser desenvolvidos visando a alcançar tais objetivos.

A idéia é evoluir o conjunto de teste de modo a satisfazer, inicialmente, os requisitos mínimos do teste estrutural, ou seja, cobertura de comandos (critério Todos-Nós) e em seguida cobertura de decisões (critério Todas-Arestas). A seguir, critérios de teste que avaliam a relação entre a definição e uso de variáveis são considerados, visando garantir que as associações de fluxo de dados do programa estão corretas. Nesse contexto, sugere-se a utilização do critério Todos-Usos seguido do critério Todos-Pot-Usos.

Além disso, dependendo do tipo de programa sendo testado ou até dos objetivos de teste desejados, o testador pode escolher por aplicar, num primeiro momento, somente os critérios independentes de exceção e, posteriormente, conforme as restrições de tempo e custo, os critérios dependentes de exceção também podem ser aplicados, seguindo os passos da estratégia.

Observa-se que, em geral, a obtenção de conjuntos de teste adequados requer a identificação de possíveis requisitos de teste não executáveis. Tarefa essa que deve ser realizada em todas as etapas que exigem a geração de conjuntos de teste adequados com relação a algum critério de teste. Formulários específicos devem ser preenchidos durante e ao final de cada etapa para anotar os dados pertinentes.

\subsection{Considerações Finais}

Este capítulo apresentou as contribuições desta tese no que se refere ao teste de fluxo de controle e de dados intra-métodos em programas OO. Visando a buscar uma solução que pudesse ser aplicada/utilizada de modo mais genérico tanto a programas quanto a componentes de software optou-se por identificar um mecanismo que viabilizasse o teste intra-métodos de bytecode Java.

Foi definido e apresentado o modelo de representação de programa, o grafo definiçãouso $\mathcal{D} \mathcal{U G}$, que é utilizado para representar o fluxo de controle e de dados intra-método tanto durante a execução normal do programa quanto na presença de exceções. Para viabilizar a coleta das informações sobre definição e uso de variáveis em bytecode um modelo de fluxo de dados foi definido. O modelo em questão estendeu um modelo exis- 
tente acrescentando definições e uso intra-métodos de variáveis de instância e variáveis agregadas.

Como base no grafo $\mathcal{D U \mathcal { G }}$, oito critérios de teste estruturais foram definidos. Esses critérios foram derivados de critérios de teste estruturais conhecidos e utilizados previamente no teste de programas procedimentais. A diferença é a extensão dos mesmos de modo a considerar não somente o fluxo de controle e de dados durante a execução normal do programas, mas também o fluxo de controle e de dados associados ao tratamento de exceção intra-método.

Uma análise da relação de inclusão entre os critérios de teste definidos demonstrou que os mesmos satisfazem os requisitos mínimos exigidos para um bom critério de teste e apresentam uma complexidade de ordem exponencial no pior caso. Com base na relação de inclusão e em experiências anteriores, um estratégia incremental de aplicação dos critérios de teste foi definida. No Capítulo 6 é apresentado um exemplo de aplicação de alguns dos critérios definidos, respeitando os passos estabelecidos pela estratégia incremental.

Um fator de fundamental importância para viabilizar a aplicação desses critérios de teste é a existência de uma ferramenta de teste que os apóie. No Capítulo 5 é descrita a arquitetura e os aspectos de implementação de uma ferramenta de teste, denominada JaBUTi, proposta neste trabalho. 


\section{Teste de Mutação OO}

1 ESTE capítulo são descritas as contribuições desta tese no que se refere ao estabeleprincipal é fazer uma análise crítica de operadores de mutação já desenvolvidos, destinados ao teste de programas procedimentais e OO, avaliando a aplicabilidade dos mesmos no contexto de programas OO, considerando as linguagens Java e C++. Na Seção 4.1 são discutidas as motivações deste capítulo. A terminologia e os conceitos básicos relacionados ao teste de mutação são descritos na Seção 4.2. Os conjuntos de operadores de mutação para o teste intra-método, inter-método e inter-classe são apresentados na Seção 4.3. Alguns operadores de mutação definidos especificamente para modelar defeitos em programas concorrentes implementados em Java também são identificados e discutidos os principais problemas para o emprego do teste de mutação no teste desse tipo de programa. Na Seção 4.4 são discutidas a análise de inclusão e os aspectos de custo relacionados ao teste de mutação. Uma estratégia incremental de aplicação dos operadores de mutação é apresentada e uma técnica para auxiliar na determinação de mutantes equivalentes é também definida e ilustrada com um exemplo. Finalmente, na Seção 4.5 são feitas as considerações finais deste capítulo.

\subsection{Motivação}

Da mesma forma que os critérios de fluxo de dados, o teste de mutação também foi proposto inicialmente para o teste de unidade de programas procedimentais (DeMillo et 
al., 1978). Entretanto, como mencionado no Capítulo 2 - Seção 2.5.4, já foram propostas extensões desse critério para o teste de integração de programas C (Delamaro et al., 2001a) e para o teste de especificações em Máquinas de Estados Finitos (Fabbri et al., 1993, 1994), Redes de Petri (Fabbri et al., 1995; Simão, 2000), Statecharts (Fabbri, 1996; Sugeta, 1999), Estelle (Probert e Guo, 1991; Souza et al., 1999), SDL (Sugeta et al., 2004) e Especificações Algébricas (Woodward, 1993). No caso específico dos operadores de mutação destinados ao teste de programas $\mathrm{C}$, uma avaliação empírica foi realizada comparando o conjunto de operadores de unidade e de integração, visando ao estabelecimento de estratégias de teste incrementais baseadas em mutação (Vincenzi, 1998; Vincenzi et al., 2001).

É importante ressaltar que a essência do critério é a mesma, ou seja, realizar alterações sintáticas no produto sendo testado produzindo-se um conjunto de produtos mutantes e desenvolver um conjunto de teste que mostre que o conjunto de mutantes não se comporta corretamente em relação à especificação. Feito isso evidencia-se que o produto em teste não apresenta os defeitos representados pelo conjunto de mutantes.

A flexibilidade de extensão do critério vem do fato de que para se aplicar o teste de mutação é necessária a existência de um modelo que seja executável e que aceite uma entrada e produza uma saída que possa ser comparada com a saída do mutante. Além disso, é necessária a definição de um conjunto de operadores de mutação responsável pela representação do modelo de defeitos correspondente à entidade executável em questão. Tal flexibilidade, a reconhecida eficácia em detectar defeitos do teste de mutação e a experiência do grupo de Engenharia de Software do ICMC na definição de critérios de teste baseados em mutação, desenvolvimento de ferramentas de apoio e na condução de estudos empíricos, motivam investigar a aplicação desse critério no contexto de programas OO.

Atualmente, vários pesquisadores têm trabalhado na definição de operadores de mutação para programas OO. Dentre eles destacam-se os trabalhos de Kim et al. (1999a, 2000a) que definem um conjunto de operadores de mutação de classes, mas que não exploram todas as características de um programa OO; de Bieman et al. (2001) que definem um conjunto de operadores de mutação específico para o teste de determinadas classes da Java API; e de Ma et al. (2002) os quais propõem um conjunto de operadores de mutação de classe para Java que incluem os operadores propostos por Kim et al. (1999a, 2000a). Entretanto, todos os conjuntos de mutação propostos para OO foram desenvolvidos para a linguagem Java e focam somente o teste de classe, não levando em consideração o teste intra-método e inter-método da forma como é realizado pelos critérios Análise de Mutantes e Mutação de Interface em programas procedimentais, respectivamente, o que motiva tal investigação, principalmente devido à similaridade de várias estruturas sintáticas entre as linguagens $\mathrm{C}, \mathrm{C}++$ e Java. 


\subsection{Terminologia e Conceitos Básicos}

Um dos primeiros artigos que descrevem a idéia de teste de mutação foi publicado em 1978 (DeMillo et al., 1978). A idéia básica da técnica apresentada por DeMillo et al. (1978), conhecida como hipótese do programador competente (competent programmer hypothesis), assume que programadores experientes escrevem programas corretos ou muito próximos do correto. Assumindo a validade desta hipótese, pode-se afirmar que defeitos são introduzidos nos programas por meio de pequenos desvios sintáticos que, embora não causem erros sintáticos, alteram a semântica do programa e, conseqüentemente, conduzem o programa a um comportamento incorreto. Para revelar tais defeitos, o teste de mutação identifica os desvios sintáticos mais comuns e, por meio de pequenas transformações sobre o programa em teste, encoraja o testador a construir casos de teste que mostrem que tais transformações levam a um programa incorreto (Agrawal et al., 1989).

Uma outra hipótese explorada na aplicação do teste de mutação é o efeito de acoplamento (coupling effect) (DeMillo et al., 1978), a qual assume que defeitos complexos estão relacionados a defeitos simples. Assim sendo, espera-se, e alguns estudos empíricos já confirmaram esta hipótese (Acree et al., 1979; Budd, 1980), que conjuntos de teste capazes de revelar defeitos simples são também capazes de revelar defeitos complexos. Nesse sentido, aplica-se uma mutação de cada vez no programa $P$ em teste, ou seja, cada mutante contém apenas uma transformação sintática. Um mutante com $k$ transformações sintáticas é referenciado por $k$-mutante; nesta tese são utilizados apenas 1-mutantes.

Partindo-se da hipótese do programador competente e do efeito de acoplamento, a princípio, o testador deve fornecer um programa $P$ a ser testado e um conjunto de teste $\mathcal{T}$ cuja adequação deseja-se avaliar. O programa é executado com $\mathcal{T}$ e se apresentar resultados incorretos então um erro foi encontrado e o teste termina. Caso contrário, o programa ainda pode conter defeitos que o conjunto $\mathcal{T}$ não conseguiu revelar. O programa $P$ sofre então pequenas alterações, dando origem aos programas $P_{1}, P_{2}, \ldots, P_{n}$ denominados mutantes de $P$, diferindo de $P$ apenas pela ocorrência de defeitos simples.

Com o objetivo de modelar os desvios sintáticos mais comuns, operadores de mutação (mutant operators) são aplicados a um programa $P$, transformando-o em programas similares: mutantes de $P$. Entende-se por operador de mutação as regras que definem as alterações que devem ser aplicadas no programa original $P$. Os operadores de mutação são construídos para satisfazer a um entre dois propósitos: 1) induzir mudanças sintáticas simples com base nos enganos típicos cometidos pelos programadores (como trocar o nome de uma variável); ou 2) forçar determinados objetivos de teste (como executar cada desvio de execução do programa) (Offutt et al., 1996a). 
A seguir, considerando $D$ o domínio de entrada de $P$, os mutantes são executados com o mesmo conjunto de teste $\mathcal{T} \subseteq D$. O objetivo é obter casos de teste que resultem apenas em mutantes mortos (para algum caso de teste o resultado do mutante e o do programa original diferem entre si) e equivalentes (o mutante e o programa original apresentam sempre o mesmo resultado, para qualquer $d \in D$ ); neste caso, tem-se um conjunto de teste $\mathcal{T}$ adequado ao programa $P$ em teste, no sentido de que, ou $P$ está correto, ou possui defeitos pouco prováveis de ocorrerem (DeMillo et al., 1978).

Um ponto importante destacado por DeMillo (1980) é que o teste de mutação fornece uma medida objetiva do nível de confiança da adequação dos casos de teste analisados com a definição de um escore de mutação (mutation score), que relaciona o número de mutantes mortos com o número de mutantes gerados. O escore de mutação é calculado da seguinte forma:

$$
m s(P, \mathcal{T})=\frac{D M(P, \mathcal{T})}{M(P)-E M(P)}
$$

sendo:

$D M(P, \mathcal{T})$ : número de mutantes mortos pelos casos de teste em $\mathcal{T}$.

$M(P)$ : número total de mutantes gerados.

$E M(P)$ : número de mutantes gerados equivalentes a $P$.

O escore de mutação varia no intervalo entre $[0,1]$ sendo que, quanto maior o escore mais adequado é o conjunto de teste para o programa sendo testado. Percebe-se com essa fórmula que apenas $D M(P, T)$ depende do conjunto de teste utilizado e que, $\operatorname{EM}(P)$ é obtido à medida que o testador, manualmente ou com o apoio de heurísticas, decide que determinado mutante vivo é equivalente.

Um dos maiores problemas para a aplicação do teste de mutação está relacionado ao seu alto custo, uma vez que o número de mutantes gerados, mesmo para pequenos programas, pode ser muito grande, exigindo um tempo de execução muito alto e um esforço na determinação de mutantes equivalentes.

Várias estratégias têm sido propostas para fazer com que o teste de mutação possa ser utilizado de modo mais eficiente, dentro de limites economicamente viáveis. A utilização de arquiteturas de hardware avançadas para diminuir o tempo de execução dos mutantes (Choi et al., 1989; Krauser et al., 1991; Mathur e Krauser, 1988; Choi e Mathur, 1993) e o uso da análise estática de anomalias de fluxo de dados para reduzir o número de mutantes gerados (Marshall et al., 1990) são algumas dessas estratégias. Além disso, critérios alternativos, derivados do teste de mutação, também foram criados com o intuito de 
reduzir o custo a ele associado: Mutação Aleatória (Randomly Selected X\% Mutation), Mutação Restrita (Constrained Mutation) e Mutação Seletiva (Selective Mutation). Tais critérios procuram selecionar apenas um subconjunto do total de mutantes gerados, reduzindo o custo associado, mas com a expectativa de não se reduzir a eficácia do critério.

É preciso ressaltar que, em geral, a equivalência entre programas é uma questão indecidível e requer a intervenção do testador. Essa limitação teórica, no entanto, não significa que o problema deva ser abandonado por não apresentar solução. Diferentes técnicas têm sido desenvolvidas e investigadas tanto para a detecção automática de mutantes equivalentes, considerando classes específicas de programas, quanto na definição de diretrizes que facilitem tal atividade (Harman et al., 2000; Hierons et al., 1999; DeMillo e Offutt, 1991; Offutt e Craft, 1994; Offutt e Pan, 1996, 1997; Vincenzi et al., 2002). Na Seção4.4.2.2 é descrita a técnica BaLBEDeT que fornece diretrizes ao testador para auxiliá-lo na identificação de mutantes equivalentes e não-equivalentes.

Como mencionado na seção anterior, uma das vantagens do critério baseado em mutação é sua flexibilidade no teste de diversas "entidades" executáveis. Essa flexibilidade vem do fato de que para se aplicar o teste de mutação é necessária a existência de um modelo que seja executável que aceite uma entrada e produza uma saída que possa ser comparada com a saída do mutante. Além disso, é necessária a definição de um conjunto de operadores de mutação responsável pela representação do modelo de defeitos correspondente à entidade executável em questão. Na próxima seção são descritos os operadores de mutação que podem ser utilizados no teste de programas $\mathrm{OO}$, visando não somente ao teste de classe, mas também o teste intra-método e inter-método.

\subsection{Definição dos Critérios}

Os operadores de mutação são dependentes da linguagem de programação. No contexto desta tese, as linguagens Java e $\mathrm{C}++$ são consideradas durante o desenvolvimento de operadores de mutação para o teste de programas OO. Dada a semelhança de algumas construções sintáticas dessas linguagens com a linguagem C, torna-se natural avaliar qual a aplicabilidade de operadores de mutação desenvolvidos para C no contexto de Java e $\mathrm{C}++$, ou seja, avaliar quais defeitos modelados pelos operadores de mutação desenvolvidos para C também modelam defeitos que possam ocorrer em programas OO. Inicialmente, são identificados operadores de mutação que podem ser utilizados para o teste intra-método (Seção 4.3.1). Em seguida, são identificados operadores de mutação que podem ser utilizados no teste inter-método (Seção 4.3.2). Finalmente, são identificados os operadores de mutação destinados ao teste inter-classes (Seção 4.3.3). Para compreender o significado 
dos operadores de mutação, o Apêndice A traz a descrição completa dos operadores de mutação apresentados neste capítulo.

\subsubsection{Teste Intra-Método}

O teste intra-método visa a avaliar se a funcionalidade de um método está implementada corretamente, identificando defeitos de lógica e programação. Observa-se que Java e $\mathrm{C}++$ possuem diversas construções sintáticas comuns à linguagem $\mathrm{C}$, principalmente no nível de unidade. Com isso, o conjunto de operadores de mutação definido para a linguagem C (Agrawal et al., 1989) foi avaliado de modo a identificar quais deles poderiam ser utilizados no contexto de programas $\mathrm{OO}$ escritos em $\mathrm{C}++$ e Java. A análise realizada resultou nos dados mostrados na Tabela 4.1.

Na primeira coluna da Tabela 4.1 estão listados os nomes dos 80 operadores de mutação para o teste de unidade de programas C, extraídos de (Agrawal et al., 1989). Esses operadores estão divididos em quatro classes: mutação de constantes ( 5 operadores - Tabela 4.1(a)), mutação de comandos (16 operadores - Tabela 4.1(b)), mutação de variáveis (12 operadores - Tabela 4.1(c)) e mutação de operadores (47 operadores - Tabela 4.1(d)).

Cada conjunto descreve operadores que modelam diferentes tipos de defeitos em um mesmo tipo de estrutura, e seus nomes são descritos por quatro letras; a primeira (sempre em letra maiúscula) indica qual a classe do operador: $\mathbf{C}$ (Constant), $\mathbf{S}$ (statement), O (operator) ou $\mathbf{V}$ (variable). As outras letras fazem parte da descrição do operador como no caso do operador CGCR - Constant for Global Constant Replacement. Para mais informações sobre os tipos de mutações realizadas por esses operadores podem ser consultados (Agrawal et al., 1989; Vincenzi et al., 2004a).

O símbolo $(\checkmark)$ é utilizado para indicar quando um operador de mutação é aplicável para a linguagem em questão, o símbolo $(\times)$ quando o operador não é aplicável e o símbolo $(\odot)$ indica os operadores que podem ser aplicados com alguma pequena modificação semântica. O símbolo $(\rightarrow)$ antes do nome do operador indica os operadores novos que foram definidos. Tendo em vista que no caso da linguagem $\mathrm{C}$ existem operadores de mutação específicos para realizar mutações em variáveis locais e globais, uma observação é necessária para definir como esses conceitos de variáveis globais e locais foram mapeados para o teste intra-método de linguagens OO.

No caso de $\mathrm{C}++$, por ser um superconjunto de $\mathrm{C}$, o conjunto de variáveis globais é composto por variáveis globais tradicionais (como conhecidas em C) e pelos atributos de uma classe uma vez que esses atributos podem ser compartilhados entre os diversos métodos de uma mesma classe como se fossem variáveis globais da classe. Já o conjunto 
de variáveis locais é definido como as variáveis declaradas dentro do método, da mesma forma como as variáveis locais em $\mathrm{C}$ que são aquelas declaradas dentro de uma função.

Tabela 4.1: Operadores de mutação de unidade para o teste intra-método.

\begin{tabular}{|l|c|c|}
\hline Operador & Java & C++ \\
\hline \hline u-CGCR & $\checkmark$ & $\checkmark$ \\
\hline u-CGSR & $\checkmark$ & $\checkmark$ \\
\hline u-CLCR & $\checkmark$ & $\checkmark$ \\
\hline u-CLSR & $\checkmark$ & $\checkmark$ \\
\hline u-CRCR & $\checkmark$ & $\checkmark$ \\
\hline \hline Total & $5 / 5$ & $5 / 5$ \\
\hline
\end{tabular}

(a) Mutação de Constantes

\begin{tabular}{|l|c|c|}
\hline Operador & Java & C++ \\
\hline \hline u-SBRC & $\checkmark$ & $\checkmark$ \\
\hline u-SBRn & $\checkmark$ & $\checkmark$ \\
\hline u-SCRB & $\checkmark$ & $\checkmark$ \\
\hline u-SCRn & $\checkmark$ & $\checkmark$ \\
\hline u-SDWD & $\checkmark$ & $\checkmark$ \\
\hline u-SGLR & $\odot$ & $\checkmark$ \\
\hline$\rightarrow$ u-SBLR & & \\
$\rightarrow$ u-SCLR & $\checkmark$ & $\times$ \\
$\rightarrow$ u-SLBC & & \\
$\rightarrow$ u-SLCB & & $\checkmark$ \\
\hline u-SMTC & $\checkmark$ & $\checkmark T T$ \\
\hline u-SMVB & $\checkmark$ & $\checkmark$ \\
\hline u-SRSR & $\checkmark$ & $\checkmark$ \\
\hline u-SSDL & $\checkmark$ & $\checkmark$ \\
\hline u-SSOM & $\checkmark$ & $\checkmark$ \\
\hline u-SSWM & $\checkmark$ & $\checkmark$ \\
\hline u-STRI & $\checkmark$ & $\checkmark$ \\
\hline u-STRP & $\checkmark$ & $\checkmark$ \\
\hline u-SWDD & $\checkmark$ & $\checkmark$ \\
\hline \hline Total & $15 / 16$ & $16 / 16$ \\
\hline
\end{tabular}

(b) Mutação de Comandos

\begin{tabular}{|l|c|c|}
\hline Operador & Java & C++ \\
\hline \hline $\mathrm{u}$-VASM & $\checkmark$ & $\checkmark$ \\
\hline $\mathrm{u}$-VDTR & $\checkmark$ & $\checkmark$ \\
\hline $\mathrm{u}$-VGAR & $\checkmark$ & $\checkmark$ \\
\hline $\mathrm{u}$-VGPR & $\odot$ & $\checkmark$ \\
\hline$\rightarrow$ u-VGCR & $\checkmark$ & $\checkmark$ \\
\hline $\mathrm{u}-$ VGSR & $\checkmark$ & $\checkmark$ \\
\hline $\mathrm{u}$-VGTR & $\odot$ & $\checkmark$ \\
\hline $\mathrm{u}$-VLAR & $\checkmark$ & $\checkmark$ \\
\hline $\mathrm{u}$-VLPR & $\odot$ & $\checkmark$ \\
\hline$\rightarrow$ u-VLCR & $\checkmark$ & $\checkmark$ \\
\hline $\mathrm{u}$-VLSR & $\checkmark$ & $\checkmark$ \\
\hline $\mathrm{u}$-VLTR & $\odot$ & $\checkmark$ \\
\hline $\mathrm{u}$-VSCR & $\odot$ & $\checkmark$ \\
\hline$\rightarrow$ u-VCAR & $\checkmark$ & $\checkmark$ \\
\hline $\mathrm{u}$-VTWD & $\checkmark$ & $\checkmark$ \\
\hline \hline Total & $7 / 12$ & $12 / 12$ \\
\hline
\end{tabular}

(c) Mutação de Variáveis

\begin{tabular}{|c|c|c|}
\hline Operador & Java & C++ \\
\hline \hline u-OAAA & $\checkmark$ & $\checkmark$ \\
\hline u-OAAN & $\checkmark$ & $\checkmark$ \\
\hline u-OABA & $\checkmark$ & $\checkmark$ \\
\hline u-OABN & $\checkmark$ & $\checkmark$ \\
\hline u-OAEA & $\checkmark$ & $\checkmark$ \\
\hline u-OALN & $\times$ & $\checkmark$ \\
\hline u-OARN & $\times$ & $\checkmark$ \\
\hline u-OASA & $\checkmark$ & $\checkmark$ \\
\hline u-OASN & $\checkmark$ & $\checkmark$ \\
\hline u-OBAA & $\checkmark$ & $\checkmark$ \\
\hline u-OBAN & $\checkmark$ & $\checkmark$ \\
\hline u-OBBA & $\checkmark$ & $\checkmark$ \\
\hline u-OBEA & $\checkmark$ & $\checkmark$ \\
\hline u-OBLN & $\times$ & $\checkmark$ \\
\hline u-OBNG & $\checkmark$ & $\checkmark$ \\
\hline u-OBRN & $\times$ & $\checkmark$ \\
\hline u-OBSA & $\checkmark$ & $\checkmark$ \\
\hline u-OBSN & $\checkmark$ & $\checkmark$ \\
\hline u-OCNG & $\checkmark$ & $\checkmark$ \\
\hline u-OCOR & $\checkmark$ & $\checkmark$ \\
\hline u-OEAA & $\checkmark$ & $\checkmark$ \\
\hline u-OEBA & $\checkmark$ & $\checkmark$ \\
\hline u-OESA & $\checkmark$ & $\checkmark$ \\
\hline u-OIPM & $\times$ & $\checkmark$ \\
\hline u-OLAN & $\times$ & $\checkmark$ \\
\hline u-OLBN & $\times$ & $\checkmark$ \\
\hline u-OLLN & $\checkmark$ & $\checkmark$ \\
\hline u-OLNG & $\checkmark$ & $\checkmark$ \\
\hline u-OLRN & $\times$ & $\checkmark$ \\
\hline u-OLSN & $\times$ & $\checkmark$ \\
\hline u-OMMO & $\checkmark$ & $\checkmark$ \\
\hline u-OPPO & $\checkmark$ & $\checkmark$ \\
\hline u-ORAN & $\times$ & $\checkmark$ \\
\hline u-ORBN & $\times$ & $\checkmark$ \\
\hline u-ORLN & $\times$ & $\checkmark$ \\
\hline u-ORRN & $\checkmark$ & $\checkmark$ \\
\hline u-ORSN & $\times$ & $\checkmark$ \\
\hline u-OSAA & $\checkmark$ & $\checkmark$ \\
\hline u-OSAN & $\checkmark$ & $\checkmark$ \\
\hline u-OSBA & $\checkmark$ & $\checkmark$ \\
\hline u-OSBN & $\checkmark$ & $\checkmark$ \\
\hline u-OSEA & $\checkmark$ & $\checkmark$ \\
\hline u-OSLN & $\times$ & $\checkmark$ \\
\hline u-OSRN & $\times$ & $\checkmark$ \\
\hline u-OSSA & $\checkmark$ & $\checkmark$ \\
\hline u-OSSN & $\checkmark$ & $\checkmark$ \\
\hline \hline Total & $32 / 47$ & $47 / 47$ \\
\hline UD MAT & Oped \\
\hline
\end{tabular}

(d) Mutação de Operadores

\begin{tabular}{|l|}
\hline \multicolumn{1}{|c|}{ Legenda } \\
\hline$\checkmark-$ operadores aplicáveis \\
$\times-$ operadores não-aplicáveis \\
$\odot-$ operadores aplicáveis com modificações \\
$\rightarrow-$ operadores definidos \\
\hline
\end{tabular}


No caso de Java, não existe o conceito de variável global como na linguagem $\mathrm{C}$, ou seja, em Java existem somente atributos e variáveis locais. Toda variável em Java deve obrigatoriamente ser declarada dentro de uma classe. Assim sendo, o conjunto de variáveis globais para a linguagem Java é composto apenas dos atributos de uma classe e o conjunto de variáveis locais é composto das variáveis declaradas dentro de um método.

Feitas tais considerações, como pode ser observado na Tabela 4.1, todos os 80 operadores de unidade de $\mathrm{C}$ são aplicáveis no teste intra-método de programas $\mathrm{C}++$, o que é natural uma vez que $\mathrm{C}++$ é, na verdade, um super-conjunto de $\mathrm{C}$.

Para o teste de programas Java, observa-se que a maioria dos operadores também é diretamente aplicável (59 dos 80 operadores de mutação). Os demais 21 operadores, analisados em seqüência, são pertencentes às seguintes classes de mutação:

Mutação de comandos : 1 operador (u-SGLR);

Mutação de variáveis : 5 operadores ( $u$-VGPR, u-VGTR, u-VLPR, u-VLTR e uVSCR);

Mutação de operadores : 15 operadores (u-OALN, u-OARN, u-OBLN, u-OBRN, uOIPM, u-OLAN, u-OLBN, u-OLRN, u-OLSN, u-ORAN, u-ORBN, u-ORLN, uORSN, u-OSLN, u-OSRN).

\section{Análise e Definição de Novos Operadores para o Teste Intra-Método}

Nesta seção é realizada uma análise dos operadores de $\mathrm{C}$ que não são aplicáveis a programas Java. O objetivo é identificar operadores cuja semântica possa ser utilizada para o desenvolvimento de operadores de mutação adicionais.

\section{- Operadores de Mutação de Comandos}

O operador de mutação de comando u-SGLR é responsável pela troca de rótulos de comandos goto. Como Java não possui comandos goto esse operador não é diretamente aplicável a programas Java.

Entretanto, Java possui comandos break e continue com rótulos, comandos estes não presentes em $\mathrm{C}$ e $\mathrm{C}++$. Desse modo, é possível mapear o conceito desse operador para o teste intra-método de programas Java. Com isso, quatro outros operadores foram definidos:

- u-SBLR - break Label Replacement: Esse operador tem por objetivo substituir comandos break e comandos break rotulados (labeled break) por todos os demais comandos break e break rotulados válidos dentro de um bloco; 
- u-SCLR - continue Label Replacement: Esse operador tem por objetivo substituir comandos continue e comandos continue rotulados (labeled continue) por todos os demais comandos continue e continue rotulados válidos dentro de um bloco;

- u-SLBC - Labeled break By continue's Label Replacement: Esse operador troca o rótulo de cada comando break rotulado por todos os demais rótulos de comandos continue s válidos dentro de um bloco;

- u-SLCB - Labeled continue By break's Label Replacement: Esse operador troca o rótulo de cada comando continue rotulado por todos os demais rótulos de comandos break s válidos dentro de um bloco;

Como pode ser observado na Tabela 4.1, esses quatro novos operadores são específicos para o teste de programas Java, não sendo utilizados no teste de programas $\mathrm{C}++$.

\section{- Operadores de Mutação de Variáveis}

Considerando os operadores de mutação de variáveis, observa-se que cinco deles (u-VGPR, u-VGTR, u-VLPR, u-VLTR e u-VSCR) não são diretamente aplicáveis a Java. A justificativa é que esses operadores são específicos para a realização de mutação de ponteiros e registros (struct) existentes em $\mathrm{C}$ e $\mathrm{C}++$ mas não presentes em Java.

Entretanto, o conceito desses operadores pode ser mapeado para Java. No caso dos operadores u-VGPR e u-VLPR, embora Java não tenha variáveis tipo ponteiro, ela apresenta variáveis tipo referência; portanto, operadores de mutação específicos para realizar mutações em variáveis tipo referência podem ser desenvolvidos. Já no caso dos operadores u-VGTR, u-VLTR e u-VSCR, os quais se referem a struct, embora Java não apresente variáveis tipo estrutura, ela apresenta o conceito de classe (a qual pode ser vista como uma estrutura que contém os dados e funções de acesso a esses dados) de modo que o conceito desses operadores também pode ser mapeado para Java.

A partir desses operadores, como pode ser observado na Tabela 4.1, três novos foram definidos:

1. u-VGCR - Mutate Global Class References: Este operador foi definido a partir dos operadores u-VGPR e u-VGTR e é aplicado em variáveis de referência globais. Nesse operador, os tipos das variáveis são preservados de modo que somente variáveis de referência globais de tipos compatíveis são mutadas. 
2. u-VLCR - Mutate Local Class References: Este operador foi definido a partir dos operadores u-VLPR e u-VLTR e é é aplicado em variáveis de referência locais. Nesse operador, os tipos da variáveis são preservados de modo que somente variáveis de referência locais de tipos compatíveis são mutadas.

3. u-VCAR - Class Attributes Replacement: Este operador foi definido a partir do operador u-VSCR e é responsável pela mutação de referências a atributos de uma classe que são substituídas por referências aos demais atributos da mesma classe, respeitando os tipos dos atributos.

Observa-se que tais operadores podem ser também utilizados no contexto de $\mathrm{C}++$ uma vez que as estruturas sintáticas exigidas por esses operadores também estão presentes nessa linguagem.

\section{- Operadores de Mutação de Operadores}

Observa-se que os 15 operadores de mutação de unidade de C que não são aplicáveis a Java pertencem à classe de mutação de operadores.

A razão para isso é que ao contrário de $\mathrm{C}$ e $\mathrm{C}++$, toda expressão lógica em Java é do tipo booleana, ou seja, no comando abaixo, expression deve resultar em um valor boolean ou um erro de compilação é gerado. Tal característica reduz a ocorrência de enganos, tal como a utilização do símbolo "=" ao invés de "==" no teste de igualdade, limitando o número de operadores de mutação que podem ser utilizados em expressões lógicas.

\section{if (expression) statement}

Com a definição desses novos operadores considera-se que os desvios sintáticos mais comuns cometidos durante a codificação de métodos em Java e $\mathrm{C}++$ estão sendo modelados. Java passa a ter $59+7=66$ operadores e $\mathrm{C}++$ passa a ter $80+3=83$ operadores destinados ao teste intra-método.

Obviamente, quanto maior o número de operadores de mutação, mais mutantes são gerados e conseqüentemente, maior é o custo para a aplicação do critério no que se refere ao tempo de execução e análise dos mutantes vivos. Como foi mencionado anteriormente, além de estudos que visam a redução do custo de aplicação do teste de mutação por meio da utilização de critérios alternativos como a Mutação Aleatória (Randomly Selected X\% Mutation) (Acree et al., 1979), a Mutação Restrita (Constrained Mutation) (Mathur, 1991) e a Mutação Seletiva (Selective Mutation) (Offutt et al., 1993), destaca-se também os estudos que visam a determinação de Conjuntos Essenciais de Operadores de Mutação (Offutt et al., 1996a; Wong et al., 1997; Barbosa et al., 2001) e os estudos que visam 
a auxiliar na determinação de mutantes equivalentes (Harman et al., 2000; Hierons et al., 1999; Offutt e Craft, 1994; Offutt e Pan, 1996, 1997; Vincenzi et al., 2002).

Um ponto importante a ser observado é que dentre os operadores de mutação considerados essenciais para o teste de unidade em programas C (u-SWDD, u-SMTC, u-SSDL, u-OLBN u-ORRN, u-VTWD, u-VDTR, u-CGCR, u-CLCR, u-CGSR e u-CLSR), todos eles, exceto o u-OLBN no caso de Java, são também aplicáveis em programas Java e $\mathrm{C}++$, o que motiva a investigar se a mesma relação de inclusão entre esses operadores se mantém no teste de programas OO.

\subsubsection{Teste Inter-Método}

Ao contrário do teste intra-método, o teste inter-método visa a descobrir defeitos nas interfaces de comunicação entre os métodos. Ele pode ser considerado similar ao teste de integração em programas procedimentais.

Delamaro et al. (2001a) propuseram o critério Mutação de Interface que pode ser visto como uma extensão da Análise de Mutantes e preocupa-se em assegurar que as interações entre unidades sejam testadas. Assim, o objetivo do critério Mutação de Interface é inserir perturbações nas conexões entre duas unidades.

Utilizando o raciocínio do teste de mutação, casos de teste capazes de distinguir mutantes de interface também devem ser capazes de revelar grande parte dos defeitos de integração. Essa afirmação depende, evidentemente, de quais mutantes são utilizados ou, em outras palavras, quais operadores de mutação são aplicados (Delamaro et al., 2001a).

Segundo Haley e Zweben (1984), os erros de integração podem ser classificados em erros de integração de domínio ${ }^{1}$ e computacional. Dada uma função $f$ que chama $g$, o primeiro ocorre quando um erro de domínio em $g$ causa uma saída incorreta em $f$. O segundo ocorre quando um erro computacional em $g$ produz um valor incorreto que é passado para $f$ que, por sua vez, produz uma saída incorreta. Em ambos os casos existe algum valor incorreto sendo passado entre as unidades, o que resulta em uma saída incorreta. Considerando esses aspectos é possível classificar os erros de integração em três categorias.

Considere um programa $P$ e um caso de teste $t$ para $P$. Suponha que em $P$ existam funções $f$ e $g$ tal que $f$ chama $g$. Considere $S I(g)$ como o conjunto de valores passados para $g$ e $S O(g)$ os valores retornados por $g$. Ao executar $P$ com o caso de teste $t$, um erro de integração é identificado na chamada de $g$ a partir de $f$ quando (Delamaro et al., 2001a):

\footnotetext{
${ }^{1}$ Um erro de domínio ocorre quando um caminho incorreto é executado; um erro computacional ocorre quando o caminho correto é executado mas o valor computado é incorreto.
} 
- Erro Tipo 1 (Figura 4.1 (a)): os valores contidos em $S I(g)$ não são os esperados por $g$, influenciando a produção de saídas erradas antes do retorno de $g$. Esse tipo de erro ocorre, por exemplo, quando uma função é chamada com parâmetros incorretos fazendo com que a função chamada produza uma saída incorreta;

- Erro Tipo 2 (Figura 4.1 (b)): os valores contidos em $S I(g)$ não são os esperados por $g$, desse modo, $S O(g)$ assume valores errados fazendo com que $f$ produza uma saída incorreta após o retorno de $g$. Um erro desse tipo pode ocorrer, por exemplo, quando um parâmetro incorreto passado para a função é utilizado para calcular o valor de retorno; e

- Erro Tipo 3 (Figura 4.1 (c)): os valores contidos em $S I(g)$ são os esperados por $g$, mas valores incorretos em $S O(g)$ são produzidos dentro de $g$ e esses valores fazem com que $f$ produza um resultado incorreto após o retorno de $g$. Esse tipo de erro pode ocorrer se uma função é chamada com todos os parâmetros corretos, mas internamente ela realiza um cálculo incorreto produzindo um valor de retorno não esperado que, posteriormente, leva a um resultado incorreto.

Percebe-se que esta classificação dos tipos de erros é abrangente e não especifica o local do defeito que causa o erro. Ela simplesmente considera a existência de um valor incorreto entrando ou saindo de uma função chamada. Isso exclui, por exemplo, o caso em que $S I(g)$ tem os valores esperados mas um erro dentro de $g$ produz uma saída incorreta antes do retorno de $g$. Neste caso, não existe nenhuma propagação de erro entre a conexão $f-g$ e esse tipo de erro deveria ser detectado no teste de unidade.

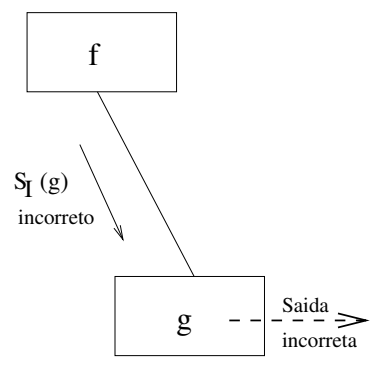

(a)

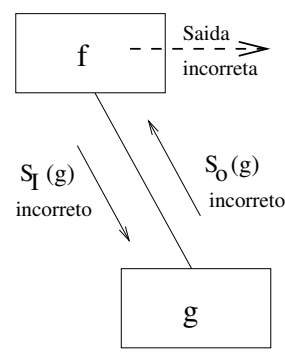

(b)

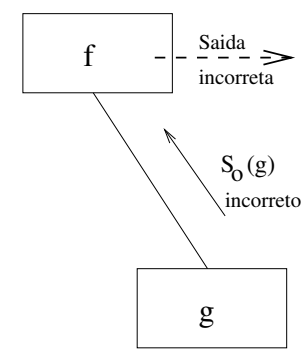

(c)

Figura 4.1: Tipos de erros de integração (Delamaro et al., 2001a): (a) Erro tipo 1, (b) Erro tipo 2, (c) Erro tipo 3.

Operadores de mutação destinados ao teste de unidade possuem semelhanças e diferenças em relação aos operadores de mutação destinados ao teste de integração. A idéia básica de ambos é a mesma, ou seja, introduzir modificações sintáticas no programa em teste transformando-o em programas similares: mutantes. Por outro lado, os operadores de mutação de interface estão relacionados a uma conexão entre duas unidades. Desse 
modo, os operadores, quando utilizados para testar uma conexão $f$ - $g$, são aplicados de dois modos diferentes: 1 ) nos pontos onde $f$ chama $g$; e 2) nos pontos dentro de $g$ relacionados com a interface de comunicação entre as unidades. No segundo caso é necessário um mecanismo adicional que permita identificar o ponto a partir do qual $g$ foi chamada. Visto que somente a conexão $f$ - $g$ está sendo testada, a mutação só deve estar ativa se $g$ foi chamada a partir de $f$. De outro modo, $g$ deve se comportar da mesma forma que no programa original. Essa característica pode requerer, em linguagens tais como C, que a decisão de aplicar ou não a mutação seja tomada em tempo de execução (Delamaro et al., 2001a).

Na definição dos operadores para C são utilizados os seguintes conjuntos, supondo-se que a Mutação de Interface está sendo aplicada na conexão entre as funções $f$ e $g$ :

$P(g)$ : é o conjunto dos parâmetros formais de $g$. Esse conjunto inclui também derreferências a parâmetros do tipo ponteiro ou vetor. Por exemplo, se um parâmetro formal $v$ é definido como "int *v", $v$ e "* $v$ " pertencem a esse conjunto ${ }^{2}$.

$G(g)$ : é o conjunto de variáveis globais utilizadas na função $g$.

$L(g)$ : é o conjunto de variáveis declaradas em $g$ (variáveis locais).

$E(g)$ : é o conjunto de variáveis globais não utilizadas em $g$.

$C(g)$ : é o conjunto de constantes utilizadas em $g$.

Para evitar confusão, os elementos do conjunto $G$ são chamados de "variáveis globais" e os do conjunto $E$ são chamados de "variáveis externas". Os elementos pertencentes aos conjuntos $P$ e $G$ são aqueles por meio dos quais valores podem ser passados para a função $g$ ou dela retornados, fazendo parte da interface da função. Assim, os elementos desses dois conjuntos são chamados de "variáveis de interface". Os elementos dos demais conjuntos são chamados de "variáveis não de interface e constantes".

Em adição, mais um conjunto é definido. O conjunto $R$ de "constantes requeridas" contém valores especiais, relevantes para alguns tipos primitivos de dados da linguagem C e operações associadas a esses tipos. A Tabela 4.2 sumariza essas constantes.

Observa-se que os conceitos apresentados nesta seção, relacionados ao teste de integração de programas procedimentais, podem ser facilmente mapeados para o contexto OO,

\footnotetext{
${ }^{2}$ Como a linguagem $\mathrm{C}$ faz passagem de parâmetros sempre por valor e a passagem por referência é simulada passando-se como valor o endereço da variável, incluiu-se no conjunto $P(g)$ a derreferenciação dos parâmetros ponteiros ou vetores de forma que esse tipo de interface seja exercitada de maneira completa.
} 
Tabela 4.2: Conjunto de constantes requeridas

\begin{tabular}{|l|l|}
\hline Tipo de variável & Constantes requeridas \\
\hline \hline $\begin{array}{l}\text { signed integer } \\
\text { signed char } \\
\text { signed long }\end{array}$ & $-1,1,0, M A X I N T, M I N I N T$ \\
\hline $\begin{array}{l}\text { unsigned integer } \\
\text { unsigned char } \\
\text { unsigned long } \\
\text { enum }\end{array}$ & $-1,1,0, M A X U N S I G N E D$ \\
\hline $\begin{array}{l}\text { float } \\
\text { double }\end{array}$ & $-1.0,1.0,0.0,-0.0$ \\
\hline $\begin{array}{l}\text { As constantes MAXINT, MININT e MAXUNSIGNED correspondem respectivamente ao maior } \\
\text { inteiro positivo, ao inteiro mais negativo e ao maior inteiro sem sinal. Esses valores são dependentes } \\
\text { de máquina e de tipos de dados. }\end{array}$ \\
\hline
\end{tabular}

considerando o teste inter-métodos. Basicamente, uma vez que a grande maioria dos operadores de interface baseiam-se nos conjuntos definidos acima para realizar as mutações, basta redefini-los considerando as linguagens $\mathrm{OO}$ em questão, Java e C++.

Novamente, no caso de $\mathrm{C}++$, tudo o que é válido em $\mathrm{C}$ continua sendo válido e resta apenas adicionar ao conjunto de variáveis globais $G(g)$ os atributos da classe utilizados pela função (método) $g$, e no caso do conjunto de variáveis externas $E(g)$ deve-se adicionar os atributos da classe não utilizados pela função (método) $g$.

Já para a linguagem Java, as variáveis globais podem ser vistas como os atributos de uma classe ou atributos estáticos e, desse modo, supondo que a mutação será aplicada na conexão entre dois métodos $f$ e $g$, a definição dos conjuntos para Java ficaria sendo:

$P(g)$ : é o conjunto dos parâmetros formais de $g$.

$G(g)$ : é o conjunto de variáveis globais utilizadas no método $g$.

$L(g)$ : é o conjunto de variáveis declaradas em $g$ (variáveis locais).

$E(g)$ : é o conjunto de variáveis globais não utilizadas em $g$.

$C(g)$ : é o conjunto de constantes utilizadas em $g$.

Além disso, o conjunto $R$ de "constantes requeridas" também é alterado como mostrado na Tabela 4.3.

Apresentadas tais definições, da mesma forma como no teste intra-método, fazendose uma análise dos operadores de mutação de interface definidos por Delamaro et al. (2001a), a Tabela 4.4 indica qual a possibilidade de aplicação de cada um considerando as linguagens Java e $\mathrm{C}++$. 
Como pode ser observado, por apresentar um nível de abstração maior, todos os 33 operadores de mutação de interface podem ser utilizados para viabilizar o teste intermétodo em programas $\mathrm{OO}$, considerando as linguagens $\mathrm{C}++$ e Java. Um ponto importante destacado por Binder (1999) e Ma et al. (2002) é que, em geral, a complexidade dos métodos em programas $\mathrm{OO}$ não é muito grande. A idéia é desenvolver métodos simples que, pela interação com outros métodos da mesma ou de outras classes, implementem a funcionalidade desejada. Nesse sentido, o teste de inter-métodos é de fundamental importância no teste de programas OO. Nesse sentido, considera-se que tal conjunto de operadores de mutação venha a trazer importantes contribuições no teste de programas OO, restando agora a realização de estudos empíricos para verificar os aspectos de custo, eficácia e dificuldade de satisfação desses operadores.

Tabela 4.3: Conjunto de constantes requeridas para Java

\begin{tabular}{|c|c|}
\hline Tipo de variável & Constantes requeridas \\
\hline byte & -1, 1, 0, Byte.MAX_VALUE, Byte.MIN_VALUE \\
\hline short & $-1,1,0$, Short.MAX_VALUE, Short.MIN_VALUE \\
\hline int & -1, 1, 0, Integer.MAX_VALUE, Integer.MIN_VALUE \\
\hline long & -1L, 1L, 0L, Long.MAX_VALUE, Long.MIN_VALUE \\
\hline float & -1.0f, 1.0f, 0.0f, -0.0f, Float.MAX_VALUE, Float.MIN_VALUE \\
\hline double & -1.0d, 1.0d, 0.0d, -0.0d, Double.MAX_VALUE, Double.MIN_VALUE \\
\hline char & 1, Character.MAX_VALUE, Character.MIN_VALUE \\
\hline boolean & true, false \\
\hline String & "", null \\
\hline Outros objetos & null \\
\hline \multicolumn{2}{|c|}{$\begin{array}{l}\text { tipo }>\text {.MAX_VALUE, <tipo }>\text {.MIN_VALUE correspondem respectivamente ao maior valor posi- } \\
\text { tivo e ao menor valor negativo do tipo de dado representado por }<\text { tipo }>\text {. Ao contrário de } \mathrm{C} \text { e } \\
\mathrm{C}++ \text {, em Java esses valores não são dependentes da plataforma. }\end{array}$} \\
\hline
\end{tabular}

Outro ponto importante a ser observado é que, da mesma forma como foi determinado o conjunto de operadores essenciais para o teste de unidade, Vincenzi et al. $(1999,2001)$ realizaram um experimento aplicando o procedimento Essencial (Barbosa et al., 2001) ao conjunto de operadores de mutação de interface considerando os dados coletados para 5 programas C utilitários do UNIX. Desse experimento, Vincenzi et al. (2001) chegaram a um subconjunto de 8 operadores (I-CovAllNod, I-DirVarBitNeg, I-IndVarBitNeg, I-IndVarRepExt, I-IndVarRepGlo, I-IndVarRepLoc, I-IndVarRepReq e II-ArgAriNeg) os quais compõem o conjunto essencial de operadores de mutação de interface. Para o experimento em questão, a utilização desse subconjunto resultou em uma redução de custo do critério Mutação de Interface superior a 73\% mantendo-se um escore de mutação em relação ao conjunto total de operadores de interface na ordem de 0,998 (Vincenzi et al., 2001). Tais resultados motivam reavaliar se os mesmos resultados se confirmam no teste de programas $\mathrm{OO}$. 
Tabela 4.4: Operadores de mutação de interface para o teste inter-método.

\begin{tabular}{|l|c|c|}
\hline \multicolumn{3}{|c|}{ Grupo-I } \\
\hline Operador & Java & C++ \\
\hline \hline I-CovAllEdg & $\checkmark$ & $\checkmark$ \\
\hline I-CovAllNod & $\checkmark$ & $\checkmark$ \\
\hline I-DirVarAriNeg & $\checkmark$ & $\checkmark$ \\
\hline I-DirVarBitNeg & $\checkmark$ & $\checkmark$ \\
\hline I-DirVarIncDec & $\checkmark$ & $\checkmark$ \\
\hline I-DirVarLogNeg & $\checkmark$ & $\checkmark$ \\
\hline I-DirVarRepCon & $\checkmark$ & $\checkmark$ \\
\hline I-DirVarRepExt & $\checkmark$ & $\checkmark$ \\
\hline I-DirVarRepGlo & $\checkmark$ & $\checkmark$ \\
\hline I-DirVarRepLoc & $\checkmark$ & $\checkmark$ \\
\hline I-DirVarRepPar & $\checkmark$ & $\checkmark$ \\
\hline I-DirVarRepReq & $\checkmark$ & $\checkmark$ \\
\hline I-IndVarAriNeg & $\checkmark$ & $\checkmark$ \\
\hline I-IndVarBitNeg & $\checkmark$ & $\checkmark$ \\
\hline I-IndVarIncDec & $\checkmark$ & $\checkmark$ \\
\hline I-IndVarLogNeg & $\checkmark$ & $\checkmark$ \\
\hline I-IndVarRepCon & $\checkmark$ & $\checkmark$ \\
\hline I-IndVarRepExt & $\checkmark$ & $\checkmark$ \\
\hline I-IndVarRepGlo & $\checkmark$ & $\checkmark$ \\
\hline I-IndVarRepLoc & $\checkmark$ & $\checkmark$ \\
\hline I-IndVarRepPar & $\checkmark$ & $\checkmark$ \\
\hline I-IndVarRepReq & $\checkmark$ & $\checkmark$ \\
\hline I-RetStaDel & $\checkmark$ & $\checkmark$ \\
\hline I-RetStaRep & $\checkmark$ & $\checkmark$ \\
\hline \hline Total & $24 / 24$ & $24 / 24$ \\
\hline
\end{tabular}

\begin{tabular}{|l|c|c|}
\hline \multicolumn{3}{|c|}{ Grupo-II } \\
\hline Operador & Java & C++ \\
\hline \hline II-ArgAriNeg & $\checkmark$ & $\checkmark$ \\
\hline II-ArgBitNeg & $\checkmark$ & $\checkmark$ \\
\hline II-ArgDel & $\checkmark$ & $\checkmark$ \\
\hline II-ArgIncDec & $\checkmark$ & $\checkmark$ \\
\hline II-ArgLogNeg & $\checkmark$ & $\checkmark$ \\
\hline II-ArgRepReq & $\checkmark$ & $\checkmark$ \\
\hline II-ArgSwiAli & $\checkmark$ & $\checkmark$ \\
\hline II-ArgSwiDif & $\checkmark$ & $\checkmark$ \\
\hline II-FunCalDel & $\checkmark$ & $\checkmark$ \\
\hline \hline Total & $9 / 9$ & $9 / 9$ \\
\hline \multicolumn{2}{|c|}{ (b) } \\
\end{tabular}

(a)

\begin{tabular}{|l|}
\hline \multicolumn{1}{|c|}{ Legenda } \\
\hline$\checkmark-$ operadores aplicáveis \\
$\times-$ operadores não-aplicáveis \\
$\odot-$ operadores aplicáveis com modificações \\
$\rightarrow-$ operadores definidos \\
\hline
\end{tabular}

\subsubsection{Teste Inter-Classe}

Conforme definido por Ma et al. (2002), no teste inter-classe o objetivo é identificar defeitos relacionados com características específicas de programas OO, tais como encapsulamento, herança, polimorfismo e acoplamento dinâmico.

O principal problema nesse contexto é a identificação de um modelo de defeitos adequado a partir do qual os operadores de mutação possam ser derivados. Ma et al. (2002) propuseram 24 operadores de mutação para o teste inter-classe de programas Java com base nos modelos de defeitos propostos por Offutt et al. (2001), Chevalley (2001) e Kim et al. (1999a, 2000a). Juntos, esses três modelos incluem os seguintes tipos de defeitos (Ma et al., 2002):

- Defeitos identificadas por Offutt et al. (2001):

- Anomalia na visibilidade do estado

- Inconsistência na definição do estado (devido à ocultação de variável de estado)

- Anomalia na definição do estado (devido a sobrecarga)

- Definição indireta de estado inconsistente 
- Comportamento de construção anômala

- Construção incompleta

- Uso de tipo inconsistente

- Defeitos identificadas por Kim et al. (1999a, 2000a):

- Uso incorreto de sobrecarga de métodos

- Uso incorreto de modificador de acesso

- Uso incorreto do modificador static

- Defeitos identificadas por Chevalley (2001):

- Implementação de métodos sobrecarregados incorreta

- Uso incorreto da palavra reservada super

- Uso incorreto da palavra reservada this

- Defeitos provenientes de enganos de programação comuns

Os operadores de mutação inter-classe de Ma et al. (2002) estão divididos em seis grupos:

1. Ocultação de informação (Information Hiding - Access Control) - 1 operador;

2. Herança (Inheritance) - 7 operadores;

3. Polimorfismo (Polymorphism) - 4 operadores;

4. Sobrecarga (Overloading) - 4 operadores;

5. Características específicas de Java (Java-Specific Features) - 4 operadores;

6. Enganos comuns de programação (Common Programming Mistakes) - 4 operadores.

Os quatro primeiros estão baseados em características comuns à maioria das linguagens OO. O quinto grupo inclui características específicas da linguagem Java e o último grupo é formado por operadores que representam enganos comuns quando se programa utilizando o paradigma OO. A Tabela 4.5 mostra o conjunto completo de operadores e a possibilidade de aplicação dos mesmos também na linguagem $\mathrm{C}++$. A primeira letra do nome do operador identifica a qual grupo ele pertence: A - Access Control, I - Inheritance, $\mathrm{P}$ Polymorphism, O - Overloading, J - Java-Specific Features e E - Common Programming Mistakes. 
Como era de se esperar, os operadores específicos para a linguagem Java não são aplicados a $\mathrm{C}++$, mas todos os demais operadores podem ser mapeados para $\mathrm{C}++$. Um ponto a ser observado é que $\mathrm{C}++$ é muito mais flexível do que Java e um conjunto de operadores de mutação adequado ao teste de programas $\mathrm{C}++$ deve ser muito mais abrangente do que esse. Por exemplo, dentre algumas características de $\mathrm{C}++$ não contempladas por esses operadores estão: herança múltipla, sobrecarga de operadores, funções friends e templates (Cornelius, 1997). A definição de operadores de mutação que contemple essas características adicionais da linguagem $\mathrm{C}++$ deve ser feita em breve, como continuidade dos trabalhos relacionados com esta tese.

Tabela 4.5: Operadores de mutação para o teste inter-classe.

\begin{tabular}{|l|c|c|}
\hline Operador & Java & C++ \\
\hline \hline AMC & $\checkmark$ & $\checkmark$ \\
\hline IHD & $\checkmark$ & $\checkmark$ \\
\hline IHI & $\checkmark$ & $\checkmark$ \\
\hline IOD & $\checkmark$ & $\checkmark$ \\
\hline IOP & $\checkmark$ & $\checkmark$ \\
\hline IOR & $\checkmark$ & $\checkmark$ \\
\hline ISK & $\checkmark$ & $\checkmark$ \\
\hline IPC & $\checkmark$ & $\checkmark$ \\
\hline PNC & $\checkmark$ & $\checkmark$ \\
\hline PMD & $\checkmark$ & $\checkmark$ \\
\hline PPD & $\checkmark$ & $\checkmark$ \\
\hline PRV & $\checkmark$ & $\checkmark$ \\
\hline OMR & $\checkmark$ & $\checkmark$ \\
\hline OMD & $\checkmark$ & $\checkmark$ \\
\hline OAO & $\checkmark$ & $\checkmark$ \\
\hline OAN & $\checkmark$ & $\checkmark$ \\
\hline JTD & $\checkmark$ & $\times$ \\
\hline JSC & $\checkmark$ & $\times$ \\
\hline JID & $\checkmark$ & $\times$ \\
\hline JDC & $\checkmark$ & $\times$ \\
\hline EOA & $\checkmark$ & $\checkmark$ \\
\hline EOC & $\checkmark$ & $\checkmark$ \\
\hline EAM & $\checkmark$ & $\checkmark$ \\
\hline EMM & $\checkmark$ & $\checkmark$ \\
\hline
\end{tabular}

\begin{tabular}{|l|}
\hline \multicolumn{1}{|c|}{ Legenda } \\
\hline$\checkmark-$ operadores aplicáveis \\
$\times$ - operadores não-aplicáveis \\
$\odot-$ operadores aplicáveis com modificações \\
$\rightarrow-$ operadores definidos \\
\hline
\end{tabular}

Ma et al. (2002) denominam o conjunto de operadores de mutação apresentado na Tabela 4.5 como sendo um conjunto abrangente (comprehensive set) em oposição aos definidos por Kim et al. (1999a, 2000a) que visaram à definição de um conjunto seletivo (ou essencial). A definição de um conjunto abrangente, embora leve a um aumento no custo de aplicação do critério, reduz a chance de que tipos de defeitos importantes deixem de ser contemplados, aumentando a eficácia do critério. Uma vez definido o conjunto mais abrangente, estudos empíricos podem ser realizados visando a determinação de um 
conjunto essencial. Essa é a idéia utilizada no desenvolvimento do procedimento Essencial (Barbosa et al., 2001) e motiva a investigar sua aplicação, visando a determinação do conjunto essencial de operadores de mutação de classe.

Além dos operadores para o teste inter-classe de programas Java apresentados na Tabela 4.5, outros conjuntos de operadores de mutação para o teste de características mais específicas da linguagem vêm sendo propostos, como por exemplo, os operadores para o teste de classes que implementam as interfaces Iterator, Collection e a classe abstrata InputStream propostos por Alexander et al. (2002) e os operadores para o teste de programas concorrentes Java, propostos por Delamaro et al. (2001b); estes últimos são descritos em mais detalhes na próxima seção.

\subsubsection{Operadores de Mutação para o Teste de Programas Concor- rentes}

Considerando o aspecto de concorrência em programas Java, Delamaro et al. (2001c) conduziram um estudo preliminar visando a avaliar a adequação do critério Mutação de Interface - destinado ao teste de integração para programas $\mathrm{C}$ - no teste de programas concorrentes em Java. Desse estudo, Delamaro et al. (2001c) verificaram que as características da linguagem Java, relacionadas com o aspecto de concorrência, não eram adequadamente cobertas pelos operadores de mutação de interface. Como conseqüência, Delamaro et al. (2001b) definiram um novo conjunto de operadores de mutação que modelam defeitos específicos de concorrência em programas Java. A seguir são descritas as principais dificuldades relacionadas ao teste de mutação em programas concorrentes; em seguida é apresentada uma breve revisão sobre o aspecto de concorrência em programas Java e, finalmente, são apresentados os operadores de mutação que modelam enganos típicos que podem ser cometidos quando se desenvolve programas concorrentes em Java.

\section{Dificuldades no Teste de Programas Concorrentes}

O teste de programas concorrentes traz uma complicação intrínseca devido ao não determinismo de sua execução o que, no caso do teste de mutação, dificulta a análise do comportamento do mutante. Uma vez que um programa em um contexto pode apresentar diferentes resultados corretos, o simples fato do mutante apresentar um resultado diferente do programa original para um caso de teste $t$ não representa necessariamente que $t$ revelou um defeito no mutante. A discrepância pode ser devida ao não determinismo e não devido ao defeito modelado pelo mutante. No teste de programas seqüenciais é possível confiar no fato de que existe somente uma saída correta para cada caso de teste. Os comandos 
são executados em uma ordem determinada que não é alterada de uma execução para outra, ou seja, não há não-determinismo.

Já a execução paralela ou concorrente de diversos processos (determinísticos) pode resultar em diferentes saídas corretas, dependendo da ordem de execução dos diferentes processos. Isso traz um problema para o teste de mutação no seguinte sentido: quando um mutante $M$ é executado com um caso de teste $t$ ele deveria ser morto se o seu comportamento não é o esperado de acordo com a especificação. No caso de um programa seqüencial isso é equivalente a dizer que o resultado da execução de $M$ com $t$ é diferente do resultado da execução de $P \operatorname{com} t$. No caso de programas concorrentes seria necessário comparar o conjunto de todos os possíveis resultados de $M$ com $t$ contra o conjunto de todos os possíveis resultados de $P$ com $t$ e então considerar $M$ como distinguido se esses conjuntos forem distintos. Infelizmente, em geral, não é possível determinar o conjunto completo de todos os resultados de um programa concorrente para um dado valor de entrada.

Offutt et al. (1996b) propuseram uma técnica que calcula um conjunto aproximado $\Omega$, definido como um subconjunto de todos os possíveis resultados de $\mathrm{P}(\mathrm{t})$ (programa $P$ executado com um caso de teste $t$ ). Esse conjunto é calculado executando-se $\mathrm{P}(\mathrm{t})$ diversas vezes. Um mutante $M$ é distinguido se ele produzir pelo menos um resultado $M(t) \notin \Omega$. Outra abordagem, chamada Análise de Mutantes Comportamental (Behavior Mutation Analysis - BMA), é definida por Silva-Barradas (1997). Uma instrumentação especial de um programa $P$ escrito em ADA pode ser utilizada para registrar a seqüência de execução de suas tarefas. Posteriormente, as seqüências armazenadas podem ser utilizadas para reproduzir o comportamento em uma execução subseqüente de $P(t)$. Incorporando essa seqüência de sincronização $s$ como parte do caso de teste, é esperado que $M(t, s)=P(t, s)$, ou seja, o resultado da execução de um mutante $M$ com $t$ reproduzindo a mesma seqüência de sincronização $s$ deveria ser o mesmo do programa original $P$.

A técnica BMA considera o mutante como distinguido se uma de duas condições é verificada: 1) $M(t, s) \neq P(t, s)$; ou 2) $M$ não pode reproduzir a seqüência de sincronização $s$. O segundo caso pode ocorrer, por exemplo, se o mutante elimina um comando que, quando executado, adiciona um evento à seqüência de sincronização. Neste caso, BMA considera que o mutante tem um comportamento incorreto (deadlock ou terminação anormal) e, desse modo, poderia ser distinguido.

Dentre essas técnicas, a proposta por Offutt et al. (1996b) é mais pragmática e mais simples de ser implementada, devendo ser utilizada inicialmente para viabilizar a aplicação dos critérios de teste baseados em mutação no teste de programas concorrentes. Posteriormente, a técnica proposta por Silva-Barradas (1997), que exige um maior esforço de programação, também deve ser implementada de modo que seja possível avaliar qual 
dessas técnicas permite a aplicação do teste de mutação em programas concorrentes de modo mais eficiente, maximizando a eficácia em revelar defeitos.

\section{Revisão sobre Concorrência em Java}

Basicamente, o mecanismo de sincronização de threads em Java consiste de métodos e blocos sincronizados (synchronized). Cada objeto em Java possui um monitor associado responsável por garantir que somente uma thread de cada vez tem acesso ao objeto. O trecho de código abaixo mostra um exemplo de método synchronized. Em um programa com duas ou mais threads compartilhando um objeto $X$ do tipo MyClass, somente uma de cada vez pode ter acesso o método myMethod utilizando tal objeto. O acesso ao método myOtherMethod não apresenta tal restrição. Desse modo, uma thread $T_{1}$ pode executar, por exemplo, myMethod com o objeto $X$ concorrentemente com uma thread $T_{2}$, executando myOtherThread utilizando o mesmo objeto $X$.

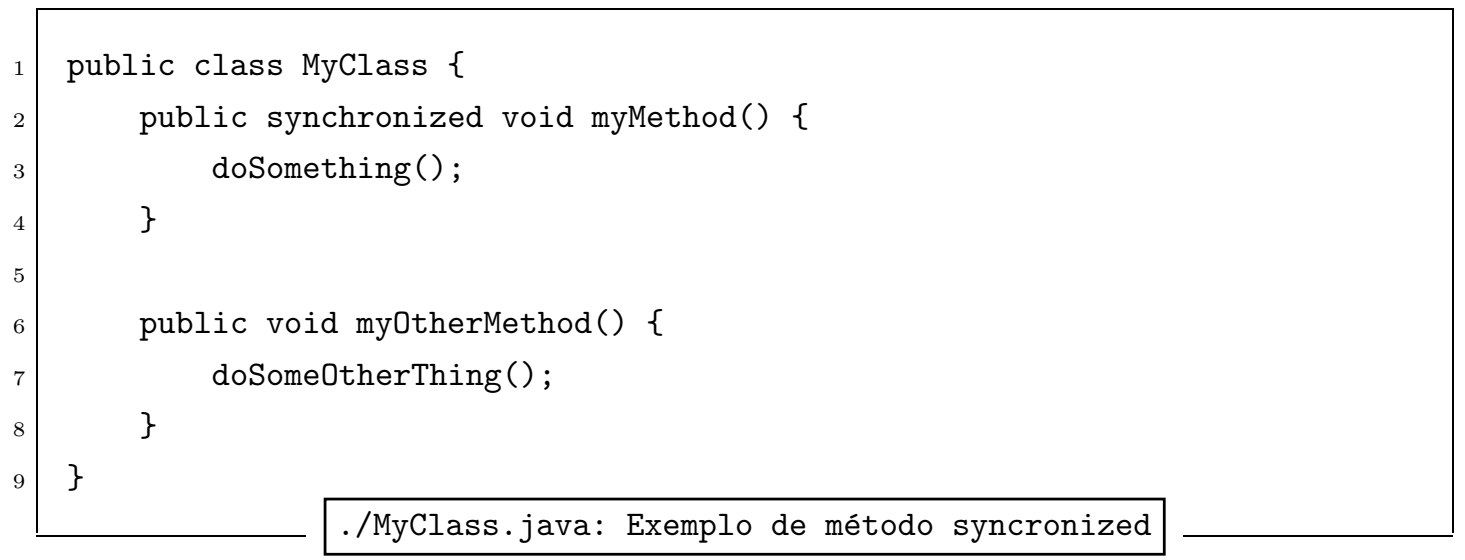

Se uma dada thread $T_{1}$ está executando um método synchronized de um dado objeto $X$ e outra thread $T_{2}$ tenta o acesso ao mesmo método synchronized de $X$, o sistema bloqueia a execução de $T_{2}$ até que $T_{1}$ termine a execução do método synchronized. Terminada a execução de $T_{1}, T_{2}$ pode executar, ou mais precisamente, $T_{2}$ pode competir para ganhar o acesso ao objeto, visto que outras threads também podem estar tentando fazer o mesmo. Quando uma thread $T_{1}$ obtém acesso a um método synchronized de um objeto $X$ é dito que $T_{1}$ bloqueou o monitor de $X$.

A Figura 4.2 ilustra um modelo em Redes de Petri que representa duas threads que compartilham um mesmo objeto $X$. O lugar chamado "Exec Normal" representa o estado de cada thread quando executando código não sincronizado em relação ao objeto de interesse $X$. Uma thread que deseje executar um método synchronized utilizando $X$ pode ir para o lugar "Contation", tentando bloquear o monitor caso este esteja disponível. Se estiver, o token (marca) é removido do lugar "Monitor" e fica retido pela thread durante 
o acesso ao recurso compartilhado (um método synchronized no exemplo) sendo liberado após o acesso ter sido concluído, permitindo que outra thread possa ter acesso ao recurso.

Blocos synchronized têm o mesmo comportamento de métodos synchronized, exceto que o código protegido é restrito a um trecho do código de um método (Delamaro et al., 2001b). Por exemplo, no trecho de código a seguir a thread deve obter primeiro monitor de myObject antes de executar doSomeOtherThing no método myOtherMethod.

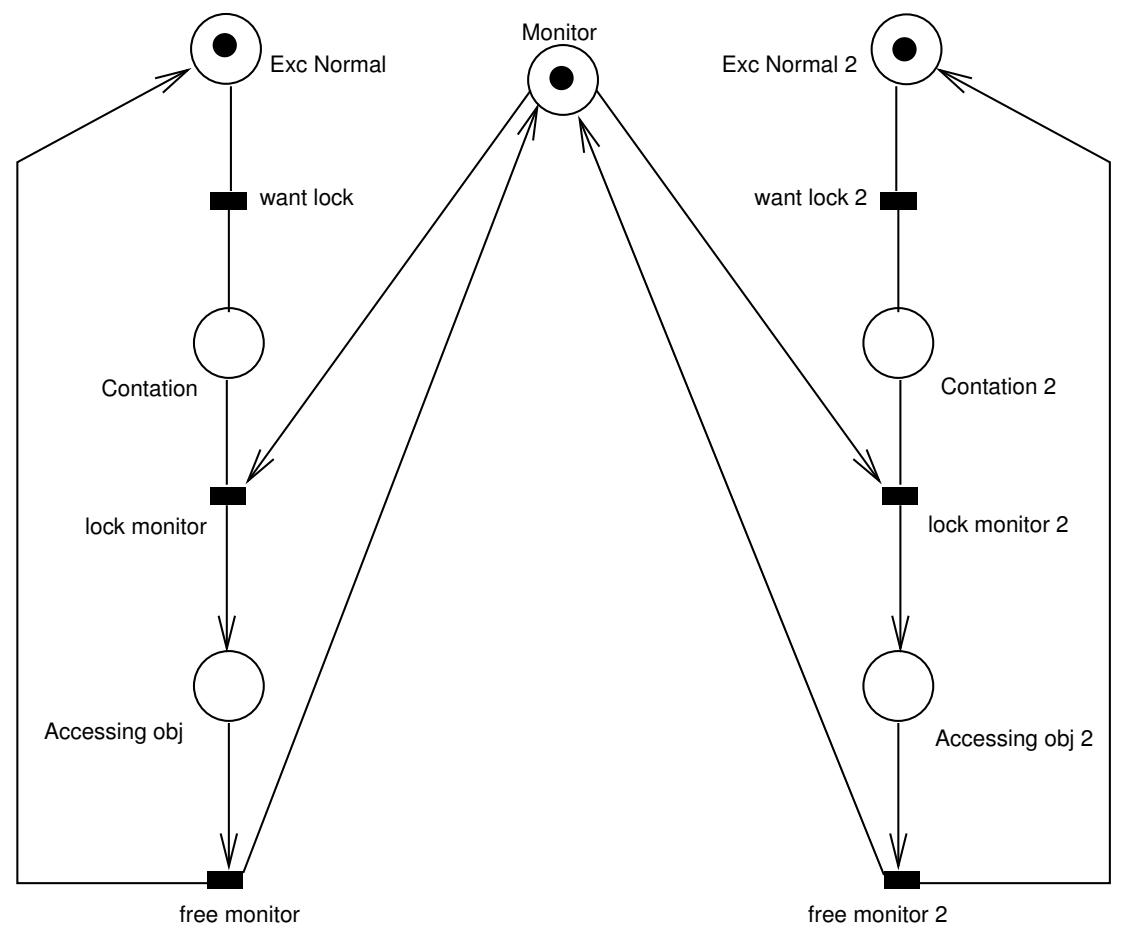

Figura 4.2: Modelo básico de duas threads compartilhando um objeto (Delamaro et al., 2001b).

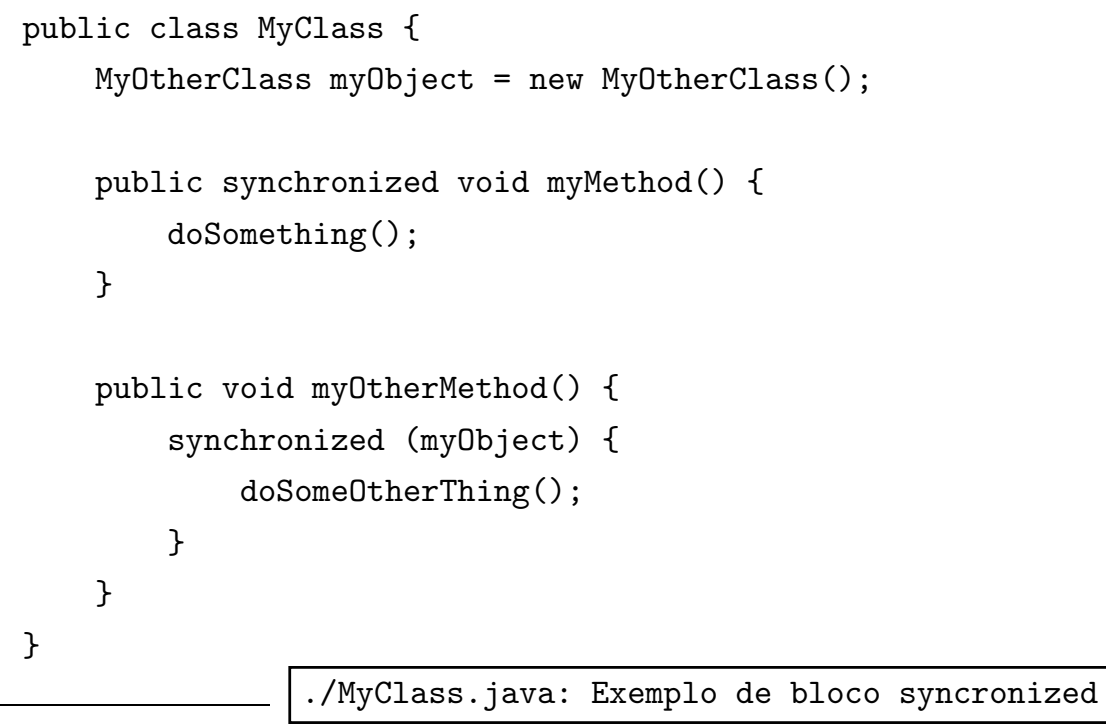


Considerando tal esquema, cada objeto criado pela Java Virtual Machine - JVM tem associado a ele um conjunto de espera (wait set). Um conjunto de espera permite que uma thread em posse de dado monitor disponibilize o monitor até que dado evento ocorra. A classe Object - raiz da hierarquia das classes de Java - define um método wait que disponibiliza o monitor do objeto sendo utilizado e insere a thread que tinha o acesso no conjunto de espera, bloqueando temporariamente sua execução. Para que uma thread possa invocar o método wait, é necessário que ela tenha posse do monitor do objeto, do contrário uma exceção é gerada.

A classe Object também declara um método denominado notify. A função desse método é "acordar" uma thread que foi posta no conjunto de espera. Quando o método notify é chamado em um objeto $X$, o conjunto de espera é consultado e uma das threads é aleatoriamente selecionada e removida do conjunto, tornando-se pronta para executar. Isso não significa que ela irá executar imediatamente. Primeiro porque para uma thread poder chamar o método notify ela deve estar de posse do monitor do objeto; com isso, a thread removida do conjunto de espera só poderá executar após a thread corrente liberar o monitor. Além disso, mesmo após a thread liberar o monitor, não é garantido que a thread removida do conjunto de espera adquira o monitor pois podem existir outras threads concorrendo entre si pelo mesmo monitor.

A thread removida do conjunto de espera irá continuar sua execução a partir do próximo comando após o wait que causou sua interrupção e seu estado é restaurado de acordo. A Figura 4.3 ilustra um modelo com duas threads compartilhando um objeto, incluindo a chamada para o método wait. Observe que o modelo torna-se significativamente mais complexo do que o apresentado na Figura 4.2.

Tanto o método wait quanto o método notify possuem variantes. No caso do método wait, este pode aceitar como argumento um valor de timeout. A semântica do método é similar à descrita acima, ou seja, após sua invocação a thread é inserida no conjunto de espera até que um chamada ao método notify a remova. A diferença é que se dentro do tempo especificado não ocorrer uma chamada ao método notify, a thread é removida automaticamente do conjunto de espera. No caso do método notify, sua variante é o método notifyAll que, quando invocado para um dado objeto $X$, remove todas as threads do conjunto de espera de $X$. Observa-se que existem outros métodos na API de Java que completam os recursos destinados a concorrência, dentre eles os métodos da classe Thread, responsáveis pela criação e gerenciamento de novas threads.

Desse modo, na construção de operadores de mutação que modelem defeitos relacionados ao aspecto de concorrência, são essas construções da linguagem que devem ser levadas em consideração. 


\section{Conjunto de Operadores de Mutação de Concorrência}

Com base na descrição apresentada acima sobre os aspecto de concorrência da linguagem Java, quatro grupos de estruturas de Java relacionadas foram identificados:

- Código de bloqueio do monitor (Monitor lock code);

- Métodos da API de Java relacionados com a manipulação de conjuntos de espera (Methods related to wait set manipulation that are defined in the Java core API;);

- Uso de métodos com sincronização (Use of synchronized methods); e

- Uso de outros métodos relacionados com sincronização e concorrência (Use of other methods related to synchronization and concurrency).

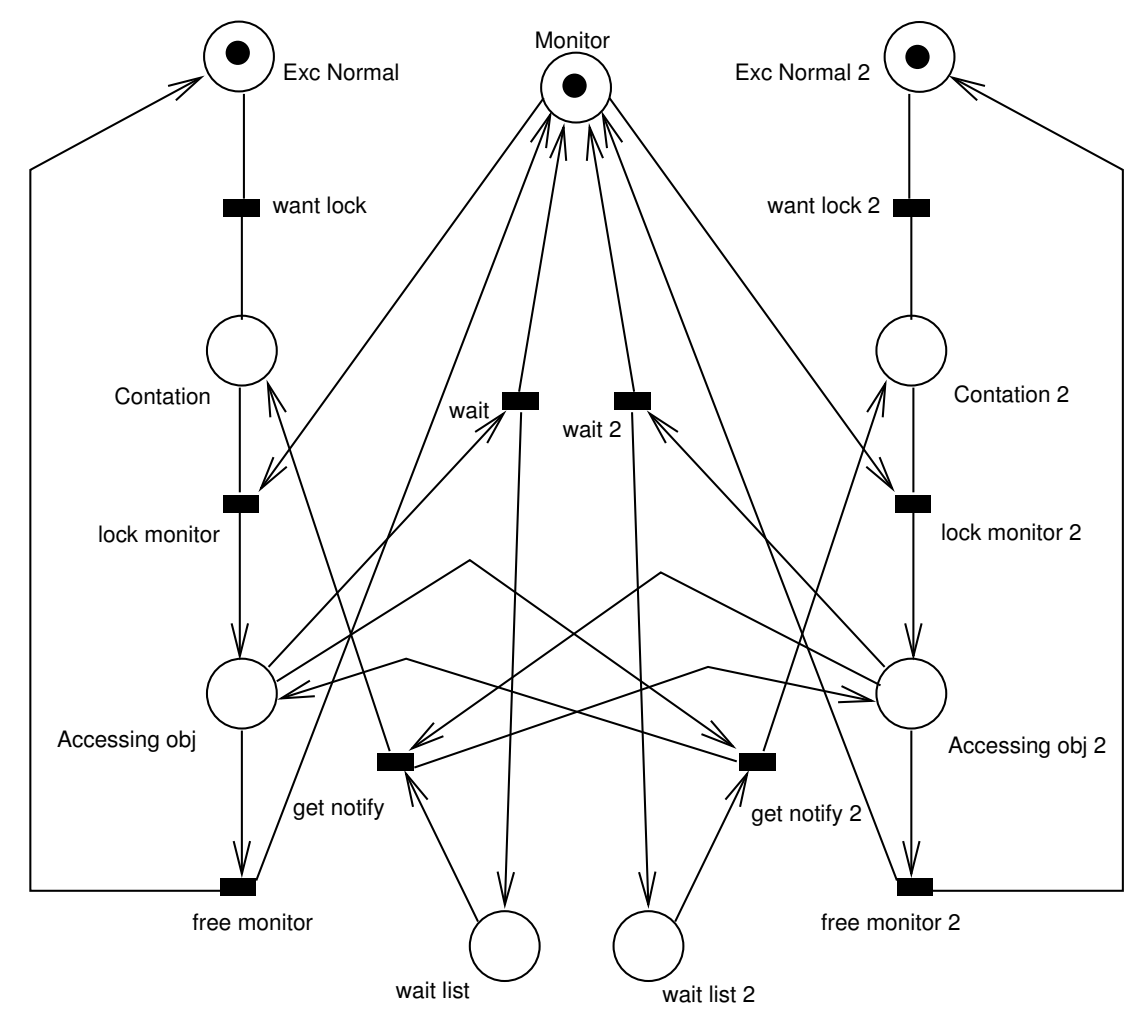

Figura 4.3: Modelo de duas threads compartilhando um objeto, incluindo os conjuntos de espera (wait sets) (Delamaro et al., 2001b).

A título de ilustração, a Tabela 4.6 apresenta uma breve descrição dos operadores que foram definidos por Delamaro et al. (2001b) relacionando as características de concorrência cobertas pelos mesmos. Informações mais detalhadas a respeito dos operadores de mutação podem ser encontradas em (Delamaro et al., 2001b).

Esse conjunto de operadores de mutação visa a modelar a maior parte dos defeitos relacionados com o uso de características de concorrência e sincronização da linguagem 
Java, preocupando-se em manter o custo do critério não muito elevado, restringindo o número de operadores e mutantes que eles podem gerar.

Tabela 4.6: Conjunto de Operadores de Mutação de Concorrência para Java (Delamaro et al., 2001b).

\begin{tabular}{|c|c|c|}
\hline Operador & Descrição & $\begin{array}{l}\text { Característica de Concorrência Rela- } \\
\text { cionada }\end{array}$ \\
\hline DelSync & $\begin{array}{l}\text { Remove o atributo synchronized da decla- } \\
\text { ração de um método ou remove um co- } \\
\text { mando synchronized }\end{array}$ & $\begin{array}{l}\text { Bloqueio do monitor - cobertura de méto- } \\
\text { dos sincronizados }\end{array}$ \\
\hline DelStat & $\begin{array}{l}\text { Remove um comando dentro de um método } \\
\text { ou bloco synchronized }\end{array}$ & $\begin{array}{l}\text { Bloqueio do monitor - cobertura de coman- } \\
\text { dos de um método ou bloco sincronizado }\end{array}$ \\
\hline MoveBrace & Move $\{$ e $\}$ para cima e para baixo & $\begin{array}{l}\text { Bloqueio do monitor - verifica os limites de } \\
\text { um comando sincronizado }\end{array}$ \\
\hline ReplSyncObject & Troca objetos de sincronização & $\begin{array}{l}\text { Bloqueio do monitor - verifica se a expres- } \\
\text { são correta está sendo utilizada }\end{array}$ \\
\hline DelWait & Remove a chamada ao método wait & $\begin{array}{l}\text { Conjuntos de espera - verifica a relevância } \\
\text { de cada chamada ao método wait }\end{array}$ \\
\hline ReplWait & $\begin{array}{l}\text { Troca a chamada de um método wait tem- } \\
\text { porizado por uma chamada ao método wait } \\
\text { não temporizado e vice-versa }\end{array}$ & $\begin{array}{l}\text { Conjuntos de espera - exercita os aspectos } \\
\text { temporais do programa }\end{array}$ \\
\hline IncrDecrWait & $\begin{array}{l}\text { Incrementa e decrementa o argumento para } \\
\text { métodos wait temporizados }\end{array}$ & $\begin{array}{l}\text { Conjuntos de espera - exercita os aspectos } \\
\text { temporais do programa }\end{array}$ \\
\hline DelNotify & $\begin{array}{l}\text { Remove a chamada ao método notify ou } \\
\text { notifyAll }\end{array}$ & $\begin{array}{l}\text { Conjuntos de espera - verifica a relevância } \\
\text { de cada chamada dos métodos notify e no- } \\
\text { tifyAll }\end{array}$ \\
\hline ReplNotify & $\begin{array}{l}\text { Troca a chamada de um método notify por } \\
\text { uma chamada ao método notifyAll e vice- } \\
\text { versa }\end{array}$ & $\begin{array}{l}\text { Conjuntos de espera - verifica os aspectos } \\
\text { de sincronização do programa }\end{array}$ \\
\hline ReplArg & $\begin{array}{l}\text { Troca o argumento de uma chamada para } \\
\text { um método synchronized por uma cons- } \\
\text { tante }\end{array}$ & $\begin{array}{l}\text { Chamada a métodos sincronizados - veri- } \\
\text { fica a correção dos argumentos nas chama- } \\
\text { das dos métodos sincronizados }\end{array}$ \\
\hline DelSyncCall & $\begin{array}{l}\text { Remove a chamada a um método synchro- } \\
\text { nized }\end{array}$ & $\begin{array}{l}\text { Chamada a métodos sincronizados - veri- } \\
\text { fica a cobertura das chamadas a métodos } \\
\text { sincronizados }\end{array}$ \\
\hline SwitchArg & $\begin{array}{l}\text { Troca os argumentos de uma chamada para } \\
\text { um método synchronized }\end{array}$ & $\begin{array}{l}\text { Chamada a métodos sincronizados - veri- } \\
\text { fica a correção dos argumentos nas chama- } \\
\text { das a métodos sincronizados }\end{array}$ \\
\hline ReplMeth & $\begin{array}{l}\text { Troca chamada a método sincronizado por } \\
\text { outra utilizando métodos com mesmo nome } \\
\text { e assinaturas diferentes }\end{array}$ & $\begin{array}{l}\text { Chamada a métodos sincronizados - veri- } \\
\text { fica a correção das chamadas a métodos sin- } \\
\text { cronizados }\end{array}$ \\
\hline InsNegArg & $\begin{array}{l}\text { Insere operador unário (negação) em um ar- } \\
\text { gumento }\end{array}$ & $\begin{array}{l}\text { Chamada a métodos sincronizados - veri- } \\
\text { fica a correção dos argumentos nas chama- } \\
\text { das a métodos sincronizados }\end{array}$ \\
\hline ReplTargObj & $\begin{array}{l}\text { Troca o objeto destino utilizado na cha- } \\
\text { mada ao método synchronized }\end{array}$ & $\begin{array}{l}\text { Chamada a métodos sincronizados - veri- } \\
\text { fica a correção das chamadas aos métodos } \\
\text { sincronizados }\end{array}$ \\
\hline
\end{tabular}

A implementação de uma ferramenta de teste que apóie a aplicação do teste de mutação em programa concorrentes está em desenvolvimento. Observe que, nesse caso, é necessário implementar um mecanismo que permita decidir quando distinguir um mutante do programa original. A característica intrínseca de não-determinismo em programas concorrentes faz com que a execução de um programa com um dado valor de entrada possa produzir diferentes saídas corretas. Num primeiro momento, pretende-se utilizar a abordagem proposta por Offutt et al. (1996b) por ser mais pragmática e de fácil implementação. Posteriormente, outras formas de implementação, considerando outras técnicas, como a 
sugerida por Silva-Barradas (1997), podem ser implementadas e comparadas de modo a obter a que traga a melhor relação custo/benefício.

Observe-se que, além de operadores específicos para o teste de programas concorrentes, outras características de Java permitem que outros operadores de mutação sejam definidos, visando a modelar defeitos mais específicas. Por exemplo, podem ser definidos operadores de mutação específicos para modelar defeitos relacionadas ao uso incorreto das estruturas de tratamento de exceções, classes relacionadas a conexão com bando de dados (JDBC), dentre outras. Com isso, dependendo da aplicação sendo testada, o testador pode decidir quais operadores de mutação utilizar de modo a maximizar a detecção de defeitos com um menor custo.

\subsection{Análise de Propriedades}

Da mesma forma como realizado com os critérios de fluxo de controle e de dados, nas duas seções a seguir são discutidas duas das propriedades dos critérios baseados em mutação: análise de inclusão e análise de complexidade.

\subsubsection{Análise de Inclusão}

Do ponto de vista teórico, tanto os critérios de teste de mutação entre si quanto os critérios de teste de mutação em relação a critérios de fluxo de dados são incomparáveis de acordo com a relação de inclusão (Frankl e Weyuker, 1993b; Delamaro et al., 2001a; Zhu et al., 1997). Assim sendo, estudos empíricos vêm sendo realizados de modo a comparar a adequação de conjuntos de teste entre esses critérios.

Considerando os operadores de mutação de unidade, descritos na Seção 4.3.1 e apresentados na Tabela 4.1, Mathur e Wong (1994) conduziram um experimento para verificar a dificuldade de satisfação entre os Análise de Mutantes e Todos-Usos, bem como seus custos, uma vez que esses critérios são incomparáveis do ponto de vista teórico. Nesse estudo, os conjuntos de teste Análise de Mutantes-adequados também se mostraram Todos-Usos-adequados. No entanto, os conjuntos de teste Todos-Usos-adequados não se mostraram, em muitos dos casos, adequados para o critério Análise de Mutantes. Esses resultados demonstram que é mais difícil satisfazer o critério Análise de Mutantes do que o critério Todos-Usos, podendo-se dizer que, na prática, a Análise de Mutantes inclui Todos-Usos (Mathur e Wong, 1994).

Nessa mesma linha de pesquisa, Souza (1996) realizou um estudo empírico com a finalidade de avaliar o strength e o custo do critério Análise de Mutantes empregando, para efeito comparativo, os critérios Potenciais Usos (Maldonado, 1991), os quais incluem 
o critério Todos-Usos. Os resultados demonstraram que o custo de aplicação do critério Análise de Mutantes, estimado pelo número de casos de teste necessário para satisfazer o critério, apresentou-se maior do que o custo dos critérios Potenciais-Usos. Em relação à dificuldade de satisfação (strength) observou-se que, de uma maneira geral, os critérios Análise de Mutantes e Todos-Potenciais-Usos são incomparáveis mesmo do ponto de vista empírico.

Com respeito ao teste de mutação para o teste de integração descritos na Seção 4.3.2 e apresentados na Tabela 4.4, Delamaro et al. (2001a) destaca que, a exemplo do que ocorre em nível de unidade, os critérios Mutação de Interface e os critérios de fluxo de dados de integração são incomparáveis (Delamaro et al., 2001a). Segundo Delamaro et al. (2001a), esse resultado é importante porque aponta para os aspectos complementares, já ressaltados em nível de unidade, entre os critérios baseados em fluxo de dados e critérios baseados em mutação e sugere a utilização conjunta desses critérios na atividade de teste tanto em nível de unidade quanto de integração.

Além disso, considerando somente os critérios de teste baseados em mutação, um estudo empírico realizado por Vincenzi et al. (2001) utilizando cinco programas utilitários do UNIX demonstrou que os critérios Análise de Mutantes e Mutação de Interface são incomparáveis do ponto de vista da relação de inclusão, ou seja, um conjunto de teste Análise de Mutantes-adequado não é adequado para o critério Mutação de Interface e vice-versa, fornecendo evidências de que os mesmos devem ser utilizados em conjunto para uma máxima detecção de defeitos no produto sendo testado.

Em relação aos operadores de mutação destinados ao teste inter-classe, - descritos na Seção 4.3.3 e apresentados na Tabela 4.5 -, observa-se que ainda não existem estudos de análise de inclusão nesse contexto. Entretanto, visto que cada conjunto de operadores de mutação visa a modelar defeitos específicos relacionados a cada fase de teste, embora possa existir alguma sobreposição de alguns operadores entre esses diferentes conjuntos, é improvável que um conjunto de teste adequado para um determinado conjunto seja também adequado para outro, destinado a outra fase de teste. Tais observações são feitas com base em experiências anteriores na avaliação da inclusão entre os operadores de mutação de unidade e de interface (Vincenzi et al., 2001). No entanto, faz-se necessária a realização de estudos teóricos e empíricos para confirmar tais hipóteses.

Considerando os operadores destinados ao teste de concorrência, pode-se dizer que estes também se mostram incomparáveis do ponto de vista da relação de inclusão se comparados, por exemplo, com os operadores de Mutação de Interface. Tal observação foi feita por Delamaro et al. (2001c) com base nos dados de um estudo piloto que precedeu a definição dos operadores de concorrência. O estudo piloto objetivava avaliar a adequação dos operadores de mutação de interface, adaptados para a linguagem Java, no teste 
de programas concorrentes. Entretanto, conjuntos de teste adequados aos operadores de interface não foram capazes de cobrir características (tanto funcionais quanto estruturais) relacionadas com os aspectos de concorrência, de modo que um defeito existente não seria revelado (Delamaro et al., 2001c). Além disso, a comparação de operadores de concorrência com os operadores convencionais é ainda mais difícil, pois, como destacado por Silva-Barradas (1997), a utilização dos operadores de concorrência pressupõe a existência de não determinismo e de uma forma de se compararem os resultados dos mutantes, utilizando-se, por exemplo, seqüências de sincronização. Fatores estes não presentes no teste de mutação convencional, caracterizando duas técnicas de mutação distintas, embora baseadas nos mesmos princípios.

\subsubsection{Análise de Complexidade}

O teste de mutação tem demonstrado ser bastante eficaz em revelar defeitos quando comparado com outros critérios de teste de cobertura, tanto no teste de unidade quanto no teste de integração de programas procedimentais (Wong et al., 1994b; Wong e Mathur, 1995b; Offutt et al., 1996a; Delamaro et al., 2001a). Entretanto, apesar de sua eficácia, o teste de mutação é considerado de alto custo computacional devido, principalmente, ao grande número de mutantes que são criados e precisam ser executados e, posteriormente, analisados para identificar os mutantes equivalentes. Para o teste de mutação, ao invés do número e casos de teste necessários para satisfazer o critério, tem-se utilizado o número de mutantes gerados como um indicador de complexidade. Obviamente, esse número depende do conjunto de operadores de mutação utilizado.

Teste Intra-Método: Diversas fórmulas têm sido desenvolvidas visando a definir analiticamente a complexidade do teste de mutação, considerando os operadores de unidade. Uma delas define a complexidade do critério Análise de Mutantes como sendo $O\left(N^{2}\right)$, onde $N$ é o número de linhas de código. Dentre os operadores de mutação de unidade que mais geram mutantes estão aqueles que são aplicados sobre ocorrências de variáveis no programa. A partir disso, Budd (Budd, 1980) determinou que o número esperado de mutantes é proporcional ao número de variáveis do programa $(V a l s)$ vezes o número de referências às variáveis (Defs), ou seja, $O($ Vals $*$ Defs $)$. Essa aproximação, reconhecidamente grosseira, tem sido adotada por outros pesquisadores (como por exemplo Offutt et al. (1996a)) e pode ser usada como medida de custo (complexidade) para o critério (Delamaro, 1997).

Teste Inter-Método: Quanto ao critério Mutação de Interface, em estudos realizados por Delamaro (1997), observou-se que o número de mutantes gerados pelos operadores de interface é determinado, principalmente, pelo número de variáveis vezes o 
número de referências a essas variáveis, assim como ocorre com o critério Análise de Mutantes, e pelo número de parâmetros formais da função chamada. Como ressalta Delamaro (1997), apesar dos pontos de aplicação dos operadores de Mutação de Interface serem limitados a pontos relacionados com uma conexão, a quantidade de mutantes gerados pode ser elevada, revelando a necessidade de adoção de abordagens alternativas que restrinjam o número de mutantes.

Teste Inter-Classe: No que se refere aos operadores de classe, Ma et al. (2002) ressaltam que a fórmula de complexidade que prevalece é dependente das características de cada programa. Entretanto, de modo geral, considerando todos os operadores de mutação de classe definidos, Ma et al. (2002) concluíram que a complexidade dos operadores para o teste inter-classe é da ordem de $O(N M * C M)$, onde $N M$ o número de métodos modificadores (set) e de acesso (get) e $C M$ o número de chamadas a esses métodos, resultados estes também obtidos por Chevalley (2001) em um estudo de caso desenvolvido avaliando a complexidade dos operadores de mutação por eles definidos.

Operadores de Concorrência: Considerando os operadores de concorrência definidos por Delamaro et al. (2001b) e apresentados na Tabela 4.6, observa-se que o número de mutantes gerados a partir de cada operador também é dependente das características e da quantidade de recursos relacionados ao aspecto de concorrência utilizados.

Seja $N_{m s}$ o número de métodos sincronizados, $N_{b s}$ o número de blocos sincronizados, $N_{s t}$ o número de comando em um bloco ou método sincronizado, $N_{o b}$ o número de objetos que apresentam recursos de sincronização. Além disso, considere $l v$ o número de variáveis locais, $f p$ o número de parâmetros formais, $s f$ o número de atributos estáticos e if o número de atributos de instância do tipo referência válidos escopo de um bloco sincronizado. Denota-se por mutantes $(o p)$ o número de mutantes gerados por um determinado operador op. Com isso, o número de mutantes gerados pelos operadores relacionados com o bloqueio do monitor é dado por:

- mutantes $($ DelSync $)=N_{m s}+N_{b s}$

- mutantes $($ DelStat $)=N_{s t} *\left(N_{m s}+N_{b s}\right)$

- mutantes $($ MoveBrace $)=4 * N_{b s}$

- mutantes $($ ReplSyncObject $)=(l v+f p+s f+i f) * N_{b s}$

Em relação aos operadores pertencentes ao conjunto de espera, seja $N_{w}$ o número de chamadas a métodos wait não temporizados, $N_{w t}$ o número de chamadas a 
métodos wait temporizados, $N_{n}$ o número de chamadas a métodos notify e $N_{n a}$ o número de chamadas a métodos notifyAll. O número de mutantes gerados por esses operadores é:

- mutantes $($ DelWait $)=N_{w}+N_{w t}$

- $\operatorname{mutantes}($ ReplWait $)=N_{w}+N_{w t}$

- mutantes $($ IncrDecrWait $)=2 * N_{w t}$

- mutantes $($ DelNotify $)=N_{n}+N_{n a}$

- mutantes $($ ReplNotify $)=N_{n}+N_{n a}$

Para o cálculo do número de mutantes gerados pelos operadores de mutação de chamadas a métodos sincronizados, considere $N_{c s}$ o número de chamadas a métodos sincronizados e $N_{\text {arg }}$ o número de argumentos de um método sincronizados. Tem-se que:

- mutantes $(\operatorname{ReplArg})=5 * N_{c s} * N_{\text {arg }}$

- mutantes $($ DelSyncCall $)=N_{c s}$

- mutantes $($ SwitchArg $)=\left(\left(N_{\text {arg }}-1\right) * N_{\text {arg }}\right) * N_{c s}$

- mutantes $($ ReplMeth $)=N_{n}+N_{n a}$

- mutantes $($ InsNegArg $)=2 * N_{c s} * N_{\text {arg }}$

- mutantes $(\operatorname{ReplTargObj})=(l v+f p+s f+i f) * N_{c s}$

Com base nas fórmulas definidas acima e considerando que as características de concorrência podem ser avaliadas por meio do número de blocos e métodos synchronized, dados por $N_{b s}$ e $N_{m s}$, respectivamente, pode-se estabelecer um limitante superior para o número de mutantes gerados como sendo de $N_{s t} *\left(N_{m s}+N_{b s}\right)$, ou seja, a complexidade dos operadores de mutação de concorrência é $O(N)$ onde $N$ corresponde ao número de comandos em métodos e blocos sincronizados.

Embora o teste de mutação leve à geração de um grande número de mutantes, é possível reduzir significativamente o custo de sua aplicação com o desenvolvimento de estratégias alternativas as quais visam, principalmente, utilizar apenas parte dos operadores de mutação e mesmo assim manter uma alta eficácia em relação ao conjunto completo de operadores. 


\subsubsection{Estabelecendo uma Estratégia Incremental}

Com base em experiências anteriores considerando a aplicação do teste de mutação em programas C (Vincenzi, 1998), tanto para o teste de unidade quanto para o teste de integração, e tendo em vista que um dos maiores problemas relacionados ao teste de mutação está relacionado ao grande número de mutantes gerados, Vincenzi et al. (2001) realizam um experimento visando a definição de algumas estratégias de teste para a aplicação incremental dos operadores de mutação de unidade e de integração, de modo a identificar subconjuntos de operadores que levem a geração de conjuntos de teste adequados em relação a todos os operadores destinados a cada fase de teste. O experimento é dividido em duas fases. Na primeira fase, os critérios Análise de Mutantes (Análise de Mutantes) e Mutação de Interface (Mutação de Interface) são avaliados individualmente. A idéia é minimizar o custo de aplicação desses critérios, considerando o utilização de cada um em isolado. Duas estratégias de teste são definidas a partir dos conjuntos essenciais de unidade e de integração: uma denominada Sufficient Incremental Unit Testing Strategy (SUS), destinada ao teste de unidade, e outra denominada Sufficient Incremental Interface Testing Strategy (SIS), destinada ao teste de integração. Na segunda fase, os resultados obtidos da primeira fase são combinados visando a verificar qual é a redução no custo dos critérios se um conjunto de teste Mutação de Interface-adequado é obtido a partir de um conjunto Análise de Mutantes-adequado. Nesse contexto, outras estratégias de teste são definidas definidas, dentre elas a Unit-Interface Incremental Testing Strategy (U-IS), que visa a obtenção de um conjunto de teste Mutação de Interface-adequado a partir de um conjunto de teste Análise de Mutantes-adequado, e a Sufficient Unit-Interface Incremental Testing Strategy (SU-IS), que determina conjunto de teste com um alto escore de mutação utilizando somente os conjuntos de operadores essenciais de mutação de unidade e de integração.

A Figura 4.4 ilustra as possíveis seqüências para a aplicação dos critérios Análise de Mutantes e Mutação de Interface de modo incremental. As linhas sólidas correspondem a aplicação da estratégia $S U S$ seguida da estratégia $S I S$, resultando em conjuntos de teste adequados para ambos os critérios de teste.

Por outro lado, se um conjunto de teste MI-adequado deve ser obtido a partir de um conjunto AM-adequado a estratégia de teste $U$-IS é uma possibilidade. O testador deveria seguir as linhas sólidas da Figura 4.4: (1) aplicar os operadores do conjunto essencial de unidade (AM-ess), obtendo um conjunto de teste AM-ess-adequado; (2) aplicar os demais operadores de unidade, respeitando a ordem estabelecida pela estratégia $S U S$, até que um conjunto AM-adequado seja obtido; (3) aplicar os operadores do conjunto essencial de interface (MI-ess) e complementar o conjunto AM-adequado até torná-lo MI-ess-adequado; 
e (4) aplicar os demais operadores, conforme definido pela estratégia $U$ - $I S$, até que o conjunto de teste MI-adequado seja obtido.

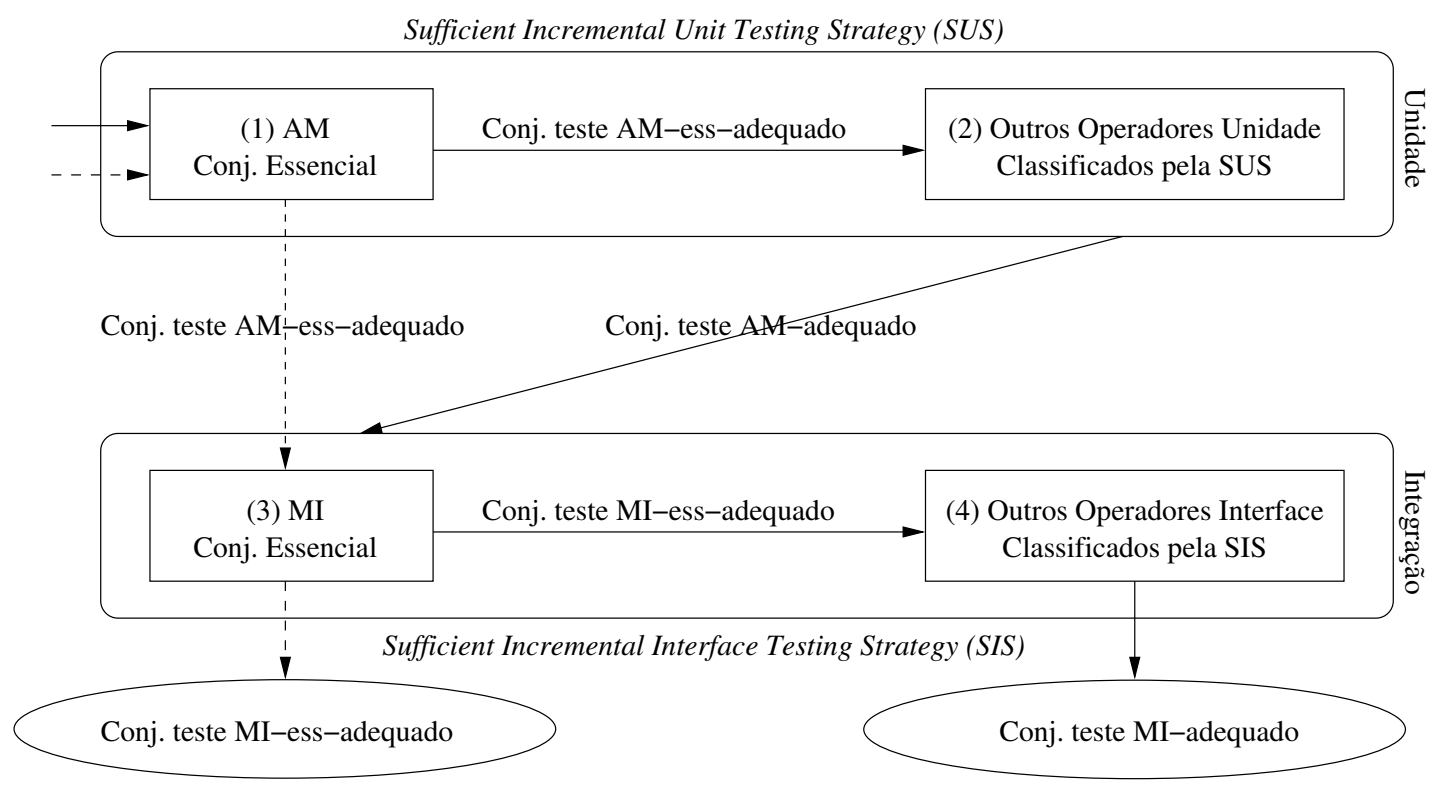

Figura 4.4: Estratégias de teste incrementais baseadas no teste de mutação.

Os resultados obtidos com a aplicação de cada uma das estratégias é sintetizado na Tabela 4.7. Com a estratégia SUS, um conjunto de teste Análise de Mutantes-adequado é obtido utilizando-se 20 dos 80 operadores, o que representa uma redução de custo da ordem de 40\%. Com apenas 5 operadores de mutação é possível obter um conjunto de teste que determine um escore de mutação superior a 0.99 e, nesse caso, a redução de custo é em torno de $87 \%$. Em termos do número de mutantes equivalentes, a estratégia $S U S$ gera $648(78 \%)$ dos 829 mutantes equivalentes identificados. Considerando somente os 5 primeiros operadores propostos pela estratégia, 142 mutantes equivalentes são gerados, o que representa $17 \%$ do total de mutantes gerados.

Tabela 4.7: Síntese das estratégias incrementais.

\begin{tabular}{|l|l|r|r|r|r|}
\hline Estratégia. & Conj. de Teste Adeq. & Custo Total & Custo Estratégia & Escore & Redução de Custo \\
\hline \hline$S U S$ & MA & 12,839 & 7,642 & 1.000 & 40.46 \\
\hline$S I S$ & IM & 14,024 & 10,384 & 1.000 & 25.96 \\
\hline$U-I S$ & MA e IM & 26,858 & 17,772 & 1.000 & 33.83 \\
\hline$S U-I S$ & MA-ess e IM-ess & 26,858 & 6,060 & 0.997 & 77.44 \\
\hline
\end{tabular}

Com a utilização da estratégia SIS, um conjunto de teste Mutação de Interfaceadequado pode ser obtido utilizando-se 18 dos 33 operadores de mutação de interface, o que representa uma redução de custo da ordem de $26 \%$. Utilizando-se apenas 6 operadores é possível obter um conjunto de teste que determina um escore de mutação superior 
a 0.99 e uma redução de custo da ordem de 87\%. Em relação ao número de mutantes equivalentes, SIS gera 990 do total de 1,347 mutantes equivalentes (em torno de 73,5\% do total). Se somente os 6 primeiros operadores definidos pela estratégia são utilizados apenas 156 mutantes equivalentes são gerados, aproximadamente 11,6\% do total.

Com a combinação dessas estratégias, uma redução ainda maior no custo de aplicação dos critérios é obtida. Por exemplo, considerando a estratégia $U$ - $I S$ que visa a obtenção de um conjunto de teste Mutação de Interface-adequado a partir de um conjunto Análise de Mutantes-adequado, observa-se que o conjunto de operadores definidos por $U$-IS gera ao todo 17772 mutantes (7642 mutantes de unidade e 10130 mutantes de interface). Se todos os operadores de mutação fosse utilizados 26858 mutantes (12834 de unidade e 14024 de interface) seriam gerados. Desse modo, 17772 mutantes correspondem a uma redução de aproximadamente $34 \%$ no custo de aplicação dos critérios e, mesmo assim, conjunto de teste adequados a ambos são obtidos.

Se um escore de mutação menor do que 1.00 for aceitável, a estratégia $S U$-IS pode ser uma boa opção. Essa estratégia utiliza somente os operadores de mutação de unidade e de integração. A estratégia $S U$-IS permite que escores de mutação superior a 0.99 em relação a ambos os critérios de teste (Análise de Mutantes e Mutação de Interface) sejam obtidos com uma redução de custo superior a 77\%. Para mais informações sobre os passos seguidos na definição das estratégias de teste, bem como o conjunto de operadores de mutação que deve ser utilizado em cada uma delas pode-se consultar Vincenzi et al. (2001).

É importante observar que, embora essas estratégias tenham sido definidas para o teste de programas procedimentais, a seqüência de passos necessários para defini-las é facilmente aplicável considerando outros conjuntos de operadores de mutação definidos para outras linguagens de programação, motivando investigar se os mesmos resultados podem ser obtidos, por exemplo, quando esses mesmos operadores são aplicados em programas OO. Outro ponto importante é que, em geral, independentemente da estratégia de teste utilizada, para se obter um conjunto de teste adequado ao teste de mutação é necessário a determinação dos mutantes equivalentes. A próxima seção apresenta uma técnica que auxilia o testador nessa atividade.

\subsubsection{Auxiliando a Identificar Mutantes Equivalentes: Estratégia Bayseana}

Além das estratégias de teste incrementais que visam a redução do custo em termos do número de mutantes gerados, um outro aspecto importante para o teste de mutação é o desenvolvimento de heurísticas que auxiliem o testador na hora de analisar os mutantes vivos.

Por se tratar de um problema indecidível determinar se dois programas são equivalentes, diferentes técnicas têm sido desenvolvidas e investigadas tanto para a detec- 
ção automática de mutantes equivalentes, considerando classes específicas de programas, quanto na definição de diretrizes que facilitem tal atividade, como por exemplo, o uso de Análise de Dependência (Harman et al., 2000), Particionamento Amorfo (Amorphous Slicing) (Hierons et al., 1999), Restrições (DeMillo e Offutt, 1991), Técnicas de Otimização de Compiladores (Offutt e Craft, 1994; Offutt e Pan, 1996, 1997) e Técnicas de Inteligência Artificial (Vincenzi et al., 2002).

A abordagem desenvolvida por Vincenzi et al. (2002), denominada Bayesian LearningBased Equivalent Detection Technique (BaLBEDeT), utiliza uma técnica de inteligência artificial chamada Aprendizado Bayesiano (Bayesian Learning) (Mitchell, 1997) para estimar quais os grupos de mutantes que deveriam ser analisados primeiro, após a execução de um certo número de casos de teste, considerando a decisão do testador em gerar casos de teste adicionais ou determinar mutantes equivalentes.

Como descrito a seguir, a técnica BaLBEDeT necessita da existência de dados históricos para ser utilizada. Nesse contexto, dados coletados de experimentos anteriores (Vincenzi, 1998), resultantes da avaliação dos critérios baseados em mutação no contexto de programas procedimentais, são utilizados para definir e exemplificar a utilização da técnica. Observa-se que embora a técnica seja definida a partir de dados provenientes do teste de programas procedimentais, ela é diretamente aplicável no contexto de programas OO, exigindo somente a existência de dados históricos sobre mutantes equivalentes nesse contexto.

\section{Aprendizado Bayesiano}

O Aprendizado Bayesiano visa a fornecer uma abordagem probabilística para inferência. Ele se baseia na suposição que as quantidades de interesse são governadas por distribuições de probabilidade e que decisões ótimas são tomadas com base nessas probabilidades juntamente com os dados observados.

Tal raciocínio é também a base para o desenvolvimento de algoritmos de aprendizado que manipulam probabilidades diretamente, além de fornecer um framework (arcabouço) para a análise de operações que não manipulam probabilidades explicitamente. Algoritmos de Aprendizado Bayesiano calculam probabilidades explícitas para hipóteses e são considerados uma das abordagens práticas para a solução de certos tipos de problemas de aprendizagem (Mitchell, 1997).

\section{Teorema de Bayes}

O teorema de Bayes é a base para todos os algoritmos de Aprendizado Bayesiano. Tal teorema é dado pela Equação 4.1: 


$$
P(h \mid D)=\frac{P(D \mid h) P(h)}{P(D)}
$$

onde:

- $P(h)$ denota a probabilidade inicial de que a hipótese $h$ se mantém antes da observação dos dados de treinamento. $P(h)$ é denominada probabilidade a priori de $h$ e pode refletir qualquer conhecimento prévio que indique as chances de que $h$ é a hipótese correta;

- $P(D)$ denota a probabilidade a priori de que os dados de treinamento $D$ serão observados;

- $P(D \mid h)$ denota a probabilidade da observação do dado $D$ considerando uma situação na qual a hipótese $h$ se mantenha. De forma mais genérica, utiliza-se $P(x \mid y)$ para denotar a probabilidade de $x$ dado $y$; e

- $P(h \mid D)$ é chamado de probabilidade a posteriori de $h$, visto que reflete a confiança de que $h$ se mantenha após os dados de treinamento $D$ terem sido observados.

Note que o termo $P(D)$ é um termo independente de $h$ e pode ser descartado, como mostrado na Equação 4.2 .

$$
P(h \mid D)=P(D \mid h) P(h)
$$

Em diversos cenários de aprendizagem, o aprendiz (learner) considera o conjunto de hipóteses candidatas $H$ visando a encontrar a hipótese mais provável de ocorrer $h \in H$, considerando o conjunto de dados observados $D$. A probabilidade com a máxima probabilidade de ocorrência é denominada hipótese Máxima a Posteriori (Maximum a Posteriori $-M A P)$.

O algoritmo de aprendizagem, denominado algoritmo Força-Bruta (Brute-Force algorithm), baseia-se na MAP para encontra a melhor solução do problema sendo proposto. Os dois passos desse algoritmo são (Mitchell, 1997):

1. Para cada hipótese $h \in H$, calcular a probabilidade a posteriori utilizando a Equação 4.2; e

2. Determinar a hipótese $h_{M A P}$ que consiste na hipótese de maior probabilidade a posteriori obtida:

$$
h_{M A P}=\max (P(h \mid D)), h \in H
$$


Cada operador de mutação possui características específicas, ou seja, um determinado operador de mutação pode ser responsável por gerar um maior número de mutantes equivalentes do que outro. Do mesmo modo, um determinado operador pode ser responsável por gerar mutantes que revelam um maior número de defeitos do que outros. Com isso, com base em informações históricas obtidas de experimentos realizados previamente (Barbosa et al., 2001; Vincenzi et al., 2001), o algoritmo Força-Bruta (Mitchell, 1997) é usado para guiar a análise dos mutantes vivos, objetivando a reduzir o esforço na determinação dos mutantes equivalentes. A idéia é fornecer diretrizes que facilitem a análise dos mutantes vivos. Dado o número de casos de teste executados, a técnica indica, para cada operador de mutação op, a probabilidade dos mutantes vivos de op serem equivalentes ou não-equivalentes.

Para ilustrar o aspecto de custo, em termos do número de mutantes gerados, cinco programas utilitários do UNIX foram utilizados. A Tabela 4.8 apresenta a complexidade dos programas em termos do número de linhas de código (LOC), o total de mutantes gerados para cada programa e a respectiva porcentagem em relação ao total, para cada uma das classes de operadores de mutação. Observe que mesmo para programas com poucas linhas de código o teste de mutação pode gerar um grande número de mutantes e mecanismos que reduzam o número de mutantes e facilitem a identificação de mutantes equivalentes são de fundamental importância para viabilizar a utilização prática do critério.

Tabela 4.8: Número total e porcentagem de mutantes gerados para cada classe de operadores.

\begin{tabular}{|l|r|r|r|r|r|r|r|r|r|r|}
\hline \multirow{2}{*}{ Programa } & \multirow{2}{*}{ LOC } & \multicolumn{2}{|c|}{ Constantes } & \multicolumn{2}{|c|}{ Operadores } & \multicolumn{2}{|c|}{ Comandos } & \multicolumn{2}{|c|}{ Variáveis } & \multirow{2}{*}{ Total } \\
\cline { 3 - 9 } & & \# Mut & \% Tot & \# Mut & \% Tot & \# Mut & \% Tot & \# Mut & \% Tot & \\
\hline \hline Cal & 119 & 1.780 & 41,1 & 1.409 & 32,5 & 352 & 8,1 & 791 & 18,3 & 4.332 \\
Checkeq & 76 & 1.111 & 35,9 & 937 & 30,2 & 268 & 8,6 & 783 & 25,3 & 3.099 \\
Comm & 119 & 314 & 18,2 & 642 & 37,2 & 405 & 23,4 & 367 & 21,2 & 1.728 \\
Look & 107 & 371 & 18,1 & 720 & 35,0 & 319 & 15,5 & 646 & 31,4 & 2.056 \\
Uniq & 103 & 244 & 15,1 & 621 & 38,3 & 348 & 21,5 & 406 & 25,1 & 1.619 \\
\hline \hline Total & 524 & 3.820 & 29,8 & 4.329 & 33,7 & 1.692 & 13,2 & 2.993 & 23,3 & 12.834 \\
\hline
\end{tabular}

Os mutantes equivalentes desses cinco programas foram determinados previamente durante a condução de experimentos realizados por Barbosa et al. (2001) e Vincenzi et al. (2001). A Tabela 4.9 ilustra o total de mutantes equivalentes que foram determinados manualmente para cada um dos cinco programas considerando as quatro classes de operadores de mutação. A porcentagem dos mutantes equivalentes em relação ao total de equivalentes é também apresentada. Esse conjunto de informações históricas sobre equivalência de mutantes é que é a base para a utilização da técnica proposta.

Para cada um dos programas acima foi construído um conjunto de teste $\mathcal{T}$ composto de 500 casos de teste. Tais casos de teste são compostos de casos de teste ad hoc, desen- 
volvidos com base na especificação do programa, e casos de teste aleatórios, desenvolvidos por Wong (1993) durante a realização de um outros experimento que comparava critérios de teste baseados em mutação e baseados em análise de fluxo de dados.

Tabela 4.9: Número total e porcentagem de mutantes equivalentes para cada classe de operadores.

\begin{tabular}{|l|r|r|r|r|r|r|r|r|r|}
\hline \multirow{2}{*}{ Programa } & \multicolumn{2}{|c|}{ Constantes } & \multicolumn{2}{c|}{ Operadores } & \multicolumn{2}{c|}{ Comandos } & \multicolumn{2}{c|}{ Variáveis } \\
\cline { 2 - 9 } & \# Equiv & \% Tot & \# Equiv & \% Tot & \# Equiv & \% Tot & \# Equiv & \% Tot & \\
\hline Cal & 72 & 21,8 & 113 & 34,2 & 12 & 3,7 & 133 & 40,3 & 330 \\
Checkeq & 2 & 0,9 & 105 & 47,1 & 5 & 2,2 & 111 & 49,8 & 223 \\
Comm & 28 & 14,4 & 123 & 63,1 & 9 & 4,6 & 35 & 17,9 & 195 \\
Look & 46 & 17,9 & 111 & 43,2 & 26 & 10,1 & 74 & 28,8 & 257 \\
Uniq & 14 & 8,4 & 119 & 71,2 & 4 & 2,4 & 30 & 18,0 & 167 \\
\hline \hline Total & 162 & 13,8 & 571 & 48,7 & 56 & 4,8 & 383 & 32,7 & 1.172 \\
\hline
\end{tabular}

A seguir são descritos os passos do experimento realizado para a coleta dos dados históricos utilizados pelo algoritmo Força-Bruta e posteriormente é descrito um exemplo que utiliza o algoritmo Força-Bruta para predizer a porcentagem de mutantes equivalentes gerados para cada operador de mutação. Informações mais detalhadas a respeito de Aprendizado Bayesiano e sobre o algoritmo Força-Bruta podem ser encontrados em (Mitchell, 1997).

\section{Coleta dos Dados Requeridos pelo Algoritmo Força-Bruta}

A seguir, os símbolos $\oplus$ e $\ominus$ são usados para representar os mutantes equivalentes e não-equivalentes, respectivamente. Seja $L M$ o número total de mutantes vivos após a execução de um conjunto de teste $\mathcal{T}, L M_{o p}$ o número total de mutantes vivos de um determinado operador op, $E M$ o número total de mutantes equivalentes, e $E M_{o p}$ o número total de mutantes equivalentes de um determinado operador op. De acordo com o teorema de Bayes, a probabilidade a posteriori dos mutantes vivos de um determinado operador op serem equivalentes é dada pela Equação 4.4:

$$
P(\oplus \mid o p)=P(o p \mid \oplus) P(\oplus)
$$

onde:

- $P(\oplus)$ - probabilidade de um mutante vivo ser equivalente (Equação 4.5)

$$
P(\oplus)=E M / L M
$$


- $P(o p \mid \oplus)$ - probabilidade de um mutante vivo de op ser equivalente (Equação 4.6)

$$
P(o p \mid \oplus)=E M_{o p} / L M_{o p}
$$

$P(\ominus), P(o p \mid \ominus)$, e $P(\ominus \mid o p)$ são calculados da mesma forma considerando, entretanto, os mutantes não-equivalentes. Visto que os mutantes vivos ou são equivalentes ou são nãoequivalentes, a probabilidade dos mutantes vivos serem não-equivalentes é o complemento da probabilidade deles serem equivalentes.

Para investigar a relação entre mutantes vivos equivalentes e não-equivalentes à medida que os casos de teste são executados, os 500 casos de teste de cada programa foram subdivididos em 19 subconjuntos de teste contendo 0, 10, 20, 30, 40, 50, 60, 70, 80, 90, 100, 150, 200, 250, 300, 350, 400, 450 e 500 elementos cada. As Tabelas 4.10(a), 4.10(b), e 4.10(c) ilustram como o teorema de Bayes é utilizado para estimar a probabilidade de um operador op produzir mutantes equivalentes, considerando conjuntos de teste com 0 , 20 e 500 elementos, respectivamente.

Por exemplo, a Tabela 4.10(a) ilustra os dados coletados para um conjunto de teste vazio. A aplicação dos operadores de mutação de unidade no conjunto de cinco programas resultou em 12.834 mutantes gerados. Visto que nenhum caso de teste foi executado, 12.834 ainda estão vivos: 1.172 são equivalentes (determinados previamente) e 11.662 são não-equivalentes. No final da Tabela 4.10(a) é mostrado como as probabilidades $P(\ominus)$ e $P(\oplus)$ são calculadas. Como pode ser observado, para um conjunto de teste vazio, a probabilidade de um mutante vivo ser não-equivalente é de 0,91 contra 0,09 de ser equivalente.

Do mesmo modo, para cada operador op, a probabilidade dos mutantes vivos de op serem equivalentes também é calculada. Por exemplo, considere o operador OLBN (Logical Operator by Bitwise Operator). Ele gera 81 mutantes (considerando todos os cinco programas) dos quais 30 são equivalentes. A probabilidade de um mutante vivo do operador OLBN ser equivalente $(P(O L B N \mid \oplus))$ é $30 / 81=0,37$ e a probabilidade de ser não-equivalente é $P(O L B N \mid \ominus)=0,63(1-P(O L B N \mid \oplus))$.

Agora, aplicando-se o teorema de Bayes, é possível estimar a probabilidade a posteriori de um mutante vivo ser equivalente ou não-equivalente se ele foi gerado pelo operador op . Novamente, considerando o operador OLBN (Tabela 4.10(a)):

$$
\begin{aligned}
P(\oplus, O L B N) & =P(O L B N \mid \oplus) * P(\oplus) \\
& =0,37 * 0,09 \\
& =0,03
\end{aligned}
$$




$$
\begin{aligned}
P(\ominus, O L B N) & =P(O L B N \mid \ominus) * P(\ominus) \\
& =0,63 * 0,91 \\
& =0,57
\end{aligned}
$$

Normalizando tais valores de modo que o somatório seja 1, a Equação 4.7 é utilizada para obter a probabilidade a posteriori dos mutantes vivos de op serem equivalentes, e a

Tabela 4.10: Média dos dados coletados para os cinco programas.

(a) Conjunto de teste vazio

\begin{tabular}{|l|r|r|r|r|r|r|r|}
\hline Operador & Total & Vivos & Não-Equiv & Equiv & $P(o p \mid \oplus)$ & $P(\oplus \mid o p)$ & $P_{\text {nor }}(\oplus \mid o p)$ \\
\hline \hline Cccr & 1.676 & 1.676 & 1.524 & 152 & 0,09 & 0,01 & 0,01 \\
Ccsr & 1.393 & 1.393 & 1.389 & 4 & 0,00 & 0,00 & 0,00 \\
$\ldots$ & $\ldots$ & $\ldots$ & $\ldots$ & $\ldots$ & $\ldots$ & $\ldots$ & $\ldots$ \\
OLBN & 81 & 81 & 51 & 30 & 0,37 & 0,03 & 0,06 \\
ORRN & 515 & 515 & 449 & 66 & 0,13 & 0,01 & 0,01 \\
$\ldots$ & $\ldots$ & $\ldots$ & $\ldots$ & $\ldots$ & $\ldots$ & $\ldots$ & $\ldots$ \\
SCRB & 6 & 6 & 3 & 3 & 0,50 & 0,05 & 0,09 \\
SSDL & 446 & 446 & 428 & 18 & 0,04 & 0,00 & 0,00 \\
$\ldots$ & $\ldots$ & $\ldots$ & $\ldots$ & $\ldots$ & $\ldots$ & $\ldots$ & $\ldots$ \\
VDTR & 633 & 633 & 322 & 311 & 0,49 & 0,04 & 0.09 \\
VTWD & 422 & 422 & 393 & 29 & 0,07 & 0,01 & 0,01 \\
\hline \hline Total & 12.834 & 12.834 & 11.662 & 1.172 & & & - \\
\hline
\end{tabular}

$P(\oplus)=1.172 / 12.834=0,09$

(b) Conjunto de teste com 20 elementos

\begin{tabular}{|l|r|r|r|r|r|r|r|}
\hline Operador & Total & Vivos & Não-Equiv & Equiv & $P(o p \mid \oplus)$ & $P(\oplus \mid o p)$ & $P_{\text {nor }}(\oplus \mid o p)$ \\
\hline \hline Cccr & 1.676 & 343 & 191 & 152 & 0,44 & 0,20 & 0,40 \\
Ccsr & 1.393 & 200 & 196 & 4 & 0,02 & 0,01 & 0,02 \\
$\ldots$ & $\ldots$ & $\ldots$ & $\ldots$ & $\ldots$ & $\ldots$ & $\ldots$ & $\ldots$ \\
OLBN & 81 & 40 & 10 & 30 & 0,75 & 0,34 & 0,72 \\
ORRN & 515 & 142 & 76 & 66 & 0,46 & 0,21 & 0,42 \\
$\ldots$ & $\ldots$ & $\ldots$ & $\ldots$ & $\ldots$ & $\ldots$ & $\ldots$ & $\ldots$ \\
SCRB & 6 & 3 & 0 & 3 & 1,00 & 0,46 & 1,00 \\
SSDL & 446 & 53 & 35 & 18 & 0,34 & 0,16 & 0,30 \\
$\ldots$ & $\ldots$ & $\ldots$ & $\ldots$ & $\ldots$ & $\ldots$ & $\ldots$ & $\ldots$ \\
VDTR & 633 & 353 & 42 & 311 & 0,88 & 0,40 & 0,86 \\
VTWD & 422 & 94 & 65 & 29 & 0,31 & 0,14 & 0,27 \\
\hline \hline Total & 12834 & 2569 & 1397 & 1172 & - & & - \\
\hline
\end{tabular}

$P(\ominus)=0,54$

$P(\oplus)=0,46$

(c) Conjunto de teste com 500 elementos

\begin{tabular}{|l|r|r|r|r|r|r|r|}
\hline Operador & Total & Vivos & Não-Equiv & Equiv & $P(o p \mid \oplus)$ & $P(\oplus \mid o p)$ & $P_{\text {nor }}(\oplus \mid o p)$ \\
\hline \hline Cccr & 1.676 & 162 & 10 & 152 & 0,94 & 0,79 & 0,99 \\
Ccsr & 1.393 & 19 & 15 & 4 & 0,21 & 0,18 & 0,58 \\
$\ldots$ & $\ldots$ & $\ldots$ & $\ldots$ & $\ldots$ & $\ldots$ & $\ldots$ & $\ldots$ \\
OLBN & 81 & 34 & 4 & 30 & 0,88 & 0,74 & 0,97 \\
ORRN & 515 & 97 & 31 & 66 & 0,68 & 0,57 & 0,92 \\
$\ldots$ & $\ldots$ & $\ldots$ & $\ldots$ & $\ldots$ & $\ldots$ & $\ldots$ & $\ldots$ \\
SCRB & 6 & 3 & 0 & 3 & 1,00 & 0,84 & 1,00 \\
SSDL & 446 & 19 & 1 & 18 & 0,95 & 0,79 & 0,99 \\
$\ldots$ & $\ldots$ & $\ldots$ & $\ldots$ & $\ldots$ & $\ldots$ & $\ldots$ & $\ldots$ \\
VDTR & 633 & 318 & 7 & 311 & 0,98 & 0,82 & 1,00 \\
VTWD & 422 & 40 & 11 & 29 & 0,73 & 0,61 & 0,93 \\
\hline \hline Total & 12.834 & 1.401 & 229 & 1.172 & & & - \\
\hline
\end{tabular}


Equação 4.8 é utilizada para obter a probabilidade a posteriori dos mutantes vivos de op serem não-equivalentes.

$$
\begin{aligned}
& P_{\text {nor }}(\oplus \mid o p)=\frac{P(\oplus \mid o p)}{P(\oplus \mid o p)+P(\ominus \mid o p)} \\
& P_{\text {nor }}(\ominus \mid \text { op })=\frac{P(\ominus \mid \text { op })}{P(\ominus \mid o p)+P(\oplus \mid o p)}
\end{aligned}
$$

Aplicando as Equações 4.7 e 4.8 a todos os operadores de mutação é possível estimar a probabilidade dos mutantes vivos de cada um deles ser equivalente ou não-equivalente, considerando diferentes conjuntos de teste. Por exemplo, considerando a Tabela 4.10 e o operador OLBN, têm-se:

- Tabela 4.10(a) - Conjunto de teste vazio

$$
\begin{aligned}
& -P_{\text {nor }}(\oplus \mid O L B N)=0,06 \\
& -P_{\text {nor }}(\ominus \mid O L B N)=0,94
\end{aligned}
$$

- Tabela 4.10(b) - Conjunto de teste com 20 elementos

$$
\begin{aligned}
& -P_{\text {nor }}(\oplus \mid O L B N)=0,72 \\
& -P_{\text {nor }}(\ominus \mid O L B N)=0,28
\end{aligned}
$$

- Tabela 4.10(c) - Conjunto de teste com 500 elementos

$$
\begin{aligned}
& -P_{\text {nor }}(\oplus \mid O L B N)=0,97 \\
& -P_{\text {nor }}(\ominus \mid O L B N)=0,03
\end{aligned}
$$

Observe que após a execução de 20 casos de teste (Tabela 4.10(b)) a probabilidade de um mutante vivo ser equivalente aumenta. Desse modo, quanto mais casos de teste são executados, maior a confiança de um mutante vivo ser equivalente.

Tais probabilidades foram calculadas para os 19 subconjuntos de casos de teste. Com base em tais probabilidades, o testador, aplicando o teste de mutantes a outros programas, pode selecionar as probabilidades referentes ao número de casos de teste já executados e estimar qual a porcentagem dos mutantes vivos do programa em questão serem equivalentes ou não-equivalentes. A seguir é apresentado um exemplo de aplicação da técnica BaLBEDeT utilizando um programa procedimental. 


\section{Exemplo de Utilização da Técnica BaLBEDeT na Identificação de Mutantes Equi- valentes}

Considere que existe um programa a ser testado do qual não se sabe a priori o número de mutantes equivalentes existentes. As informações probabilísticas obtidas previamente a partir do conjunto de cinco programas é utilizada pela técnica BaLBEDeT para estimar a quantidade de mutantes equivalentes no teste desse novo programa. O programa utilizado neste estudo de caso é o programa Sort que faz a classificação de registros em um ou mais arquivos e tem, aproximadamente, 624 LOC's. Para viabilizar a comparação e possibilitar o cálculo do erro obtido pela técnica, os mutantes equivalentes desse programa também foram identificados manualmente.

No caso do programa Sort a aplicação de todos os operadores de mutação de unidade resultou em 22.419 mutantes gerados, dos quais 2.750 foram identificados manualmente como equivalentes. A Tabela 4.11 mostra as informações detalhadas sobre o número de mutantes gerados (primeira linha) e o total de equivalentes (segunda linha), bem como as respectivas porcentagens, considerando cada uma das classes de operadores de mutação.

Tabela 4.11: Total e porcentagem de mutantes gerados e equivalentes do programa Sort.

\begin{tabular}{|l|r|r|r|r|r|r|r|r|r|}
\cline { 2 - 10 } \multicolumn{1}{c|}{} & \multicolumn{3}{c|}{ Constantes } & \multicolumn{2}{c|}{ Operadores } & \multicolumn{2}{c|}{ Comandos } & \multicolumn{3}{c|}{ Variáveis } & \multirow{2}{*}{ Total } \\
\cline { 2 - 12 } & \# Mut & \% Tot & \# Mut & \% Tot & \# Mut & \% Tot & \# Mut & \% Tot & \\
\hline Gerados & 3.769 & 16,81 & 5.104 & 22,77 & 2.745 & 12,24 & 10.801 & 48,18 & 22.419 \\
Equivalentes & 857 & 31,16 & 878 & 31,93 & 124 & 4,51 & 891 & 32,40 & 2.750 \\
\hline
\end{tabular}

Em seguida, supondo que todos os 22.419 mutantes foram executados com 20 e posteriormente 100 casos de teste, as Tabelas 4.12 e 4.13 mostram o número de mutantes vivos remanescentes, o número real de mutantes equivalentes de cada operador e as probabilidades calculadas pela técnica BaLBEDeT dos mutantes vivos de cada operador serem equivalentes ou não-equivalentes.

Por exemplo, de acordo os dados da Tabela 4.12, 905 dos 1.208 mutantes do operador Cccr estão vivos após a execução de 20 casos de teste: 374 desses 905 mutantes vivos são não-equivalentes e os 531 restantes são equivalentes. Considerando os dados históricos obtidos a partir dos cinco programas, para um conjunto de teste com 20 elementos a probabilidade dos mutantes vivos de Cccr serem equivalentes é de 0,40 contra 0,60 de serem não-equivalentes, ou seja, aplicando essas probabilidades considerando os 905 mutantes vivos de Cccr tem-se uma estimativa de que 545,45 desses mutantes vivos são não-equivalentes e 359,55 são equivalentes. Tais valores correspondem a uma taxa de erro na classificação dos mutantes vivos de aproximadamente 18,9\%. A taxa de erro representa a discrepância entre os números reais de mutantes equivalentes e não-equivalentes com os valores estimados pela técnica BaLBEDeT. 
Tabela 4.12: Programa Sort: dados reais $\times$ valores estimados para um conjunto de teste de 20 elementos

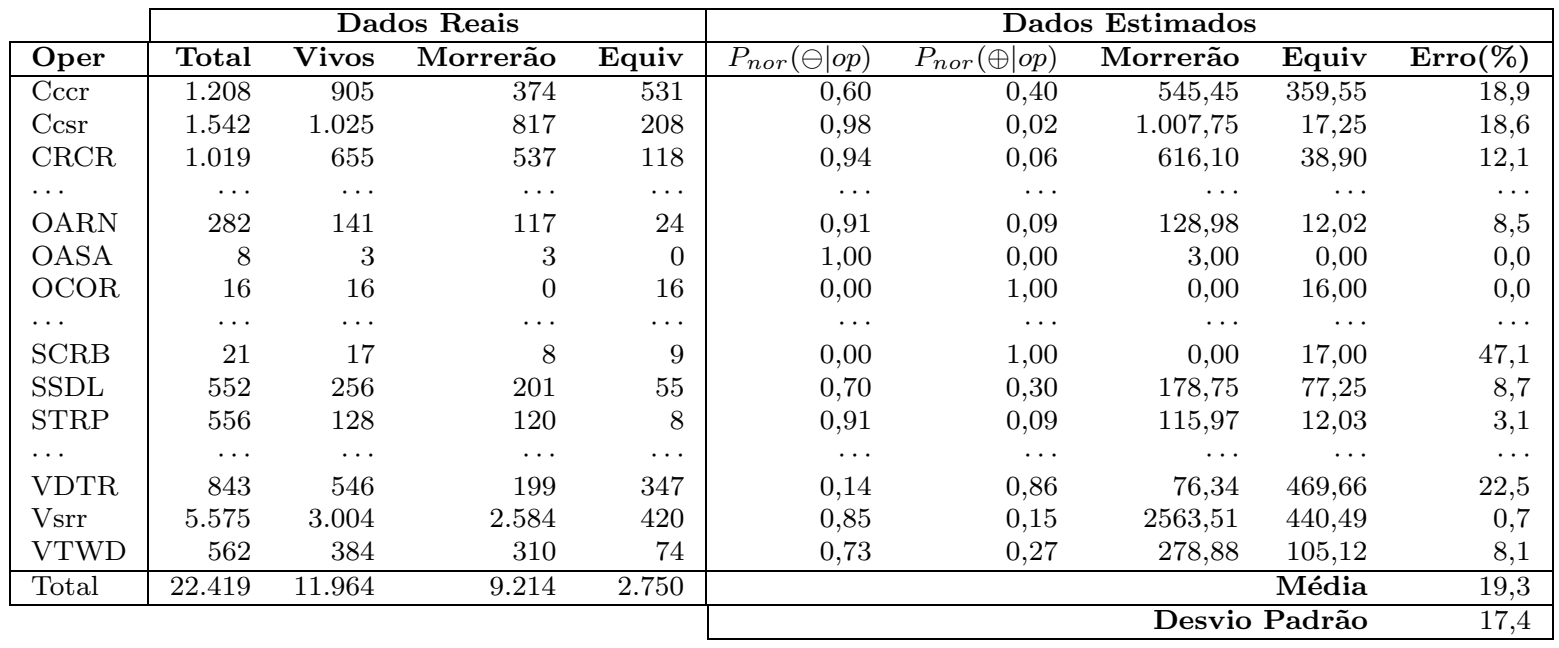

Tabela 4.13: Programa Sort: dados reais $\times$ valores estimados para um conjunto de teste de 100 elementos

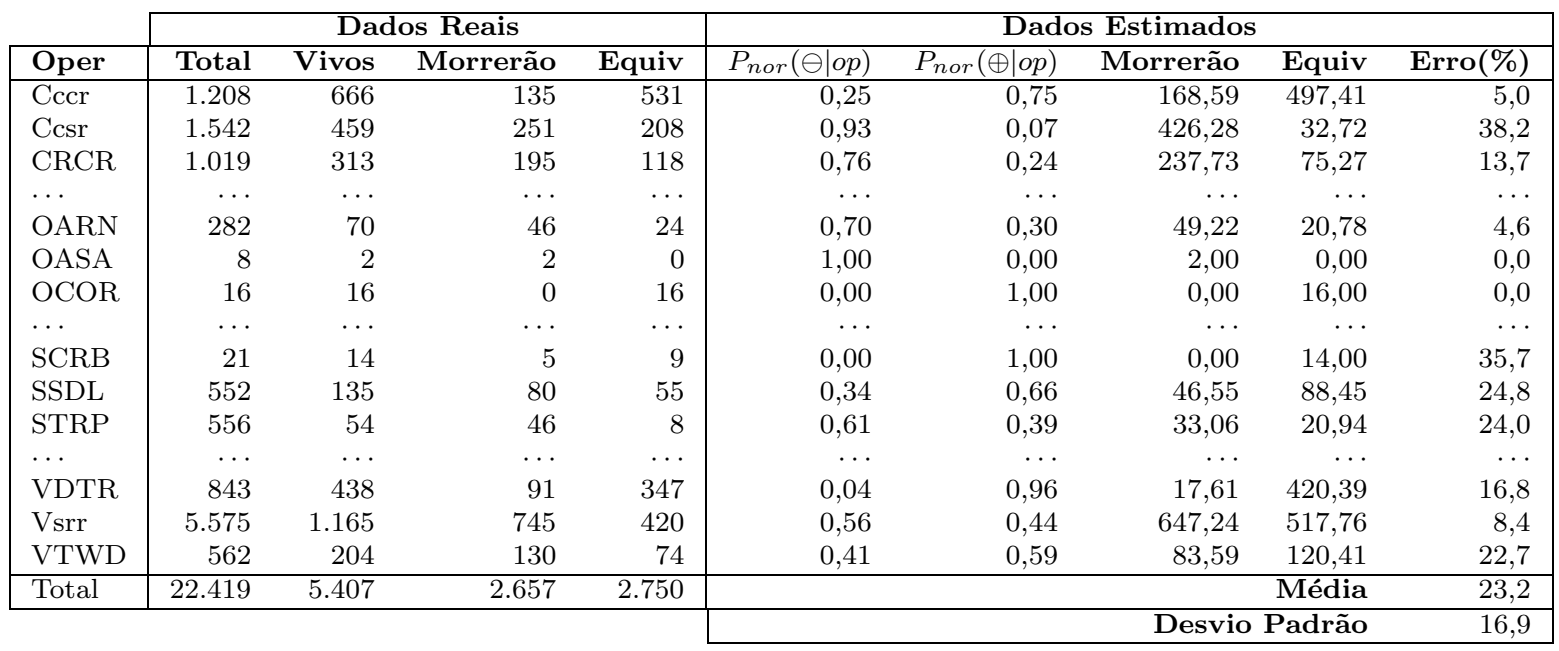

Observe que, para determinados operadores, os valores estimados podem ser bem diferentes dos valores reais. Na média, considerando um conjunto de teste com 20 elementos, a taxa de erro na estimativa é de aproximadamente 19,3\% com um desvio padrão de 17,4\%. Considerando um conjunto de teste com 100 elementos, a taxa de erro passa para $23,2 \%$, e o desvio padrão cai para $16,9 \%$.

A Tabela 4.14 mostra as taxas de erro na estimativa do número de mutantes equivalentes e não-equivalentes considerando conjuntos de teste com 20 e 100 elementos. Para o conjunto de teste com 20 elementos (Tabela 4.14(a)), o número de mutantes vivos de 
17 operadores de mutação são estimados com uma taxa de erro entre $0 \%-10 \%$, sendo que 9 desses 17 operares são classificados em uma taxa de erro menor do que 5\%. A maioria dos operadores de mutação foram classificados com uma taxa de erro superior a $10 \%$.

Tabela 4.14: Taxa de erro: (a) 20 casos de teste; e (b) 100 casos de teste

(a)

\begin{tabular}{|c|c|c|c|c|c|c|}
\hline Taxa de Erro & \multicolumn{3}{|c|}{ Operador (Erro \%) } & \multicolumn{3}{|c|}{ Operador (Erro \%) } \\
\hline \multirow{6}{*}{$0 \%-10 \%$} & $\overline{\text { OASA }(0,0)}$ & $\overline{\mathrm{OCCOR}}(0,0)$ & 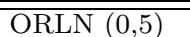 & $\overline{\text { OASA }(0,0)}$ & OCOR $(0,0)$ & $\overline{\text { SBRC }(0,0)}$ \\
\hline & Vsrr $(0,7)$ & OALN $(0,7)$ & OABN $(2,6)$ & $\operatorname{VSCR}(0,0)$ & OASN $(3,4)$ & STRI $(4,2)$ \\
\hline & $\operatorname{STRP}(3,1)$ & STRI $(3,8)$ & Vprr $(4,4)$ & OARN $(4,6)$ & Cccr $(5,0)$ & OBSN $(5,7)$ \\
\hline & $\operatorname{SMTC}(5,2)$ & Oido $(5,3)$ & OLNG $(6,5)$ & ORLN $(6,2)$ & Vsrr $(8,4)$ & SWDD $(8,6)$ \\
\hline & OASN $(6,7)$ & VTWD $(8,1)$ & OBAN $(8,2)$ & & & \\
\hline & OARN $(8,5)$ & $\operatorname{SSDL}(8,7)$ & & & & \\
\hline \multirow{6}{*}{$10 \%-20 \%$} & OLLN $(10,0)$ & OLRN $(10,5)$ & OCNG $(10,9)$ & OIPM $(10,0)$ & OESA $(12,4)$ & Vprr $(13,1)$ \\
\hline & OESA $(11,2)$ & OBSN $(11,5)$ & CRCR $(12,1)$ & CRCR $(13,7)$ & OABA $(14,2)$ & OALN $(14,3)$ \\
\hline & ORRN $(12,3)$ & ORAN $(12,7)$ & ORSN $(14,2)$ & ORAN $(14,9)$ & OLNG $(15,8)$ & ORRN $(16,6)$ \\
\hline & SWDD $(14,4)$ & Varr $(16,4)$ & OBRN $(16,9)$ & VDTR $(16,8)$ & OBAN $(17,2)$ & OEBA $(19,1)$ \\
\hline & OIPM $(18,2)$ & $\operatorname{Ccsr}(18,6)$ & Cccr $(18,9)$ & ORSN $(19,2)$ & & \\
\hline & ORBN $(19,3)$ & & & & & \\
\hline \multirow{4}{*}{$20 \%-30 \%$} & OAAN $(20,5)$ & VDTR $(22,5)$ & SMVB $(24,1)$ & OLBN $(20,7)$ & ORBN $(20,7)$ & OLAN $(21,2)$ \\
\hline & OLAN $(24,9)$ & OLSN $(25,2)$ & OLBN $(26,4)$ & VTWD $(22,7)$ & OBRN $(23,4)$ & STRP $(24,0)$ \\
\hline & SSWM $(29,0)$ & & & SSDL $(24,8)$ & Oido $(24,8)$ & OEAA $(25,0)$ \\
\hline & & & & OAAN $(27,8)$ & SMVB $(29,0)$ & \\
\hline \multirow{2}{*}{$30 \%-40 \%$} & OABA $(30,8)$ & OEBA $(33,4)$ & OEAA $(37,4)$ & OLSN $(31,4)$ & OABN $(32,0)$ & OLLN $(33,3)$ \\
\hline & & & & OCNG $(34,8)$ & $\operatorname{SCRB}(35,7)$ & $\operatorname{Ccsr}(38,2)$ \\
\hline \multirow{2}{*}{$40 \%-50 \%$} & SRSR $(40,5)$ & OAAA $(44,4)$ & OBLN $(44,4)$ & OBLN $(44,4)$ & SMTC $(47,4)$ & OLRN $(49,2)$ \\
\hline & OBNG $(45,6)$ & OBBN $(46,6)$ & SCRB $(47,1)$ & & & \\
\hline \multirow{2}{*}{ [50\%-100\%] } & SBRC $(54,4)$ & VSCR $(86,9)$ & & OAAA $(50,0)$ & SSWM $(50,0)$ & OBBN $(50,2)$ \\
\hline & & & & Varr $(55,9)$ & SRSR $(60,4)$ & OBNG $(62,8)$ \\
\hline
\end{tabular}

Para o conjunto de teste com 100 elementos (Tabela 4.14(b)), os mutantes vivos de 12 operadores são classificados com uma taxa de erro menor do que $10 \%$ e mais operadores de mutação são classificados com uma taxa de erro abaixo de $20 \%$ do que os apresentados na Tabela 4.14(a). Em Inteligência Artificial, uma taxa de erro na estimativa da ordem de $10 \%$ é considerada razoável (Mitchell, 1997).

A conclusão é que mais dados históricos devem ser coletadas, considerando programas com características similares ao Sort, visando a obter uma estimativa mais precisa no número de mutantes vivos. A idéia é classificar os dados históricos com base nas características dos programas a partir dos quais eles foram coletados de modo que, para cada novo programa a ser testado, possa existir uma instância da técnica BaLBEDeT que seja mais adequada para determinado tipo de programa, resultando em melhores estimativas no número de mutantes equivalentes e não-equivalentes.

Os resultados apresentados aqui devem ser vistos como uma primeira iniciativa no desenvolvimento de diretrizes que auxiliem o testador a identificar mutantes equivalentes. Por exemplo, considerando os dados apresentados na Tabela 4.12, o operador OASA gera 8 mutantes. Após a execução de 20 casos de teste, 3 ainda permanecem vivos. As informações probabilísticas sobre este operador dizem que todos os seus mutantes devem 
morrer, uma vez que a probabilidade de seus mutantes ser equivalente é zero. Desse modo, se o testador deseja avaliar os mutantes vivos visando a melhorar o conjunto de teste, sugere-se que mutantes gerados por operadores como o OASA sejam avaliados primeiro visto que tais operadores, em geral, produzem menos mutantes equivalentes que outros.

Por outro lado, considerando o operador OCOR que gera 16 mutantes, as informações probabilísticas dizem que todos os seus mutantes vivos, após a execução de 20 casos de teste, são equivalentes. Desse modo, se o testador deseja determinar mutantes equivalentes, uma boa opção é iniciar a análise por mutantes gerados por operadores do tipo do OCOR. No meio desses dois extremos estão os operadores cujos mutantes vivos têm maior ou menor probabilidade de serem equivalentes, como por exemplo o operador STRP, cuja probabilidade de seus mutantes vivos serem equivalentes é da ordem de 0,09. Nesse caso, o testador tem a possibilidade de analisar os mutantes desse operador após a execução de mais alguns casos de teste terem sido executados e o número de mutantes vivos tiver sido reduzido.

Ressalta-se que, embora a técnica BaLBEDeT tenha sido definida e exemplificada utilizando-se programas procedimentais - devido à necessidade de informações históricas sobre mutantes equivalentes -, ela é diretamente aplicável a programas OO bastandose, para isso, a realização de estudos empíricos que forneçam dados históricos sobre a equivalência de mutantes nesse contexto.

\subsection{Considerações Finais}

Neste capítulo foram discutidas as contribuições desta tese no contexto do teste de mutação aplicados a programas OO. Foram apresentados três diferentes conjuntos de operadores de mutação os quais podem ser utilizados no teste intra-método, inter-método e inter-classe, considerando as linguagens Java e $\mathrm{C}++$.

No caso dos operadores intra-método e inter-método, por terem sido derivados de operadores previamente definidos para o teste de programas $\mathrm{C}$, a análise crítica realizada considerou a aplicação dos mesmos no contexto de Java e $\mathrm{C}++$. Observou-se que, no caso de $\mathrm{C}++$ todos os operadores de $\mathrm{C}$ são diretamente aplicáveis. Já no caso da linguagem Java alguns dos operadores destinados ao teste de unidade de programas C não são diretamente aplicáveis devido a não existência de ponteiros e expressões lógicas que aceitem valores escalares na linguagem Java.

Considerando os operadores destinados ao teste inter-classe, definidos originalmente para o teste de programas Java, a análise crítica, considerando a viabilidade de utilização dos mesmos no contexto da linguagem $\mathrm{C}++$, demonstrou que diversas características de 
$\mathrm{C}++$ não foram contempladas pelos operadores de Java, tais como o uso de templates e herança múltipla, deixando margem para pesquisas futuras nessa área.

Considerando operadores de mutação que modelam defeitos específicos de Java, foi descrito um conjunto de operadores destinado ao teste de programas concorrentes. Os problemas relacionados à aplicação do teste de mutação nesse contexto foram identificados e duas alternativas de como distinguir mutantes nesse contexto, propostas na literatura, foram discutidas.

A análise de inclusão entre os operadores de mutação avaliados foi discutida, sendo os mesmos considerados incomparáveis do ponto de vista da relação de inclusão. No que se refere à complexidade dos operadores, foram apresentadas as fórmulas tradicionalmente utilizadas para predizer o número máximo de mutantes gerados pelos critérios no pior caso.

Com base em dados históricos obtidos de estudos empíricos realizados no contexto de programas procedimentais, estratégias incrementais de utilização dos operadores de mutação de unidade e de integração foram estabelecidas e uma técnica para auxiliar na determinação de mutantes equivalentes, denominada BaLBEDeT, foi definida. Observase que, embora as estratégias e a técnica tenham sido desenvolvidas e definidas com base em programas procedimentais, os mecanismos e procedimentos utilizados na definição das estratégias e da técnica são aplicáveis indistintamente no contexto de programas OO.

A aplicação e a condução de estudos empíricos envolvendo um ou mais critérios de teste estão fortemente relacionadas à existência de uma ferramenta de teste que automatize a utilização dos critérios. No próximo capítulo são apresentas as contribuições desta tese relacionadas à automatização dos critérios de teste propostos. 


\section{Aspectos de Automatização}

1 QUALIDADE e produtividade da atividade de teste são dependentes dos critérios cação. Sem a existência de uma ferramenta, o teste torna-se uma atividade propensa a erros e limitada a programas muito simples. Neste capítulo são apresentadas as contribuições desta tese no que se refere ao aspecto de automatização dos critérios de testes propostos nos Capítulos 3 e 4. Na Seção 5.1 são identificadas as motivações para o desenvolvimento de ferramentas de teste. Na Seção 5.2 são descritos os aspectos operacionais e de implementação da ferramenta JaBUTi. Tal ferramenta apóia os critérios de teste estruturais definidos nesta tese e descritos anteriormente na Seção 3.3 do Capítulo 3. A idéia básica desta ferramenta é viabilizar o teste de programas Java em nível de bytecode, possibilitando com isso, não somente o teste de programas Java para os quais o código fonte esteja disponível mas também o teste de componentes Java.

Posteriormente, na Seção 5.3, é apresentada a arquitetura de uma ferramenta de teste que vem sendo desenvolvida para apoiar a aplicação dos critérios de teste baseados em mutação, considerando o teste intra-método, inter-método e inter-classe, implementando os operadores de mutação descritos nas Seções 4.3.1, 4.3.2 e 4.3.3 do Capítulo 4, respectivamente. 


\subsection{Motivação}

A disponibilidade de ferramentas de teste contribui para a formação de recursos humanos e permite a transferência de tecnologia para as indústrias, viabilizando uma contínua evolução de tais ambientes, fatores indispensáveis para a produção de software de alta qualidade. Além disso, a existência de ferramentas auxilia pesquisadores e alunos de Engenharia de Software a adquirirem os conceitos básicos e experiência na comparação, seleção e estabelecimento de estratégias de teste.

Outro fator importante é o suporte oferecido pelas ferramentas aos testes de regressão. Os casos de teste utilizados durante a atividade de teste podem ser facilmente recuperados para revalidação do software após uma modificação. Com isso, é possível verificar se a funcionalidade do software foi alterada, reduzir o custo para gerar os testes de regressão e comparar os resultados obtidos nos testes de regressão com os resultados do teste original (Maldonado, 1997; Maldonado et al., 1998).

Como comentado anteriormente, diversos trabalhos vêm sendo realizados nessa direção. Para o teste de programas OO, conforme apresentado na Seção 2.8, além da ferramenta ${ }_{\mathcal{X}}$ Suds (Agrawal et al., 1998; Telcordia Technologies - USA, 1998), existem outras ferramentas disponíveis, com por exemplo, a ferramenta SoftTest (BENDER \& Associates Inc., 1998), a ferramenta Panorama (INTERNATIONAL SOFTWARE AUTOMATION (ISA), 1999a,b) e as ferramentas Rational PureCoverage (RATIONAL Software Corporation, 2000a) e Rational Purify (RATIONAL Software Corporation, 2000b), dentre outras. Entretanto, dentre as que se destinam ao teste estrutural de programas, observou-se que a maioria requer o código fonte para viabilizar a aplicação dos critérios de teste e, além disso, nenhuma delas apóia o teste de fluxo de dados em programas OO. No contexto do teste de mutação, as ferramentas desenvolvidas apóiam a realização do teste inter-classe em programas Java utilizando diferentes conjuntos de operadores de mutação (Alexander et al., 2002; Bieman et al., 2001; Chevalley, 2001; Ma et al., 2002; Bybro, 2003). Nenhuma delas apóia o teste intra-método ou inter-método de programas OO.

\subsection{A Ferramenta JaBUTi - Teste de Fluxo de Dados 00}

A ferramenta JaBUTi (Java Bytecode Understanding and Testing) visa a ser um ambiente completo para o entendimento e teste de programas e componentes Java. JaBUTi fornece ao testador diferentes critérios de teste estruturais para a análise de cobertura, um conjunto de métricas estáticas para se avaliar a complexidade das classes que compõem do programa/componente, e implementa ainda algumas heurísticas de particionamento de programas que visam a auxiliar a localização de defeitos. 
No contexto desta tese, ênfase é dada à parte da ferramenta responsável pela análise de cobertura. Mais informações sobre as demais funcionalidades da ferramenta podem ser obtidas a partir do Manual do Usuário (Vincenzi et al., 2004b). Considerando o suporte à análise de cobertura de programas Java, a ferramenta JaBUTi implementa atualmente seis dos oito critérios de teste intra-métodos definidos no Capítulo 3, sendo quatro critérios de fluxo de controle (Todos-Nós ${ }_{e i}$, Todos-Nós ${ }_{e d}$, Todas-Arestas ${ }_{e i}$,Todas-Arestas $e d$ ) e dois critérios de fluxo de dados (Todos-Usos ${ }_{e i}$ e Todos-Usos ${ }_{e d}$ ). Os critérios Todos-Pot-Usos ${ }_{e i}$ e Todos-Pot-Usos $e_{e d}$ ainda estão fase de implementação. Como descrito na Seção 3.3 do Capítulo 3, observe-se que os pares de critérios Todos-Nós ${ }_{e i}$, Todos-Nós Tod $_{e d}$ Todas-Arestas ${ }_{e i}$, Todas-Arestas $_{e d}$ compõem os critérios Todos-Nós e Todos-Arcos, respectivamente (Roper, 1994), da mesma forma que os pares de critérios Todos-Usos ${ }_{e i}$, Todos-Usos $_{e d}$ e Todos-Pot-

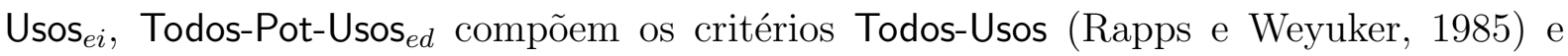
Todos-Pot-Usos (Maldonado, 1991), respectivamente.

A decisão por dividir esses critérios foi tomada em virtude da distinção entre partes de código relacionadas com a execução "normal" do programa daquelas relacionadas com o tratamento de exceções. Tal distinção permite ao testador se concentrar em aspectos diferentes do programas, um de cada vez, realizando a atividade de teste de modo incremental e respeitando as restrições de tempo e custo que lhe forem impostas (Vincenzi et al., 2003a).

As principais atividades executadas pela JaBUTi para realizar a análise de cobertura são: instrumentar arquivos .class, coletar informação de cobertura durante a execução do programa (execution trace information), e determinar quão bem cada um dos métodos de todas as classes foram testados de acordo com os critérios de teste disponíveis.

Para facilitar a geração de casos de teste de modo a aumentar a cobertura em relação aos critérios de teste, utilizando o conceito de dominadores e super-bloco (Agrawal, 1994), a ferramenta atribui diferentes pesos aos requisitos de teste indicando qual o requisito de teste que, se coberto, aumentaria a cobertura em relação ao critério considerado o máximo possível. Para avaliar o andamento da atividade de teste, relatórios de teste com diferentes níveis de granularidade (por projeto, por classe, por método, por caso de teste) podem ser gerados para auxiliar o testador a decidir quando parar os testes ou quais partes ainda não foram suficientemente testadas.

Na Seção 5.2.1 é apresentada a arquitetura da ferramenta e discutidos os aspectos de implementação. Na Seção 5.2.2 são descritos os aspectos operacionais da ferramenta JaBUTi. 


\subsubsection{Arquitetura e Aspectos de Implementação}

A ferramenta JaBUTi é completamente implementada em Java, principalmente pela portabilidade oferecida pela linguagem, viabilizando a utilização da ferramenta por desenvolvedores em diferentes plataformas. A implementação da ferramenta segue o diagrama apresentado na Figura 5.1.

Como pode ser observado, a JaBUTi têm duas partes principais. A primeira (correspondente a parte superior da Figura 5.1) é responsável pela realização da análise estática, computação dos requisitos de teste e avaliação da cobertura dos casos de teste. A segunda (correspondente a parte inferior da Figura 5.1) é responsável pela instrumentação, carregamento, execução das classes sendo testadas e pela coleta das informações de execução (trace information) que são utilizadas para avaliar a cobertura dos requisitos de teste.

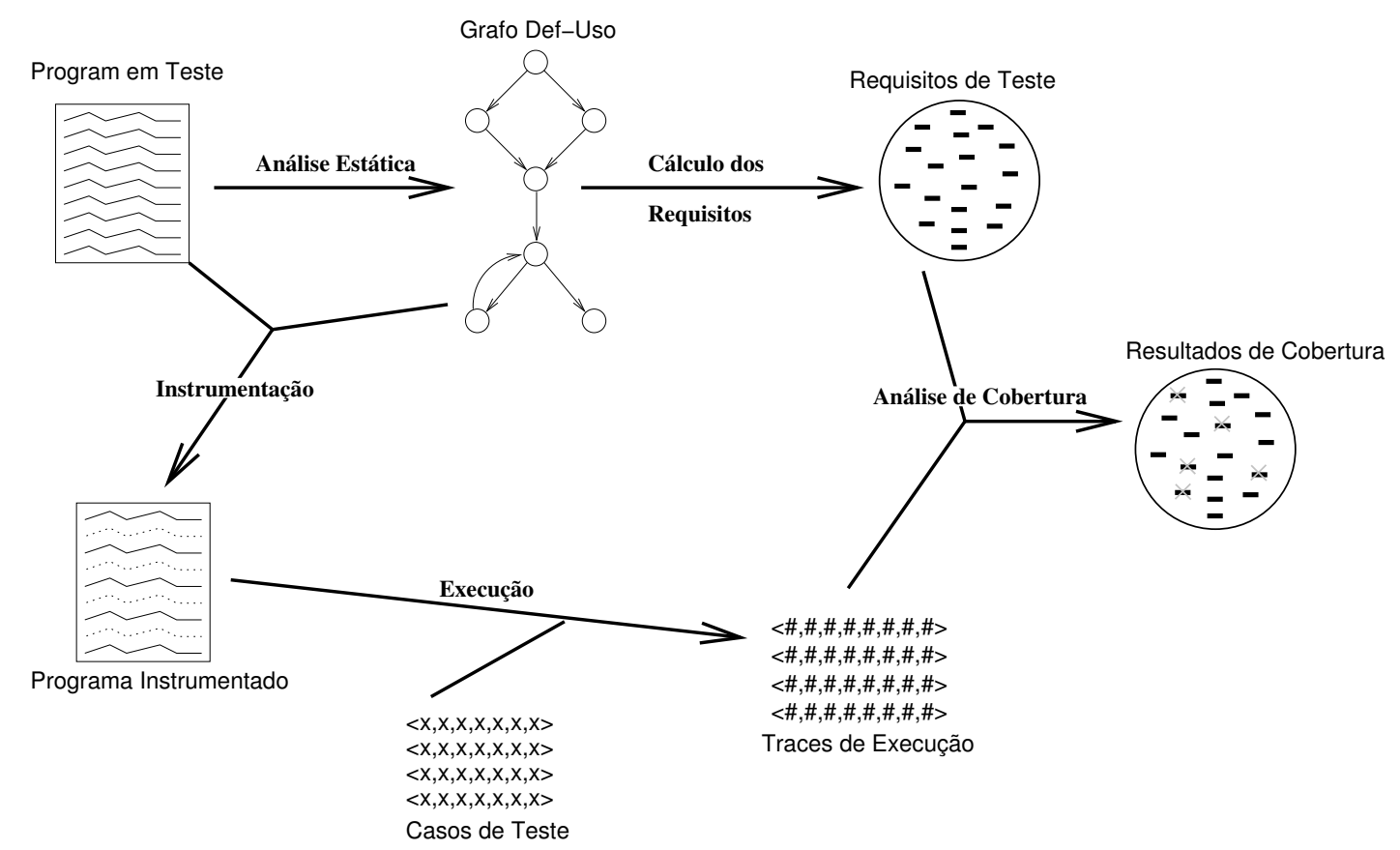

Figura 5.1: Síntese das operações realizadas para análise de cobertura.

As classes que implementam a ferramenta estão agrupadas em 11 pacotes. Seis deles (criteria, graph, lookup, metrics, project and verifier) são responsáveis pela realização da análise estática, implementação dos critérios de teste e avaliação da cobertura. Os demais estão relacionados com a implementação da interface gráfica e com a coleta e armazenamento das informações de execução. A Tabela 5.1 ilustra a complexidade de cada um desses pacotes em termos do número de linhas de código (LOC) e instruções de bytecode (Size), além de apresentar a razão entre o número de instruções de bytecode por linha de código (Size/LOC). Por exemplo, as classes que compõem o pacote graph têm 1117 LOC 
as quais correspondem a 4566 instruções de bytecode, uma média de 4,09 instruções por linha de código. Ao todo, o conjunto completo das classes que implementam a ferramenta correspondem a 13096 LOC, equivalentes a 64545 instruções de bytecode, ou seja, 4,93 instruções por linha de código. O tamanho de cada pacote varia de 282 LOC (para o pacote probe) a 4434 LOC (para o pacote gui), resultando em um tamanho médio de 1190,55 LOC por pacote.

Tabela 5.1: Complexidade dos pacotes que compõem a ferramenta JaBUTi.

\begin{tabular}{|l|r|r|r|}
\hline Pacote & LOC & Size & Size/LOC \\
\hline \hline criteria & 556 & 2547 & 4,58 \\
\hline graph & 1117 & 4566 & 4,09 \\
\hline gui & 4434 & 19958 & 4,50 \\
\hline gvf & 428 & 2060 & 4,81 \\
\hline instrumenter & 2389 & 15816 & 6,62 \\
\hline lookup & 386 & 1729 & 4,48 \\
\hline metrics & 553 & 2601 & 4,70 \\
\hline probe & 282 & 1409 & 5,00 \\
\hline project & 1248 & 5670 & 4,54 \\
\hline util & 682 & 3408 & 5,00 \\
\hline verifier & 1021 & 4781 & 4,68 \\
\hline \hline Total & 13096 & 64545 & 4,93 \\
\hline Média & 1190,55 & 5867,73 & 4,82 \\
\hline
\end{tabular}

A ferramenta utiliza ainda alguns pacotes de terceiros, também desenvolvidos em Java, tais como o BCEL (Bytecode Engineering Library) (Dahm, 2001), necessário para a manipulação do bytecode. A Figura 5.2 ilustra a utilização dos módulos principais da JaBUTi durante a análise de cobertura.

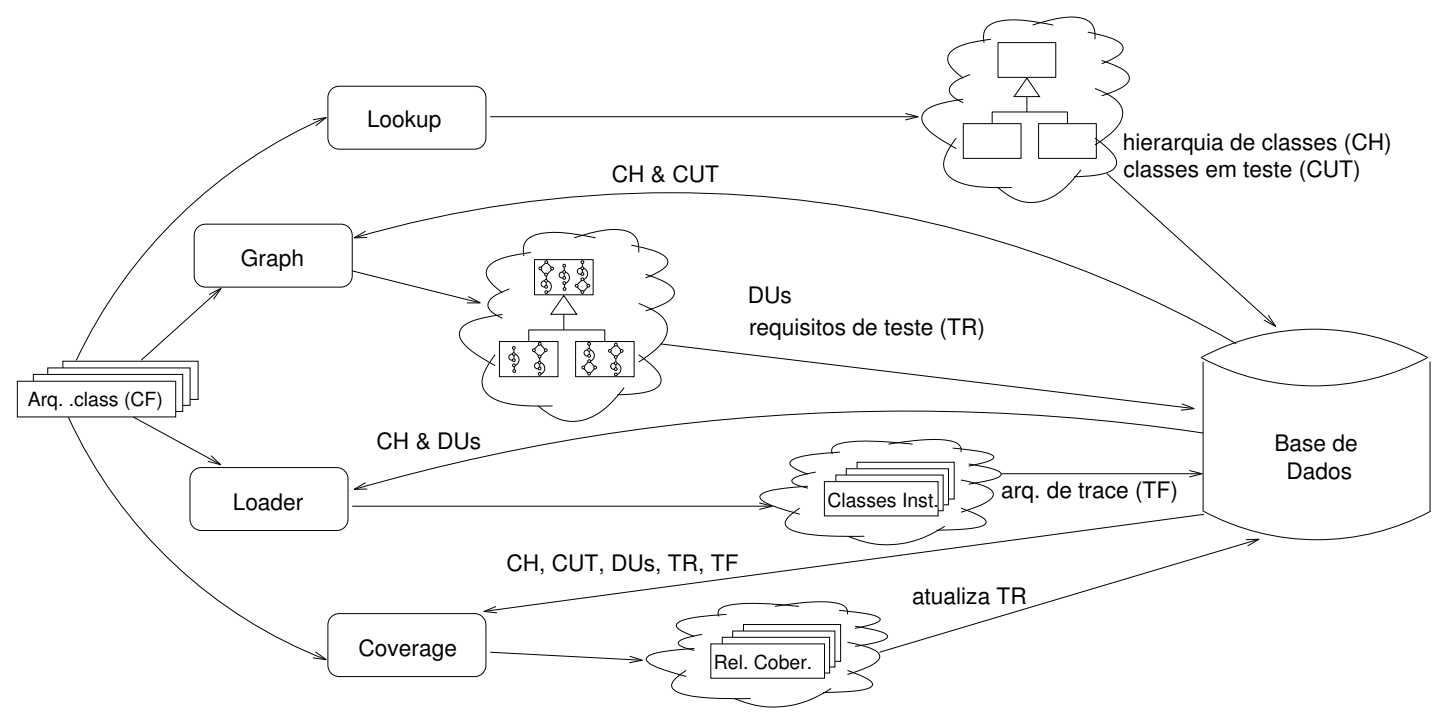

Figura 5.2: Módulos principais da ferramenta JaBUTi.

O primeiro passo para se conduzir uma sessão de teste na JaBUTi é a criação de um projeto de teste (um arquivo .jbt, e.g. vending.jbt), o qual identifica o conjunto de classes 
em teste (CUTs). O módulo Lookup é utilizado para identificar a hierarquia completa das classes que compõem a aplicação. Ele recebe como entrada um determinado arquivo .class $(\mathrm{CF})$, o qual corresponde a classe base da aplicação, e produz como saída toda a hierarquia de classes $(\mathrm{CH})$ necessária para se executar a classe base, incluindo tanto classes do sistema quanto classes definidas pelo usuário. A partir das classes definidas pelo usuário qualquer subconjunto de classes pode ser selecionado, caracterizando as classes a serem testadas CUTs. CH e CUT são armazenadas em uma base de dados do projeto. Selecionadas as CUTs, a ferramenta utiliza o módulo Graph para a construção dos grafos def-uso $(\mathcal{D U} \mathcal{G})$ de cada método. A partir do $\mathcal{D U \mathcal { G }}$, os requisitos de teste (TRs) referentes aos oito critérios estruturais implementados pela JaBUTi são derivados e armazenados na base de dados do projeto para serem utilizados posteriormente para a análise de cobertura.

O módulo Loader é o carregador de classes (class loader) da JaBUTi. Tal módulo instrumenta as CUTs, carrega as classes instrumentadas para serem executadas, e armazena as informações de execução em um arquivo de trace (TF) (um arquivo com extensão .trc, e.g. vending.trc). Cada execução do carregador de classes da JaBUTi corresponde a um novo caso de teste sendo adicionado. Observa-se que o carregador de classes sempre realiza a instrumentação das classes on-the-fly, acarretando um atraso na execução das classes sendo testadas. Opcionalmente, o testador pode criar um arquivo ".jar" contendo as classes já instrumentadas evitando o atraso no processo de instrumentação.

O módulo Coverage utiliza as informações produzidas pelos outros módulos, incluindo o conjunto de requisitos de teste (TR) e o arquivo de trace (TF), para identificar o conjunto de requisitos que foram cobertos considerando a execução dos casos de teste armazenados em TF. Ele também é responsável pela geração dos diferentes relatórios de teste, os quais são utilizados pelo testador para avaliar a qualidade do conjunto de teste e decidir quando parar os testes.

\subsubsection{Aspectos Operacionais}

A forma mais fácil de se utilizar a ferramenta JaBUTi é por meio de sua interface gráfica. Outra alternativa seria a utilização da ferramenta invocando seus módulos diretamente via scripts de teste. Entretanto, os módulos para a invocação da ferramenta via scripts ainda estão sendo desenvolvidos.

Considerando a utilização da ferramenta via interface gráfica, o primeiro passo para conduzir uma atividade de teste com a JaBUTi é a criação de um projeto de teste, o qual contém informações sobre as classes a serem testadas. 


\subsubsection{Programa Exemplo}

Para ilustrar os aspectos operacionais da JaBUTi, um exemplo simples, adaptado de Orso et al. (2001), será utilizado. O exemplo implementa o comportamento de uma máquina de venda (vending machine) típica e é composto de duas classes: uma que implementa um componente Dispenser e outra, VendingMachine, que utiliza o componente Dispenser. O código fonte em Java de ambas as classes é apresentado na Figura 5.3.

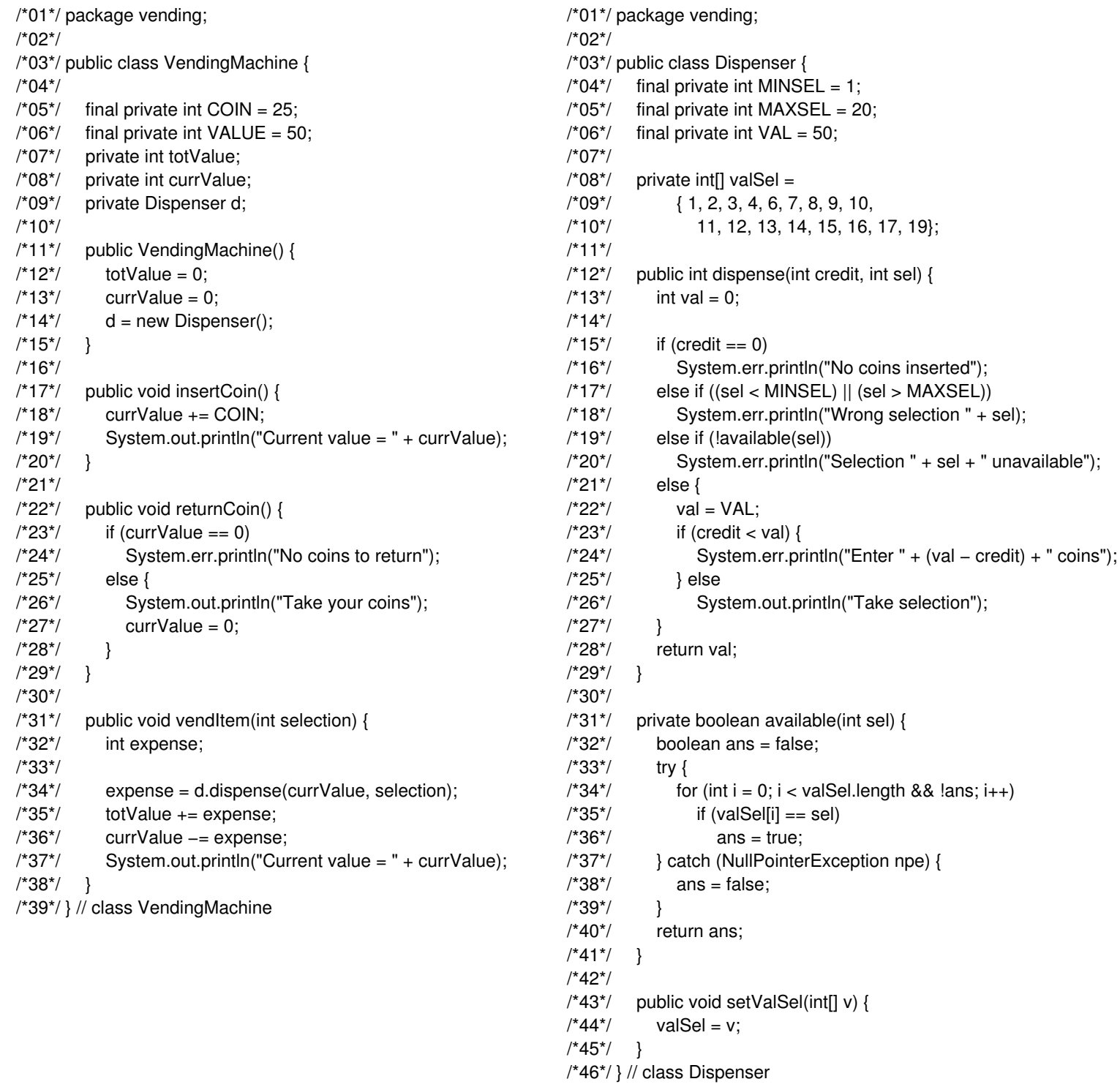

Figura 5.3: Exemplo de uma aplicação Java (VendingMachine) e um componente (Dispenser) (Orso et al., 2001).

O componente Dispenser é responsável por manter as informações sobre o preço de cada item e quais deles são válidos e estão disponíveis. O método mais importante da classe Dispenser é o método Dispenser.dispense(), o qual é responsável por receber como 
parâmetros a quantia em dinheiro depositada na máquina e o número do item selecionado pelo usuário e decidir se o item pode ou não ser entregue ao usuário. Tal método realiza os seguintes passos:

1. Verifica se pelo menos uma moeda foi depositada na máquina;

2. Verifica se um item válido foi selecionado;

3. Verifica se o item válido encontra-se disponível (para isso utiliza o método Dispenser.available());

4. Verifica se o valor fornecido é suficiente para comprar o item válido e disponível selecionado.

Se todos os pré-requisitos acima forem satisfeitos o componente Dispenser entrega o item desejado pelo usuário. Do contrário, caso alguma das condições acima não seja satisfeita uma mensagem de erro é emitida e nenhum item é entregue ao usuário.

\subsubsection{Criando um Projeto de Teste}

Para a criação do projeto de teste o testador deve, primeiramente, fornecer o nome de uma classe base, ou seja, o nome de uma classe tipo aplicação a partir da qual as demais classes relacionadas serão derivadas. Fornecido o nome da classe base, a ferramenta exibe a janela do Gerenciador de Projeto (Project Manager), como ilustrado na Figura 5.4. Do lado esquerdo desta janela encontra-se o conjunto completo das classes que foram identificadas a partir da classe base pelo módulo Lookup (descrito na seção anterior) e que podem ser selecionadas para serem testadas. No exemplo, duas foram as classes selecionadas VendingMachine e Dispenser.

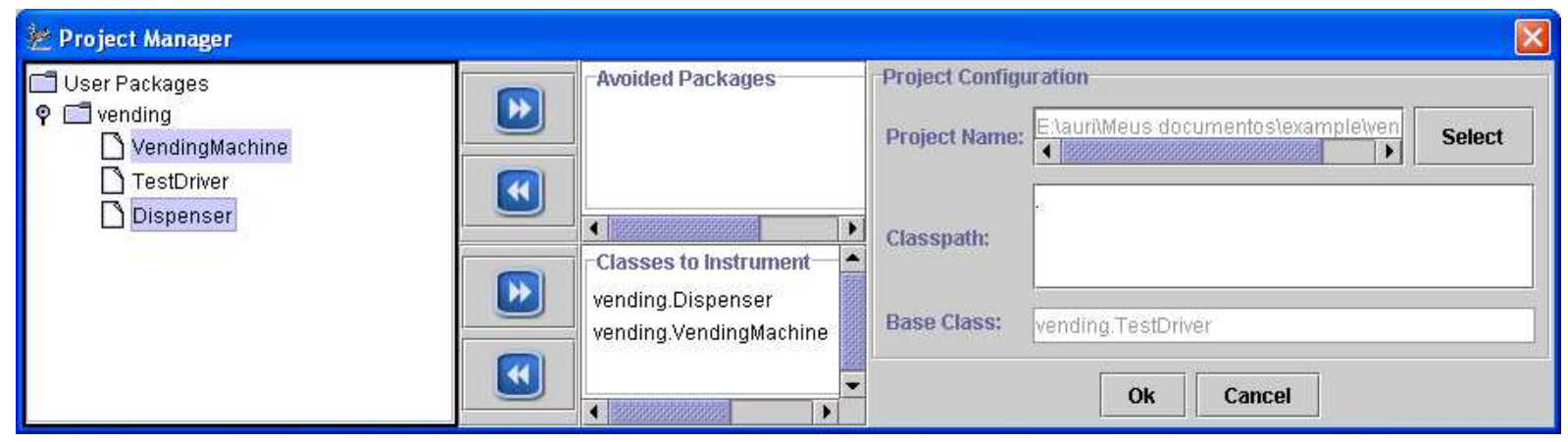

Figura 5.4: Janela do gerenciador de projetos.

Pressionando o botão Ok, JaBUTi cria um novo projeto (vending.jbt no exemplo), constrói o grafo definição-uso $(\mathcal{D U \mathcal { G }})$ para cada método de cada classe a ser testada 
(conforme descrito no Capítulo 3), deriva os requisitos de teste de cada critério, calcula o peso desses requisitos, e apresenta na tela o bytecode de uma das classes sendo testadas, como ilustrado na Figura 5.5. Além da visualização do bytecode, a ferramenta oferece ainda a visualização do grafo $\mathcal{D U} \mathcal{G}$ de cada método, conforme ilustrado na Figura 5.6, e também do código fonte correspondente ao bytecode, conforme ilustrado na Figura 5.7 (quando tal código fonte encontra-se disponível). Observa-se que as telas apresentadas neste capítulo são referentes a uma versão da ferramenta na qual os critérios independentes de exceção eram denominados critérios primários e os critérios dependentes de exceção eram denominados critérios secundários. Assim sendo, o critério All-Pri-Nodes que aparece nas telas corresponde ao critério Todos-Nós ${ }_{e i}$ e o critério All-Sec-Nodes corresponde ao

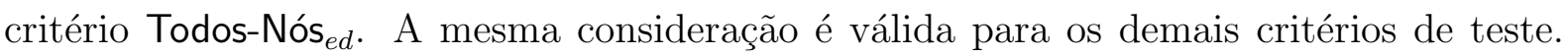
No texto, o nome dos critérios conforme definido no Capítulo 3 é utilizado.

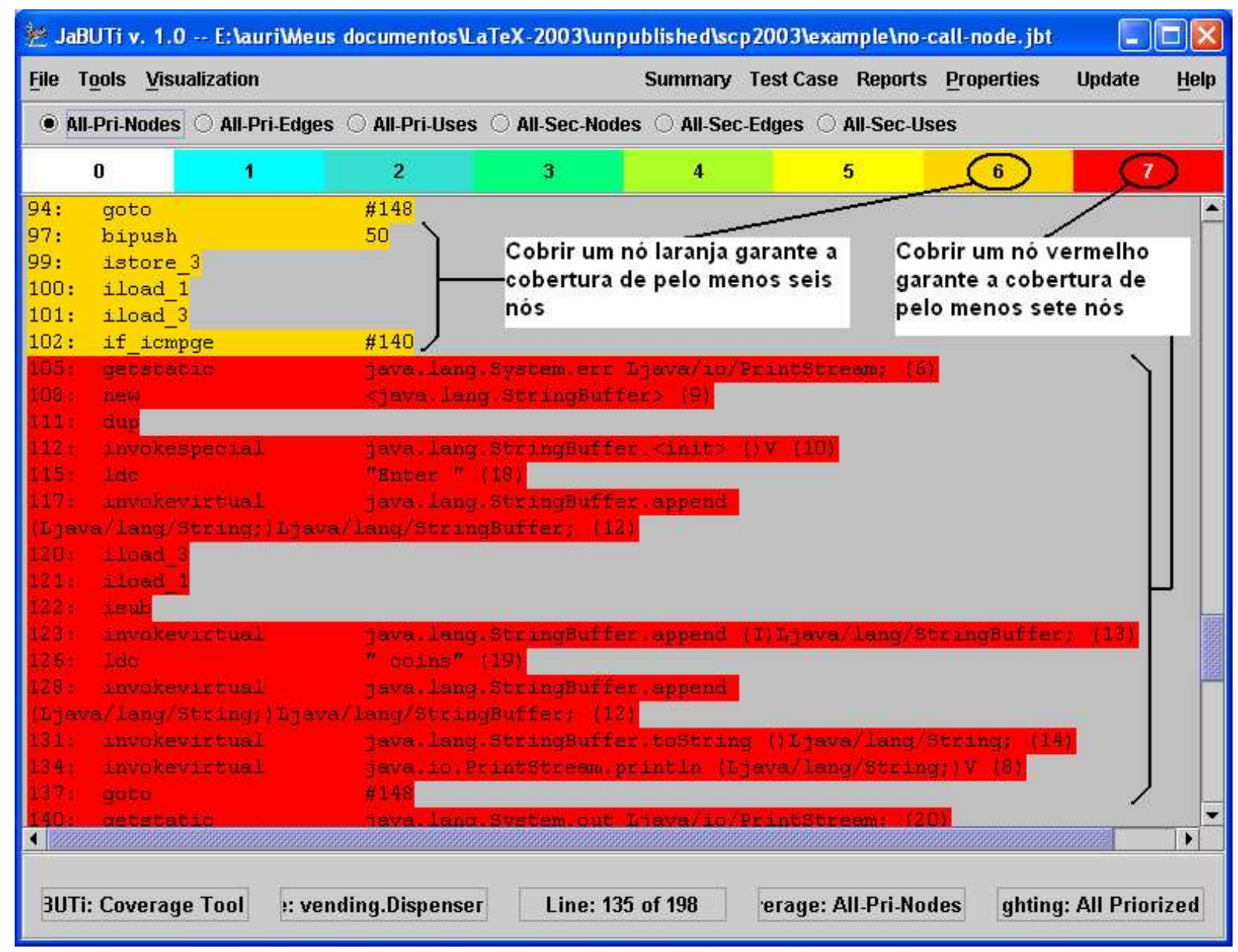

Figura 5.5: Tela da JaBUTi considerando ativo o critério Todos-Nós ${ }_{e i}$ : Bytecode inicial. 


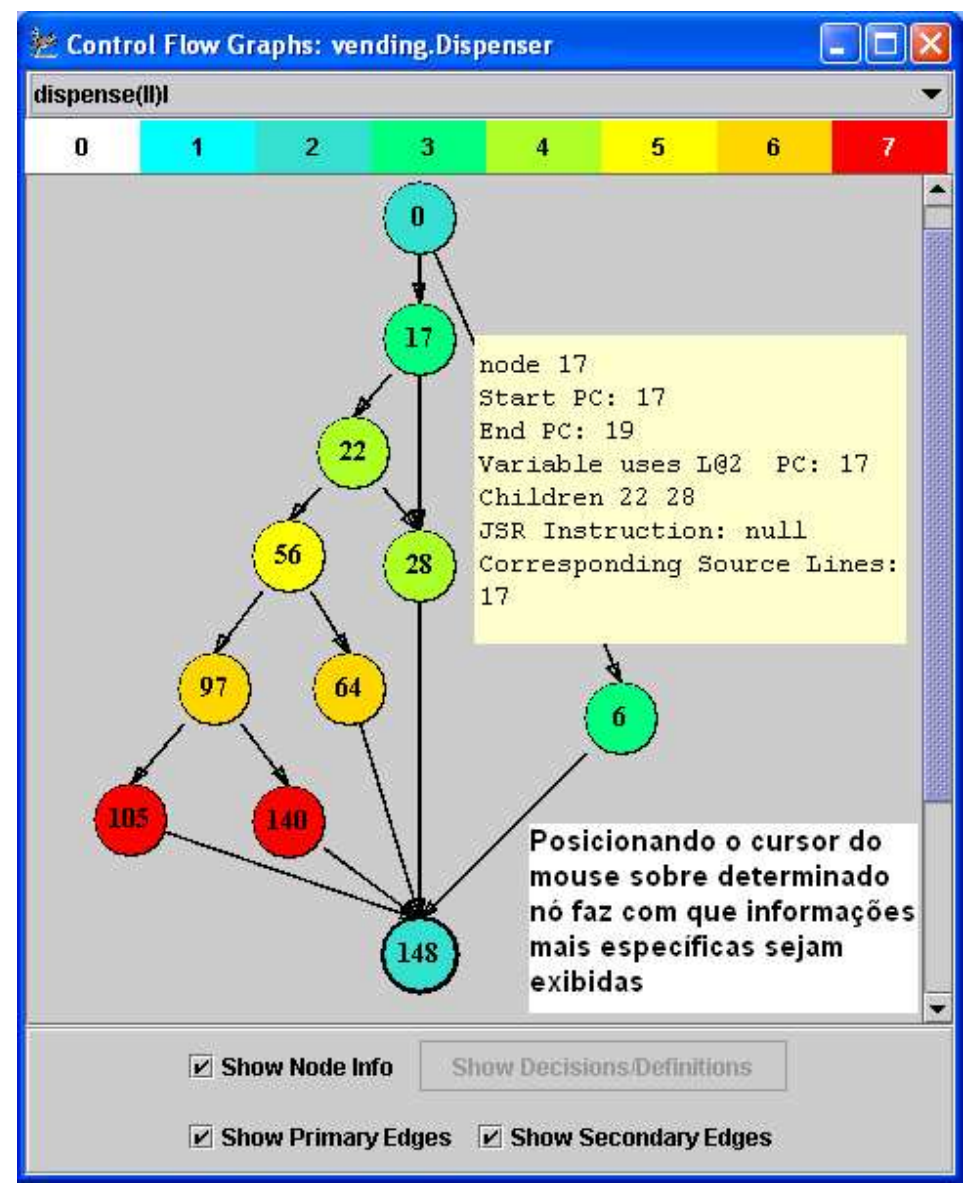

Figura 5.6: Tela da JaBUTi considerando ativo o critério Todos-Nós ${ }_{e i}$ : $\mathcal{D U G}$ inicial.

\subsubsection{Melhorando a Cobertura dos Requisitos de Teste}

Uma vez que o conjunto de requisitos de teste de cada critério foi determinado, tais requisitos podem ser utilizados para avaliar a qualidade de um conjunto de teste existente e/ou para desenvolver novos casos de teste visando a melhorar a cobertura dos requisitos pelo conjunto de teste.

Por exemplo, o testador pode decidir criar um conjunto de teste com base em critérios de teste funcionais ou mesmo gerar um conjunto de teste $a d$-hoc e avaliar a cobertura desse conjunto de teste em relação a cada um dos critérios de teste estruturais da JaBUTi. Por outro lado, o testador pode visualizar o conjunto de requisitos de teste de cada critério gerados para cada um dos métodos das classes sendo testadas, verificar quais deles ainda não foram cobertos por algum caso de teste e então desenvolver um novo caso de teste que cubra tais requisitos. As Figuras 5.8(a), 5.8(b), e 5.8(c) ilustram parte dos requisitos de teste do método Dispenser.avaliable() gerados pelos critérios Todos-Nós ${ }_{e i}$, Todas-Arestas ${ }_{e i}$, e Todos-Usos ${ }_{e i}$, respectivamente. 


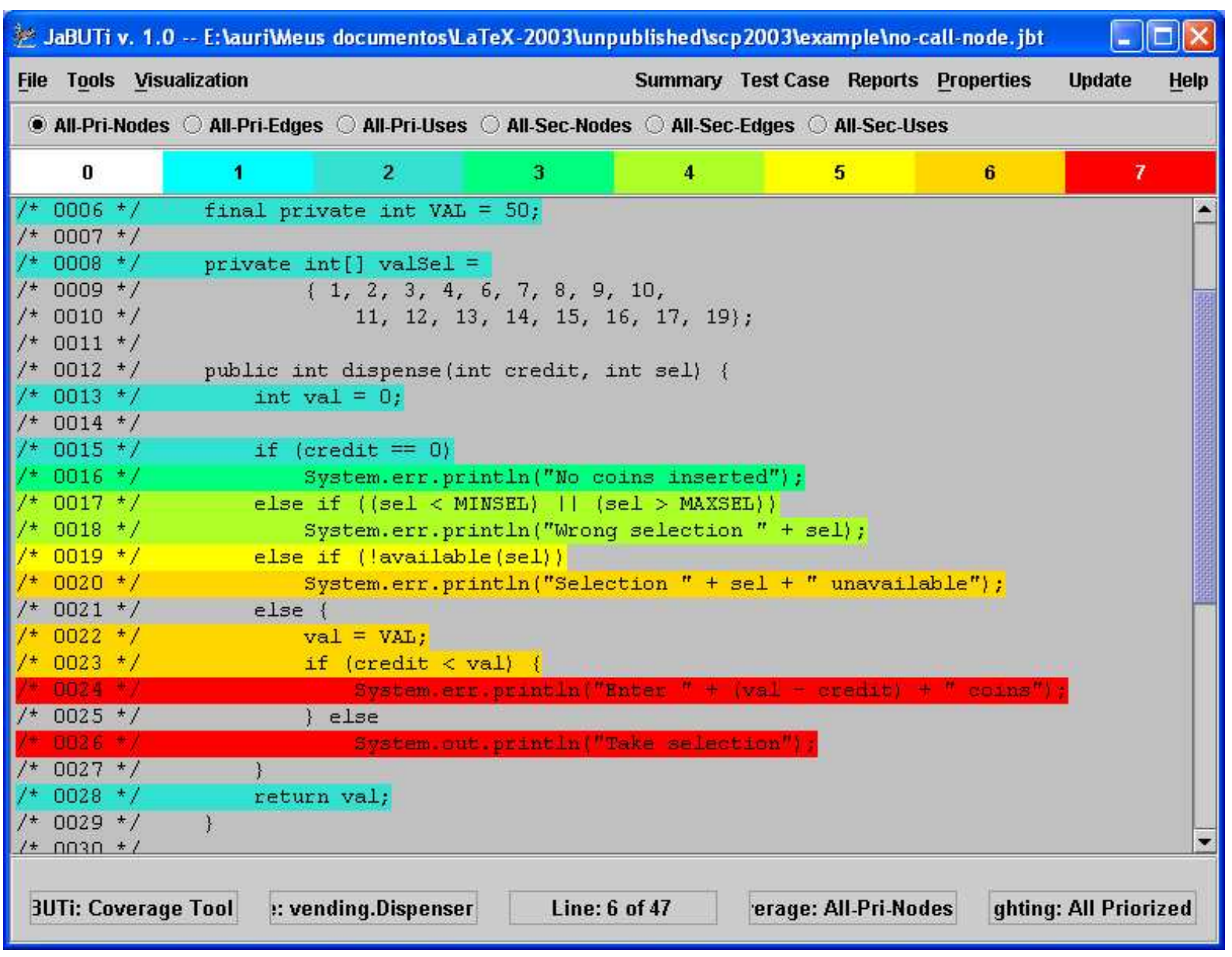

Figura 5.7: Tela da JaBUTi considerando ativo o critério Todos-Nós ${ }_{e i}$ : Código fonte inicial.

Como pode ser observado na Figura 5.8, a ferramenta permite ao testador ativar/desativar diferentes combinações de requisitos de teste, bem como marcar um determinado requisito de teste como não-executável quando não existir um caso de teste capaz de cobri-lo.

Estudos têm demonstrado que, para programas C, conjuntos de teste que determinam as maiores coberturas têm uma maior probabilidade de detectar defeitos no programa em teste (Piwowarski et al., 1993; Wong et al., 1994a). O mesmo se aplica para Java sem perda de generalidade. Uma vez que, em geral, existe um grande número de requisitos de teste para serem cobertos, a ferramenta JaBUTi utiliza cores diferentes dando indicações ao testador para facilitar a geração de casos de teste que cubram um maior número de requisitos em menor tempo. As diferentes cores representam diferentes pesos que são associados aos requisitos de teste de cada critério (Agrawal, 1994). Informalmente, os pesos correspondem ao número de requisitos de teste que são cobertos quando um requisito de teste particular é coberto. Assim sendo, cobrindo os requisitos de teste de maior peso levará a um aumento na cobertura de forma mais rápida. 


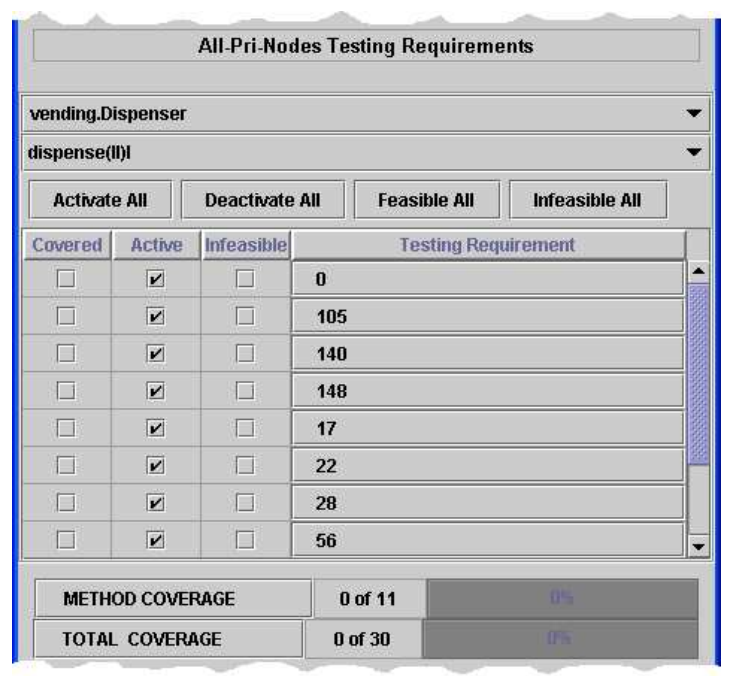

(a) Todos-Nós ${ }_{e i}$

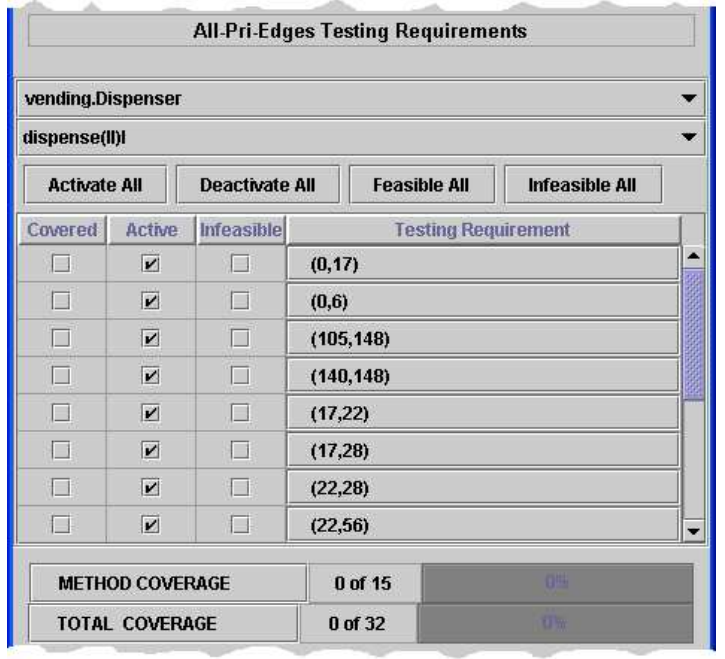

(b) Todas-Arestas Ti

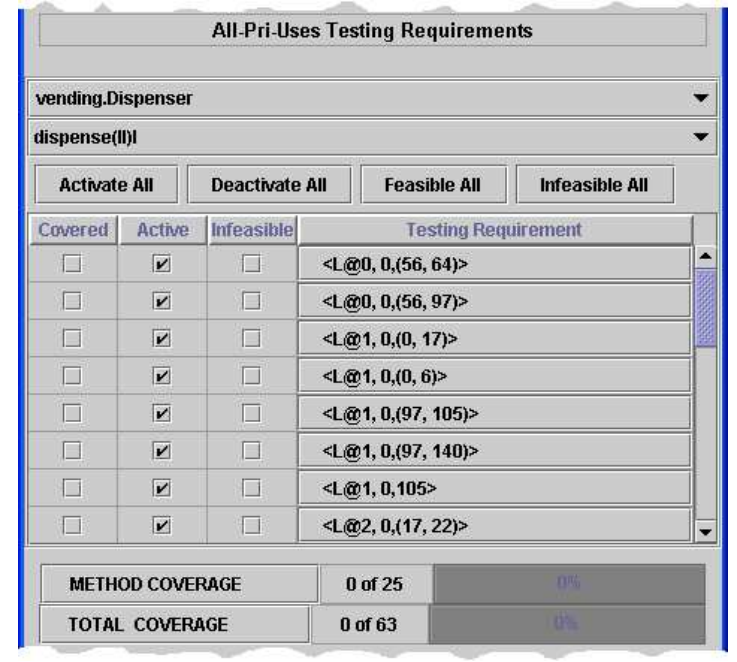

(c) Todos-Usos ei

Figura 5.8: Parte dos requisitos de teste de três critérios estruturais para o método Dispenser.dispense().

Observe que o peso é calculado considerando somente informações sobre cobertura e por esse motivo devem ser vistos como "indicações" ao testador. No cálculo do peso não é levado em conta, por exemplo, a complexidade ou a criticalidade de uma determinada parte do programa. Além disso, o cálculo do peso por meio do uso de superblocos e de dominadores não é preciso quando não se pode garantir a execução normal do método até um nó de saída, o que pode ocorrer em Java quando uma exceção é levantada. O testador, baseado em sua experiência pode decidir cobrir outros requisitos de teste que estejam com trechos de código que apresentam uma alta complexidade e não tenham os maiores pesos. Posteriormente, após os trechos de código desejado terem sido suficientemente testados o, 
testador pode então utilizar as dicas para melhorar a cobertura do conjunto de teste de forma mais rápida.

As Figuras 5.5, 5.6 e 5.7 mostram parte do bytecode, do grafo $\mathcal{D U G}$ e do código fonte do método Dispenser.dispense(), respectivamente, antes da execução de qualquer caso de teste. As cores correspondem aos diferentes pesos dos requisitos do critério Todos-Nós ${ }_{e i}$. Observe que a barra de corres vai do branco (peso 0) ao vermelho (peso 7 neste exemplo). O nó 105 da Figura 5.6, composto das instruções de bytecode que vão do pc 105 ao pc 112 (Figura 5.5), é um dos nós de maior peso. Isso representa que um caso de teste que exercite o nó 105 irá aumentar a cobertura em relação ao critério Todos-Nós ${ }_{e i}$ em pelo menos 7 nós. Requisitos com peso zero indicam requisitos que já foram cobertos e são pintados em branco.

Por exemplo, o caso de teste 0001, desenvolvido para executar o comando localizado no nó 105 da Figura 5.6, determina uma cobertura de 56\% em relação ao critério TodosNós $_{e i}$, o que corresponde a execução de 17 dos 30 nós independentes de exceção requeridos pelo critério em relação aos métodos de todas as classes sendo testadas (veja relatório da Figura 5.13(c)). Toda vez que um novo caso de teste é inserido, as telas da ferramenta são atualizadas considerando as possíveis mudanças nos pesos dos requisitos de teste.

A Figura 5.9 ilustra os novos pesos dos requisitos de teste do critério Todos-Nós ${ }_{e i}$ para o método Dispenser.dispense(). Nessa figura é possível ver claramente que muitos blocos estão pintados de branco porque foram cobertos pelo caso de teste 0001. Também é possível observar que o requisito de maior peso passou para outra parte do código, dando indicações a respeito de qual o próximo caso de teste que deveria ser gerado visando a maximizar o número de requisitos cobertos. A diferença no peso dos requisitos após a execução do caso de teste 0001 pode ser facilmente identificada comparando-se as Figuras 5.5 e 5.9. No exemplo, o requisito de maior peso foi reduzido de 7 para 1 . Isso é consistente com o entendimento dos critérios baseados em cobertura para os quais torna-se cada vez mais difícil melhorar a cobertura após alguns casos de teste terem sido executados.

A título de comparação, supondo que ao invés de utilizar as dicas fornecidas pela ferramenta o testador gerasse um outro caso de teste, por exemplo, o caso de teste 0003 da Figura 5.13(c), o número máximo de nós independentes de exceção que teria sido coberto seria 7. Com isso é possível notar uma diferença significativa entre a cobertura total do critério Todos-Nós ${ }_{e i}$ determinada pelo caso de teste 0001, que foi de $56 \%$, e aquela determinada pelo caso de teste 0003 , que foi de $23 \%$. Uma diferença semelhante é também encontrada em relação aos demais critérios de teste. 


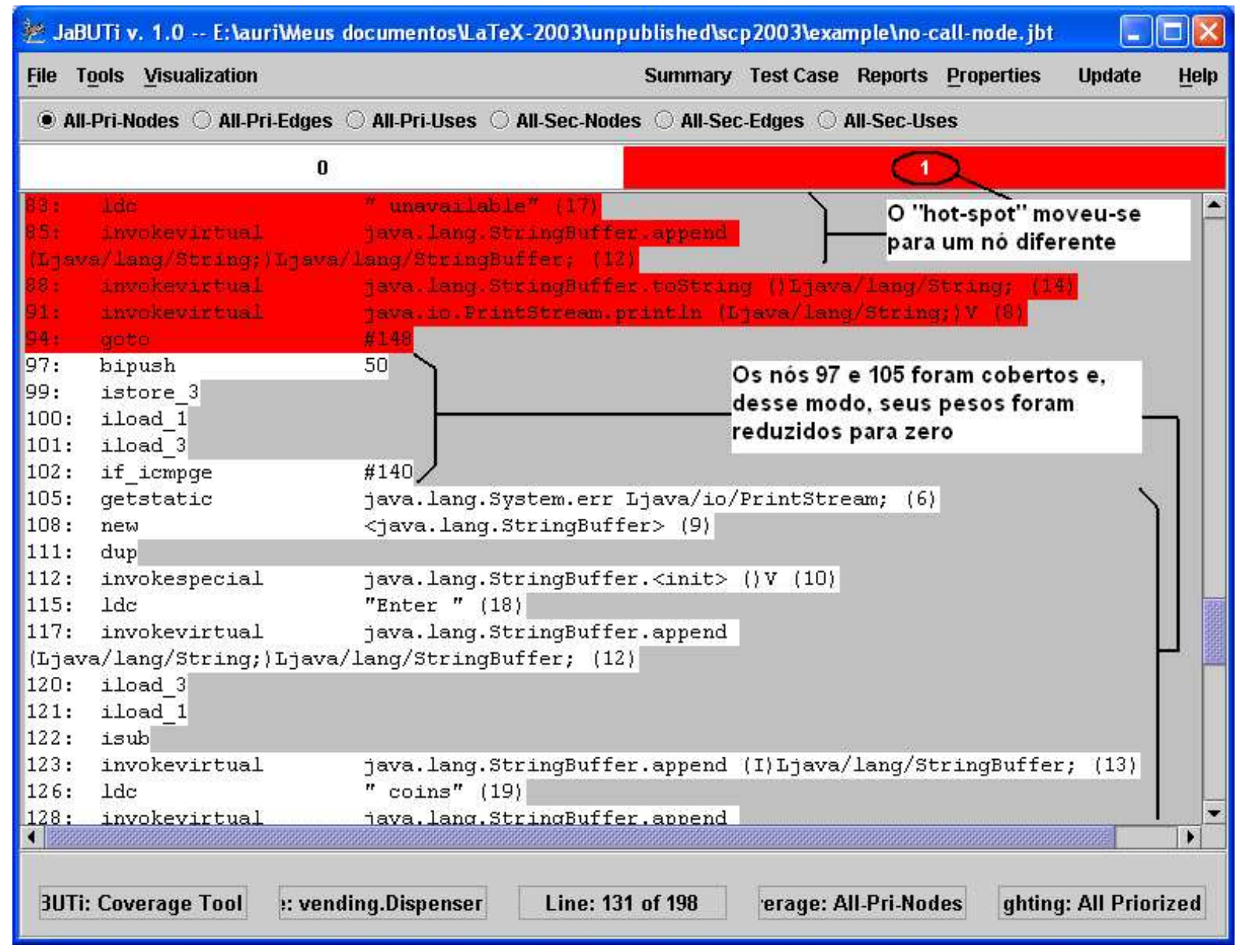

Figura 5.9: Tela atualizada do bytecode do método Dispenser.dispense() para o critério Todos-Nós ${ }_{e i}$ após a execução do caso de teste 0001.

\subsubsection{Visualizando a Cobertura em Programas/Componentes Java e seus Grafos Def-Uso}

A ferramenta JaBUTi permite que os requisitos de teste de cada um de seus critérios possam ser visualizados no bytecode, código fonte e no grafo $\mathcal{D U \mathcal { G }}$ de cada método de cada uma das classes em teste. Diferentes cores são associadas a esses requisitos para indicar os seus pesos. Por exemplo, as Figuras 5.5 e 5.6 ilustram os requisitos do critério Todos-Nós ${ }_{e i}$.

Considerando os critérios Todas-Arestas ${ }_{e i}$ e Todas-Arestas ${ }_{e d}$, seus requisitos (arestas do grafo $\mathcal{D U G})$ são coloridos em duas etapas. Para o critério Todas-Arestas ${ }_{e i}$, somente os nós que apresentem mais de uma aresta regular saindo, ou seja, nós de decisão, aparecem pintados na primeira etapa para indicar os pontos do código onde os comandos de decisão estão localizados. Por exemplo, as Figuras 5.11(a) e 5.11(b) ilustram parte dos nós de decisão do método Dispenser.dispense() e como eles são coloridos na primeira etapa após três casos de teste terem sido executados. 


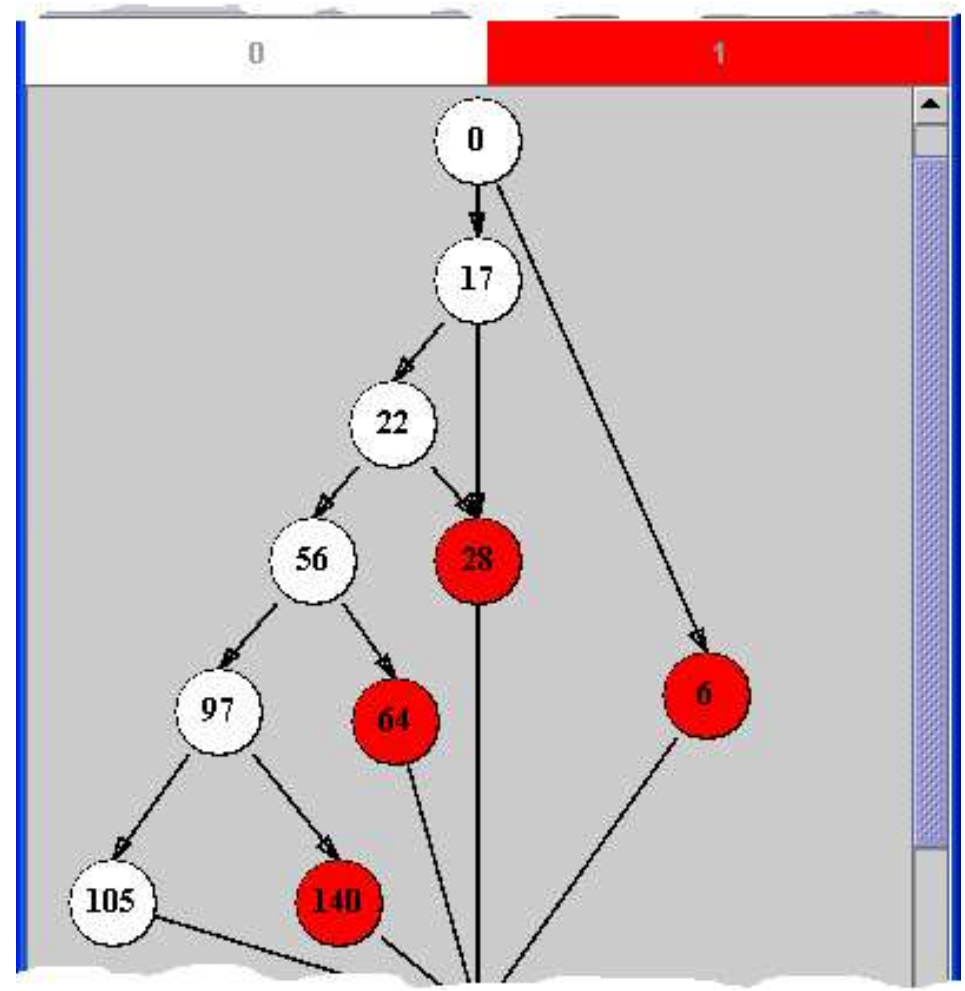

Figura 5.10: Tela atualizada do $\mathcal{D U G}$ do método Dispenser.dispense() para o critério Todos-Nós ${ }_{e i}$ após a execução do caso de teste 0001.

Para cada nó de decisão, seu peso é o maior peso de seus arcos correspondentes. Por exemplo, supondo um nó de decisão $n_{d}$ com duas arestas saindo, uma com peso 0 e outra com peso 2, fará com que o nó $n_{d}$ tenha peso 2. Este é o caso do nó 0 no grafo $\mathcal{D U} \mathcal{G}$ do exemplo sendo utilizado (5.11(b)). Os cinco nós de decisão da Figura 5.11(b) (nós 0, 17, 22, 56 e 97) estão em diferentes cores porque possuem diferentes pesos associados. Um nó de decisão tem peso zero se e somente se todos os arcos a ele associados tiverem sido cobertos. Tal nó é pintado de branco neste caso. Ao selecionar um nó de decisão faz com que a segunda etapa seja realizada (Figuras 5.12(a) e 5.12(b)), identificando-se todas as arestas regulares associadas com o ponto de decisão selecionado. No caso da Figura 5.12(b) são duas as arestas regulares correspondentes: uma do nó 0 para o nó 6 que ainda não foi coberta e está pintada de vermelha, e outra do nó 0 para o nó 17 que já foi coberta e aparece pintada de branco.

Os demais critérios de fluxo de dados também são pintados de forma similar em duas etapas. Mais informações podem ser obtidas no manual de usuário da ferramenta (Vincenzi et al., 2004b). 


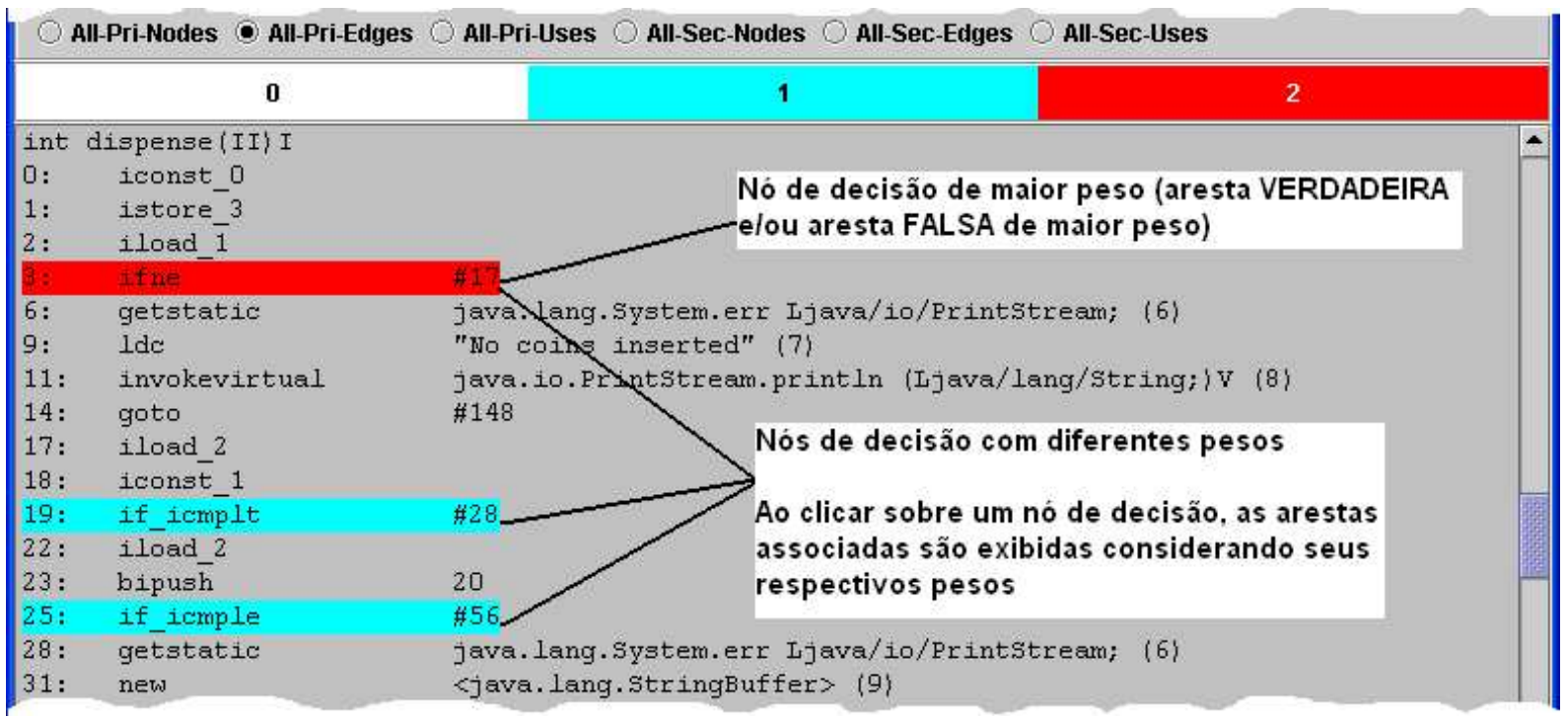

(a) Bytecode $1^{\mathrm{a}}$ etapa

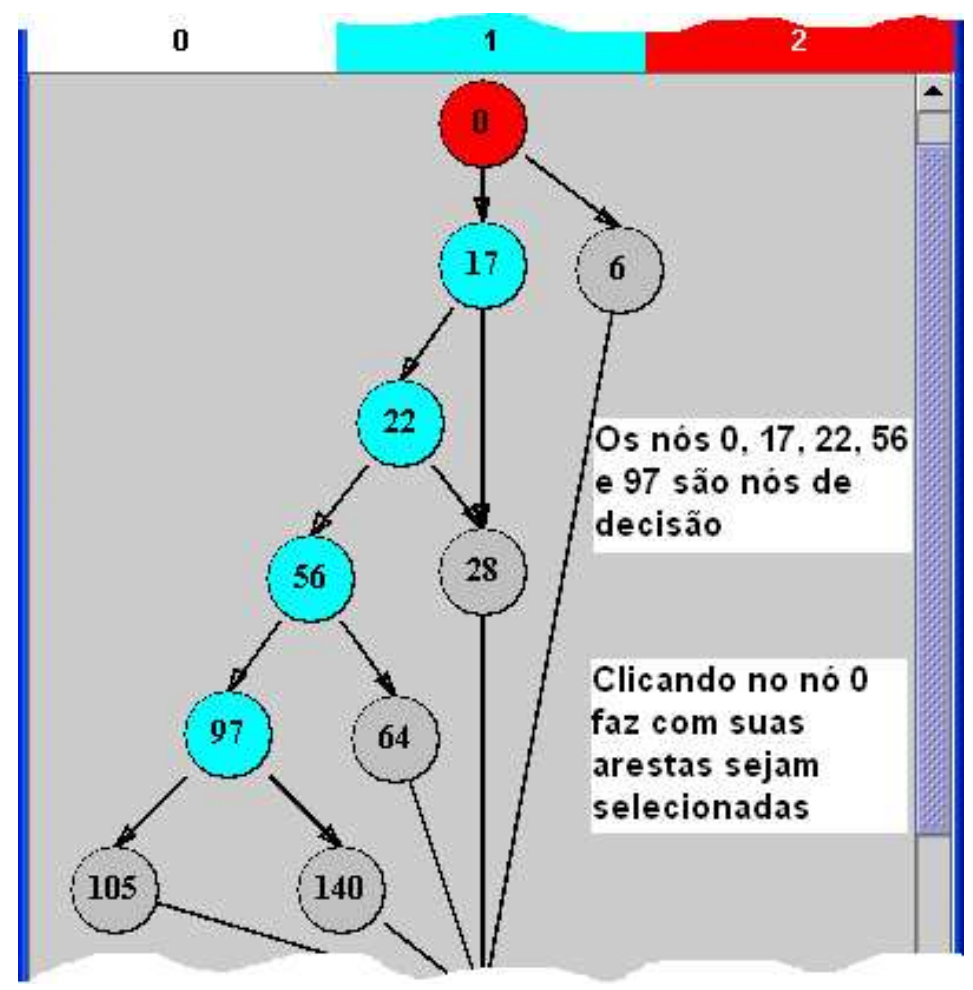

(b) Grafo $\mathcal{D U G} 1^{\mathrm{a}}$ etapa

Figura 5.11: Primeira etapas da exibição dos requisitos do critério Todas-Arestas ${ }_{e i}$ para o método Dispenser.dispense().

\subsubsection{Gerando Relatórios de Teste}

Para avaliar o andamento da atividade de teste o testador pode gerar diferentes tipos de relatórios de teste, em diferentes granularidades, dependendo do nível de detalhe de- 
sejado. Por exemplo, o testador pode estar interessado em avaliar a cobertura do critério Todos-Nós ${ }_{e i}$ em relação a cada método para descobrir quais desses métodos ainda não foi suficientemente testado. Esse tipo de relatório é fornecido pela JaBUTi como ilustrado na Figura 5.13(a).

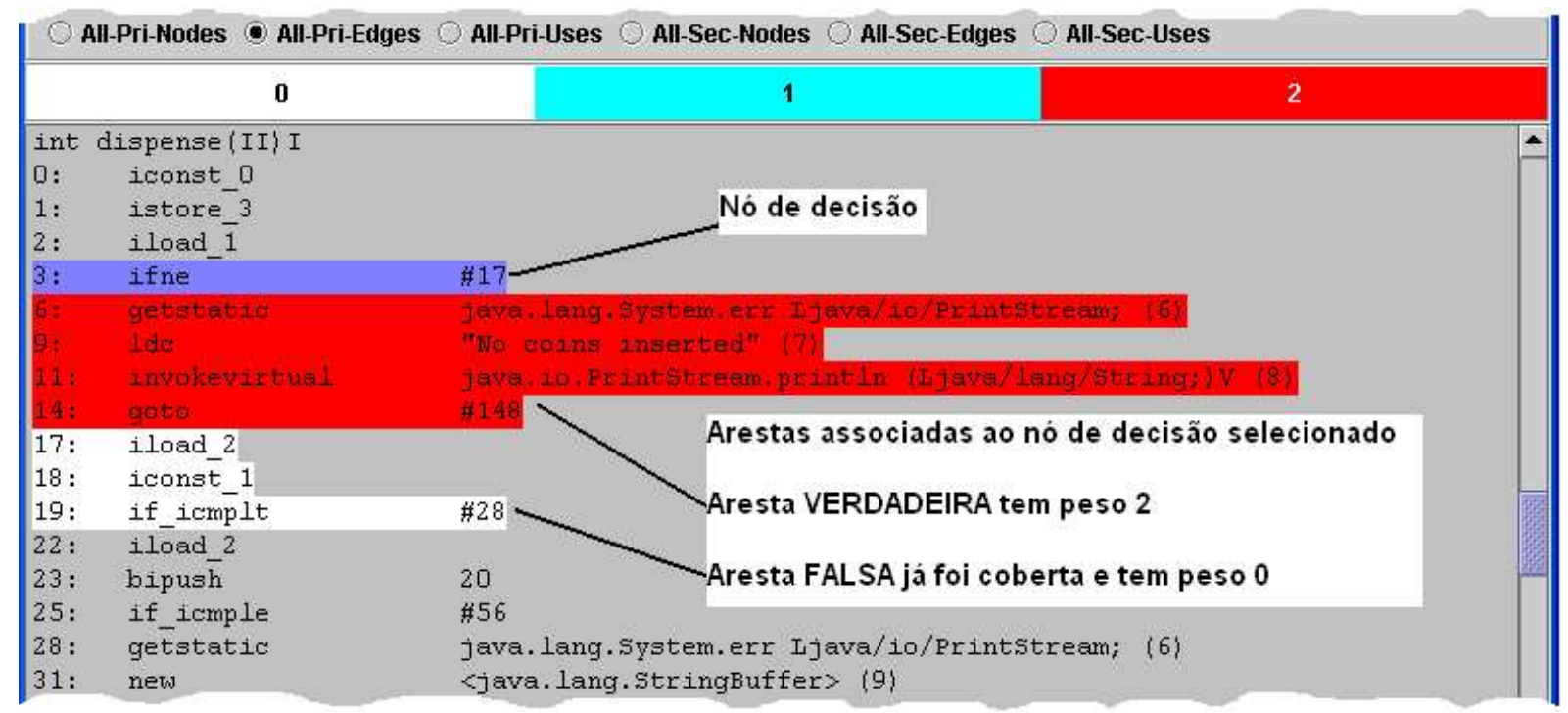

(a) Bytecode $2^{\text {a }}$ etapa

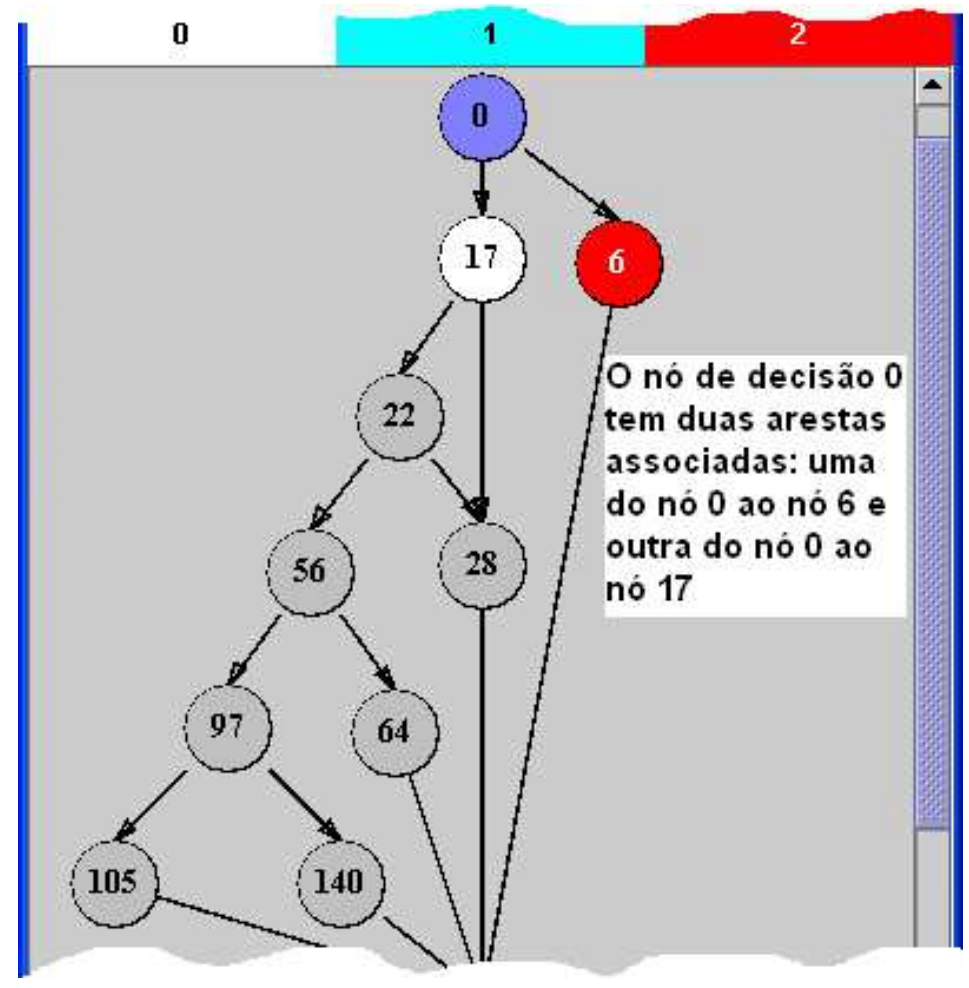

(b) Grafo $\mathcal{D U G} 2^{\text {a }}$ etapa

Figura 5.12: Segunda etapa da exibição dos requisitos do critério Todas-Arestas ${ }_{e i}$ para o método Dispenser.dispense(). 


\begin{tabular}{|c|c|c|}
\hline \multicolumn{3}{|c|}{ All-Pri-Nodes Coverage per Method } \\
\hline Method Names & Cowerage & Percentage \\
\hline vending.Dispenser sinit>0 $\mathrm{V}$ & 2 of 2 & $100^{\mathrm{m}}$ \\
\hline vending.Dispenser available(l)Z & 8 of 8 & $100 \%$ \\
\hline vending.Dispenser dispense(II)I & 9 of 11 & $\theta 1 \%$ \\
\hline vending.Dispenser setValSel([I)V & 0 of 1 & \\
\hline vending. Vendinghlachine $<$ init $>0 \mathrm{~V}$ & 0 of 2 & \\
\hline vending.Vendinghachine insertCoin()V & 0 of 1 & \\
\hline vending.VendingMachine returnCoing $\mathrm{V}$ & 0 of 4 & 08 \\
\hline vending.Vendinghachine venditem(I)V & 0 of 1 & \\
\hline
\end{tabular}

(a) Cobertura de cada método: critério Todos-Nós ${ }_{e i}$

\begin{tabular}{|c|c|c|}
\hline \multicolumn{3}{|c|}{ Overall Coverage Summary by Criterion } \\
\hline Testing Criterion & Coverage & Percentage \\
\hline All-Pri-Nodes & 19 of 30 & $63 \%$ \\
\hline All-Sec-Nodes & 0 of 1 & $0 \%$ \\
\hline All-Pri-Edges & 20 of 32 & $62 \%$ \\
\hline All-Sec-Edges & 0 of 6 & $0 \%$ \\
\hline All-Pri-Uses & 37 of 63 & $58 \%$ \\
\hline All-Sec-Uses & 0 of 14 & $0 \%$ \\
\hline
\end{tabular}

(b) Cobertura obtida em relação a cada critério

\begin{tabular}{|c|c|c|c|c|c|}
\hline \multicolumn{6}{|c|}{ All-Pri-Nodes Coverage per Test Case } \\
\hline \multicolumn{2}{|c|}{ Activate All } & Deactivete All & Delete AlI & Undel & \\
\hline Active & Delete & Test Case & \multicolumn{2}{|c|}{ Total Cowerage } & Percentage \\
\hline V & $\square$ & 0001 & \multicolumn{2}{|c|}{17 of 30} & $56 \%$ \\
\hline 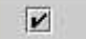 & 口 & 0002 & \multicolumn{2}{|c|}{5 of 30} & $16^{4 \%}$ \\
\hline$\sqrt{v}$ & $\square$ & 0003 & \multicolumn{2}{|c|}{7 of 30} & $23 \%$ \\
\hline
\end{tabular}

(c) Cobertura de cada caso de teste: critério Todos-Nós ${ }_{e i}$

Figura 5.13: Relatórios de teste da cobertura em relação a cada método, critério e caso de teste.

Pode também ser importante avaliar a cobertura de todo o projeto em relação a cada um dos critérios de teste. Essa informação pode ajudar o testador a decidir se o "efeito de saturação" de determinado critério de teste já foi atingido. Em caso afirmativo, um critério de teste mais forte pode ser utilizado para continuar a evolução do conjunto de 
teste, por exemplo, passar do critério Todos-Nós ${ }_{e i}$ para o critério Todas-Arestas ${ }_{e i}$. A ferramenta JaBUTi gera esse tipo de relatório considerando os seis critérios de teste estruturais implementados pela mesma: Todos-Nós ${ }_{e i}$, Todas-Arestas ${ }_{e i}$, Todos-Usos $_{e i}$, Todos-Nós ${ }_{e d}$,

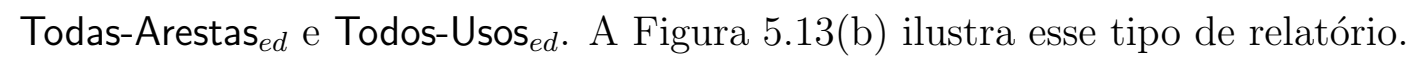

Pode ser interessante também identificar os slices de execução de cada caso de teste, onde o slice pode ser definido em relação a um conjuntos de nós independentes/dependentes de exceção (considerando o critério Todos-Nós ${ }_{e i} /$ Todos-Nós $_{e d}$ ), arestas independentes/dependentes de exceção, associações independentes/dependentes de exceção e potenciais-associações independentes/dependentes de exceção, obtidas a partir dos critérios de teste correspondentes. Isso porque tais slices podem ser utilizados, por exemplo, de forma similar às metodologias desenvolvidas para a programas C (Agrawal et al., 1998; Wong et al., 1999), para auxiliar aos testadores em atividades de depuração e entendimento de programas/componentes Java. Para um dado caso de teste, seu slice de execução pode ser facilmente construído se a cobertura determinada por tal caso de teste é conhecida, tal como o relatório gerado pela ferramenta JaBUTi, mostrado na Figura 5.13(c). Observe que é possível ativar/desativar diferentes combinações de casos de teste de modo que o slice de execução de cada um tanto no bytecode quando no grafo $\mathcal{D U G}$ possa ser visualizado, com mostrado anteriormente na Figura 5.5, por exemplo.

\subsubsection{Utilizando JaBUTi em uma Estratégia de Teste}

A ferramenta JaBUTi foi implementada considerando funcionalidades que são úteis para a realização de estudos empíricos, tais como permitir que diferentes combinações de requisitos e casos de teste sejam habilitados/desabilitados, viabilizando a utilização de estratégias de teste incrementais, conforme a descrita na Seção 3.5 do Capítulo 3.

A idéia básica é que para atingir uma alta cobertura dos requisitos de teste é possível utilizar um conjunto de teste gerado em dois estágios diferentes. Primeiro, casos de teste podem ser gerados por meio de algum algoritmo de geração aleatório, com base em algum critério de teste funcional, ou até mesmo com base no conhecimento do testador sobre o programa sendo testado. Esses casos de teste servem como um bom ponto de partida para a avaliação de cobertura. Se os resultados obtidos não satisfizerem os objetivos preestabelecidos (como por exemplo, a cobertura desejada do critério Todos-Nós ${ }_{e i}$ é de $90 \%$ e a cobertura obtida é de apenas 60\%) as dicas fornecidas pela JaBUTi podem ser utilizadas visando ao desenvolvimento de casos de teste adicionais de modo a aumentar a cobertura dos requisitos de modo mais eficiente, por exemplo, de $60 \%$ para $90 \%$ no exemplo sendo considerado. 
Vale lembrar que embora os pesos computados pela ferramenta forneçam indicações úteis aos testadores para o desenvolvimento de casos de teste que maximizem a cobertura dos requisitos de teste, esses pesos não servem para identificar a funcionalidade principal das classes sendo testadas ou identificar partes críticas do código a serem cobertas. Com base em seu conhecimento sobre a aplicação e sobre as partes críticas da mesma, uma boa estratégia de teste seria desenvolver casos de teste que exercitem essas partes críticas antes de outras partes do código. A cobertura dessas partes pode ser verificada utilizando-se a JaBUTi, como mostrado nas Figuras 5.5. Dito de forma diferente, as partes críticas de determinada aplicação devem ser testadas primeiro, independentemente dos pesos de seus requisitos e, posteriormente, os pesos podem ser utilizados para acelerar a cobertura do restante do código da aplicação.

Outro conceito importante a ser utilizado é a abordagem de teste incremental. Estudos tais como os desenvolvidos por Rapps e Weyuker (1985) e Clarke et al. (1989) relatam que, em geral, o critério All-Nodes é mais fácil de ser satisfeito do que o critério All-Edges que por sua vez é mais fácil de ser satisfeito do que o critério All-Uses. Embora tais conclusões sejam baseadas em experimentos desenvolvidos para programas $\mathrm{C}$, o mesmo também deverá ser válido no contexto de programas/componentes Java. No caso, considerando os critérios de teste estruturais implementados na JaBUTi, o testador poderia iniciar com o desenvolvimento de um conjunto de teste adequado para o critério Todos-Nós ${ }_{e i}$, em seguida, se necessário, acrescentar novos casos de teste ao conjunto Todos-Nós ${ }_{e i}$-adequado para torná-lo Todas-Arestas ${ }_{e i}$-adequado. Posteriormente, o conjunto Todas-Arestas $e_{i}$-adequado pode ser evoluído para se tornar adequado ao critério Todos-Usos ${ }_{e i}$, o qual pode ser evoluído até que um conjunto Todos-Pot-Usos ${ }_{e i}$-adequado seja obtido. Com isso, utilizando todos os critério independentes de exceção, todos os diferentes requisitos de teste relacionados com os trechos de código não relacionados com o tratamento de exceção seriam cobertos. Desejando-se avaliar a cobertura dos requisitos de teste envolvidos com o tratamento de exceções, os critérios de teste dependentes de exceção poderiam ser utilizados também de forma incremental visando a maximizar a deteç̧ão de defeitos e respeitar as restrições de tempo e custo associadas.

Com o apóio da ferramenta JaBUTi, no Capítulo 6 é apresentado um estudo de caso para ilustrar a estratégia incremental descrita na Seção 3.5 do Capítulo 3 utilizando-se os critérios de teste independentes de exceção.

\subsection{A Ferramenta Proteum/OO - Teste de Mutação 00}

Nesta seção são descritos os requisitos de implementação (Seção 5.3.1) e operacionais (Seção 5.3.2) da ferramenta de teste que visa a apoiar o teste de mutação em progra- 
mas OO, denominada Proteum/OO (Program Testing Using Mutants for Object Oriented programs). É importante observar que a ferramenta encontra-se em desenvolvimento e a descrição apresentada aqui é o que espera-se que a ferramenta venha a implementar. Por ter sido projetada após o desenvolvimento da ferramenta de teste JaBUTi, a Proteum/OO traz algumas diferenças, principalmente no que se refere à interface gráfica e à forma como são gerenciados os projetos de teste. Posteriormente, a ferramenta JaBUTi também deve ser implementada considerando tais características, culminando em um ambiente integrado de teste e validação que apóie a aplicação de critérios de fluxo de controle, de dados e de mutação.

A Proteum/OO será uma ferramenta WEB desenvolvida para dar apoio ao teste de mutação para programas em OO. Além do tipo de interface gráfica sendo desenvolvida, a principal diferença em relação à sua predecessora, a ferramenta $\mathcal{P R O T E M} M / \mathcal{M}$ - destinada ao teste de programas procedimentais, é que esta última utiliza uma linguagem intermediária (LI) para implementar o conceito de multi-linguagem, ou seja, permitir que a ferramenta possa ser utilizada para o teste de programas implementados em diferentes linguagens de programação (Delamaro et al., 2000). Já a Proteum/OO, ao invés da LI, utiliza a própria árvore sintática como estrutura de representação intermediária para implementar o conceito de multi-linguagem.

Com base na avaliação de diversas ferramentas de teste para programas OO (Domingues et al., 2002) e na experiência do grupo no desenvolvimento de outras ferramentas de teste (Maldonado et al., 2000), o modelo de base de dados a ser utilizado pela ferramenta de mutação foi desenvolvido (Figura 5.14). Tal base de dados foi projetada visando a atender os requisitos mínimos exigidos por uma ferramenta de apóio ao teste de mutação: 1) tratamento de casos de teste (execução, inclusão/exclusão e habilitação/desabilitação); 2) tratamento de mutantes (geração, seleção, execução e análise); e 3) análise de adequação (escore de mutação e relatórios estatísticos).

\subsubsection{Requisitos de Implementação}

A arquitetura da Proteum/OO é apresentada na Figura 5.15. As funcionalidades da ferramenta encontram-se divididas entre módulos independentes e dependentes do teste de mutação para programas OO. Os módulos independentes são compostos pelas funcionalidades comuns entre a Proteum/OO e as ferramentas Proteum/CPN e Proteum/SML, que estão sendo desenvolvidas para dar apoio ao teste de mutação para especificações em Redes de Petri Coloridas (Simão, 2004) e SML (Standard Meta Language) (Yano et al., 2003), respectivamente. Buscou-se, dessa forma, identificar e isolar as funcionalidades de uma ferramenta de apoio ao teste de mutação que sejam independentes da linguagem/especificação alvo, promovendo o reuso de código. Por sua vez, os módulos depen- 
dentes possuem as funcionalidades que são estritamente relacionadas à aplicação do teste de mutação em programas OO. Por exemplo, é necessário realizar um tratamento no código fonte de programas OO para sua execução e definir como será feita a distinção dos mutantes.

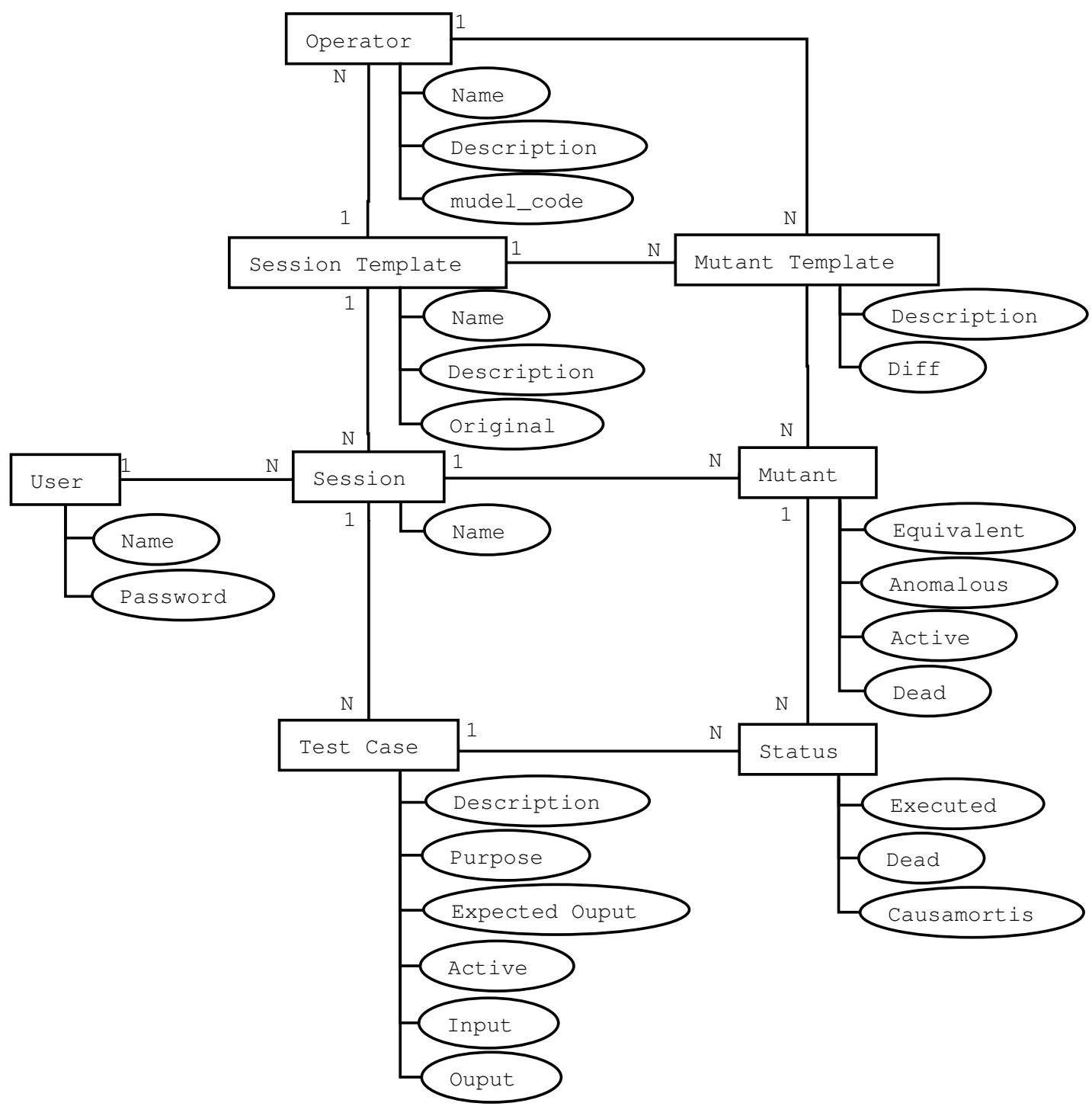

Figura 5.14: Projeto da base de dados para a ferramenta de mutação - Proteum/OO.

A interação da ferramenta é realizada via interface WEB. O módulo gerenciador de skins é responsável pela formatação das páginas, separando os demais módulos de detalhes específicos de exibição. Dessa forma, pode-se alterar toda a aparência das páginas que compõem a ferramenta sem a necessidade de modificar os códigos referentes às funcionalidades. Além disso, é possível personalizar a interface para se adequar às necessidades de uma linguagem/especificação particular. 


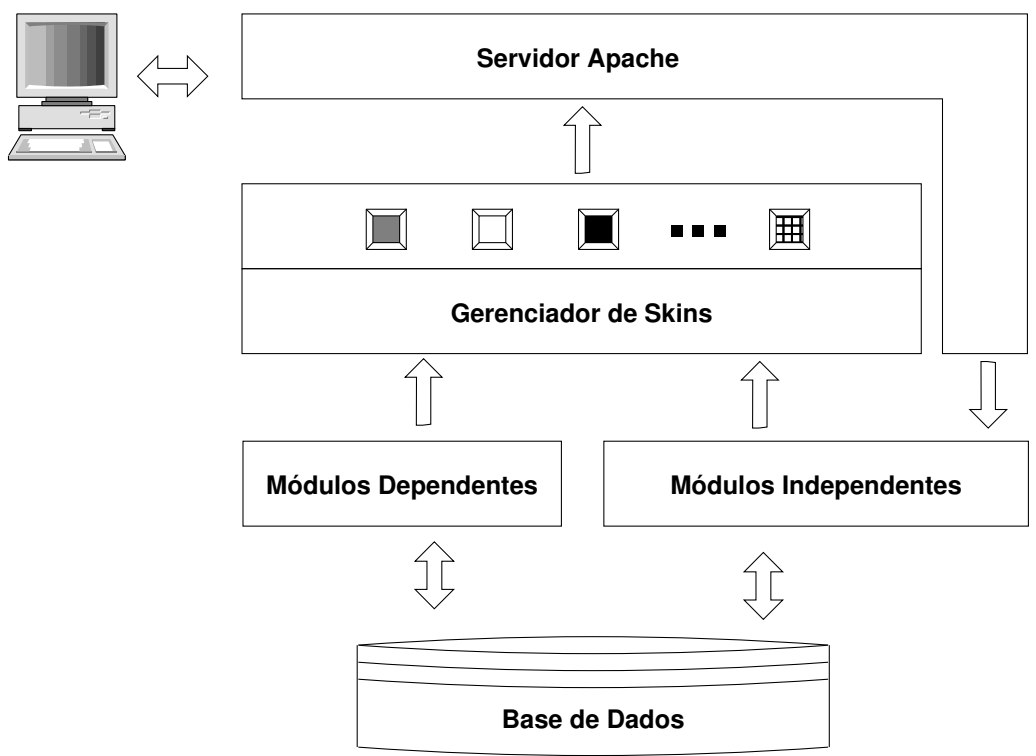

Figura 5.15: Arquitetura da ferramenta Proteum/OO, adaptada de (Yano et al., 2003).

Os operadores de mutação, utilizados para a geração dos mutantes serão os apresentados na Seção 4.3 do Capítulo 4, que visam a modelar defeitos cometidos em programas OO nos níveis intra-método, inter-método e inter-classe (Vincenzi et al., 2004a). Esses operadores são descritos na linguagem $\mathcal{M} u \mathcal{D} e \mathcal{L}$ (MUtant DEscription Language), definida por Simão e Maldonado (2002). A linguagem $\mathcal{M} u \mathcal{D} e \mathcal{L}$ visa a fornecer precisão e formalidade na descrição dos operadores e a facilitar a automatização da geração de mutantes. Tendo a descrição de um operador de mutação na linguagem $\mathcal{M} u \mathcal{D} e \mathcal{L}$ e a gramática livre de contexto $G$ da linguagem OO desejada, o sistema mudelgen (Simão et al., 2002) é utilizado para compilar a descrição dos operadores e gerar os mutantes, com base em $G$.

Um aspecto interessante no uso da linguagem $\mathcal{M} u \mathcal{D} e \mathcal{L}$ é a possibilidade de reutilização da descrição de um dado operador no contexto de mais de uma linguagem de programação. Por exemplo, devido à similaridade sintática entre as linguagens de programação $\mathrm{C}, \mathrm{C}++$ e Java em diversas estruturas de controle, durante a implementação dos 80 operadores de mutação de unidade definidos por Agrawal et al. (1989) e apresentados na Seção 4.3.1 do Capítulo 4, foram identificados diversos operadores para os quais a mesma descrição em $\mathcal{M} u \mathcal{D} e \mathcal{L}$ poderia ser reutilizada indistintamente para a geração de mutantes nas três linguagens de programação.

A Figura 5.16 ilustra um diagrama de Venn que sintetiza os resultados obtidos da avaliação desses operadores. No centro do diagrama estão os operadores de mutação cuja mesma descrição em $\mathcal{M} u \mathcal{D} e \mathcal{L}$ pode ser utilizada indistintamente para a geração de mutantes nas três linguagens consideradas. Eles correspondem a 31 dos 80 operadores intra-método, o que representa uma porcentagem de reutilização de 38,75\%. Conside- 
rando somente as linguagens $\mathrm{C}$ e $\mathrm{C}++$ observa-se que outras 34 descrições de operadores de mutação em $\mathcal{M} u \mathcal{D} e \mathcal{L}$, o que corresponde a $42,50 \%$ dos operadores, podem ser reutilizadas. Obviamente, existem também operadores de mutação cuja descrição em $\mathcal{M} u \mathcal{D} e \mathcal{L}$ é distinta para as três linguagens, tais operadores correspondem a 18,75\%, 18,75\% e 35\% para as linguagens $\mathrm{C}, \mathrm{C}++$ e Java, respectivamente.

Com isso, observa-se que além de $\mathcal{M} u \mathcal{D}$ e $\mathcal{L}$ e mudelgen viabilizarem a construção de ferramentas de teste multi-linguagens, indiretamente, dependendo da característica da estrutura sintática das linguagens sendo consideradas é possível reutilizar descrições de operadores de mutação, facilitando a implementação da ferramenta de teste e da validação da descrição do operador de mutação.

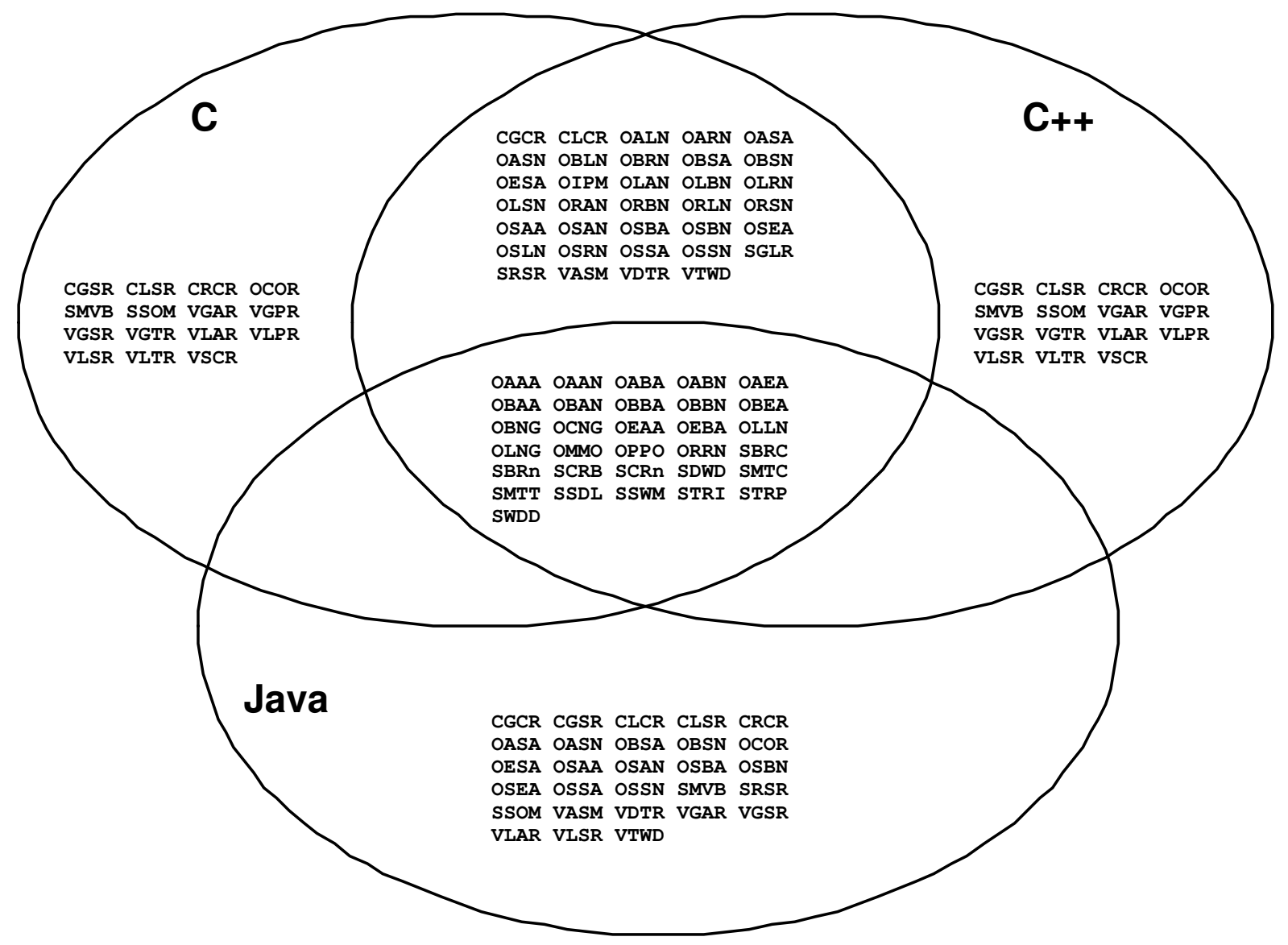

Figura 5.16: Reuso das descrições em $\mathcal{M} u \mathcal{D} e \mathcal{L}$ dos operadores intra-método.

\subsubsection{Requisitos Operacionais}

A estrutura da Proteum/OO é baseada no conceito de projetos e sessões, a qual permite minimizar o número de gerações de mutantes e execuções de casos de teste. Isso é de 
grande importância para a condução de estudos empíricos que utilizam um produto a ser testado com o mesmo conjunto de mutantes (ou um subconjunto desse) e/ou com casos de teste similares.

Cada projeto determina o código fonte do programa a ser testado e o conjunto de operadores que serão utilizados para a geração dos mutantes. Um projeto pode possuir uma ou mais sessões de teste. Uma sessão pode importar qualquer subconjunto dos mutantes gerados no projeto ao qual pertence, informando a porcentagem ou quantidade de mutantes de cada operador ou, então, selecionando o número do mutante ou as linhas nas quais a mutação for realizada.

Existe também a noção de grupo de sessões que facilita o trabalho colaborativo entre um grupo de testadores. Um grupo é formado por usuários de várias sessões de um mesmo projeto, sendo que os mutantes são particionados entre as sessões do grupo conforme o número máximo de mutantes que cada um pode possuir.

O acesso à ferramenta é controlado por meio de contas de usuário protegidas por senha. Existem três categorias de contas de usuário: administrador, proprietário de projeto e usuário de sessão. O usuário administrador é criado na instalação da Proteum/OO e é responsável pelas autorizações à entrada de outros usuários ao sistema. Um proprietário de projeto tem permissão para criar novos projetos e determina quais usuários podem pertencer ao seu projeto. Por sua vez, um usuário de sessão tem permissão para criar sessões em um projeto já existente.

Após a criação de uma sessão, pode-se incluir casos de teste tanto interativamente quanto por importação. Na inclusão interativa, o usuário fornece o caso de teste no campo do formulário respectivo. Na importação, o usuário fornece um arquivo ASCII com os casos de teste.

Após a execução dos mutantes com o conjunto de teste, aqueles que permaneceram vivos devem ser analisados para verificar se são equivalentes ou não ao programa em teste. A análise pode ser feita observando-se as linhas do código nas quais a mutação ocorreu. Para tanto, a ferramenta permite a visualização lado a lado do programa em teste e de um mutante, destacando-se as linhas alteradas.

A geração de relatório também está prevista. Pelo menos dois tipos de relatório devem estar disponíveis. O primeiro, apresenta a quantidade de mutantes vivos, mortos e equivalentes referente a cada operador. O segundo reúne informações sobre a execução de cada caso de teste. Tais relatórios permitem realizar uma análise detalhada da adequação dos casos de teste em relação aos mutantes gerados. 


\subsection{Considerações Finais}

Neste capítulo foram descritos os aspectos operacionais e de implementação relacionados à ferramenta de teste JaBUTi, desenvolvida para apoiar o teste estrutural em programas e componentes Java.

A ferramenta JaBUTi implementa os conceitos definidos no Capítulo 3, permitindo que os requisitos de teste exigidos pelos critérios de teste estruturais possam ser obtidos, independentemente da disponibilidade do código fonte do programa sendo testado. Observa-se que a disponibilidade de tal ferramenta viabiliza a condução de diversos estudos empíricos, tanto no que diz respeito ao desenvolvimento de estratégias de teste incrementais, quanto na utilização das informações obtidas durante os testes em atividades de depuração e entendimento de programas. Além disso, a ferramenta JaBUTi é a única que apóia a aplicação do teste de fluxo de dados em programas e componentes Java, podendo ser utilizada na transferência tecnológica para a industria e na atividade de ensino/aprendizagem em disciplinas da área de teste de software.

Referente ao teste baseado em mutação, a arquitetura foi definida e a ferramenta Proteum/OO encontra-se em fase de implementação e deve ser posteriormente integrada com a ferramenta de fluxo de dados de modo a formar um ambiente integrado de teste e validação que ofereça ao testador uma grande flexibilidade em relação ao critérios de teste apoiados, de modo que diferentes estratégias de teste possam ser utilizadas em função da criticalidade do programa sendo testado e do tempo e custo disponíveis.

No próximo capítulo, a ferramenta JaBUTi é utilizada para ilustrar a aplicação de alguns dos critérios de teste definidos, considerando a estratégia de teste incremental que foi proposta no Capítulo 3. 


-

\title{
Aplicando os Critérios de Teste Estruturais
}

\begin{abstract}
T ESTE capítulo ilustra-se a aplicação dos critérios de fluxo de controle e de dados 1 implementados na ferramenta de teste JaBUTi, considerando dois conjuntos de programas, descritos na Seção 6.1. Na Seção 6.2 são apresentadas as informações estáticas sobre o número de requisitos de teste gerados para esses programas e, na Seção 6.3, um programa de cada conjunto é utilizado para exemplificar a aplicação da estratégia de teste incremental definida na Seção 3.4.1 do Capítulo 3. A idéia do exemplo é mostrar o aspecto complementar dos critérios de teste e avaliar o número de casos de teste necessários para satisfazê-los.
\end{abstract}

\subsection{Programas Utilizados}

Para o exemplo, dois conjuntos de programas são considerados. O primeiro conjunto (Conjunto I), extraído do livro de Weiss (2002), é composto de 365 classes que correspondem a 83 programas Java. O segundo conjunto de programas (Conjunto II) corresponde às classes que implementam a ferramenta JaBUTi.

No caso do Conjunto I, seus programas foram divididos em dois subgrupos: Conjunto $\mathrm{I}_{d s}$, correspondente a 34 programas que implementam diversas estruturas de dados, e Conjunto $\mathrm{I}_{a p p}$, correspondente a 49 programas aplicativos que utilizam as estruturas de dados do Conjunto $I_{d s}$. A Tabela 6.1 ilustra a complexidade dos programas do Conjunto $\mathrm{I}_{d s}$ em termos de número de linhas de código (lines of code - LOC) e em termos do número de instruções de bytecode (Size). A relação entre Size e LOC também 
é apresentada. Os programas estão classificados em ordem alfabética. Por exemplo, as classes que implementam o programa AATree têm 122 LOC e 497 instruções de bytecode, resultando em uma média de 4,07 instruções de bytecode por linha de código. No total, os programas do Conjunto $\mathrm{I}_{d s}$, correspondem a 4041 LOC ou 16579 instruções de bytecode (4,10 instruções por linha de código). O tamanho médio dos programas é de 118,85 LOC ou 487,62 instruções de bytecode (4,06 instruções por linha de código na média).

Tabela 6.1: Complexidade dos programas do Conjunto $\mathrm{I}_{d s}$.

\begin{tabular}{|c|c|c|c|c|c|c|c|c|c|}
\hline \multirow{2}{*}{ Programas } & \multirow{2}{*}{ LOC } & \multirow{2}{*}{ Size } & \multirow{2}{*}{ Size/LOC } & \multicolumn{2}{|c|}{ Todos-Nós } & \multicolumn{2}{|c|}{ Todas-Arestas } & \multicolumn{2}{|c|}{ Todos-Usos } \\
\hline & & & & $e i$ & $e d$ & $e i$ & $e d$ & $e i$ & $e d$ \\
\hline AATree & 122 & 497 & 4,07 & 92 & 0 & 94 & 0 & 251 & 0 \\
\hline AbstractCollection & 50 & 161 & 3,22 & 52 & 0 & 52 & 0 & 71 & 0 \\
\hline ArrayList & 150 & 614 & 4,09 & 137 & 0 & 125 & 0 & 245 & 0 \\
\hline ArrayQueue & 37 & 151 & 4,08 & 25 & 0 & 20 & 0 & 52 & 0 \\
\hline Arrays & 37 & 126 & 3,41 & 35 & 0 & 24 & 0 & 62 & 0 \\
\hline ArrayStack & 29 & 123 & 4,24 & 25 & 0 & 19 & 0 & 44 & $\overline{0}$ \\
\hline BinaryHeap & 73 & 344 & 4,71 & 56 & 0 & 57 & 0 & 169 & 0 \\
\hline BinarySearch & 20 & 95 & 4,75 & 17 & 0 & 18 & 0 & 52 & 0 \\
\hline BinarySearchRecursive & 19 & 103 & 5,42 & 17 & 0 & 15 & 0 & 50 & 0 \\
\hline BinarySearchTree & 89 & 362 & 4,07 & 89 & 0 & 90 & 0 & 178 & 0 \\
\hline BinarySearchTreeWRank & 115 & 482 & 4,19 & 112 & 0 & 106 & 0 & 265 & 0 \\
\hline BinaryTree & 97 & 331 & 3,41 & 66 & 0 & 55 & 0 & 134 & 0 \\
\hline Collections & 23 & 73 & 3,17 & 24 & 0 & 14 & 0 & 18 & 0 \\
\hline DisjointSetsFast & 44 & 225 & 5,11 & 35 & 0 & 37 & 0 & 123 & $\overline{0}$ \\
\hline DisjointSetsSlow & 40 & 188 & 4,70 & 30 & 0 & 30 & 0 & 95 & 0 \\
\hline Graph & 412 & 1828 & 4,44 & 278 & 5 & 305 & 60 & 829 & 6 \\
\hline HashMap & 323 & 1336 & 4,14 & 275 & 0 & 238 & 0 & 546 & 0 \\
\hline HashSet & 179 & 711 & 3,97 & 157 & 0 & 149 & 0 & 332 & 0 \\
\hline Hzip & 278 & 1152 & 4,14 & 188 & 0 & 182 & 0 & 482 & 0 \\
\hline LinkedList & 69 & 279 & 4,04 & 68 & 0 & 69 & 0 & 134 & 0 \\
\hline LinkedList2 & 186 & 708 & 3,81 & 155 & 0 & 127 & 0 & 247 & 0 \\
\hline LinkedListlterator & 14 & 45 & 3,21 & 17 & 0 & 14 & 0 & 19 & $\overline{0}$ \\
\hline ListNode & 6 & 14 & 2,33 & 4 & 0 & 2 & 0 & 3 & 0 \\
\hline ListQueue & 27 & 96 & 3,56 & 23 & 0 & 16 & 0 & 26 & 0 \\
\hline ListStack & 28 & 89 & 3,18 & 23 & 0 & 14 & 0 & 24 & 0 \\
\hline PairingHeap & 125 & 557 & 4,46 & 86 & 0 & 92 & 0 & 267 & 0 \\
\hline PriorityQueue & 84 & 395 & 4,70 & 62 & 0 & 61 & 0 & 173 & 0 \\
\hline RedBlackTree & 105 & 437 & 4,16 & 90 & 0 & 91 & 0 & 260 & 0 \\
\hline SimpleArrayList & 29 & 159 & 5,48 & 21 & 0 & 19 & 0 & 57 & 0 \\
\hline SortedLinkedList & 97 & 386 & 3,98 & 90 & 0 & 94 & 0 & 176 & $\overline{0}$ \\
\hline SplayTree & 131 & 516 & 3,94 & 86 & 0 & 87 & 0 & 283 & 0 \\
\hline Stack & 174 & 706 & 4,06 & 160 & 0 & 140 & 0 & 265 & 0 \\
\hline TreeMap & 444 & 1754 & 3,95 & 354 & 0 & 295 & 0 & 753 & 0 \\
\hline TreeSet & 385 & 1536 & 3,99 & 311 & 0 & 275 & 0 & 703 & 0 \\
\hline Total & 4041 & 16579 & 4,10 & 3260 & 5 & 3026 & 60 & 7388 & 6 \\
\hline Média & 118,85 & 487,62 & 4,06 & 95,88 & 0,15 & 89,00 & 1,76 & 217,29 & 0,18 \\
\hline
\end{tabular}

A Tabela 6.2 apresenta as mesmas informações para os 49 programas do Conjunto $\mathrm{I}_{\text {app }}$. Observa-se que esse conjunto de programas apresenta uma complexidade média em termos do número de linhas de código inferior aos programas do Conjunto $I_{d s}$.

Conforme apresentado na Seção 5.2 do Capítulo 5, a ferramenta JaBUTi é totalmente implementada em Java e as classes que a compõem estão divididas em 11 pacotes diferentes. Na Tabela 6.3, referente ao Conjunto II, é ilustrada a complexidade média de cada um desses pacotes. 
Tabela 6.2: Complexidade dos programas do Conjunto $I_{\text {app }}$.

\begin{tabular}{|c|c|c|c|c|c|c|c|c|c|}
\hline \multirow{2}{*}{ Programas } & \multirow{2}{*}{ LOC } & \multirow{2}{*}{ Size } & \multirow{2}{*}{ Size/LOC } & \multicolumn{2}{|c|}{ Todos-Nós } & \multicolumn{2}{|c|}{ Todas-Arestas } & \multicolumn{2}{|c|}{ Todos-Usos } \\
\hline & & & & $e i$ & $e d$ & $e i$ & $e d$ & $e i$ & $e d$ \\
\hline BadEqualsDemo & 11 & 66 & 6,00 & 15 & 0 & 14 & 0 & 18 & 0 \\
\hline BasicGUI & 96 & 460 & 4,79 & 36 & 1 & 31 & 7 & 79 & 2 \\
\hline BorderTest & 14 & 63 & 4,50 & 3 & 0 & 1 & 0 & 0 & 0 \\
\hline Date & 24 & 142 & 5,92 & 14 & 0 & 12 & 0 & 33 & 0 \\
\hline DecoratorDemo & 79 & 391 & 4,95 & 41 & 35 & 32 & 81 & 34 & 26 \\
\hline DivideByTwo & 13 & 43 & 3,31 & 5 & 2 & 3 & 4 & 2 & 2 \\
\hline DoubleSpace & 25 & 85 & 3,40 & 18 & 18 & 19 & 42 & 20 & 13 \\
\hline DuplicateTest & 16 & 80 & 5,00 & 15 & 0 & 15 & 0 & 39 & 0 \\
\hline Echo & 8 & 41 & 5,13 & 9 & 0 & 9 & 0 & 16 & 0 \\
\hline EqualsWithInheritance & 18 & 103 & 5,72 & 19 & 0 & 17 & 0 & 30 & 0 \\
\hline Evaluator & 117 & 577 & 4,93 & 91 & 2 & 89 & 5 & 168 & 1 \\
\hline Exiting & 4 & 8 & 2,00 & 4 & 1 & 2 & 2 & 0 & 0 \\
\hline Factorial & 8 & 28 & 3,50 & 9 & 0 & 7 & 0 & 9 & 0 \\
\hline FileSystem & 31 & 134 & 4,32 & 20 & 0 & 20 & 0 & 51 & 0 \\
\hline FractalStar & 22 & 102 & 4,64 & 7 & 0 & 3 & 0 & 10 & 0 \\
\hline IntCell & 4 & 10 & 2,50 & 4 & 0 & 1 & 0 & 0 & 0 \\
\hline Josephus & 199 & 858 & 4,31 & 183 & 1 & 196 & 4 & 412 & 1 \\
\hline ListFiles & 25 & 74 & 2,96 & 18 & 14 & 19 & 30 & 20 & 8 \\
\hline MakeChange & 36 & 172 & 4,78 & 19 & 1 & 22 & 2 & 84 & 1 \\
\hline MatrixDemo & 17 & 179 & 10,53 & 13 & 0 & 13 & 0 & 36 & 0 \\
\hline MaxSumTest & 72 & 361 & 5,01 & 61 & 0 & 71 & 0 & 212 & 0 \\
\hline MaxTest & 20 & 64 & 3,20 & 10 & 2 & 8 & 10 & 11 & 2 \\
\hline MemoryCell & 3 & 10 & 3,33 & 4 & 0 & 1 & 0 & 0 & 0 \\
\hline MinTest & 6 & 20 & 3,33 & 7 & 0 & 5 & 0 & 6 & 0 \\
\hline ModemSim & 171 & 812 & 4,75 & 113 & 0 & 105 & 0 & 291 & 0 \\
\hline MyContainer & 31 & 159 & 5,13 & 29 & 0 & 22 & 0 & 52 & 0 \\
\hline Numerical & 63 & 363 & 5,76 & 50 & 0 & 52 & 0 & 117 & 0 \\
\hline OperatorTest & 14 & 108 & 7,71 & 3 & 0 & 1 & 0 & 0 & 0 \\
\hline PersonDemo & 39 & 197 & 5,05 & 27 & 0 & 12 & 0 & 32 & 0 \\
\hline Printlnt & 20 & 77 & 3,85 & 17 & 0 & 17 & 0 & 31 & 0 \\
\hline Random & 53 & 258 & 4,87 & 37 & 0 & 31 & 0 & 68 & 0 \\
\hline RandomNumbers & 13 & 62 & 4,77 & 12 & 0 & 13 & 0 & 24 & 0 \\
\hline ReadStrings & 27 & 101 & 3,74 & 17 & 1 & 18 & 6 & 43 & 1 \\
\hline ReadStringsWArrayList & 17 & 61 & 3,59 & 11 & 1 & 11 & 4 & 17 & 1 \\
\hline RecSum & 19 & 67 & 3,53 & 13 & 1 & 12 & 2 & 22 & $\overline{4}$ \\
\hline Rotations & 17 & 55 & 3,24 & 8 & 0 & 2 & 0 & 2 & 0 \\
\hline Ruler & 14 & 62 & 4,43 & 7 & 0 & 3 & 0 & 7 & 0 \\
\hline Shape & 48 & 236 & 4,92 & 41 & 0 & 26 & 0 & 69 & 0 \\
\hline Sort & 127 & 627 & 4,94 & 102 & 0 & 127 & 0 & 441 & 0 \\
\hline Squares & 11 & 41 & 3,73 & 11 & 0 & 11 & 0 & 22 & 0 \\
\hline StaticParamsDemo & 20 & 50 & 2,50 & 12 & 0 & 3 & 0 & 0 & 0 \\
\hline StorageCellDemo & 13 & 42 & 3,23 & 12 & 0 & 4 & 0 & 1 & 0 \\
\hline StringArrayList & 29 & 159 & 5,48 & 21 & 0 & 19 & 0 & 57 & 0 \\
\hline TestArrayList & 29 & 119 & 4,10 & 18 & 0 & 21 & 0 & 26 & 0 \\
\hline TicTacToe & 181 & 847 & 4,68 & 169 & 0 & 196 & 0 & 543 & 0 \\
\hline Tokenizer & 82 & 326 & 3,98 & 83 & 2 & 104 & 7 & 182 & 0 \\
\hline WordSearch & 91 & 395 & 4,34 & 60 & 2 & 73 & 5 & 212 & 3 \\
\hline WrapperDemo & 7 & 33 & 4,71 & 3 & 0 & 1 & 0 & 0 & 0 \\
\hline Xref & 127 & 504 & 3,97 & 110 & 16 & 134 & 33 & 228 & 12 \\
\hline Total & 2131 & 9832 & 4,61 & 1611 & 100 & 1628 & 244 & 3777 & 77 \\
\hline Média & 43,49 & 200,65 & 4,47 & 32,88 & 2,04 & 33,22 & 4,98 & 77,08 & 1,57 \\
\hline
\end{tabular}

Por exemplo, as classes que compõem o pacote criteria (sete no total) têm 556 LOC as quais correspondem a 2547 instruções de bytecode, uma relação (Size/LOC) de 4.58 instruções de bytecode para cada linha de código fonte. Na média, cada pacote tem em torno de 1190,55 LOC correspondendo a aproximadamente 5867,53 instruções de bytecode, uma taxa de 4,82 instruções por linha de código. Observa-se que, na média, a complexidade 
desse conjunto de classes é em torno de 10 vezes superior à complexidade das classes do Conjunto $\mathrm{I}_{d s}$ e em torno de 27 vezes superior à complexidade das classes do Conjunto $\mathrm{I}_{\text {app }}$.

Tabela 6.3: Complexidade dos pacotes do Conjunto II.

\begin{tabular}{|c|c|c|c|c|c|c|c|c|c|}
\hline \multirow{2}{*}{ Pacotes } & \multirow{2}{*}{ LOC } & \multirow{2}{*}{ Size } & \multirow{2}{*}{ Size/LOC } & \multicolumn{2}{|c|}{ Todos-Nós } & \multicolumn{2}{|c|}{ Todas-Arestas } & \multicolumn{2}{|c|}{ Todos-Usos } \\
\hline & & & & $e i$ & $e d$ & $e i$ & $e d$ & $e i$ & $e d$ \\
\hline criteria & 556 & 2547 & 4,58 & 401 & 0 & 476 & 0 & 1352 & 0 \\
\hline graph & 1117 & 4566 & 4,09 & 711 & 2 & 767 & 2 & 2180 & 0 \\
\hline gui & 4434 & 19958 & 4,50 & 2250 & 67 & 2378 & 327 & 5632 & 56 \\
\hline gvf & 428 & 2060 & 4,81 & 385 & 4 & 396 & 16 & 1080 & 4 \\
\hline instrumenter & 2389 & 15816 & 6,62 & 1677 & 65 & 1912 & 88 & 5255 & 171 \\
\hline lookup & 386 & 1729 & 4,48 & 253 & 5 & 273 & 16 & 796 & 0 \\
\hline metrics & 553 & 2601 & 4,70 & 350 & 8 & 398 & 17 & 1329 & 10 \\
\hline probe & 282 & 1409 & 5,00 & 139 & 3 & 162 & 39 & 508 & 4 \\
\hline project & 1248 & 5670 & 4,54 & 1278 & 26 & 1457 & 72 & 3285 & 30 \\
\hline util & 682 & 3408 & 5,00 & 305 & 8 & 349 & 22 & 923 & 6 \\
\hline verifier & 1021 & 4781 & 4,68 & 632 & 5 & 784 & 16 & 2049 & 8 \\
\hline Total & 13096 & 64545 & 4,93 & 8381 & 193 & 9352 & 615 & 24389 & 289 \\
\hline Média & 1190,55 & 5867,73 & 4,82 & 761,91 & 17,55 & 850,18 & 55,91 & 2217,18 & 26,27 \\
\hline
\end{tabular}

\subsection{Análise Estática: Número de Requisitos}

Nesta seção é apresentada a complexidade dos programas em termos do total de requisitos de teste gerados para cada um dos critérios de teste estruturais implementados na ferramenta JaBUTi.

Considerando o Conjunto $I_{d s}$ (Tabela 6.1), para o programa AATree, somente os critérios independentes de exceção geram requisitos de teste: o critério Todos-Nós ${ }_{e i}$ gera 92 requisitos, o critério Todas-Arestas ${ }_{e i}$ gera 94 e o critério Todos-Usos ${ }_{e i}$ gera 251 requisitos de testes. Na verdade, à exceção do programa Graph, os critérios dependentes de exceção não geram requisitos de teste para os programas do Conjunto $I_{d s}$. Em termos do número de requisitos de teste independentes de exceção, são gerados ao todo 3260, 3026 e 7388 requisitos de teste para os critérios Todos-Nós ${ }_{e i}$, Todas-Arestas ${ }_{e i}$ e Todos-Usos ${ }_{e i}$, respectivamente. Na média, o número de requisitos para cada um desses critérios independentes de exceção é de 95,88, 89,00 e 217,29, respectivamente. Observa-se que o número de requisitos de teste gerados deve diminuir após os algoritmos de otimização, envolvendo o uso de arcos-primitivos (Chusho, 1987; Maldonado, 1991), serem implementados.

No caso dos programas aplicativos (Conjunto $I_{a p p}$ - Tabela 6.2), observa-se que é maior o número de programas para os quais os critérios de teste dependentes de exceção geram requisitos de testes. No total, o número de requisitos de teste de exceção para o Conjunto $\mathrm{I}_{a p p}$ é de 100, 244 e 77, considerando os critérios Todos-Nós ${ }_{e d}$, Todas-Arestas Td $_{\text {e }}$ Todos-Usos $_{e d}$, respectivamente. Observe que, conforme discutido na Seção 3.4.1 do Capítulo 3, a relação de inclusão entre os critérios Todos-Usos ${ }_{e d}$ e Todas-Arestas Te $_{\text {não se }}$ 
mantém devido a forma como o modelo de dados foi definido. Com isso, o número de associações def-uso dependentes de exceção é em torno de $30 \%$ inferior ao o número de arestas dependentes de exceção. Na média, a quantidade de requisitos de teste dependentes de exceção gerados para os 49 programas pelos critérios Todos-Nós ${ }_{e d}$, Todas-Arestas ${ }_{e d}$ e Todos-Usos ${ }_{e d}$ é da ordem de 2,04, 4,98 e 1,57, respectivamente.

Em relação aos critérios independentes de exceção aplicados no Conjunto $\mathrm{I}_{\text {app }}$, os critérios Todos-Nós ${ }_{e i}$, Todas-Arestas ${ }_{e i}$ e Todos-Usos Tor $_{e i}$ geram no total 1611, 1628 e 3777 requisitos de teste, respectivamente. Na média, tais critérios geram 32,88, 33,22 e 77,08 requisitos de testes para cada programa, respectivamente.

Em relação ao número de requisitos de teste gerados para o Conjunto II (Tabela 6.3), observa-se que o pacote criteria é o único para o qual os critérios dependentes de exceção não geram requisitos de testes. Além disso, devido à maior complexidade das classes do Conjunto II, a quantidade de requisitos é superior à gerada para o Conjunto I. No total, considerando os critérios independentes de exceção, Todos-Nós ${ }_{e i}$, Todas-Arestas ${ }_{e i}$ e Todos-Usos $_{e i}$ geram, respectivamente, 8382, 9352 e 24389 requisitos de teste. Na média, considerando os 11 pacotes, a quantidade de requisitos de teste gerada pelos critérios acima é de 762,00, 850,18 e 2217,18, respectivamente.

Considerando os critérios dependentes de exceção, no total, Todos-Nós ${ }_{e d}$, Todas-

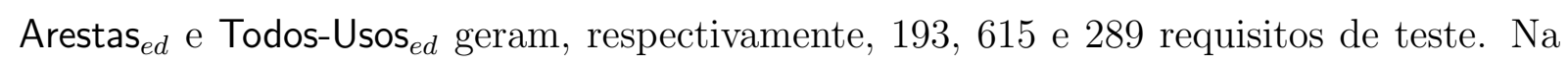
média, a quantidade de requisitos de teste gerada pelos critérios dependentes de exceção é de 17,55, 55,91 e 26,27, respectivamente.

Observe que, em geral, o número de requisitos de teste aumenta à medida que a complexidade do critério de teste também aumenta, ou seja, o critério Todos-Usos ${ }_{e i}$ (TodosUsos $_{e d}$ ) requer mais requisitos do que o critério Todas-Arestas ${ }_{e i}$ (Todas-Arestas Ted $_{\text {) o qual }}$ requer mais requisitos de teste do que o critério Todos-Nós ${ }_{e i}\left(\right.$ Todos-Nós $_{e d}$ ). Em geral, um critério de teste mais complexo deveria requerer um maior esforço e um maior número de casos de teste para ser satisfeito.

No caso do Conjunto II que possui classes mais complexas o incremento no número de requisitos é sempre observado à medida que um critério de teste independente de exceção mais rigoroso é aplicado.

Já no caso dos critérios dependentes de exceção, conforme discutido na Seção 3.4.1 do Capítulo 3, da forma como foi definido o modelo de fluxo de dados nem sempre o critério Todos-Usos $_{e d}$ inclui o critério Todas-Arestas ${ }_{e d}$. Assim sendo, pode ser observado, em alguns casos, um decréscimo no número de requisitos exigido pelo critério TodosUsos $_{e d}$ em relação ao critério Todas-Arestas ${ }_{e d}$, como por exemplo, o programa BasicGUI na Tabela 6.1 e o pacote graph da Tabela 6.3. Se considerada a extensão no modelo de fluxo de dados proposta na Seção 3.4.1, não haveria decréscimo no número de requisitos entre 
o critério Todas-Arestas ${ }_{e d}$ e o critério Todos-Usos ${ }_{e d}$, prevalecendo a relação de inclusão mostrada na Figura 3.9(a) do Capítulo 3.

Um ponto que deve ser observado é que o número de casos de teste para cobrir $100 \%$ dos requisitos de teste de um critério de teste é significantemente menor do que o número de requisitos de teste gerados pelo critério (McCabe, 1976; Maldonado, 1991; Weyuker, 1990). Este aspecto necessita ser investigado no contexto de programas OO (bytecode Java). Além disso, uma estratégia de teste incremental, similar à definida por Vincenzi et al. (2001), também precisa ser definida, fornecendo ao testador indicações mais precisas a respeito do custo e eficácia dos critérios de modo que o mesmo possa decidir, em função de suas restrições de tempo e custo, quais critérios devem ser utilizados para o teste de um produto de software. Na próxima seção, a título de ilustração, um programa do Conjunto I e um programa do Conjunto II são utilizados para exemplificar a aplicação da estratégia de teste incremental definida na Seção 3.5 do Capítulo 3. O objetivo é ilustrar a dificuldade de satisfação entre os critérios de teste independentes de exceção, bem como o número de casos de teste necessários para satisfazê-los.

\subsection{Exemplo de Aplicação da Estratégia Incremental}

Para o exemplo, escolheu-se um dos programas Java do Conjunto I, o qual implementa uma estrutura de dados denominada Árvore de Busca Binária com Ranqueamento, e um dos programas do Conjunto II, o qual corresponde ao pacote criteria que agrupa as classes responsáveis pela implementação dos critérios de teste da ferramenta JaBUTi. Na descrição apresentada abaixo, o primeiro programa é identificado por Programa I e o segundo por Programa II.

Ao todo, o Programa I é formado por seis classes: BinaryNode, BinaryNodeWithSize, BinarySearchTree, BinarySearchTreeWithRank, DuplicateltemException e ItemNotFoundException. A Tabela 6.4 mostra a complexidade de cada uma das classes em termos do número de linhas de código (LOC) e instruções de bytecode (Size), bem como a relação (Size/LOC). O número de requisitos gerados para cada um dos critérios independentes de exceção também é apresentado. Os valores referentes a uma dada classe corresponde ao somatório dos valores obtidos para cada um dos métodos que a compõe.

No caso do Programa II, os dados de complexidade das classes são apresentados na Tabela 6.5. Por exemplo, a classe AbstractCriterion é composta de 17 métodos (vide Tabela 6.15 no final da seção) os quais correspondem a 105 linhas de código fonte (LOC) ou a 429 instruções de bytecode (Size), uma relação de aproximadamente 4,09 instruções por linha de código (Size/LOC). 
Tabela 6.4: Complexidade das classes do Programa I.

\begin{tabular}{|c|c|c|c|c|c|c|}
\hline Classes & LOC & Size & Size/LOC & Todos-Nós $_{e i}$ & Todas-Arestas $_{e i}$ & Todos-Usos $_{e i}$ \\
\hline BinaryNode & 4 & 12 & 3,00 & 2 & 1 & 2 \\
\hline BinaryNodeWithSize & 3 & 7 & 2,33 & 2 & 1 & 1 \\
\hline BinarySearchTree & 59 & 243 & 4,12 & 60 & 59 & 149 \\
\hline BinarySearchTreeWithRank & 41 & 206 & 5,02 & 40 & 41 & 113 \\
\hline DuplicateltemException & 4 & 7 & 1,75 & 4 & 2 & 0 \\
\hline ItemNotFoundException & 4 & 7 & 1,75 & 4 & 2 & 0 \\
\hline Total & 115 & 482 & 4,19 & 112 & 106 & 265 \\
\hline Média & 19,17 & 80,33 & 3,00 & 18,67 & 17,67 & 44,17 \\
\hline
\end{tabular}

Tabela 6.5: Complexidade das classes do Programa II.

\begin{tabular}{|c|c|c|c|c|c|c|}
\hline Classes & LOC & Size & Size/LOC & Todos-Nós $_{e i}$ & Todas-Arestas $_{e i}$ & Todos-Usos $_{e i}$ \\
\hline AbstractCriterion & 105 & 429 & 4,09 & 86 & 85 & 241 \\
\hline AllEdges & 74 & 340 & 4,59 & 48 & 62 & 161 \\
\hline AllNodes & 52 & 224 & 4,31 & 35 & 41 & 99 \\
\hline AllPotUses & 122 & 564 & 4,62 & 81 & 113 & 330 \\
\hline AllUses & 143 & 660 & 4,62 & 95 & 133 & 374 \\
\hline DefUse & 38 & 200 & 5,26 & 38 & 31 & 106 \\
\hline Edge & 21 & 94 & 4,48 & 18 & 11 & 41 \\
\hline Total & 555 & 2511 & 4,52 & $\overline{401}$ & $\overline{476}$ & 1352 \\
\hline Média & 79,29 & 358,71 & 4,57 & 57,29 & 68,00 & 193,14 \\
\hline
\end{tabular}

Observa-se que, no total, as sete classes apresentam uma complexidade média em torno de 79,29 LOC ou 358,71 instruções de bytecode, uma média de 4,57 instruções por linha de código.

De posse desses dois programas, considerando a aplicação dos critérios independentes de exceção, os sete primeiros passos da estratégia de teste incremental definida na Seção 3.5 do Capítulo 3 são retomados abaixo:

Passo 1: Elaborar um conjunto de teste funcional $\left(\mathcal{T}_{f}\right)$, utilizando um critério funcional, considerando a especificação das classes sendo testadas (CST);

Passo 2: Avaliar a cobertura de $\mathcal{T}_{f}$ em relação aos critérios de teste estruturais;

Passo 3: Evoluir $\mathcal{T}_{f}$ até obter um conjunto de teste $\left(\mathcal{T}_{n}\right)$, adequado ao critério Todos-Nós (Todos-Nós Todos-Nós $_{e d}$ ) para as CST;

Passo 4: Avaliar a cobertura de $\mathcal{T}_{n}$ em relação aos demais critérios de teste estruturais;

Passo 5: Evoluir $\mathcal{T}_{n}$ até obter um conjunto de teste $\left(\mathcal{T}_{a}\right)$, adequado ao critério TodasArestas (Todas-Arestas ${ }_{e i} /$ Todas-Arestas $_{e d}$ ) para as CST;

Passo 6: Avaliar a cobertura de $\mathcal{T}_{a}$ em relação aos demais critérios de teste estruturais;

Passo 7: Evoluir $\mathcal{T}_{a}$ até obter um conjunto de teste $\left(\mathcal{T}_{u}\right)$, adequado ao critério Todos-Usos (Todos-Usos $_{e i} /$ Todos-Usos $_{e d}$ ) para as CST. 
Observa-se que, em geral, a obtenção de conjuntos de teste adequados requer a identificação de possíveis requisitos de teste não executáveis. No caso do Programa I não foram encontrados requisitos de teste não executáveis, ao passo que para o Programa II alguns requisitos de teste não executáveis foram identificados. A Tabela 6.6 apresenta o número de requisitos de teste gerados para as classes do Programa II, considerando todos os critérios de teste independentes de exceção. Para cada critério de teste, a coluna (\#Req) corresponde ao total de requisitos gerados, a coluna (\#Inf) corresponde ao número de requisitos de teste considerados não executáveis, e a coluna (\#Fea) corresponde ao número de requisitos de teste efetivamente utilizados, ou seja, os requisitos de teste executáveis. As informações de cobertura apresentadas no restante do capítulo, referentes ao Programa II, são computadas em relação aos requisitos executáveis.

Tabela 6.6: Número de requisitos de teste para as classes do Programa II.

\begin{tabular}{|l|r|r|r|r|r|r|r|r|r|}
\hline \multirow{2}{*}{ Classes } & \multicolumn{3}{|c|}{ Todos-Nós $_{e i}$} & \multicolumn{3}{c|}{ Todas-Arestas $_{e i}$} & \multicolumn{3}{c|}{ Todos-Usos $_{e i}$} \\
\cline { 2 - 11 } & \#Req & \#Inf & \#Fea & \#Req & \#Inf & \#Fea & \#Req & \#Inf & \#Fea \\
\hline AbstractCriterion & 86 & 1 & 85 & 85 & 1 & 84 & 241 & 5 & 236 \\
\hline AllEdges & 48 & 0 & 48 & 62 & 0 & 62 & 161 & 5 & 156 \\
\hline AllNodes & 35 & 0 & 35 & 41 & 0 & 41 & 99 & 0 & 99 \\
\hline AllPotUses & 81 & 0 & 81 & 113 & 2 & 111 & 330 & 18 & 312 \\
\hline AllUses & 95 & 1 & 94 & 133 & 2 & 131 & 374 & 21 & 353 \\
\hline DefUse & 38 & 1 & 37 & 31 & 1 & 30 & 106 & 4 & 102 \\
\hline Edge & 18 & 0 & 18 & 11 & 0 & 11 & 41 & 0 & 41 \\
\hline Total & 401 & 3 & 398 & 476 & 6 & 470 & 1352 & 53 & 1299 \\
\hline Média & 57,29 & 0,43 & 56,86 & 68,00 & 0,86 & 67,14 & 193,14 & 7,57 & 185,57 \\
\hline
\end{tabular}

\section{Programa I: Aplicação da Estratégia Incremental}

A seguir são mostradas as tabelas que ilustram os resultados obtidos com a aplicação da estratégia incremental para o Programa I. O conjunto de teste funcional $\mathcal{T}_{\text {f }}$, composto de 44 casos de teste ao todo, foi avaliado em relação aos critérios de teste estruturais e os dados de cobertura obtidos são apresentados na Tabela 6.7.

Por exemplo, considerando a classe BinarySearchTree, $T_{f}$ foi capaz de cobrir 55 (\#Cob) de um total de 60 (\#Req) requisitos de teste do critério Todos-Nós ${ }_{e i}$, o que representa uma porcentagem de cobertura (\%) de 91,67\% do critério em questão. Em relação às demais classes, $T_{f}$ só foi capaz de cobrir $100 \%$ dos requisitos de testes das classes BinaryNode e BinaryNodeWithSize que estão entre as classes mais simples do Programa I, com 4 e 3 LOC, respectivamente (vide Tabela 6.4).

Para tornar o conjunto $T_{f}$ adequado ao critério Todos-Nós ${ }_{e i}$ mais 6 casos de teste foram adicionados, originando o conjunto de teste $T_{n}$. A cobertura de $T_{n}$ em relação aos critérios estruturais é mostrada na Tabela 6.8. Observa-se que tal conjunto, embora 
desenvolvido para ser adequado ao critério Todos-Nós ${ }_{e i}$, também se mostrou adequado ao critério Todas-Arestas $_{e i}$ de modo que $T_{a} \subseteq T_{n}$. Entretanto, $T_{n}$ não se mostrou adequado ao critério Todos-Usos ${ }_{e i}$. A classe BinarySearch apresenta uma cobertura de 98,66\%. Com isso, mais seis casos de teste foram adicionados a $T_{n}$, originando o conjunto de teste $T_{u}$, adequado para o critério Todos-Usos ${ }_{e i}$, como mostrado na Tabela 6.9.

Tabela 6.7: Cobertura do conjunto de teste $T_{f}$ em relação aos critérios estruturais.

\begin{tabular}{|c|c|c|c|c|c|c|c|c|c|}
\hline \multirow{2}{*}{ Classes } & \multicolumn{3}{|c|}{ Todos-Nós ${ }_{e i}$} & \multicolumn{3}{|c|}{ Todas-Arestas $_{e i}$} & \multicolumn{3}{|c|}{ Todos-Usos $_{e i}$} \\
\hline & \#Cob & \#Req & $\%$ & \#Cob & \#Req & $\%$ & \#Cob & \#Req & $\%$ \\
\hline BinaryNode & 2 & 2 & 100,00 & 1 & 1 & 100,00 & 2 & 2 & 100,00 \\
\hline BinaryNodeWithSize & 2 & 2 & 100,00 & 1 & 1 & 100,00 & 1 & 1 & 100,00 \\
\hline BinarySearchTreeWithRank & 37 & 40 & 92,50 & 38 & 41 & 92,68 & 100 & 113 & 88,50 \\
\hline DuplicateltemException & 2 & 4 & 50,00 & 1 & 2 & 50,00 & 0 & 0 & 0,00 \\
\hline Média & 16,67 & 18,67 & 80,69 & 15,83 & 17,67 & 80,42 & 38,00 & 44,17 & 62,06 \\
\hline
\end{tabular}

Tabela 6.8: Cobertura do conjunto de teste $T_{n}$ em relação aos critérios estruturais.

\begin{tabular}{|c|c|c|c|c|c|c|c|c|c|}
\hline \multirow{2}{*}{ Classes } & \multicolumn{3}{|c|}{ Todos-Nós $_{e i}$} & \multicolumn{3}{|c|}{ Todas-Arestas $_{e i}$} & \multicolumn{3}{|c|}{ Todos-Usos $_{e i}$} \\
\hline & \#Cob & \#Req & $\%$ & \#Cob & \#Req & $\%$ & \#Cob & \#Req & $\%$ \\
\hline BinaryNode & $\overline{2}$ & 2 & 100,00 & 1 & $\overline{1}$ & 100,00 & 2 & 2 & 100,00 \\
\hline BinaryNodeWithSize & 2 & 2 & 100,00 & 1 & 1 & 100,00 & 1 & 1 & 100,00 \\
\hline BinarySearchTreeWithRank & 40 & 40 & 100,00 & 41 & 41 & 100,00 & 113 & 113 & 100,00 \\
\hline DuplicateltemException & 4 & 4 & 100,00 & 2 & 2 & 100,00 & 0 & 0 & 0,00 \\
\hline Média & 18,67 & 18,67 & 100,00 & 17,67 & 17,67 & 100,00 & 43,83 & 44,17 & 66,44 \\
\hline
\end{tabular}

Tabela 6.9: Cobertura do conjunto de teste $T_{u}$ em relação aos critérios estruturais.

\begin{tabular}{|c|c|c|c|c|c|c|c|c|c|}
\hline \multirow{2}{*}{ Classes } & \multicolumn{3}{|c|}{ Todos-Nós $_{e i}$} & \multicolumn{3}{|c|}{ Todas-Arestas $_{e i}$} & \multicolumn{3}{|c|}{ Todos-Usos $_{e i}$} \\
\hline & \#Cob & \#Req & $\%$ & \#Cob & \#Req & $\%$ & \#Cob & \#Req & $\%$ \\
\hline BinaryNode & 2 & 2 & 100,00 & 1 & 1 & 100,00 & 2 & 2 & 100,00 \\
\hline BinaryNodeWithSize & 2 & 2 & 100,00 & 1 & 1 & 100,00 & 1 & 1 & 100,00 \\
\hline BinarySearchTree & 60 & 60 & 100,00 & 59 & 59 & 100,00 & 149 & 149 & 100,00 \\
\hline BinarySearchTreeWithRank & 40 & 40 & 100,00 & 41 & 41 & 100,00 & 113 & 113 & 100,00 \\
\hline DuplicateltemException & 4 & 4 & 100,00 & 2 & 2 & 100,00 & 0 & 0 & 0,00 \\
\hline Média & 18,67 & 18,67 & 100,00 & 17,67 & 17,67 & 100,00 & 44,17 & 44,17 & 66,67 \\
\hline
\end{tabular}

Assim sendo, com um conjunto de teste com 56 casos de teste ao todo foi possível cobrir 100\% dos requisitos de teste estruturais intra-método exigidos pelos critérios de teste independentes de exceção implementados na JaBUTi.

Conforme destacado na Seção 3.4.2 do Capítulo 3, na prática tem-se observado que, na prática, a complexidade dos critérios de fluxo de dados pode ser vista como linear 
em relação aos número de comandos de decisão $t$, embora, teoricamente, os mesmos apresentem uma complexidade exponencial da ordem de $2^{t}$ (Weyuker, 1990; Maldonado, 1991).

Outra análise realizada, considerando o Programa I, diz respeito à complexidade dos critérios de teste em termos do número de casos de teste necessários para satisfazer os requisitos gerados. A Tabela 6.10 ilustra essa informação considerando o critérios de teste Todos-Usos $_{e i}$, que inclui os critérios Todas-Arestas ${ }_{e i}$ e Todos-Nós ${ }_{e i}$, considerando métodos que satisfaçam a propriedade NSL.

Tabela 6.10: Custo em termos do número de casos de teste: Programa I.

\begin{tabular}{|c|c|c|c|c|c|c|}
\hline Método & \#Var & \#Def & \#Req & \#CT & $t$ & $\frac{\# C T}{\# \operatorname{Req}}$ \\
\hline$\overline{\text { BinaryNode < init }>\text { (Comparable; }) \mathrm{V}}$ & 2 & 2 & 2 & 1 & $\overline{0}$ & $\overline{0,50}$ \\
\hline BinaryNodeWithSize < init $>$ (Comparable;)V & 1 & 1 & 1 & 1 & 0 & 1,00 \\
\hline BinarySearchTree $<$ init $>() \mathrm{V}$ & 1 & 1 & 1 & 1 & 0 & 1,00 \\
\hline BinarySearchTree elementAt(BinaryNode;)Comparable; & 2 & 2 & 4 & 2 & 1 & 0,50 \\
\hline BinarySearchTree find(Comparable;)Comparable; & 0 & 0 & 0 & 0 & 0 & 0,00 \\
\hline BinarySearchTree find(Comparable;BinaryNode;)BinaryNode; & 6 & 7 & 35 & 10 & 3 & 0,29 \\
\hline BinarySearchTree findMax()Comparable; & 0 & 0 & 0 & 0 & 0 & 0,00 \\
\hline BinarySearchTree findMax(BinaryNode;)BinaryNode; & 2 & 3 & 12 & 4 & 2 & 0,33 \\
\hline BinarySearchTree findMin()Comparable; & 0 & 0 & 0 & 0 & 0 & 0,00 \\
\hline BinarySearchTree findMin(BinaryNode;)BinaryNode; & 2 & 3 & 12 & 4 & 2 & 0,33 \\
\hline BinarySearchTree insert(Comparable;)V & 0 & 0 & 0 & 0 & 0 & 0,00 \\
\hline BinarySearchTree insert(Comparable;BinaryNode;)BinaryNode; & 6 & 7 & 26 & 4 & 3 & 0,15 \\
\hline BinarySearchTree isEmpty () $\mathrm{Z}$ & 2 & 2 & 4 & 2 & 1 & 0,50 \\
\hline BinarySearchTree makeEmpty()V & 0 & 0 & 0 & 0 & 0 & 0,00 \\
\hline BinarySearchTree remove(Comparable;)V & 0 & 0 & 0 & 0 & 0 & 0,00 \\
\hline BinarySearchTree remove(Comparable;BinaryNode;)BinaryNode; & 6 & 7 & 44 & 6 & 6 & 0,14 \\
\hline BinarySearchTree removeMin()V & 0 & 0 & 0 & 0 & 0 & 0,00 \\
\hline BinarySearchTree removeMin(BinaryNode;)BinaryNode; & 4 & 4 & 11 & 3 & 2 & 0,27 \\
\hline BinarySearchTreeWithRank <init $>() \mathrm{V}$ & 0 & 0 & 0 & 0 & 0 & 0,00 \\
\hline BinarySearchTreeWithRank findKth(I)Comparable; & 0 & 0 & 0 & 0 & 0 & 0,00 \\
\hline BinarySearchTreeWithRank findKth(IBinaryNode;)BinaryNode; & 7 & 7 & 27 & 5 & 4 & 0,19 \\
\hline BinarySearchTreeWithRank insert(Comparable;BinaryNode;)BinaryNode; & 7 & 8 & 28 & 4 & 3 & 0,14 \\
\hline BinarySearchTreeWithRank remove(Comparable;BinaryNode;)BinaryNode; & 7 & 7 & 45 & 6 & 6 & 0,13 \\
\hline BinarySearchTreeWithRank removeMin(BinaryNode;)BinaryNode; & 5 & 5 & 13 & 3 & 2 & 0,23 \\
\hline DuplicateItemException <init $>() \mathrm{V}$ & 0 & 0 & 0 & 0 & 0 & 0,00 \\
\hline DuplicateItemException <init $>$ (String;)V & 0 & 0 & 0 & 0 & 0 & 0,00 \\
\hline ItemNotFoundException $<$ init $>() \mathrm{V}$ & 0 & 0 & 0 & 0 & 0 & 0,00 \\
\hline ItemNotFoundException <init $>$ (String;)V & 0 & 0 & 0 & 0 & 0 & 0,00 \\
\hline Total & 60 & 66 & 265 & 56 & 35 & 0,21 \\
\hline Média & 2,14 & 2,36 & 9,46 & 2,00 & 1,25 & 0,20 \\
\hline
\end{tabular}

Cada linha da Tabela 6.10 corresponde a um método de uma das classes que compõem o Programa I. O nome da classe precede o nome do método para facilitar a identificação, por exemplo, a primeira linha da tabela corresponde ao construtor (referenciado por <init> no bytecode) da classe BinaryNode. Por ser um programa com métodos simples, 16 dos 28 métodos $(57,2 \%)$ não satisfazem a propriedade NSL, ou seja, não possuem ao menos um comando de decisão $(t=0)$. Para esses métodos, basta satisfazer o critério Todos-Nós ${ }_{e i}$ para que todos os possíveis caminhos de execução do método sejam exercitados. Considerando métodos mais complexos, como por exemplo os métodos remove(Comparable;BinaryNode;)BinaryNode; das classes BinarySearchTree e BinarySearchTreeWithRank que apresentam $t=6$, observa-se que o número de casos de teste (\#CT) requeridos para satisfazer o critério Todos-Usos ${ }_{e i}$ é em torno de $86 \%$ inferior ao número de requisitos de teste (\#Req). Na média, foram geradas em torno de 9,46 associações para 
cada método e foram requeridos em torno de 2,00 casos de teste para satisfazê-las o que corresponde a um número de casos de teste $80 \%$ inferior ao número de requisitos.

\section{Programa II: Aplicação da Estratégia Incremental}

De forma semelhante, para o Programa II foi desenvolvido um conjunto de teste $T_{f}$ contendo os casos de teste gerados aleatoriamente, com com base na especificação de cada uma das classes. Ao todo, 45 casos de teste funcionais foram gerados. Avaliandose a cobertura de $T_{f}$ em relação aos critérios de teste estruturais obtiveram-se os dados apresentados na Tabela 6.11.

Tabela 6.11: Cobertura de um conjunto de teste $T_{f}$-adequado em relação aos critérios estruturais.

\begin{tabular}{|c|c|c|c|c|c|c|c|c|c|}
\hline \multirow{2}{*}{ Classes } & \multicolumn{3}{|c|}{ Todos-Nós ${ }_{e i}$} & \multicolumn{3}{|c|}{ Todas-Arestas $_{e i}$} & \multicolumn{3}{|c|}{ Todos-Usos $_{e i}$} \\
\hline & \#Cob & \#Req & $\%$ & \#Cob & \#Req & $\%$ & \#Cob & \#Req & $\%$ \\
\hline AbstractCriterion & 62 & 85 & 72,94 & 51 & 84 & 60,71 & 126 & 236 & 53,39 \\
\hline AllEdges & 35 & 48 & 72,92 & 37 & 62 & 59,68 & 78 & 156 & 50,00 \\
\hline AllNodes & 33 & 35 & 94,29 & 37 & 41 & 90,24 & 83 & 99 & 83,84 \\
\hline AllPotUses & 61 & 81 & 75,31 & 76 & 111 & 68,47 & 187 & 312 & 59,94 \\
\hline AllUses & 73 & 94 & 77,66 & 93 & 131 & 70,99 & 221 & 353 & 62,61 \\
\hline DefUse & 32 & 37 & 86,49 & 24 & 30 & 80,00 & 82 & 102 & 80,39 \\
\hline Edge & 18 & 18 & 100,00 & 11 & 11 & 100,00 & 41 & 41 & 100,00 \\
\hline Total & 314 & 398 & 78,95 & 329 & $\overline{470}$ & 70,00 & 818 & 1299 & $\bar{~} 62,97$ \\
\hline Média & 44,86 & 56,86 & 82,80 & 47,00 & 67,14 & 75,73 & 116,86 & 185,57 & 70,02 \\
\hline
\end{tabular}

Por exemplo, considerando a classe AbstractCriterion, $T_{f}$ foi capaz de cobrir 62 (\#Cob) de um total de 85 (\#Req) requisitos de teste do critério Todos-Nós ${ }_{e i}$, o que representa uma porcentagem de cobertura (\%) de $72,94 \%$ do critério em questão. Em relação as demais classes, $T_{f}$ só foi capaz de cobrir $100 \%$ dos requisitos de testes da classe Edge que é a classe mais simples do pacote criteria, com 21 LOC (vide Tabela 6.5).

Visto que $T_{f}$ não se mostrou adequado ao critério Todos-Nós ${ }_{e i}$ para a maioria das classes, novos casos de teste foram desenvolvidos até obter o conjunto de teste $T_{n}$, adequado ao critério Todos-Nós ${ }_{e i}$. Ao todo, mais 32 casos de teste foram necessários, resultando num total de 77 casos de teste, até que $T_{n}$ se tornasse Todos-Nós ${ }_{e i}$-adequado. Os resultados da cobertura determinada por $T_{n}$ em relação aos demais critérios estruturais é apresentado na Tabela 6.12 .

Observa-se que embora $T_{n}$ seja Todos-Nós ${ }_{e i}$-adequado, ele não se mostra Todas-Arestas ${ }_{e i}$ adequado para quatro das sete classes sendo testadas. Para obter um conjunto de teste adequado ao critério Todas-Arestas ${ }_{e i}, T_{n}$ teve que ser acrescido de mais 6 casos de teste, dando origem ao conjunto de teste $T_{a}$, que contém 83 casos de teste e é Todas-Arestas ${ }_{e i^{-}}$ adequado. A Tabela 6.13 mostra a os resultados da cobertura determinada por $T_{a}$ em relação aos demais critérios estruturais. 
Tabela 6.12: Cobertura de um conjunto de teste $T_{n}$-adequado em relação aos critérios estruturais.

\begin{tabular}{|l|r|r|r|r|r|r|r|r|r|}
\hline \multirow{2}{*}{ Classes } & \multicolumn{3}{|c|}{ Todos-Nós $_{e i}$} & \multicolumn{3}{c|}{ Todas-Arestas $_{e i}$} & \multicolumn{3}{c|}{ Todos-Usos $_{e i}$} \\
\cline { 2 - 12 } & \#Cob & \#Req & \% & \#Cob & \#Req & \% & \#Cob & \#Req & \% \\
\hline AbstractCriterion & 85 & 85 & 100,00 & 79 & 84 & 94,05 & 210 & 236 & 88,98 \\
\hline AllEdges & 48 & 48 & 100,00 & 59 & 62 & 95,16 & 146 & 156 & 93,59 \\
\hline AllNodes & 35 & 35 & 100,00 & 40 & 41 & 97,56 & 92 & 99 & 92,93 \\
\hline AllPotUses & 81 & 81 & 100,00 & 111 & 111 & 100,00 & 312 & 312 & 100,00 \\
\hline AllUses & 94 & 94 & 100,00 & 130 & 131 & 99,24 & 350 & 353 & 99,15 \\
\hline DefUse & 37 & 37 & 100,00 & 30 & 30 & 100,00 & 102 & 102 & 100,00 \\
\hline Edge & 18 & 18 & 100,00 & 11 & 11 & 100,00 & 41 & 41 & 100,00 \\
\hline \hline Total & 398 & 398 & 100,00 & 460 & 470 & 97,87 & 1253 & 1299 & 96,46 \\
\hline Média & 56,86 & 56,86 & 100,00 & 65,71 & 67,14 & 98,00 & 179,00 & 185,57 & 96,38 \\
\hline
\end{tabular}

Tabela 6.13: Cobertura de um conjunto de teste $T_{a}$-adequado em relação aos critérios estruturais.

\begin{tabular}{|c|c|c|c|c|c|c|c|c|c|}
\hline \multirow{2}{*}{ Classes } & \multicolumn{3}{|c|}{ Todos-Nós ${ }_{e i}$} & \multicolumn{3}{|c|}{ Todas-Arestas $_{e i}$} & \multicolumn{3}{|c|}{ Todos-Usos $_{e i}$} \\
\hline & \#Cob & \#Req & $\%$ & \#Cob & \#Req & $\%$ & \#Cob & \#Req & $\%$ \\
\hline AbstractCriterion & 85 & 85 & 100,00 & 84 & 84 & 100,00 & 225 & 236 & 95,34 \\
\hline AllEdges & 48 & 48 & 100,00 & 62 & 62 & 100,00 & 154 & 156 & 98,72 \\
\hline AllNodes & 35 & 35 & 100,00 & 41 & 41 & 100,00 & 98 & 99 & 98,99 \\
\hline AllPotUses & 81 & 81 & 100,00 & 111 & 111 & 100,00 & 312 & 312 & 100,00 \\
\hline AllUses & 94 & 94 & 100,00 & 131 & 131 & 100,00 & 351 & 353 & 99,43 \\
\hline DefUse & 37 & 37 & 100,00 & 30 & 30 & 100,00 & 102 & 102 & 100,00 \\
\hline Edge & 18 & 18 & 100,00 & 11 & 11 & 100,00 & 41 & 41 & 100,00 \\
\hline Total & 398 & 398 & 100,00 & 470 & 470 & 100,00 & 1283 & 1299 & 98,77 \\
\hline Média & 56,86 & 56,86 & 100,00 & 67,14 & 67,14 & 100,00 & 183,29 & 185,57 & 98,93 \\
\hline
\end{tabular}

Avaliando-se a cobertura de $T_{a}$ em relação ao critério de fluxo de dado, observa-se que $T_{a}$ mostra-se não adequado ao critério Todos-Usos ${ }_{e i}$. Para quatro das sete classes sendo testadas $T_{a}$ determinou uma cobertura inferior a $100 \%$ em relação ao critério Todos-Usos ${ }_{e i}$. Visando a obter um conjunto de teste adequado a esse critério, outros 10 casos de teste foram inseridos em $T_{a}$, dando origem ao conjunto $T_{u}$. Na Tabela 6.14 são apresentados os dados de cobertura determinado pelo conjunto de teste $T_{u}$, composto de 93 casos de teste. Observa-se que tal conjunto de teste mostra-se adequado aos três critérios de teste estrutural considerados.

Em seguida, da mesma forma com realizado para as classes do Programa I, a Tabela 6.15 apresenta, para cada método de cada uma das classes que compõem o Programa I, o número de casos de teste necessários para satisfazer os requisitos exigidos pelo critério Todos-Usos ${ }_{e i}$.

Observa-se que, neste caso, mesmo apresentado métodos que demandam um maior número de requisitos de teste do que os métodos do Programa I, a complexidade do critério Todos-Usos ${ }_{e i}$ para o Programa II pode ser vista como sendo de ordem linear em relação ao número de comandos de decisão $t$. Na verdade, quanto maior o número de comandos de decisão do método, menor a relação entre o número de casos de teste (\#CT) e o número de 
requisitos de teste (\#Req). Na média, para o Programa II, observa-se que foram gerados em torno de 32,48 requisitos de teste e requeridos 2,33 casos de teste para satisfazê-los, o que corresponde a um número de casos de teste $92,8 \%$ inferior ao número de requisitos.

Tabela 6.14: Cobertura de um conjunto de teste $T_{u}$-adequado em relação aos critérios estruturais

\begin{tabular}{|c|c|c|c|c|c|c|c|c|c|}
\hline \multirow{2}{*}{ Classes } & \multicolumn{3}{|c|}{ Todos-Nós $_{e i}$} & \multicolumn{3}{|c|}{ Todas-Arestas $_{e i}$} & \multicolumn{3}{|c|}{ Todos-Usos $_{e i}$} \\
\hline & \#Cob & \#Req & $\%$ & \#Cob & \#Req & $\%$ & \#Cob & \#Req & $\%$ \\
\hline AbstractCriterion & 85 & 85 & 100,00 & 84 & 84 & 100,00 & 236 & 236 & 100,00 \\
\hline AllEdges & 48 & 48 & 100,00 & 62 & 62 & 100,00 & 156 & 156 & 100,00 \\
\hline AllNodes & 35 & 35 & 100,00 & 41 & 41 & 100,00 & 99 & 99 & 100,00 \\
\hline AllPotUses & 81 & 81 & 100,00 & 111 & 111 & 100,00 & 312 & 312 & 100,00 \\
\hline AllUses & 94 & 94 & 100,00 & 131 & 131 & 100,00 & 353 & 353 & 100,00 \\
\hline DefUse & 37 & 37 & 100,00 & 30 & 30 & 100,00 & 102 & 102 & 100,00 \\
\hline Edge & 18 & 18 & 100,00 & 11 & 11 & 100,00 & 41 & 41 & 100,00 \\
\hline Total & 399 & 399 & 100,00 & 470 & 470 & 100,00 & 1299 & 1299 & 100,00 \\
\hline Média & 56,86 & 56,86 & 100,00 & 67,14 & 67,14 & 100,00 & 185,57 & 185,57 & 100,00 \\
\hline
\end{tabular}

Tabela 6.15: Custo em termos do número de casos de teste: Programa II.

\begin{tabular}{|c|c|c|c|c|c|c|}
\hline Método & \#Var & \#Def & \#Req & \#CT & $t$ & $\frac{\# C T}{\# R e q}$ \\
\hline AbstractCriterion <init $>($ Graph;)V & 1 & 1 & 1 & 1 & $\overline{0}$ & $\overline{1,00}$ \\
\hline AbstractCriterion changePath(Graph;[String;)[String; & 11 & 15 & 68 & 5 & 5 & 0,07 \\
\hline AbstractCriterion getCoverage ()$[\mathrm{I}$ & 3 & 3 & 6 & 1 & 1 & 0,17 \\
\hline AbstractCriterion getCoveredRequirementsByPath(String;)HashSet; & 3 & 3 & 9 & 1 & 1 & 0,11 \\
\hline AbstractCriterion getCoveredRequirementsByTestCase(String;)HashSet; & 5 & 5 & 11 & 2 & 2 & 0,18 \\
\hline AbstractCriterion getName(I)String; & 3 & 3 & 7 & 1 & 2 & 0,14 \\
\hline AbstractCriterion getPossibleCoveredRequirements()HashSet; & 4 & 4 & 15 & 2 & 3 & 0,13 \\
\hline AbstractCriterion getPossibleRequirements()[Object; & 6 & 7 & 34 & 5 & 3 & 0,15 \\
\hline AbstractCriterion getRequirementByLabel(String;)Object; & 5 & 7 & 25 & 2 & 3 & 0,08 \\
\hline AbstractCriterion isActive(Object;)Z & 3 & 3 & 6 & 2 & 1 & 0,33 \\
\hline AbstractCriterion isCovered(Object;) Z & 3 & 3 & 4 & 1 & 1 & 0,25 \\
\hline AbstractCriterion isFeasible(Object;)Z & 3 & 3 & 6 & 2 & 1 & 0,33 \\
\hline AbstractCriterion removeAllPaths()V & 4 & 5 & 10 & 2 & 1 & 0,20 \\
\hline AbstractCriterion setActive(Object;)Z & 3 & 3 & 7 & 2 & 1 & 0,29 \\
\hline AbstractCriterion setFeasible(Object;)Z & 3 & 3 & 7 & 2 & 1 & 0,29 \\
\hline AbstractCriterion setInactive(Object;)Z & 3 & 3 & 7 & 2 & 1 & 0,29 \\
\hline AbstractCriterion setInfeasible(Object;)Z & 3 & 3 & 13 & 2 & 2 & 0,15 \\
\hline AllEdges <init $>($ Graph;I)V & 17 & 25 & 70 & 5 & 8 & 0,07 \\
\hline AllEdges addPath([Object;String; $)$ I & 13 & 17 & 53 & 4 & 7 & 0,08 \\
\hline AllEdges getCoveredRequirements()HashSet; & 6 & 6 & 15 & 2 & 2 & 0,13 \\
\hline AllEdges removePath(String;)I & 6 & 6 & 18 & 1 & 2 & 0,06 \\
\hline AllNodes < init > (Graph;I)V & 8 & 9 & 21 & 3 & 3 & 0,14 \\
\hline AllNodes addPath([Object;String;)I & 10 & 13 & 45 & 4 & 5 & 0,09 \\
\hline AllNodes getCoveredRequirements()HashSet; & 6 & 6 & 15 & 1 & 2 & 0,07 \\
\hline AllNodes removePath(String;)I & 6 & 6 & 18 & 2 & 2 & 0,11 \\
\hline AllPotUses < init $>($ CFG;Z)V & 23 & 28 & 99 & 2 & 14 & 0,02 \\
\hline AllPotUses addPath([Object;String;)I & 26 & 38 & 180 & 4 & 19 & 0,02 \\
\hline AllPotUses getCoveredRequirements()HashSet; & 6 & 6 & 15 & 3 & 2 & 0,20 \\
\hline AllPotUses removePath(String;)I & 6 & 6 & 18 & 1 & 2 & 0,06 \\
\hline AllUses < init $>(\mathrm{CFG} ; \mathrm{Z}) \mathrm{V}$ & 27 & 39 & 142 & 3 & 20 & 0,02 \\
\hline AllUses addPath([Object;String; $)$ I & 26 & 38 & 178 & 5 & 19 & 0,03 \\
\hline AllUses getCoveredRequirements()HashSet; & 6 & 6 & 15 & 3 & 2 & 0,20 \\
\hline AllUses removePath(String;)I & 6 & 6 & 18 & 1 & 2 & 0,06 \\
\hline DefUse < init $>$ (String;String;String;String;)V & 5 & 5 & 5 & 1 & 0 & 0,20 \\
\hline DefUse compareTo(Object;)I & 9 & 9 & 44 & 2 & 6 & 0,05 \\
\hline DefUse equals(Object;)Z & 11 & 11 & 40 & 6 & 6 & 0,15 \\
\hline DefUse toString()String; & 5 & 5 & 13 & 1 & 1 & 0,08 \\
\hline Edge <init > (String;String;)V & 3 & 3 & 3 & 1 & 0 & 0,33 \\
\hline Edge compareTo(Object;)I & 6 & 6 & 22 & 1 & 3 & 0,05 \\
\hline Edge equals(Object;)Z & 7 & 7 & 16 & 2 & 2 & 0,13 \\
\hline Total & 310 & 375 & 1299 & 93 & 158 & 0,07 \\
\hline Média & 7,75 & 9,38 & 32,48 & 2,33 & 3,95 & 0,16 \\
\hline
\end{tabular}

Assim sendo, os resultados obtidos a partir da aplicação dos critérios, considerando Programa I e Programa II, dão evidências que os critérios de teste estruturais definidos são factíveis e demandam um número de casos de teste inferior a complexidade teórica dos 
critérios. Tais resultados motivam a realização de estudos empíricos envolvendo diversos programas em diferentes domínios de aplicação visando a avaliar na prática os aspectos de custo, eficácia e dificuldade de satisfação entre os critérios definidos.

\subsection{Considerações Finais}

Neste capítulo ilustrou-se a aplicação dos critérios de teste implementados pela ferramenta JaBUTi considerando dois conjuntos de programas, visando a avaliar o número de requisitos gerados de teste gerados pelos mesmos. Além disso, os critérios independentes de exceção implementados na JaBUTi foram aplicados de forma incremental a dois programas Java, seguindo os passos da estratégia definida no Capítulo 3.

Os resultados obtidos da aplicação desses critérios nesses dois programas dão evidências da viabilidade prática de utilização dos critérios no teste intra-método. Assim sendo, com a disponibilidade da ferramenta JaBUTi, diversos estudos empíricos devem ser realizados visando a avaliar detalhadamente os aspectos de custo, eficácia e dificuldade de satisfação entre os critérios de teste estruturais intra-métodos tanto no teste de programas quanto componentes Java.

A seguir, no Capítulo 7, são sintetizadas as contribuições desta tese e descritas as possibilidades de trabalhos futuros no contexto do teste de programas OO e de componentes. 


\title{
Conclusão
}

\begin{abstract}
$\bigcirc$ ONFORME caracterizado anteriormente, podem-se classificar as contribuições para $\checkmark$ a área de Teste de Software em: Teóricas, Empíricas e de Automatização da Atividade de Teste. Este tese apresentou contribuições nestas três perspectivas: análise e definição de critérios de teste para programas OO e componentes de software; automatização da aplicação dos critérios definidos; e condução de estudos empíricos que dêem evidências do custo/benefício dos critérios desenvolvidos, considerando critérios de teste estruturais e baseados em mutação. Essas contribuições se inserem nas seguintes linhas de pesquisa definidas por Harrold (2000): Desenvolvimento de Processos de Teste Efetivos, Teste de Sistemas Baseado em Componentes, Desenvolvimento de Ferramentas e Realização de Estudos Empíricos. Além disso, abrem margem para o desenvovimento de trabalhos nas outras linhas de pesquisa apontadas, tais como o Uso de Artefatos (informação) de Teste e o apoio ao Teste de Regressão (Harrold, 2000). A seguir tais contribuições são retomadas mais detalhadamente e posteriormente são descritas as possibilidades de trabalhos futuros.
\end{abstract}

\subsection{Contribuições}

\subsubsection{Contribuições Relacionadas ao Teste Estrutural 00}

Considerando os critérios de teste estruturais, esta tese apresentou contribuições: 
Teóricas: com a definição e análise de propriedades de oito critérios de teste destinados ao teste intra-método de programas OO. Quatro desses critérios são baseados em análise de fluxo de controle e quatro baseados em análise de fluxo de dados. Os critérios foram definidos de modo a considerar não somente o fluxo de execução normal de um programa OO mas também o fluxo de execução relacionado a exceções.

Com a análise de propriedade dos critérios demonstrou-se que os mesmos podem ser vistos como complementares do ponto de vista da relação de inclusão e preenchem a lacuna entre os critérios Todos-Caminhos e Todos-Nós, considerando que algumas propriedades sejam satisfeitas pelo programa em teste.

Uma estratégia incremental de aplicação dos critérios estruturais também foi definida com base na relação de inclusão entre eles. O objetivo da estratégia de teste é permitir ao testador aplicar os critérios de teste incrementalmente, respeitando as restrições de tempo e custo existentes.

Empíricas: com a aplicação dos critérios a dois conjuntos de programas, evidências foram obtidas de que os mesmos são factíveis e demandam um número relativamente pequeno de casos de teste se comparado com o número de requisitos gerados.

Automatização: com o desenvolvimento da ferramenta de teste JaBUTi que apóia a aplicação dos critérios definidos no teste de programas e componentes Java. A disponibilidade de tal ferramenta viabiliza a realização de estudos empíricos envolvendo os critérios de teste definidos, e contribui para a transferência tecnológica e para atividades de ensino/aprendizagem em disciplinas de teste de software. Além disso, no desenvolvimento dos critérios e da ferramenta de teste preocupou-se em defini-los e implementá-los de tal modo que fosse possível a realização do teste estrutural intramétodo tanto para programas quanto para componentes de software para os quais o código fonte nem sempre encontra-se disponível. Tal característica diferencia a JaBUTi de outras ferramentas desenvolvidas até o momento, sendo ela a única que apóia a realização de teste de fluxo de dados para componentes Java mesmo sem a disponibilidade do código fonte.

\subsubsection{Contribuições Relacionadas ao Teste Baseado em Mutação}

Tento em vista que o teste de mutação é bastante flexível e pode ser facilmente estendido para diferentes entidades executáveis, as contribuições desta tese nesse contexto foram:

Teóricas: com a realização de uma análise crítica, reavaliando os operadores de mutação definidos originalmente para o teste de programas procedimentais no contexto de 
programas OO. Nesse sentido, os conjuntos de operadores de mutação de unidade e de integração destinados ao teste de programas $\mathrm{C}$ foram reavaliados e foi feita a identificação de quais desses operadores de mutação poderiam ser utilizados no teste de programas $\mathrm{OO}$, considerando as linguagens Java e $\mathrm{C}++$. Particularmente para o teste intra-método de programas em Java, alguns operadores de mutação tiveram que ser definidos visando a modelar tipos de defeitos específicos que podem ocorrer em tal linguagem.

Para o teste inter-classe, foi também feita uma análise reaproveitando a definição de operadores previamente definidos para a linguagem Java (Ma et al., 2002). Observou-se nesse sentido que para o teste inter-classe de programas $\mathrm{C}++$ novos operadores precisam ser definidos uma vez que tipos de defeitos relacionados com algumas características específicas de $\mathrm{C}++$, tais como templates e herança múltipla, não são modelados pelos operadores destinados à linguagem Java.

Devido ao alto custo relacionado ao grande número de mutantes gerados pelos critérios baseados em mutação, estratégias incrementais de aplicação dos operadores foram definidas considerando dados coletados de experimentos anteriores envolvendo programas procedimentais.

Além disso, considerando a análise dos mutantes vivos, outra contribuição teórica desta tese ao teste de mutação foi o desenvolvimento de uma técnica, denominada BaLBEDeT. Esta técnica utiliza conceitos de inteligência artificial, mais especificamente de Aprendizado Bayesiano, para auxiliar o testador a decidir quais são os mutantes mais prováveis de serem equivalentes e quais aqueles com maior probabilidade de contribuir efetivamente para a melhoria do conjunto de teste.

Visto que tal técnica se baseia na existência de informações históricas sobre operadores de mutação previamente determinados, ela também foi desenvolvida tendo como base um conjunto de dados derivados a partir de programas procedimentais. No entanto, observa-se que a teoria utilizada em seu desenvolvimento aplica-se indistintamente a conjuntos de operadores de mutação desenvolvidos para outras linguagens de programação, dependendo apenas da existência de dados históricos sobre mutantes equivalentes para a linguagem em questão.

Obviamente, a precisão da técnica está fortemente relacionada com a abrangência dos dados históricos utilizados, de modo que cada novo experimento realizado realimenta a base de informações históricas contribuindo para a melhoria da eficácia da técnica em identificar mutantes equivalentes e não-equivalentes.

Automatização: Para apoiar a aplicação dos operadores de mutação no teste intramétodo, inter-método e inter-classe, a arquitetura de uma ferramenta de teste foi 
proposta, a qual utiliza a linguagem $\mathcal{M} u \mathcal{D} e \mathcal{L}$ para a descrição dos operadores e a ferramenta mudelgen para viabilizar a geração dos mutantes. Conforme observado, na descrição dos operadores de mutação de unidade com $\mathcal{M} u \mathcal{D} e \mathcal{L}$ um reuso significativo dessas descrições pode ser obtido, devido a similaridade das gramáticas de $\mathrm{C}, \mathrm{C}++$ e Java em determinadas construções sintáticas. Tão logo a ferramenta esteja implementara ela viabilizará a realização de diversos estudos de caso e o desenvolvimento de estratégias de teste incrementais como as já desenvolvidas para o teste de programas procedimentais contribuindo para a redução do custo do teste de mutação e disponibilizando sua utilização em ambientes reais de desenvolvimento de software.

\subsubsection{Contribuições Relacionadas ao Teste de Componentes}

No contexto de teste de componentes de software uma contribuição importante foi viabilizar a aplicação de critérios de teste estruturais a componentes implementados em Java. De acordo com os trabalhos relacionados ao teste de componentes, a grande maioria se destina à realização de teste funcional, principalmente do ponto de vista do usuário do componente. Com os critérios estruturais desenvolvidos, somente a existência do bytecode do componente é necessário, viabilizando a realização do teste estrutural tanto por parte do desenvolvedor quanto por parte do usuário dos componentes.

Com isso, observa-se que as contribuições desta tese enquadram-se nas três perspectivas destacadas por Maldonado (1997): teóricas, empíricas e de automatização. Além disso, observa-se que tais contribuições estão relacionadas às principais direções para a área de teste de software destacadas por Harrold (2000), dentre elas: a importância de estudos na área de teste de sistemas baseado em componentes, estudos demonstrando a eficácia das técnicas de teste e o desenvolvimento de métodos e ferramentas de teste de modo que os resultados obtidos possam ser empregados na prática. Em suma, na parte teórica, o presente trabalho contribuiu com a definição e avaliação de critérios para o teste de programas e componentes de software OO, com a definição de estratégias incrementais de aplicação dos critérios e, especificamente relacionado ao teste de mutação, com a definição de uma técnica para auxiliar na identificação de mutantes equivalentes. Na parte empírica as contribuições são referentes à realização de estudos de caso comparando os critérios de teste desenvolvidos, avaliando, em um primeiro momento, a viabilidade dos mesmos em termos de custo/benefício. Finalmente, na parte de automatização as contribuições referem-se à definição e implementação de uma ferramenta de apoio ao teste estrutural de programas e componentes e na especificação de uma arquitetura para uma ferramenta de teste de apoio ao teste de mutação. Tais contribuições abrem margem para 
uma vasta linha de pesquisa na área de teste de software e algumas direções de trabalhos futuros são descritas a seguir.

\subsection{Trabalhos Futuros}

\subsubsection{Definição de Critérios de Teste}

Programas OO apresentam diversas características, tais como herança, polimorfismo e acoplamento dinâmico e, conseqüentemente, diferentes tipos de defeitos as quais podem exigir diferentes critérios de teste para serem identificados. Além disso, diferentes linguagens de programação podem exigir a definição de novos critérios de teste, tais como, as linguagens Orientadas a Aspecto. Nesse sentido, estender os critérios de teste existentes e definir novos critérios de teste, como por exemplo, estender os critérios estruturais aqui apresentados para o teste de integração, tendo sempre em mente a busca pela qualidade do produto final sendo desenvolvido e testado.

\subsubsection{Desenvolvimento de Ferramentas}

Observa-se que a evolução e o desenvolvimento de novas ferramentas de teste deve ser uma preocupação constante para o aumento da qualidade e da produtividade da atividade de teste.

Nesse sentido, de posse dos critérios de teste desenvolvidos, extensões da ferramenta JaBUTi serão necessárias ou até mesmo o desenvolvimento de outras ferramentas de teste, como a ferramenta de apoio ao teste de mutação. O objetivo é culminar em um ambiente integrado de teste e validação que apóie as fases do teste de unidade e de integração utilizando diferentes critérios de teste e que possa ser utilizado tanto na condução de estudos empíricos, como na transferência tecnológica da academia para a indústria.

\subsubsection{Condução de Experimentos}

Em virtude da diversidade de critérios de teste existente, saber qual deles deve ser utilizado ou como utilizá-los de forma complementar a fim de obter o melhor resultado com o menor custo é uma questão complicada. A realização de estudos empíricos procura, por meio da comparação entre os critérios, obter uma estratégia que seja eficaz para revelar defeitos no programa, ao mesmo tempo em que apresente um baixo custo de aplicação.

Para entender a importância desses estudos, considere a seguinte situação (Mathur e Wong, 1994): é preciso testar um programa $P$ que será usado em um ambiente de 
segurança crítica e o funcionamento desse sistema depende de que $P$ tenha sido bem testado. O testador deve testar $P$ tanto quanto for possível e, para isso, decide usar vários critérios de teste a fim de verificar a adequação dos casos de teste desenvolvidos. Inicialmente, os casos de teste são gerados de modo a satisfazerem um determinado critério $C_{1}$. Assim, uma questão que surge é: "Tendo obtido um conjunto de teste $T$ adequado ao critério $C_{1}$ e, utilizando agora o critério $C_{2}$, consegue-se melhorar o conjunto de teste $T$ ?". Com a realização de estudos empíricos procura-se responder a essa e outras questões que surgem diante da dificuldade em decidir quando um programa está suficientemente testado.

De posse das ferramentas de teste e dos critérios de teste desenvolvidos para o teste de programas $\mathrm{OO}$, os estudos empíricos previamente conduzidos para programas procedimentais devem ser revisitados visando a identificar se resultados similares são obtidos, bem como contribuir para o desenvolvimento de diferentes estratégias de teste considerando as características específicas do paradigma OO.

\subsubsection{Teste de Componentes de Software}

Um ponto importante a ser investigado nesse contexto é permitir ao usuário do componente identificar qual é a porção real do componente de software que ele está utilizando. Por exemplo, embora a ferramenta de teste JaBUTi possa reportar a cobertura obtida em relação ao código de determinado componente Java, sem ter conhecimento da quantidade de código que o usuário do componente realmente está utilizando, tal medida de cobertura pode ser subestimada, ou seja, o componente de software pode fornecer funcionalidades adicionais que não estão sendo utilizadas no contexto de uma dada aplicação; com isso, uma vez que a cobertura é avaliada em relação ao componente como um todo, mesmo que as partes do componente que estão sendo utilizadas já tenham sido suficientemente testadas, devido à baixa cobertura reportada o usuário pode ter a falsa impressão de que aquele componente particular ainda necessita de testes adicionais.

Uma forma de contornar esse problema é avaliar quais informações deveriam ser adicionadas ao componente e como adicionar tais informações de modo que o usuário pudesse saber ao certo quais partes do código do componente implementam cada uma de suas funcionalidades. Com isso, seria possível avaliar a real cobertura obtida por um determinado conjunto de teste.

\subsubsection{Uso de Informações de Teste em Atividades de Depuração}

As informações oriundas da atividade de teste podem e devem ser utilizadas para auxiliar outras atividades de Engenharia de Software tais como depuração, manutenção e 
teste de regressão. Existem diversas técnicas, tais como a desenvolvida por Chaim (2001), que se beneficiam das informações do teste para auxiliar nessas outras atividades. Explorar essas técnicas no contexto de programas OO é de grande importância, contribuindo para a melhoria da qualidade e produtividade dessas demais atividades relacionadas ao desenvolvimento de software OO.

\subsubsection{Uso de Técnicas de Inteligência Artificial para Apoiar a Ativi- dade de Teste}

Da mesma forma como foi desenvolvida a técnica BaLBEDeT para auxiliar na detecção de mutantes equivalentes, outras técnicas de Inteligência Artificial, tais como Algoritmos Genéticos, Redes Neurais e Aprendizado Bayesiano, podem ser explorados no contexto de outras tarefas relacionada à atividade de teste, tais como a determinação de associações não-executáveis, no caso dos critérios de fluxo de dados, na geração automática de casos de teste e até mesmo no desenvolvimento de estratégias de teste considerando características particulares do programa que se deseja testar.

Além disso, outras linhas de pesquisa incluem o desenvolvimento e a utilização de métricas de complexidade para programas OO, o desenvolvimento e a utilização de estratégias de particionamento de programas para facilitar tanto atividades de depuração quanto de entendimento de programas, dentre outras. 


\section{Referências Bibliográficas}

Acree, A. T.; Budd, T. A.; DeMillo, R. A.; Lipton, R. J.; Sayward, F. G. Mutation analysis. Relatório Técnico GIT-ICS-79/08, Georgia Institute of Technology, Atlanta, GA, 1979.

Agrawal, H. Dominators, super block, and program coverage. In: SIGPLAN SIGACT Symposium on Principles of Programming Languages - POPL'94, Portland, Oregon: ACM Press, 1994, p. 25-34.

Agrawal, H.; Alberi, J.; Horgan, J. R.; Li, J.; London, S.; Wong, W. E.; Ghosh, S.; Wilde, N. Mining system tests to aid software maintenance. IEEE Computer, v. 31, n. 7, p. 64-73, 1998.

Agrawal, H.; Demillo, R. A.; Hathaway, R.; Hsu, W.; Hsu, W.; Krauser, E. W.; Martin, R. J.; Mathur, A. P.; Spafford, E. H. Design of mutant operators for the $C$ programming language. Relatório Técnico SERC-TR41-P, Software Engineering Research Center, Purdue University, West Lafayette, IN, 1989.

Alexander, R. T.; Bieman, J. M.; Ghosh, S.; Ji, B. Mutation of Java objects. In: 13th International Symposium on Software Reliability Engineering - ISSRE'2002, Annapolis, MD, 2002, p. 341-351.

Arnold, T. R.; Fuson, W. A. In a perfect world. Communications of the ACM, v. 37, n. 9, p. 78-86, 1994.

Banks, D.; Dashiell, W.; Gallagher, L.; Hagwood, C.; Kacker, R.; RoSENTHAL, L. Software testing by statistical methods. Relatório Técnico NISTIR 6129, NIST - National Institute of Standards and Technology, 1998.

Barbey, S.; Strohmeier, A. The problematics of testing object-oriented software. In: 2nd Conference on Software Quality Management - SQM'94, 1994, p. 411-426.

Barbosa, E. F.; Maldonado, J. C.; Vincenzi, A. M. R. Towards the determination of sufficient mutant operators for C. STVR-Software Testing, Verification and Reliability, v. 11, n. 2, p. 113-136, 2001. 
Barbosa, E. F.; Maldonado, J. C.; Vincenzi, A. M. R.; Delamaro, M. E.; SouzA, S. R. S.; Jino, M. Introdução ao teste de software. In: Minicurso apresentado no SBES'2000 - XIV Simpósio Brasileiro de Engenharia de Software, João Pessoa, PB, 2000, p. 330-378.

Beck, K.; Gamma, E. JUnit cookbook. Página WEB, disponível em: http: //www.junit.org/. Acesso em: 01/03/2004, 2002.

BeIzer, B. Software testing techniques. 2nd ed. New York: Van Nostrand Reinhold Company, 1990.

BENDER \& Associates Inc. SoftTest. Disponível em: http://www.softtest. com/ftp/demo/st53demo.zip. Acesso em: 03/03/2000, 1998.

Beydeda, S.; Gruhn, V. An integrated testing technique for component-based software. In: 1st AICCSA ACS/IEEE International Conference on Computer Systems and Applications, Beirut, Libanon: IEEE Computer Society Press, 2001, p. 328-334.

Bieman, J. M.; Ghosh, S.; Alexander, R. T. A technique for mutation of Java objects. In: 16th IEEE International Conference on Automated Software Engineering, San Diego, CA, 2001, p. 23-26.

Binder, R. V. Design for testability in object oriented systems. Communications of the $A C M$, v. 37, n. 9, p. 87-101, 1994a.

Binder, R. V. Testing object-oriented systems: A status report. American Programmer, v. 7, n. 4, p. 22-28, 1994 b.

Binder, R. V. State-based testing. Object Magazine, v. 5, n. 6, p. 75-78, 1995.

Binder, R. V. Modal testing strategies for OO software. Computer, v. 29, n. 11, p. 97-99, 1996.

BINDER, R. V. Testing object-oriented systems: Models, patterns, and tools, v. 1. Addison Wesley Longman, Inc., 1999.

Binns, A.; MCGRAw, G. Building a Java software engineering tool for testing applets. In: IntraNet 96 NY Conference, New York - USA, 1996.

Boujarwah, A.; Saleh, K.; Al-Dallal, J. Dynamic data flow analysis for Java programs. Journal of Information and Software Technology, v. 42, n. 11, p. 765-775, 2000 .

Budd, T. A. Mutation analysis of program test data. Tese de Doutoramento, Yale University, New Haven, CT, 1980.

BudD, T. A. Mutation analysis: Ideas, example, problems and prospects, cáp. Computer Program Testing North-Holand Publishing Company, p. 129-148, 1981.

Bundell, G. A.; Lee, G.; Morris, J.; Parker, K.; Lam, P. A software component verification tool. In: 1st International Conference on Software Methods and Tools (SMT'2000), Wollongong, Australia: IEEE Computer Society Press, 2000, p. 137-147. 
Bybro, M. A mutation testing tool for Java programs. Dissertação de Mestrado, Stockholm University, Stockholm, Sweden, 2003.

CBSEnet Project TeAm Cbsenet-component based software engineering network. Página WEB, disponível em: http: //www. cbsenet.org/. Acesso em: 01/03/2004, 2002.

Chaim, M. L. Poke-tool - uma ferramenta para suporte ao teste estrutural de programas baseado em análise de fluxo de dados. Dissertação de Mestrado, DCA/FEEC/UNICAMP, Campinas, SP, 1991.

Chaim, M. L. Depuração de Programas Baseada em Informação de Teste Estrutural. Tese de doutorado, Faculdade de Engenharia de Elétrica e de Computação, Universidade Estadual de Campinas, Campinas, SP, Brasil, 2001.

Chaim, M. L.; Maldonado, J. C.; Jino, M.; Vilela, P. Data-flow testing of programs with pointers and records: Implementation, effectiveness, and cost. In: International Conference on Computer Science, Software Engineering, Information Technology, e-Business, and Applications, Foz de Iguaçu, Paraná: International Association for Computer and Information Science, 2002, p. 317-323.

Chambers, C.; Pechtchanski, I.; Sarkar, V.; Serrano, M.; Srinivasan, H. Dependence analysis for Java. In: Workshop on Languages and Compilers for Parallel Computing (LCPC'99), La Jolla, CA, 1999.

Chang, K. H.; Liao, S. S.; Sheidman, S. B.; Chapman, R. Testing objectoriented programs: From formal specification to test scenario generation. The Journal of Systems and Software, v. 42, n. 2, p. 141-151, 1998.

Chen, H. Y.; Tse, T. H.; Chan, F. T.; Chen, T. Y. In black and white: an integrated approach to class-level testing of object-oriented programs. ACM Transactions on Software Engineering and Methodology, v. 7, n. 3, p. 250-295, 1998.

Chen, H. Y.; Tse, T. H.; Chen, T. Y. TACCLE: a methodology for objectoriented software Testing At the Class and Cluster LEvels. ACM Transactions on Software Engineering and Methodology, v. 10, n. 1, p. 56-109, 2001.

Chen, M.-H.; KaO, H. M. Testing object-oriented programs - an integrated approach. In: 10th International Symposium on Software Reliability Engineering, Boca Raton, Florida: IEEE Computer Society, 1999, p. 73-83.

Chen, M.-H.; KaO, M.-H. H.; TANG, M.-H. Investigating test effectiveness on object-oriented software - a case study. In: 12th International Software Quality Week - QW'99, San Jose, CA, 1999.

Chevalley, P. Applying mutation analysis for object-oriented programs using a reflective approach. In: 8th Asia-Pacific Software Engineering Conference - APSEC'01, Macao, China: IEEE Computer Society Press, 2001, p. 267-272.

Choi, B. J.; Mathur, A. P. High-performance mutation testing. The Journal of Systems and Software, v. 1, n. 20, p. 135-152, 1993. 
Choi, B. J.; Mathur, A. P.; Pattison, A. P. pmothra: Scheduling mutants for execution on a hypercube. In: 3rd Symposium on Software Testing, Analysis and Verification, Key West, FL, 1989, p. 58-65.

CHow, T. S. Testing software design modelled by finite-state machines. IEEE Transactions on Software Engineering, v. 4, n. 3, p. 178-187, 1978.

Chusho, T. Test data selection and quality estimation based on the concept of essential branches for path testing. IEEE Transactions on Software Engineering, v. 13, n. 5, p. $509-517,1987$.

ClARiFi Project Team CLARiFi - CLear And Reliable Information For Integration. Página WEB, disponível em: http://clarifi.eng.it/. Acesso em: 01/03/2004, 2000 .

Clarke, L. A.; Podgurski, A.; Richardson, D. J.; Zeil, S. J. A formal evaluation of data flow path selection criteria. IEEE Transactions on Software Engineering, v. 15, n. 11, p. 1318-1332, 1989.

Clarke, P. J.; Malloy, B. A. A taxonomy of classes for implementation-based testing. Relatório Técnico, Clemson University, 2001.

Colanzi, T. E. Uma abordagem integrada de desenvolvimento e teste de software baseada na UML. Dissertação de Mestrado, ICMC-USP, São Carlos - SP, 1999.

Coleman et AL., D. Object-oriented development: The fusion method. Englewood Cliffs, New Jersey, USA: Prentice Hall International, 1994.

Cornelius, B. Java versus $\mathrm{C}++$. Documento on-line, disponível em: http://www . dur.ac.uk/barry. cornelius/Java/java.versus. c++/. Acesso em: 01/03/2004, 1997.

Corporation, P. Using design by contract to automate Java software and component testing. Página WEB, disponível em: http://www .parasoft.com/. Acesso em: 01/03/2004, 2002.

DAнm, M. Byte code engineering with the BCEL API. Relatório Técnico B-1798, Freie Universität Berlin - Institut für Informatik, Berlin - German, disponível em: http://bcel.sourceforge.net/. Acesso em: 01/03/2004, 2001.

Delamaro, M. E. Proteum: Um ambiente de teste baseado na análise de mutantes. Dissertação de Mestrado, ICMC/USP, São Carlos - SP, 1993.

Delamaro, M. E. Mutação de interface: Um critério de adequação interprocedimental para o teste de integração. Tese de Doutoramento, Instituto de Física de São Carlos - Universidade de São Paulo, São Carlos, SP, 1997.

Delamaro, M. E.; Maldonado, J. C. Proteum - a tool for the assessment of test adequacy for C programs. In: Conference on Performability in Computing Systems (PCS'96), East Brunswick, NJ, 1996, p. 79-95. 
Delamaro, M. E.; Maldonado, J. C.; Mathur, A. P. Interface mutation: An approach for integration testing. IEEE Transactions on Software Engineering, v. 27, n. 3, p. 228-247, 2001a.

Delamaro, M. E.; Maldonado, J. C.; Vincenzi, A. M. R. Proteum/IM 2.0: An integrated mutation testing environment. In: Mutation 2000 Symposium, San Jose, CA: Kluwer Academic Publishers, 2000, p. 91-101.

Delamaro, M. E.; Pezzè, M.; Vincenzi, A. M. R.; Maldonado, J. C. Mutant operators for testing concurrent Java programs. In: SBES'2001 - Simpósio Brasileiro de Engenharia de Software, Rio de Janeiro, RJ, 2001b, p. 272-285.

Delamaro, M. E.; Pezzì, M.; Vincenzi, A. M. R.; Maldonado, J. C. Mutation testing to multi-threaded Java programs. Relatório Técnico, Departamento de Informática - Universidade de Maringá, Maringá - PR, disponível em: http: //www.din.uem.br/〜delamaro/papers/relat.ps.gz. Acesso em: 01/03/2004., 2001c.

DeMillo, R. A. Mutation analysis as a tool for software quality assurance. In: COMPSAC80, Chicago, IL, 1980.

DeMillo, R. A. Software testing and evaluation. The Benjamin/Cummings Publishing Company Inc, 1987.

DeMillo, R. A.; Lipton, R. J.; Sayward, F. G. Hints on test data selection: Help for the practicing programmer. IEEE Computer, v. 11, n. 4, p. 34-43, 1978.

DeMillo, R. A.; Offutt, A. J. Constraint based automatic test data generation. IEEE Transactions on Software Engineering, v. 17, n. 9, p. 900-910, 1991.

Domingues, A. L. D.; Simão, A. S.; Vincenzi, A. M. R.; Maldonado, J. C. Evaltool: Um ambiente de apoio à avaliação e seleção de ferramentas de teste para programas orientados a objetos. In: XVI SBES - Simpósio Brasileiro de Engenharia de Software, Gramado, RS, Brasil, 2002, p. 384-389.

Domingues, A. L. S. Avaliação de critérios e ferramentas de teste para programas OO. Dissertação de Mestrado, ICMC-USP, São Carlos - SP, 2002.

Doong, R. K.; Frankl, P. G. The ASTOOT approach to testing object-oriented programs. ACM Transactions on Software Engineering Methodology, p. 101-130, 1994.

Duncan, I.; Robson, D.; Munro, M. Test case development during OO lifecycle and evolution. Página WEB, disponível em: http://www.dur .ac.uk/computer . science/research/technical-reports/. Acesso em: 01/03/2004, 2000.

Dundan, I.; Robson, D. An exploratory study of common coding faults in C programs. Software Maintenance: Research and Practice, v. 8, n. 4, p. 241-256, 1996.

EDGE, T. Glass JAR toolkit. web page, disponível em: http://www.testersedge. com/gjtk/. Acesso em: 01/03/2004, 2002. 
EDWARDS, S. H. Black-box testing using flowgraphs: An experimental assessment of effectiveness and automation potential. STVR - Software Testing, Verification and Reliability, v. 10, n. 4, p. 249-262, 2000.

EDWARDS, S. H. A framework for practical, automated black-box testing of componentbased software. STVR - Software Testing, Verification and Reliability, v. 11, n. 2, p. $97-111,2001 \mathrm{a}$.

EDWARDS, S. H. Toward reflective metadata wrappers for formally specified software components. In: 1st Workshop on Specification and Verification of Component-Based Systems - affiliated with OOPSLA'2001, Tampa, Florida: ACM Press, 2001b, p. 14-21.

FABbri, S. C. P. F. A análise de mutantes no contexto de sistemas reativos: Uma contribuição para o estabelecimento de estratégias de teste e validação. Tese de Doutoramento, IFSC-USP, São Carlos - SP, 1996.

Fabbri, S. C. P. F.; Maldonado, J. C.; Delamaro, M. E.; Masiero, P. C. Proteum/FSM: A tool to support finite state machine validation based on mutation testing. In: XIX SCCC - International Conference of the Chilean Computer Science Society, Talca, Chile, 1999a, p. 96-104.

Fabbri, S. C. P. F.; Maldonado, J. C.; Masiero, P. C. Mutation analysis in the context of reactive system specification and validation. In: 5th Annual International Conference on Software Quality Management, Bath, UK, 1997, p. 247-258.

Fabbri, S. C. P. F.; Maldonado, J. C.; Masiero, P. C.; Delamaro, M. E. Análise de mutantes baseada em máquinas de estado finito. In: XI SBRC - Simpósio Brasileiro de Redes de Computadores, Campinas, SP, 1993, p. 407-425.

Fabbri, S. C. P. F.; Maldonado, J. C.; Masiero, P. C.; Delamaro, M. E. Mutation analysis testing for finite state machines. In: 5th International Symposium on Software Reliability Engineering (ISSRE'94), Monterey - CA: IEEE Computer Society Press, 1994, p. 220-229.

Fabbri, S. C. P. F.; Maldonado, J. C.; Masiero, P. C.; Delamaro, M. E. Mutation analysis applied to validate specifications based on petri nets. In: FORTE'95 - 8th IFIP Conference on Formal Descriptions Techniques for Distribute Systems and Communication Protocols, Montreal, Canada: Kluwer Academic Publishers, 1995, p. 329-337.

Fabbri, S. C. P. F.; Maldonado, J. C.; Sugeta, T.; Masiero, P. C. Mutation testing applied to validate specifications based on statecharts. In: ISSRE-International Symposium on Software Reliability Systems, 1999b, p. 210-219.

Fiedler, S. P. Object-oriented unit testing. Hewlett-Packard Journal, v. 40, n. 2, p. 69-74, 1989.

FRANKL, F. G. The use of data flow information for the selection and evaluation of software test data. Tese de Doutoramento, Universidade de New York, New York, NY, 1987. 
Frankl, P. G.; Weiss, S. N.; Weyuker, E. J. ASSET: A system to select and evaluate tests. In: IEEE Conference on Software Tools, New York, NY, 1985, p. 72-79.

Frankl, P. G.; Weyuker, E. J. An applicable family of data flow testing criteria. IEEE Transactions on Software Engineering, v. 14, n. 10, p. 1483-1498, 1988.

Frankl, P. G.; Weyuker, E. J. A formal analysis of the fault-detecting ability of testing methods. IEEE Transactions on Software Engineering, v. 19, n. 3, p. 202-213, 1993a.

Frankl, P. G.; Weyuker, E. J. Provable improvements on branch testing. IEEE Transactions on Software Engineering, v. 19, n. 10, p. 962-975, $1993 \mathrm{~b}$.

Frankl, P. G.; Weyuker, E. J. Testing software to detect and reduce risk. The Journal of Systems and Software, v. 53, n. 3, p. 275-286, 2000.

Friedman, A. D. Logical design of digital systems. Computer Science Press, 1975.

Fujimara, S.; Bochmann, G. V.; Khendek, F.; Amalou, M.; Ghedamsi, A. Test selection based on finite state models. IEEE Transactions on Software Engineering, v. 17, n. 6, p. 591-603, 1991.

Ghosh, S.; Mathur, A. P. Interface mutation. STVR - Software Testing, Verification and Reliability, v. 11, n. 4, p. 227-247, (Special Issue: Mutation 2000 - A Symposium on Mutation Testing. Issue Edited by W. Eric Wong), 2001.

Gimenes, I. M. S.; Barroca, L.; Huzita, E. H. M.; Carnielo, A. O processo de desenvolvimento de componentes através de exemplos. In: VIII Escola Regional de Informática, Porto Alegre, RS, 2000, p. 1-32.

GönEnÇ, G. A method for design of fault-detection experiments. IEEE Transactions on Computers, v. 19, n. 6, p. 551-558, 1970.

Haley, A.; Zweben, S. Development and application of a white box approach to integration testing. The Journal of Systems and Software, v. 4, p. 309-315, 1984.

HALL, E. M. Managing risk: Methods for software systems development. AddisonWesley, 1998.

Harman, M.; Hierons, R.; Danicic, S. The relationship between program dependence and mutation analysis. In: Mutation 2000 Symposium, San Jose, CA: Kluwer Academic Publishers, 2000, p. 5-12.

Harrold, M. J. Testing: A roadmap. In: 22th International Conference on Software Engineering - Future of SE Track, 2000, p. 61-72.

Harrold, M. J.; Liang, D.; Sinha, S. An approach to analyzing and testing component-based systems. In: First Workshop on Testing Distributed ComponentBased Systems at ICSE'1999, Los Angeles, CA: IEEE Computer Society Press, 1999. 
Harrold, M. J.; McGregor, J. D.; Fitzpatrick, K. J. Incremental testing of object-oriented class structures. In: 14th International Conference on Software Engineering, Los Alamitos, CA: IEEE Computer Society Press, 1992, p. 68-80.

Harrold, M. J.; Rothermel, G. Performing data flow testing on classes. In: Second ACM SIGSOFT Symposium on Foundations of Software Engineering, New York, NY: ACM Press, 1994, p. 154-163.

Harrold, M. J.; Soffa, M. L. Interprocedural data flow testing. In: 3rd Testing, Analysis, and Verification Symposium, Key West, Florida: ACM Press, 1989, p. 158-167.

Harrold, M. J.; Soffa, M. L. Selecting and using data for integration test. IEEE Software, v. 8, n. 2, p. 58-65, 1991.

Hartmann, J.; Robson, D. J. Techniques for selective revalidation. IEEE Software, v. 7, n. 1, p. 31-36, 1990.

Herman, P. M. A data flow analysis approach to program testing. Australian Computer Journal, v. 8, n. 3, p. 92-96, 1976.

Hierons, R. M.; Harman, M.; Danicic, S. Using program slicing to assist in the detection of equivalent mutants. STVR-Software Testing, Verification and Reliability, v. 9, n. 4, p. 233-262, 1999.

Hoffman, D.; Strooper, P. A case study in class testing. In: CASCON 93, IBM Toronto Laboratory, 1993, p. 472-482.

Hoffman, D.; Strooper, P. Classbrench: A framework for automated class testing. Software Practice and Experience, v. 27, n. 5, p. 573-597, 1997.

Horgan, J. R.; London, S. A. Atac- automatic test coverage analysis for c programs, draft, 1990.

Horgan, J. R.; London, S. A. Data flow coverage and the C language. In: Symposium Software Testing, Analysis, and Verification, Victoria, British Columbia, Canada: ACM Press, 1991, p. 87-97.

Howden, W. E. Functional program testing and analysis. New York: McGrall-Hill, 1987a.

Howden, W. E. Software engineering and technology: Functional program testing and analysis. New York: McGrall-Hill Book Co, 1987b.

IEEE IEEE standard glossary of software engineering terminology. Standard 610.121990, IEEE Computer Society Press, 1990.

INTERNATIONAL SOFTWARE AUTOMATION (ISA) Panorama C/C++. Página WEB, disponível em: http://www.softwareautomation.com/index_e.htm. Acesso em: 01/03/2004, 1999a. 
INTERNATIONAL SOFTWARE AUTOMATION (ISA) Panorama for Java. Página WEB, disponível em: http://www.softwareautomation.com/index_e.htm. Acesso em: 01/03/2004, 1999b.

JaCkson, D.; Woodward, M. Parallel firm mutation of Java programs. In: Mutation 2000 Symposium, San Jose, CA, 2000.

Jin, Z.; Offut, A. J. Integration testing based on software couplings. In: X Annual Conference on Computer Assurance (COMPASS 95), Gaithersburg, Maryland, 1995, p. $13-23$.

Jorgensen, P. C.; Erickson, C. Object oriented integration testing. Communications of the ACM, v. 37, n. 9, p. 30-38, 1994.

KIm, H.; Wu, C. A class testing technique based on data bindings. In: Asia-Pacific Software Engineering Conference, 1996, p. 104-109.

Kim, S.; Clark, J. A.; MCDermid, J. A. Assessing test set adequacy for objectoriented programs using class mutation. In: Symposium on Software Technology (SoST'99), disponível em: http://www.cs.york.ac.uk/ jac/. Acesso em: 01/03/2004, 1999a, p. 72-83.

Kim, S.; Clark, J. A.; MCDermid, J. A. The rigorous generation of Java mutation operators using HAZOP. Relatório Técnico, Department of Computer Science University of York, Heslington, York, 1999b.

Kim, S.; Clark, J. A.; Mcdermid, J. A. The rigorous generation of Java mutation operators using HAZOP. In: 12th International Conference on Software ES Systems Engineering and their Applications (ICSSEA'99), 1999c.

Kim, S.; Clark, J. A.; Mcdermid, J. A. Class mutation: Mutation testing for object-oriented programs. In: Object-Oriented Software Systems - OOSS, disponível em: http://www.cs.york.ac.uk/ jac/. Acesso em: 01/03/2004, 2000a.

Kim, S.; Clark, J. A.; MCDermid, J. A. Investigating the applicability of traditional test adequacy criteria for object-oriented programs. In: FESMA-AEMES'2000: The European Software Measurement Conference, Madrid, Spain, 2000b.

Kim, S.; Clark, J. A.; MCDermid, J. A. Investigating the effectiveness of objectoriented testing strategies with the mutation method. STVR-Software Testing, Verification and Reliability, v. 11, n. 4, 2001.

Krauser, E. W.; Mathur, A. P.; Rego, V. J. High performance software testing on simd machines. IEEE Transactions on Software Engineering, v. 17, n. 5, p. 403-422, 1991.

Kung, D.; Lu, Y.; Venugopalan, N.; Hsia, P.; Toyoshima, Y.; Chen, C.; GAO, J. Object state testing and fault analysis for reliable software systems. In: 7 th International Symposium on Software Reliability Engineering, White Plains, NY: IEEE Computer Society Press, 1996, p. 76-85. 
Kung, D. C.; Hsia, P.; GaO, J. Testing object-oriented software. Los Alamitos CA: IEEE Computer Society Press, 1998.

LAski, J. W.; Korel, B. A data flow oriented program testing strategy. IEEE Transactions on Software Engineering, v. 9, n. 3, p. 347-354, 1983.

Lindholm, T.; Yellin, F. The Java virtual machine specification. 2 ed. AddisonWesley, 1999.

Linkman, S.; Vincenzi, A. M. R.; Maldonado, J. An evaluation of systematic functional testing using mutation testing. In: 7th International Conference on Empirical Assessment in Software Engineering - EASE, Keele, UK: The IEE, 2003.

Linnenkugel, U.; MÜllerburg, M. Test data selection criteria for (software) integration testing. In: First International Conference on Systems Integration, Morristown, NJ: IEEE Computer Society, 1990, p. 709-717.

MA, Y.-S.; Kwon, Y.-R.; Offutt, J. Inter-class mutation operators for Java. In: 13th International Symposium on Software Reliability Engineering - ISSRE'2002, Annapolis, MD: IEEE Computer Society Press, 2002, p. 352-366.

Maldonado, J. C. Critérios potenciais usos: Uma contribuição ao teste estrutural de software. Tese de Doutoramento, DCA/FEE/UNICAMP, Campinas, SP, 1991.

Maldonado, J. C. Critérios de teste de software: Aspectos teóricos, empíricos e de automatização. Concurso de Livre Docência - ICMC-USP, 1997.

Maldonado, J. C.; Chaim, M. L.; Jino, M. Seleção de casos de testes baseada na análise de fluxo de dados através dos critérios potenciais usos. In: II SBES - Simpósio Brasileiro de Engenharia de Software, Canela, RS, 1988, p. 24-35.

Maldonado, J. C.; Delamaro, M. E.; Fabbri, S. C. P. F.; Simão, A. S.; Sugeta, T.; Vincenzi, A. M. R.; Masiero, P. C. Proteum: A family of tools to support specification and program testing based on mutation. In: Mutation 2000 Symposium - Tool Session, San Jose, CA: Kluwer Academic Publishers, 2000, p. 113-116.

Maldonado, J. C.; Vincenzi, A. M. R.; Barbosa, E. F.; Souza, S. R. S.; Delamaro, M. E. Aspectos teóricos e empíricos de teste de cobertura de software. Relatório Técnico 31, Instituto de Ciências Matemáticas e de Computação - ICMC-USP, 1998.

MAN MACHINE SYSTEMS JCover 2.1 - user's guide. Página WEB, disponível em: http://www.mmsindia.com/JCover.html. Acesso em: 01/03/2004, 2002.

Marshall, A. C.; Hedley, D.; Riddell, I. J.; Hennell, M. A. Static dataflowaided weak mutation analysis (sdawm). Information and Software Technology, v. 32, n. $1,1990$.

Martena, V.; Orso, A.; Pezzè, M. Interclass testing of object oriented software. In: Eighth International Conference on Engineering of Complex Computer Systems, Greenbelt, Maryland: IEEE Computer Society Press, 2002, p. 135-144. 
Martins, E.; Toyota, C. M. Construção de classes autotestáveis. In: VIII SCTF - Simpósio de Computação Tolerante a Falhas, Campinas, SP, 1999, p. 196-209.

Matena, V.; Stearns, B. Applying enterprise JavaBeans: Component-based development for the J2EE platform. 2 ed. Addison-Wesley, 2001.

Mathur, A. P. Performance, effectiveness and reliability issues in software testing. In: 15th Annual International Computer Software and Applications Conference, Tokio, Japan: IEEE Computer Society Press, 1991, p. 604-605.

Mathur, A. P.; Krauser, E. W. Modeling mutation on vector processor. In: $X$ International Conference on Software Engineering, Singapore, 1988, p. 154-161.

Mathur, A. P.; Wong, W. E. An empirical comparison of data flow and mutation based test adequacy criteria. STVR - Software Testing, Verification and Reliability, v. 4, n. 1, p. 9-31, 1994.

MCCABE, T. A complexity measure. IEEE Transactions on Software Engineering, v. 2, n. 4, p. 308-320, 1976.

McDaniel, R.; MCGregor, J. D. Testing polymorphic interactions between classes. Relatório Técnico TR-94-103, Clemson University, 1994.

McGregor, J. D. Functional testing of classes. In: Proc. 7th International Quality Week, San Francisco, CA: Software Research Institute, 1994.

McGregor, J. D.; Korson, T. D. Integrated object-oriented testing and development process. Communications of the ACM, v. 37, n. 9, p. 59-77, 1994.

Microsoft COM: Delivering on the promises of component technology. Página WEB, disponível em: http://www.computer-society.com/Redirect.php?id_ url=532. Acesso em: 01/03/2004, 2002.

Mitchell, T. Machine learning. New York, NY: McGraw-Hill, 1997.

Murphy, G. C.; Townsend, P.; Wong, P. S. Experiences with cluster and class testing. Communications of the ACM, v. 37, n. 9, p. 39-47, 1994.

Myers, G. J. The art of software testing. Wiley, New York, 1979.

NTAFos, S. C. On required element testing. IEEE Transactions on Software Engineering, v. 10, n. 6, p. 795-803, 1984.

NtAFos, S. C. A comparison of some structural testing strategies. IEEE Transactions on Software Engineering, v. 14, n. 6, p. 868-873, 1988.

Object Management Group Unified Modeling Language (UML), versão 1.5. Página WEB, disponível em: http://www.omg.org/technology/documents/formal/ uml.htm. Acesso em: 01/03/2004, 2003. 
Offutt, A. J.; Craft, W. M. Using compiler optimization techniques to detect equivalent mutants. STVR-Software Testing, Verification and Reliability, v. 4, p. 131154, 1994.

Offutt, A. J.; IRvine, A. Testing object-oriented software using the categorypartition method. In: 17th International Conference on Technology of Object-Oriented Languages and Systems, Santa Barbara, CA: Prentice-Hall, 1995, p. 293-304.

Offutt, A. J.; Lee, A.; Rothermel, G.; Untch, R. H.; Zapf, C. An experimental determination of sufficient mutant operators. ACM Transactions on Software Engineering Methodology, v. 5, n. 2, p. 99-118, 1996a.

Offutt, A. J.; Pan, J. Detecting equivalent mutants and the feasible path problem. In: COMPASS'96t'- In Annual Conference on Computer Assurance, Gaithersburg, MD: IEEE Computer Society Press, 1996, p. 224-236.

Offutt, A. J.; PAN, J. Automatically detecting equivalent mutants and infeasible paths. STVR - Software Testing, Verification and Reliability, v. 7, n. 3, p. 165-192, 1997.

Offutt, A. J.; Rothermel, G.; Zapf, C. An experimental evaluation of selective mutation. In: 15th International Conference on Software Engineering, Baltimore, MD: IEEE Computer Society Press, 1993, p. 100-107.

Offutt, A. J.; Voas, J. M.; PAYne, J. Mutation operators for ADA. Relatório Técnico ISSE-TR-96-09, George Mason University, Department of ISSE, Fairfax, VA, 1996b.

Offutt, J.; Alexander, R.; Wu, Y.; Xiao, Q.; Hutchinson, C. A fault model for subtype inheritance and polymorphism. In: 12th International Symposium on Software Reliability Engineering - ISSRE'01, Hong Kong, China: IEEE Computer Society Press, 2001, p. 84-93.

Orso, A.; Harrold, M. J.; Rosenblum, D.; Rothermel, G.; Do, H.; SoffA, M. L. Using component metacontent to support the regression testing of component-based software. In: IEEE International Conference on Software Maintenance (ICSM'01), Florence, Italy: IEEE Computer Society Press, 2001, p. 716-725.

Ostrand, T. J.; Weyuker, E. J. Using data flow analysis for regression testing. In: Sixth Annual Pacific Northwest Software Quality Conference, Portland - Oregon, 1988.

Ostrand, T. J.; Weyuker, E. J. Data flow based test adequacy for languages with pointers. In: Symposium on Software Testing, Analysis and Verification - TAV4, Victoria, British Columbia, Canada: ACM Press, 1991, p. 74-86.

PARASOFT Corporation C++ Test. Página WEB, disponível em: http://www . parasoft.com/. Acesso em: 01/03/2004, 2000a.

PARASOFT Corporation CodeWizard. Página WEB, disponível em: http: //www.parasoft.com/. Acesso em: 01/03/2004, 2000b. 
PARASOFT Corporation Insure++. Página WEB, disponível em: http://www . parasoft.com/. Acesso em: 01/03/2004, 2000c.

Perry, D. E.; KAiser, G. E. Adequate testing and object-oriented programming. Journal on Object-Oriented Programming, v. 2, n. 5, p. 13-19, 1990.

Piwowarski, P.; Ohba, M.; Caruso, J. "Coverage measurement experience during function test". In: Proceedings of the 15th International Conference on Software Engineering, Baltimore, MD, 1993, p. 287-301.

Poston, R. M. Automated testing from object models. Communications of the $A C M$, v. 37, n. 9, p. 48-58, 1994.

Pressman, R. S. Software engineering - a practitioner's approach. 5 ed. McGrawHill, 2001.

Probert, R. L.; Guo, F. Mutation testing of protocols: Principles and preliminary experimental results. In: IFIP TC6 - Third International Workshop on Protocol Test Systems, North-Holland, 1991, p. 57-76.

Productivity through Sofware Plc. ProLint Advanced Graphical Lint for C e $\mathrm{C}++$. Página WEB, disponível em: http://www.pts.com/flxlint.cfm. Acesso em: 01/03/2004, 2000.

Quest Software JProbe Suite. Página WEB, disponível em: http://www.quest. com/jprobe/. Acesso em 01/03/2004, 2003.

RAPPs, S.; WeyUker, E. J. Data flow analysis techniques for program test data selection. In: 6th International Conference on Software Engineering, Tokio, Japan, 1982, p. 272-278.

RAPPS, S.; Weyuker, E. J. Selecting software test data using data flow information. IEEE Transactions on Software Engineering, v. 11, n. 4, p. 367-375, 1985.

RATiOnAL Software Corporation PureCoverage. Página WEB, disponível em: http://www-306.ibm.com/software/awdtools/purifyplus/. Acesso em: 01/03/2004, 2000a.

RATiOnAL Software Corporation Purify. Página WEB, disponível em: http://www-306.ibm.com/software/awdtools/purifyplus/. Acesso em: 01/03/2004, 2000b.

Research, S. User's guide - TCAT for Java/Windows - version 1.2. Página WEB, disponível em: http://www. soft.com/. Acesso em: 01/03/2004, 1999.

Roper, M. Software testing. McGrall Hill, 1994.

RosA, A. C. A.; Martins, E. Using a reflexive architecture to validate object-oriented applications by fault injection. In: 1st Workshop on Reflexive Programming in $\mathrm{C}++$ and Java, Vancouver, Canada, disponível em: http://www.ic.unicamp.br/〜eliane. Acesso em: 01/03/2004, 1998, p. 76-80. 
Rosenblum, D. S. Adequate testing of component-based software. Relatório Técnico UCI-ICS-97-34, University of California, Irvine, CA, 1997.

Rothermel, G.; Harrold, M. J.; Dedhia, J. Regression testing for C++ software. STVR - Software Testing, Verification and Reliability, v. 10, n. 2, p. 77-109, 2000.

Sabnani, K. K.; Dahbura, A. Protocol test generation procedure. Computer Networks and ISDN Systems, v. 15, n. 4, p. 285-297, 1988.

Silva-BARRADAS, S. Mutation analysis of concurrent software. Phd thesis, Department of Eletronic and Informatics, Polythecnic of Milan, Milan, Italy, 1997.

Simão, A. S. Proteum-RS/PN: Uma ferramenta para a validação de redes de petri baseada na análise de mutantes. Dissertação de Mestrado, ICMC/USP, São Carlos, SP, 2000.

Simão, A. S. Teste e validação de redes de petri coloridas usando análise de mutantes. Tese de doutoramento, ICMC/USP, São Carlos, SP, doutorado em andamento, 2004.

Simão, A. S.; Maldonado, J. C. Mutation based test sequence generation for Petri nets. In: III Workshop of Formal Methods, João Pessoa, 2000.

Simão, A. S.; Maldonado, J. C. MuDeL: A language and a system for describing and generating mutants. Journal of the Brazilian Computer Society, v. 8, n. 1, p. 73-86, 2002.

Simão, A. S.; Maldonado, J. C.; Fabbri, S. C. P. F. Proteum-RS/PN: A tool to support edition, simulation and validation of Petri nets based on mutation testing. In: SBES'2000 - Simpósio Brasileiro de Engenharia de Software, João Pessoa, (aceito), 2000 .

Simão, A. S.; Maldonado, J. C.; Vincenzi, A. M. R. mudelgen: A tool for processing mutant operator descriptions. In: XVI SBES - Simpósio Brasileiro de Engenharia de Software, Gramado, RS, Brasil, 2002, p. 426-431.

Sinha, S.; Harrold, M. J. Analysis of programs with exception-handling constructs. In: ICSM'98 - International Conference on Software Maintenance, Bethesda, MD, 1998, p. $348-357$.

Sinha, S.; Harrold, M. J. Criteria for testing exception-handling constructs in Java programs. In: International Conference on Software Maintenance, Oxford, England: IEEE Computer Society Press, 1999, p. 265-274.

Smith, M. D.; Robson, D. J. Object-oriented programming - the problems of validation. In: 6th International Conference on Software Maintenance, Los Alamitos, CA: IEEE Computer Society, 1990, p. 272-281.

Soundarajan, N.; Tyler, B. Testing components. In: OOPSLA'01 Workshop on Specification and Verification of Component-Based Systems, Tampa, Florida: ACM Press, 2001, p. 4-9. 
Souter, A. L.; Pollock, L. L. Omen: A strategy for testing object-oriented software. In: 9th International Symposium on Software Testing and Analysis - ISSTA'00, ACM Press, 2000, p. 49-59.

Souter, A. L.; Pollock, L. L. The construction of contextual def-use associations for object-oriented systems. IEEE Transactions on Software Engineering, v. 29, n. 11, p. 1005-1018, 2003.

Souza, S. R. S. Avaliação do custo e eficácia do critério análise de mutantes na atividade de teste de programas. Dissertação de Mestrado, ICMC-USP, São Carlos SP, 1996.

Souza, S. R. S.; Maldonado, J. C.; Fabbri, S. C. P. F.; Lopes de Souza, W. Mutation testing applied to estelle specifications. Software Quality Journal, v. 8, n. 4, p. 285-301, 1999.

Sridhanan, B.; Mundkur, S.; Mathur, A. P. Non-intrusive testing, monitoring and control of distributed corba objects. In: TOOLS'33-33rd International Conference on Technology of Object-Oriented Languages, Mont-saint-Michel, France, 2000, p. 195206.

Sugeta, T. Proteum-rs/st: Uma ferramenta para apoiar a validação de especificações statecharts baseada na análise de mutantes. Dissertação de Mestrado, ICMC-USP, São Carlos, SP, 1999.

Sugeta, T.; Maldonado, J. C.; Wong, W. E. Mutation testing applied to validate SDL specifications. In: 16th IFIP International Conference on Testing of Communicating Systems - TestCom2004, Oxford, United Kingdom, (a ser publicado), 2004 .

Sun Microsystems, I. SunTest: How to brew perfect Java. Página WEB, disponível em: http://www.sun.com/970610/cover/. Acesso em: 01/03/2004, 1996.

Szyperski, C. Component software beyond object-oriented programming. AddisonWesley, 1998.

Tatsubori, M.; Chiba, S.; Killijian, M.-O.; Itano, K. OpenJava: A Class-Based Macro System for Java. In: Reflection and Software Engineering, v. 1826 de Lecture Notes in Computer Science, Heidelberg, Germany: Springer-Verlag, p. 117-133, 2000.

Telcordia Technologies - USA xSuds Toolsuite. Página WEB, disponível em: http://xsuds.argreenhouse.com/. Acesso em: 01/03/2004, 1998.

Thevenod-Fosse, P.; WAeselynck, H. STATEMATE applied to statistical software testing. In: 5th International Symposium on Software Testing and Analysis, Cambridge, MA: ACM Press, 1993, p. 99-109.

Thomason, S.; Brereton, P.; Linkman, S. CLARiFi - an architecture for component classification and brokerage. In: International Workshop on ComponentBased Software Engineering, disponível em: http://www.sei.cmu.edu/cbs/cbse2000/ papers/. Acesso em: 01/03/2004, 2000. 
Turner, C. D.; Robson, D. J. The state-based testing of object-oriented programs. In: Conference on Software Maintenance, Montreal Quebec, Canada: IEEE Computer Society Press, 1993a, p. 302-310.

Turner, C. D.; Robson, D. J. The testing of object-oriented programs. Relatório Técnico TR-13/92, University of Durham, Computer Science Division, Durham, UK, 1993b.

URAL, H.; YANG, B. A structural test selection criterion. Information Processing Letters, v. 28, p. 157-163, 1988.

VAradan, G. S. Trends in reliability and test strategies. IEEE Software, v. 12, n. 3, p. $10,1995$.

Veevers, A.; Marshall, A. A relationship between software coverage metrics and reliability. Software Testing, Verification and Reliability, v. 4, n. 1, p. 3-8, 1994.

Vilela, P. R. S. Critérios potenciais usos de integração: Definição e análise. Tese de Doutoramento, DCA/FEEC/UNICAMP, Campinas, SP, 1998.

Vilela, P. R. S.; Maldonado, J. C.; Jino, M. Data flow based testing of programs with pointers: a strategy based on potential uses. In: 10th International Software Quality Week - QW97, California, USA, 1997, p. 1-12.

Vincenzi, A. M.; Simão, A. S.; Maldonado, J. C. Using MuDeL to describe Java and $C++$ mutant operators. Relatório Técnico, ICMC/USP, (em preparação), 2004a.

Vincenzi, A. M.; Wong, W. E.; Delamaro, M. E.; Simão, A. S.; Maldonado, J. C. JaBUTi - Java Bytecode Understanding and Testing - user's guide - version 1.0. Relatório Técnico, ICMC/USP, em preparação, 2004b.

Vincenzi, A. M. R. Subsídios para o estabelecimento de estratégias de teste baseadas na técnica de mutação. Dissertação de Mestrado, ICMC-USP, São Carlos - SP, 1998.

Vincenzi, A. M. R.; Delamaro, M. E.; Maldonado, J. C.; Wong, W. E. Java bytecode static analysis: Deriving structural testing requirements. In: 2nd UK Software Testing Workshop - UK-Softest'2003, Department of Computer Science, University of York, York, England: University of York Press, 2003a, p. 21.

Vincenzi, A. M. R.; Maldonado, J. C.; Barbosa, E. F.; Delamaro, M. E. Operadores essenciais de interface: Um estudo de caso. In: 13th Simpósio Brasileiro de Engenharia de Software, Florianópolis, SC, 1999, p. 373-391.

Vincenzi, A. M. R.; Maldonado, J. C.; Barbosa, E. F.; Delamaro, M. E. Unit and integration testing strategies for C programs using mutation-based criteria. STVR - Software Testing, Verification and Reliability, v. 11, n. 4, p. 249-268, 2001.

Vincenzi, A. M. R.; Maldonado, J. C.; Delamaro, M. E.; Spoto, E. S.; Wong, W. E. Component-based software quality: Methods and techniques, v. 2693 de Lecture Notes in Computer Science, cáp. Component-Based Software: An Overview of Testing New York, NY: Springer-Verlag, p. 99-127, (A. Cechich and M. Piattini and A. Vallecillo ed.), 2003b. 
Vincenzi, A. M. R.; Nakagawa, E. Y.; Maldonado, J. C.; Delamaro, M. E.; Romero, R. A. F. Bayesian-learning based guidelines to determine equivalent mutants. International Journal of Software Engineering and Knowledge Engineering IJSEKE, v. 12, n. 6, p. 675-689, 2002.

WAnG, Y.; King, G.; WickBurg, H. A method for built-in tests in componentbased software maintenance. In: Third European Conference on Software Maintenance and Reengineering, Amsterdam, Netherlands: IEEE Computer Society Press, 1999, p. $186-189$.

Weiss, M. A. Data structures and problem solving using Java. 2 ed. AddisonWesley, código fonte disponível on-line em: http://www.cs.fiu.edu/ ${ }^{\sim}$ weiss/ [01-jan2004], 2002.

Werner, C. M.; Braga, R. M. Desenvolvimento baseado em componentes. Minicurso apresentado no SBES'2000 - Simpósio Brasileiro de Engenharia de Software, 2000 .

WeyUker, E. J. The cost of data flow testing: an empirical study. IEEE Transactions on Software Engineering, v. 16, n. 2, p. 121-128, 1990.

Whittaker, J. A. Stochastic software testing. Annals of Software Engineering, v. 4, p. 115-131, 1997.

Whittaker, J. A.; Thomason, M. A markov chain model for statistical software testing. IEEE Transactions on Software Engineering, v. 20, n. 10, p. 812-824, 1994.

Wong, W.; Maldonado, J.; Delamaro, M.; Souza, S. A comparison of selective mutation in $\mathrm{C}$ and fortran. In: Workshop do Projeto Validação e Teste de Sistemas de Operação, Águas de Lindóia, SP, 1997, p. 71-80.

Wong, W. E. On mutation and data flow. Tese de Doutoramento, Department of Computer Science, Purdue University, W. Lafayette, IN, 1993.

Wong, W. E.; Gokhale, S. S.; Horgan, J. R.; Trivedi, K. S. Locating program features using execution slices. In: Proceedings of the Second IEEE Symposium on Application-Specific Systems and Software Engineering Technology, Richardson, TX, 1999, p. 194-203.

Wong, W. E.; Horgan, J. R.; London, S.; Mathur, A. P. Effect of test set size and block coverage on fault detection effectiveness. In: Fifth IEEE International Symposium on Software Reliability Engineering, Monterey, CA, 1994a, p. 230-238.

Wong, W. E.; Mathur, A. P. Fault detection effectiveness of mutation and data flow testing. Software Quality Journal, v. 4, n. 1, p. 69-83, 1995a.

Wong, W. E.; Mathur, A. P. Reducing the cost of mutation testing: An empirical study. The Journal of Systems and Software, v. 31, n. 3, p. 185-196, 1995b. 
Wong, W. E.; Mathur, A. P.; Maldonado, J. C. Mutation versus all-uses: An empirical evaluation of cost, strength, and effectiveness. In: International Conference on Software Quality and Productivity, Hong Kong: Chapman and Hall, 1994b, p. 258-265.

Woodward, M. R. Mutation testing - its origin and evolution. Information and Software Technology, v. 35, n. 3, p. 163-169, 1993.

Yanagawa, R. L.; Martins, E. Avaliação empírica da eficácia dos testes baseados no modelo de fluxo de transação em sistemas orientados a objetos. In: XI Conferência Internacional de Tecnologia de Software: Qualidade de Software, Curitiba, PR, 2000, p. $18-30$.

Yano, T.; Simão, A. S.; Maldonado, J. C. Proteum/SML - uma ferramenta de apoio ao teste de mutação para a linguagem standard ML. In: Sessão de Ferramentas do XVII Simpósio Brasileiro de Engenharia de Software, 2003, p. 67-72.

Zhно, J. Dependence analysis of Java bytecode. In: 24th IEEE Annual International Computer Software and Applications Conference (COMPSAC'2000), Taipei, Taiwan: IEEE Computer Society Press, 2000, p. 486-491.

ZHu, H. A formal analysis of the subsume relation between software test adequacy criteria. IEEE Transactions on Software Engineering, v. 22, n. 4, p. 248-255, 1996.

Zhu, H.; Hall, P.; May, J. Software unit test coverage and adequacy. ACM Computing Surveys, v. 29, n. 4, p. 366-427, 1997. 


\section{Descrição dos Operadores de Mutação}

Este apêndice traz uma descrição sucinta dos operadores de mutação apresentados nesta tese. O nome e a descrição dos operadores foram mantidas conforme apresentadas em suas respectivas referências. Para mais informações a respeito do conjunto de operadores de mutação aqui apresentado pode ser consultado o relatório técnico (Vincenzi et al., 2004a).

\section{A.1 Descrição dos Operadores de Unidade}

Tabela A.1: Operadores de Mutação de Constantes e Variáveis.

\begin{tabular}{|c|c|}
\hline \multicolumn{2}{|r|}{ Constantes } \\
\hline Operador & Descrição \\
\hline u-CGCR & Constant for Global Constant Replacement \\
\hline $\mathrm{u}-\mathrm{CGSR}$ & Constant for Global Scalar Replacement \\
\hline $\mathrm{u}-\mathrm{CLCR}$ & Constant for Local Constant Replacement \\
\hline u-CLSR & Constant for Local Scalar Replacement \\
\hline $\mathrm{u}-\mathrm{CRCR}$ & Required Constant Replacement \\
\hline \multicolumn{2}{|r|}{ Variáveis } \\
\hline Operador & Descrição \\
\hline $\mathrm{u}$-VASM & Array reference Subscript Mutation \\
\hline $\mathrm{u}-\mathrm{VDTR}$ & Domain Traps \\
\hline u-VGAR & Mutate Global Array References \\
\hline $\mathrm{u}-\mathrm{VGPR}$ & Mutate Global Pointer References \\
\hline $\mathrm{u}-\mathrm{VGSR}$ & Mutate Global Scalar References \\
\hline u-VGTR & Mutate Global Structure References \\
\hline $\mathrm{u}-\mathrm{VLAR}$ & Mutate Local Array References \\
\hline $\mathrm{u}-\mathrm{VLPR}$ & Mutate Local Pointer References \\
\hline u-VLSR & Mutate Local Scalar References \\
\hline u-VLTR & Mutate Local Structure References \\
\hline u-VSCR & Structure Component Replacement \\
\hline u-VTWD & Twiddle Mutations \\
\hline
\end{tabular}


Tabela A.2: Operadores de Mutação de Operadores.

\begin{tabular}{|c|c|}
\hline Operador & Descrição \\
\hline u-OAAA & Arithmetic Assignment Mutation \\
\hline u-OAAN & Arithmetic Operator Mutation \\
\hline $\mathrm{u}-\mathrm{OABA}$ & Arithmetic Assignment by Bitwise Assignment \\
\hline $\mathrm{u}-\mathrm{OABN}$ & Arithmetic by Bitwise Operator \\
\hline u-OAEA & Arithmetic Assignment by Plain Assignment \\
\hline u-OALN & Arithmetic Operator by Logical Operator \\
\hline u-OARN & Arithmetic Operator by Relational Operator \\
\hline $\mathrm{u}$-OASA & Arithmetic Assignment by Shift Assignment \\
\hline u-OASN & Arithmetic Operator by Shift Operator \\
\hline u-OBAA & Bitwise Assignment by Arithmetic Assignment \\
\hline u-OBAN & Bitwise Operator by Arithmetic Assignment \\
\hline $\mathrm{u}-\mathrm{OBBA}$ & Bitwise Assignment Mutation \\
\hline $\mathrm{u}-\mathrm{OBBN}$ & Bitwise Operator Mutation \\
\hline u-OBEA & Bitwise Assignment by Plain Assignment \\
\hline $\mathrm{u}-\mathrm{OBLN}$ & Bitwise Operator by Logical Operator \\
\hline $\mathrm{u}-\mathrm{OBNG}$ & Bitwise Negation \\
\hline u-OBRN & Bitwise Operator by Relational Operator \\
\hline $\mathrm{u}$-OBSA & Bitwise Assignment by Shift Assignment \\
\hline $\mathrm{u}-\mathrm{OBSN}$ & Bitwise Operator by Shift Operator \\
\hline $\mathrm{u}-\mathrm{OCNG}$ & Logical Context Negation \\
\hline $\mathrm{u}-\mathrm{OCOR}$ & Cast Operator by Cast Operator \\
\hline u-OEAA & Plain assignment by Arithmetic Assignment \\
\hline u-OEBA & Plain assignment by Bitwise Assignment \\
\hline $\mathrm{u}$-OESA & Plain assignment by Shift Assignment \\
\hline $\mathrm{u}$-OIPM & Indirection Operator Precedence Mutation \\
\hline u-OLAN & Logical Operator by Arithmetic Operator \\
\hline $\mathrm{u}-\mathrm{OLBN}$ & Logical Operator by Bitwise Operator \\
\hline $\mathrm{u}$-OLLN & Logical Operator Mutation \\
\hline u-OLNG & Logical Negation \\
\hline u-OLRN & Logical Operator by Relational Operator \\
\hline $\mathrm{u}$-OLSN & Logical Operator by Shift Operator \\
\hline $\mathrm{u}-\mathrm{OMMO}$ & Decrement Mutation \\
\hline $\mathrm{u}-\mathrm{OPPO}$ & Increment Mutation \\
\hline u-ORAN & Relational Operator by Arithmetic Operator \\
\hline $\mathrm{u}-\mathrm{ORBN}$ & Relational Operator by Bitwise Operator \\
\hline u-ORLN & Relational Operator by Logical Operator \\
\hline u-ORRN & Relational Operator Mutation \\
\hline $\mathrm{u}$-ORSN & Relational Operator by Shift Operator \\
\hline u-OSAA & Shift Assignment by Arithmetic Assignment \\
\hline $\mathrm{u}$-OSAN & Shift Operator by Arithmetic Operator \\
\hline u-OSBA & Shift Assignment by Bitwise Assignment \\
\hline $\mathrm{u}-\mathrm{OSBN}$ & Shift Operator by Bitwise Operator \\
\hline u-OSEA & Shift Assignment by Plain Assignment \\
\hline $\mathrm{u}$-OSLN & Shift Operator by Logical Operator \\
\hline $\mathrm{u}$-OSRN & Shift Operator by Relational Operator \\
\hline u-OSSA & Shift Assignment Mutation \\
\hline $\mathrm{u}-\mathrm{OSSN}$ & Shift Operator Mutation \\
\hline
\end{tabular}


Tabela A.3: Operadores de Mutação de Comandos.

\begin{tabular}{|l|l|}
\hline Operador & Descrição \\
\hline \hline u-SBRC & break Replacement by continue \\
\hline u-SBRn & break Out to Nth Level \\
\hline u-SCRB & continue Replacement by break \\
\hline u-SCRn & continue Out to Nth Level \\
\hline u-SDWD & do-while Replacement by while \\
\hline u-SGLR & goto Label Replacement \\
\hline u-SMTC & n-trip continue \\
\hline u-SMTT & n-trip trap \\
\hline u-SMVB & Move Brace Up and Down \\
\hline u-SRSR & return Replacement \\
\hline u-SSDL & Statement Deletion \\
\hline u-SSOM & Sequence Operator Mutation \\
\hline u-SSWM & switch Statement Mutation \\
\hline u-STRI & Trap on if Condition \\
\hline u-STRP & Trap on Statement Execution \\
\hline u-SWDD & while Replacement by do-while \\
\hline
\end{tabular}




\section{A.2 Descrição dos Operadores de Integração}

Tabela A.4: Operadores de Mutação de Interface.

\begin{tabular}{|c|c|}
\hline \multicolumn{2}{|r|}{ Grupo-I } \\
\hline Operador & Descrição \\
\hline I-CovAllEdg & Coverage of Edges \\
\hline I-CovAllNod & Coverage of Nodes \\
\hline I-DirVarAriNeg & Inserts Arithmetic Negation at Interface Variables \\
\hline I-DirVarBitNeg & Inserts Bit Negation at Interface Variables \\
\hline I-DirVarIncDec & Increments and Decrements Interface Variables \\
\hline I-DirVarLogNeg & Inserts Logical Negation at Interface Variables \\
\hline I-DirVarRepCon & Replaces Interface Variables by Used Constants \\
\hline I-DirVarRepExt & Replaces Interface Variables by Extern Global \\
\hline I-DirVarRepGlo & Replaces Interface Variables by Global Variables \\
\hline I-DirVarRepLoc & Replaces Interface Variables by Local Variables \\
\hline I-DirVarRepPar & Replaces Interface Variables by Formal Parameters \\
\hline I-DirVarRepReq & Replaces Interface Variables by Required Constants \\
\hline I-IndVarAriNeg & Inserts Arithmetic Negation at Non Interface Variables \\
\hline I-IndVarBitNeg & Inserts Bit Negation at Non Interface Variables \\
\hline I-IndVarIncDec & Increments and Decrements Non Interface Variables \\
\hline I-IndVarLogNeg & Inserts Logical Negation at Non Interface Variables \\
\hline I-IndVarRepCon & Replaces Non Interface Variables by Used Constants \\
\hline I-IndVarRepExt & Replaces Non Interface Variables by Extern Global \\
\hline I-IndVarRepGlo & Replaces Non Interface Variables by Global Variables \\
\hline I-IndVarRepLoc & Replaces Non Interface Variables by Local Variables \\
\hline I-IndVarRepPar & Replaces Non Interface Variables by Formal Parameters \\
\hline I-IndVarRepReq & Replaces Non Interface Variables by Required Constants \\
\hline I-RetStaDel & Deletes return Statement \\
\hline I-RetStaRep & Replaces return Statement \\
\hline \multicolumn{2}{|r|}{ Grupo-II } \\
\hline Operador & Descrição \\
\hline II-ArgAriNeg & Insert Arithmetic Negation on Argument \\
\hline II-ArgBitNeg & Insert Bit Negation on Argument \\
\hline II-ArgDel & Argument Deletion \\
\hline II-ArgIncDec & Argument Increment and Decrement \\
\hline II-ArgLogNeg & Insert Logical Negation on Argument \\
\hline II-ArgRepReq & Replacement by Required Constants \\
\hline II-ArgSwiAli & Compatible Arguments \\
\hline II-ArgSwiDif & Non-compatible Arguments \\
\hline II-FunCalDel & Remove Function Call \\
\hline \multicolumn{2}{|r|}{ Definições } \\
\hline \multicolumn{2}{|c|}{$\begin{array}{l}P(B) \text { : The set of formal parameters of } B \text {. This set also } \\
\text { includes dereferences to pointer and array parameters. }\end{array}$} \\
\hline \multicolumn{2}{|c|}{$G(B)$ : The set of global variables accessed by $B$. } \\
\hline \multicolumn{2}{|c|}{$\begin{array}{l}L(B) \text { : The set of variables defined in } B \text { (local varia- } \\
\text { bles). }\end{array}$} \\
\hline \multicolumn{2}{|c|}{$E(B)$ : The set of global variables not used in $B$. } \\
\hline \multicolumn{2}{|c|}{$C(B)$ : The set of constants used in $B$. } \\
\hline \multicolumn{2}{|c|}{$\begin{array}{l}R \text { : The set of pre-defined constants relevant for each } \\
\text { data type and associated operators. }\end{array}$} \\
\hline
\end{tabular}




\section{A.3 Descrição dos Operadores de Classe}

Em relação aos operadores de mutação de classe, três conjuntos foram apresentados. O primeiro desses conjuntos, apresentado na Tabela A.5, foi proposto por Kim et al. (2000a) e é formado por 13 operadores de mutação. O segundo conjunto, composto de 3 operadores e ilustrado na Tabela A.6, foi proposto por Chevalley (2001). Finalmente, a Tabela A.7 apresenta a descrição dos operadores de mutação definidos por Ma et al. (2002), os quais incluem os operadores definidos anteriormente e é composto por 24 operadores de mutação de classe.

Tabela A.5: Operadores de Mutação de Classe - Class Mutation (Kim et al., 2000a).

\begin{tabular}{|c|c|}
\hline $\begin{array}{l}\text { Operadores de Mutação de } \\
\text { Classe }\end{array}$ & Descrição \\
\hline $\begin{array}{l}\text { CRT (Compatible } \\
\text { Type replacement) }\end{array}$ & Replace a class type with compatible types \\
\hline $\begin{array}{l}\text { ICE (Instance Creation Ex- } \\
\text { pression changes) }\end{array}$ & $\begin{array}{l}\text { Change an instance creation expression with other instance creation expressions of the } \\
\text { same and/or compatible class types. }\end{array}$ \\
\hline $\begin{array}{l}\text { POC (Parameter } \quad \text { Order } \\
\text { Change) }\end{array}$ & Change method parameter order in method declarations \\
\hline $\begin{array}{l}\text { VMR (oVerloading Method } \\
\text { Removal) }\end{array}$ & Remove the declaration of an overloading method. \\
\hline 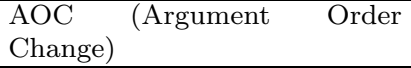 & Change method argument order in method invocation expressions \\
\hline $\begin{array}{l}\text { AND (Argument Number De- } \\
\text { crease) }\end{array}$ & Decrease arguments one by one \\
\hline $\begin{array}{l}\text { HFR (Hiding Field variable } \\
\text { Removal) }\end{array}$ & Remove a field variable declaration when it hides the variable in a superclass \\
\hline $\begin{array}{l}\text { HFA (Hiding Field variable } \\
\text { Addition) }\end{array}$ & Add a field variable of the same name as the field variable in a superclass \\
\hline $\begin{array}{l}\text { OMR (Overriding Method Re- } \\
\text { moval) }\end{array}$ & The declaration of an overriding method is removed \\
\hline $\begin{array}{lll}\text { AMC } & \text { (Access } & \text { Modifier } \\
\text { Change) } & & \\
\end{array}$ & Replace an access modifier with other modifiers \\
\hline SMC (Static Modifier Change) & Add or remove a static modifier \\
\hline $\begin{array}{l}\text { EHR (Exception Handler Re- } \\
\text { moval) }\end{array}$ & Remove exception handlers one by one \\
\hline $\begin{array}{l}\text { EHC (Exception Handling } \\
\text { Change) }\end{array}$ & $\begin{array}{l}\text { Change an exception handling statement to an exception propagation statement, and } \\
\text { vice versa }\end{array}$ \\
\hline
\end{tabular}

Tabela A.6: Operadores de Mutação de Classe adicionais de Chevalley (2001).

\begin{tabular}{|l|l|}
\hline $\begin{array}{l}\text { Operadores de Mutação de } \\
\text { Classe }\end{array}$ & Descrição \\
\hline \hline MNC (Method Name Change) & Changes a method call with another compatible method call \\
\hline $\begin{array}{l}\text { RAC (Reference Assignment } \\
\text { and Content assignment repla- } \\
\text { cement) }\end{array}$ & $\begin{array}{l}\text { Replaces a reference assignment with a content assignment by cloning the assigned } \\
\text { object. }\end{array}$ \\
\hline $\begin{array}{l}\text { RCC (Reference Comparison } \\
\text { and Content comparison repla- } \\
\text { cement) }\end{array}$ & Changes a reference comparison with a content comparison, and vice-versa \\
\hline
\end{tabular}


Tabela A.7: Operadores de Mutação para o teste Inter-Classe (Ma et al., 2002).

\begin{tabular}{|c|c|}
\hline Operadores & Descrição \\
\hline AMC (Access modifier change) & Changes the access level for instance variables and methods to other access levels \\
\hline IHD (Hiding variable deletion) & Deletes a declaration of an overriding, or hiding variable \\
\hline IHI (Hiding variable insertion) & Inserts hiding member variables to hide the parent's version of a variable \\
\hline IOD (Overriding method deletion) & Deletes an entire declaration of an overriding method \\
\hline $\begin{array}{l}\text { IOP (Overridden method calling po- } \\
\text { sition change) }\end{array}$ & $\begin{array}{l}\text { Moves calls to overridden methods to the first and last statements of the method } \\
\text { and up and down one statement }\end{array}$ \\
\hline IOR (Overridden method rename) & Renames the parent's versions of overridden methods \\
\hline ISK (super keyword deletion) & Deletes occurrences of the super keyword \\
\hline $\begin{array}{l}\text { IPC (Explicit call of a parent's cons- } \\
\text { tructor deletion }\end{array}$ & Deletes super constructor calls \\
\hline $\begin{array}{l}\text { PNC (new method call with child } \\
\text { class type) }\end{array}$ & Chan \\
\hline $\begin{array}{l}\text { PMD (Instance variable declaration } \\
\text { with parent class type) }\end{array}$ & $\begin{array}{l}\text { Changes the declared type of an object reference to the parent of the original } \\
\text { declared type }\end{array}$ \\
\hline $\begin{array}{l}\text { PPD (Parameter variable declaration } \\
\text { with child class type) }\end{array}$ & $\begin{array}{l}\text { The same as the PMD, except that it operates on parameters rather than instance } \\
\text { and local variables }\end{array}$ \\
\hline $\begin{array}{l}\text { PRV (Reference assignment with } \\
\text { other compatible type) }\end{array}$ & $\begin{array}{l}\text { Changes operands of a reference assignment to be assigned to objects of subclas- } \\
\text { ses }\end{array}$ \\
\hline $\begin{array}{l}\text { OMR (Overloading method contents } \\
\text { change) }\end{array}$ & $\begin{array}{l}\text { methods Replaces the body of a method with the body of another method that } \\
\text { has the same name }\end{array}$ \\
\hline OMD (Overloading method deletion) & Deletes overloading method declarations, one at a time in turn \\
\hline OAO (Argument order change) & Changes the order of the arguments in method invocations \\
\hline OAN (Argument number change) & Changes the number of the arguments in method invocations \\
\hline JTD (this keyword deletion) & Deletes uses of the keyword this. \\
\hline JSC (static modifier change) & $\begin{array}{l}\text { Removes/Adds the static modifier to change class/instance variables to ins- } \\
\text { tance/class variables }\end{array}$ \\
\hline $\begin{array}{l}\text { JID (Member variable initialization } \\
\text { deletion) }\end{array}$ & Removes the initialization of member variables in the variable declaration \\
\hline $\begin{array}{l}\text { JDC (Java-supported default cons- } \\
\text { tructor create) }\end{array}$ & $\begin{array}{l}\text { Forces Java to create a default constructor by deleting the implemented default } \\
\text { constructor }\end{array}$ \\
\hline $\begin{array}{l}\text { EOA (Reference assignment and con- } \\
\text { tent assignment replacement) }\end{array}$ & $\begin{array}{l}\text { Replaces an assignment of a pointer reference with a copy of the object, using } \\
\text { the Java convention of a clone ( }) \text { method }\end{array}$ \\
\hline $\begin{array}{l}\text { EOC (Reference comparison and con- } \\
\text { tent comparison replacement) }\end{array}$ & $\begin{array}{l}\text { Replaces reference comparison (==) by content comparison (equals }()) \text { and vice- } \\
\text { versa }\end{array}$ \\
\hline EAM (Accessor method change) & Changes an accessor method name for other compatible accessor method names \\
\hline EMM (Modifier method change) & Changes a modifier method name for other compatible modifier method names \\
\hline
\end{tabular}




\section{A.4 Descrição dos Operadores de Concorrência}

Tabela A.8: Conjunto de Operadores de Mutação de Concorrência para Java (Delamaro et al., 2001b).

\begin{tabular}{|l|l|}
\hline Operador & Descrição \\
\hline \hline DelSync & $\begin{array}{l}\text { Removes the synchronized attribute from a method declaration or removes a } \\
\text { synchronized statement }\end{array}$ \\
\hline DelStat & Deletes a statement in a synchronized method or block \\
\hline MoveBrace & Moves \{ and $\}$ up and down \\
\hline ReplSyncObject & Replaces synchronization object \\
\hline \hline DelWait & Deletes a call to the wait method \\
\hline ReplWait & Replaces a call to a timed wait by a call to a non-timed wait and vice-versa \\
\hline IncrDecrWait & Increment and decrement argument for timed wait \\
\hline DelNotify & Deletes a call to notify or notifyAll \\
\hline ReplNotify & Replaces a call to notify by a call to notifyAll and vice-versa. \\
\hline \hline ReplArg & Replaces argument of a call to synchronized method by constant \\
\hline DelSyncCall & Deletes a call to a synchronized method \\
\hline SwitchArg & Switch arguments in a call to synchronized method \\
\hline ReplMeth & Uses method with same name and other signature in a synchronized call \\
\hline InsNegArg & Inserts unary (negation) operators in an argument \\
\hline ReplTargObj & Replaces the target object used in a call to synchronized method \\
\hline
\end{tabular}

